UNIVERSIDADE DE SÃO PAULO

INSTITUTO DE QUÍMICA

\title{
FOTÓLISE DE BROMETOS DE ORTO-XILILA: UM ESTUDO EM SOLVENTES APOLARES
}

DAISY DE BRITO REZENDE 
"FOTOLISE DE BROMETOS DE ORTO-XILILA: UM ESTUDO EM SOLVENTES APOLARES"

\section{DAISY DE BRITO REZENDE}

Tese de Doutorado submetida ao Instituto de Química da Universidade de São Paulo como parte dos requisitos necessários à obtenção do grau de Doutor em Ciências - Área: Química Orgânica

Aprovada por:

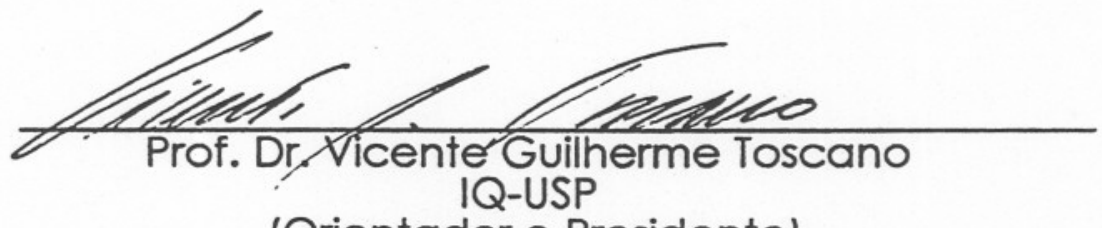

(Orientador e Presidente)

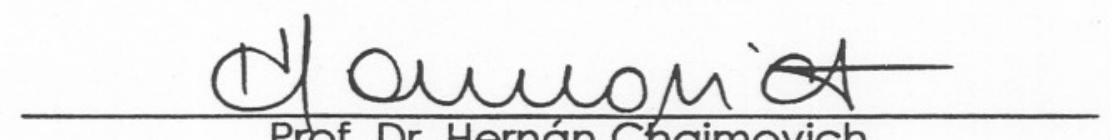

Prof. Dr. Hernán Chaimovich

IQ-USP

brardini

Profa. Dra. Vera Lúcia Pardini IQ-USP

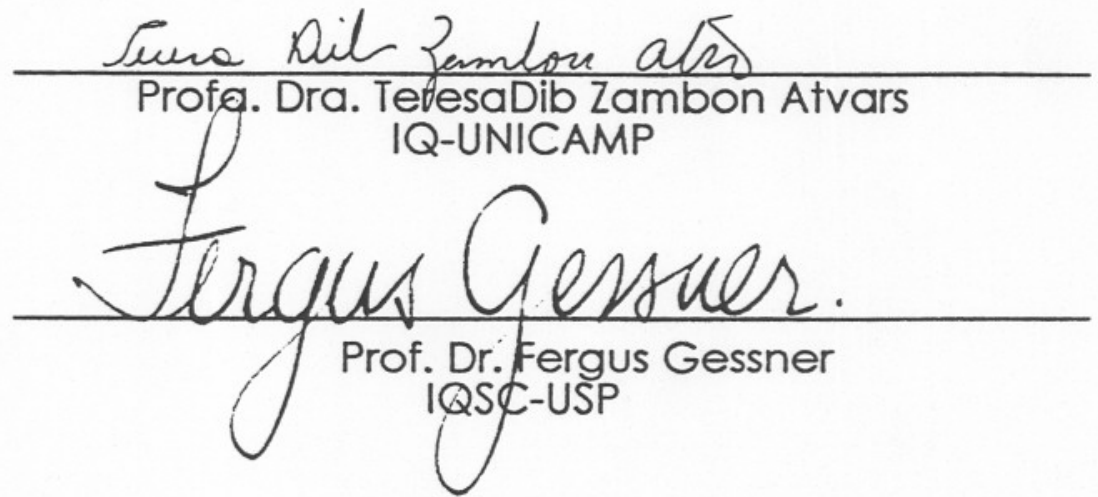

SÃO PAULO

01 DE DEZEMBRO DE 1994 
A Delma e Wilson, meus pais, pelo apoio irrestrito e permanente.

A Luiz Carlos, meu irmão, companheiro desde sempre, por seu amor carinhoso.

Ao Ivan, pela cumplicidade na construção dos caminhos,

todos. 


\section{VERDURA}

De repente me lembro do verde:

a cor verde, a mais verde que existe, a cor mais alegre, a cor mais triste, o verde que vestes, o verde que vestiste, no dia em que te vi, no dia em que me viste.

De repente vendi meus filhos prá uma família americana:

eles têm carro, eles têm grana, eles têm casa $e$ a grama é bacana... Só assim eles podem voltar e pegar um sol em Copacabana! 
Gostaria de expressar meus sinceros agradecimentos:

ao Toan, pela excecusão dos desenhos e pela meticulosa revisão do texto;

ao Giunter, amigo sempre presente, pelo auscilio preciso e eficiente na obtensão de alguns dos compostos (inclusive, quando necessário, tomando a pasto à frente da bancada);

ao Marcelo Fagundes Barros e à Regina Acantara, pela amizade e companhia constantes e por terem digitado mais de um trecho em ritmo de emergência;

ao Dennys Gorbo, pelo auscilio na revisão de parte do texto desta Tese e pela amizade constante;

aos técnicos da Gentral Analitica pelo excelente trabalho e, de corasão, aos operadores dos espectrógrafos de massas, Mário Lopes Duarte, Nário Luiz Teruo Taguchi e Mlfred Ken Matayoshi, por sua paciencia toda oriental durante a otimizasãa da metodologia para análise e acompanhamento das fotoirradiasôes, bem como à Marie Tshige, pelo excelente massa de alta-resolusâa, que permitiu a caracterizasãa de um compasto inédito (que não dava micro-análise de jeito nenhum ...). a a Roque e ao Malta (que também obteve os T.9.), pelos ressonâncias;

à Gornelia Bohne, por ter-se dado av trabalho de fazer, prontamente, as medidas de fotólise por pulso de laser, em benzeno;

ao Lique, ao Willi e ao Sud's, companheiros de laboratorio instigantes sob todos os pontos de vista;

ao pessoal do nossa grupo de Fotoquimica, Francisco Gintra, Ana Luiza, Angela, Garlos, Garmen, del Garmen, Gassius, Décio, Laime, Sascha, Luir (de Santos) Gustawo, Luiz Geraldo, Marcelo Ghristoffe Latricia Ponce, pela convivencia agradável e pelas discussões - as cientificas (e as nem tanto!!), todas bem produtivas ...,

ao pessoal do grupo do professor Ternan Ghaimovich, principalmente à Tereza Gristina (TF), Fábia Geneviva, Ana Laula e Lalmira, pelo esforso na manutensâa dos seminários conjuntos de grupo, um espasa importante para a troca de informasöes; 
ao Frank, ao Farah e à Elena, pela amizade e pelas várias reflexōes conjuntas sobre politica científica e universitária;

à Ligia, pela solidariedade amiga, em momentos bem dificeis;

à Piliana Marzorati, grande amiga, com quem compartilho e discuto tantas idéias sobre a papel do docente na construsẫo de uma Universidade mais instigante;

à Maria Gunice que, além de me ter iniciado da melhor maneira possúvel numa prática - científica e crítica - em fotoquímica, oem-me estimulando, desde a graduasão, a desbravar meu próprio caminho na Ulniversidade;

à Professora Blanka Wladislaw, pela amizade, estímulo e pelo excemplo de dedicasãa constante à construsãa deste Tnstituto;

a todas as pessoas com quem venho tendo a prazer de conviver ao longo destes anos no Tnstituta de Luimica e, em especial: aos bioquímicos do bloca 12S, tanta os remanescentes (do grupa da professora Shirley Schreier), como os membros do grupa da professora Ohara Augusto; e aos amigas do bloca 5S, Nilza, Laerte, Gosé Eduardo de Oliveira, Gonas Gruber, Marcos de Mattos, Válter Russo, Paula Lanissek, Pedro Machion, Goão Fernando Ganzerli, Regina Neves, Neusinha Fávara e Leonora Gomegno, pelas horas várias, em que é tão bom ter boa companhia;

as Losé Mário e ao Miguel, pelo escelente trabalho de apoio técnico;

e, av GNPq, pelo apoia financeiro. 


\section{ÍNDICE}

ÍNDICE DE FIGURAS

ÍNDICE DE TABELAS

RESUMO vi

ABSTRACT viii

$\begin{array}{ll}\text { I. INTRODUÇÃO } & 1\end{array}$

I.1. Processos Fotoquímicos e Fotofísicos em Solução 1

I.2. Fotólise por Pulso de Laser e Geração de Intermediários Radicalares 6

I.3. Radicais Benzila 7

I.4. Reações de foto-homólise: obtenção de radicais, bi-radicais e quinodimetanos 15

II. OBJETIVOS 30

III. MATERIAIS E MÉTODOS 31

III.1. Aparelhagem 31

III.2. Materiais $\quad 32$

III.3. Obtenção dos Compostos Submetidos à Fotólise: 33

III.3.1: Preparação de $\alpha$-bromo-o-xileno, MBX 33

III.3.2: Preparação de $\alpha, \alpha$ '-dibromo- $o$-xileno, DBX 33

III.3.3: Síntese de $\alpha, \alpha$-dibromo-o-xileno (GBX) 34

III.3.4: Preparação de $\alpha, \alpha, \alpha$-tribromo-o-xileno, TRBX 35

III.3.5: Dados de $\mathrm{RMN}$ de ${ }^{1} \mathrm{H}$ e de ${ }^{13} \mathrm{C}$, para os compostos bromados $\quad 36$

III.4. Obtenção dos Padrões para a Caracterização dos Produtos de Fotólise: 37

III.4.1: Síntese de 1,1'-biciclo-hexeno, $\operatorname{DCHex}\left(1,1^{\prime}\right)$

III.4.2: Síntese do brometo de $o$-benzil-benzila, BBzBr 38

III.5. Espectros de Massas Interpretados: 40

III.5.1: Solução benzênica de TBX, a 70eV 40

III.5.2: Solução benzênica de MBX, a $70 \mathrm{eV}$

III.5.3: Solução benzênica de DBX, a 70eV 43

III.5.4: Solução benzênica de GBX, a 70eV 44

III.5.5: Solução benzênica de TRBX, a 70eV 46

III.5.6: Solução benzênica de DCHex(1,1'), a $70 \mathrm{eV}$

III.5.7: Solução benzênica de $\mathbf{B B z B r}$, a 70eV 49

III.6. Fotólises Convencionais: $\quad 51$

III.6.1: Irradiações 51

III.6.2: Quantificação dos fotoprodutos obtidos 52

III.6.3: Actinometria 56

$\begin{array}{ll}\text { III.7. Fotólises por Pulso de Laser } & 61\end{array}$ 
IV. RESULTADOS E DISCUSSÃo 64

$\begin{array}{ll}\text { IV.1. Fotólises Convencionais: } & 64\end{array}$

IV.1.1: Em benzeno $\quad 64$

IV.1.2: Em benzeno/ciclo-hexeno $\quad 71$

IV.1.3: Em iso-octano $\quad 78$

IV.2. Quantificação dos Principais Produtos Obtidos nas Fotólises $\begin{array}{ll}\text { Convencionais } & 80\end{array}$

IV.3. Rendimentos Quânticos, nas Fotólises Convencionais 88

$\begin{array}{ll}\text { IV.4. Fotólises por Pulso de Laser } & 90\end{array}$

$\begin{array}{lr}\text { V. BIBLIOGRAFIA } & 110\end{array}$

$\begin{array}{ll}\text { CURRICULUM VIT } \boldsymbol{E} & 116\end{array}$ 


\section{ÍNDICE DE FIGURAS}

FIGURA 0: Imagem de um elétron ampliada 10000 vezes. ix

FIGURA I.1: Processos que interessam a um fotoquímico. 1

FIGURA I.2: Diagrama de Jablonski. 2

FIGURA 1.3: Descrição esquemática de superficies de energia, mostrando a relação entre processos fotofísicos não-radiativos e processos fotoquímicos.

FIGURA I.4: $\quad$ Eventos, em uma fotorreação.

FIGURA I.5: Dissociação da ligação $\sigma$, para um composto benzílico genérico.

FIGURA I.6: $\quad$ A: Orbitais moleculares (HMO), para o radical benzila, identificados segundo sua simetria e energia.

B: Configurações de ordem zero correspondentes ao estado fundamental $\left(\mathbf{D}_{\mathbf{n}}\right)$ e aos estados excitados $\left(\mathbf{D}_{\mathbf{n}}\right)$ do radical benzila, também identificados pelas designações de simetria.

FIGURA II.1: $\quad$ Bromo-derivados de $o$-xileno, utilizados no presente estudo.

FIGURA III.1: Espectro de massas de TBX, obtido no espectrômetro Finnigan MAT INCOS 50.

FIGURA III.2: Espectro de massas para MBX, obtido no espectrômetro Hewlett Packard 5988 A.

FIGURA III.3: Espectro de massas para DBX, obtido no espectrômetro Hewlett Packard 5988 A.

FIGURA II.4: Espectro de massas para GBX, obtido no espectrômetro Finnigan MAT INCOS 50.

FIGURA III.5: Espectro de massas para TRBX, obtido no espectrômetro Finnigan MAT INCOS 50.

FIGURA III.6: Espectro de massas para DCHex(1,1'), obtido no espectrômetro Finnigan MAT INCOS 50.

FIGURA III.7: Espectro de massas para $\mathbf{B B z B r}$, obtido no espectrômetro Finnigan MAT INCOS 50.

FIGURA II.8: Espectros de absorção (em loge), para o VML e para o fotoproduto $\mathbf{V M}^{+}$, em metanol/ácido clorídrico.

FIGURA III.9: Esquema simplificado do sistema utilizado nas fotólisesrelâmpago. 
FIGURA IV.1: Representações de modelos para confôrmeros de menor energia dos compostos bromados em estudo, de acordo com os volumes moleculares relativos.

FIGURA IV.2: Espectro de massas para DCHex(1,2'), obtido no espectrômetro quadrupolar Hewlett Packard 5988A.

FIGURA IV.3: $\quad$ Perfil cinético da irradiação de MBX, em benzeno. 83

FIGURA IV.4: Perfil cinético da irradiação de DBX, em benzeno. 84

FIGURA IV.5: Perfil cinético da irradiação de GBX, em benzeno. 84

FIGURA IV.6: Perfil cinético da irradiação de TRBX, em benzeno. 85

FIGURA IV.7: Perfil cinético da irradiação de TBX, em benzeno. 85

FIGURA IV.8: Perfil cinético da irradiação de MBX, em benzeno/ciclohexeno. $\quad 86$

FIGURA IV.9: Perfil cinético da irradiação de DBX, em benzeno/ciclohexeno. $\quad 86$

FIGURA IV.10: Perfil cinético da irradiação de MBX, em iso-octano. 87

FIGURA IV.11: Perfil cinético da irradiação de DBX, em iso-octano. 87

FIGURA IV.12: Decaimento, monitorado a $320 \mathrm{~nm}$, para uma solução de MBX, em iso-octano.

FIGURA IV.13: Decaimento, monitorado a $340 \mathrm{~nm}$, para uma solução de DBX, em iso-octano.

FIGURA IV.14: Decaimento, monitorado a $310 \mathrm{~nm}$, para uma solução de GBX, em iso-octano.

FIGURA IV.15: Decaimento, monitorado a $315 \mathrm{~nm}$, para uma solução de TBX, em iso-octano.

FIGURA IV.16: Espectros de absorção para os transientes gerados na fotólise de MBX, em iso-octano ( $\left.\lambda_{\text {exc }}=266 \mathrm{~nm}\right)$.

FIGURA IV.17: Espectros de absorção para os transientes gerados na fotólise de DBX, em iso-octano $\left(\lambda_{\text {exc }}=266 \mathrm{~nm}\right)$.

FIGURA IV.18: Decaimento, monitorado a $340 \mathrm{~nm}$, para uma solução de DBX, em iso-octano, em presença de ciclo-hexeno.

FIGURA IV.19: Decaimento, monitorado a $330 \mathrm{~nm}\left(\lambda_{\text {exc }}=308 \mathrm{~nm}\right)$, para uma solução de DBX, em benzeno.

FIGURA IV.20: Decaimento, monitorado a 330nm, para uma solução de TBX ( $\lambda_{\text {exc }}=308 \mathrm{~nm}$ ), em benzeno.

FIGURA IV.21: Espectros de absorção para os transientes gerados na fotólise de DBX, em benzeno $\left(\lambda_{\text {exc }}=308 \mathrm{~nm}\right)$.

FIGURA IV.22: Espectros de absorção para os transientes gerados na fotólise de TBX, em benzeno $\left(\lambda_{\text {exc }}=308 \mathrm{~nm}\right)$. 
FIGURA IV.23: Decaimento, monitorado a $550 \mathrm{~nm}$, para a fotólise de uma solução de TBX $\left(\lambda_{\text {exc }}=308 \mathrm{~nm}\right)$, em benzeno.

FIGURA IV.24: Decaimento, monitorado a $320 \mathrm{~nm}$, para uma solução de DBX $(A=0,850)$, em iso-octano. 


\section{ÍNDICE DE TABELAS}

Tabela I.1: Máximos de absorção $\left(\lambda_{0,0}\right)$ para radicais benzila em vários meios.

Tabela I.2: $\quad$ Tempos de vida de emissão de fluorescência, em matriz e à temperatura ambiente.

Tabela I.3: Constantes de terminação para radicais benzila substituídos, em ciclo-hexano, a $22^{\circ} \mathrm{C}$.

Tabela III.1: Deslocamentos químicos de ${ }^{1} \mathrm{H}$, para bromo-derivados de $o$-xileno.

Tabela III.2: Constantes de acoplamento próton-próton, para bromoderivados de $o$-xileno.

Tabela III.3: Deslocamentos químicos de ${ }^{13} \mathrm{C}$, para bromo-derivados de $o$-xileno.

Tabela III.4: Dados para obtenção do fator de resposta de $o$-xileno.

Tabela III.5: Dados para obtenção do fator de resposta de MBX.

Tabela III.6: Dados para obtenção do fator de resposta de DBX. 53

Tabela III.7: Dados para obtenção do fator de resposta de TRBX. 54

Tabela III.8: Dados para obtenção do fator de resposta de TBX. 54

Tabela III.9: Dados para obtenção do fator de resposta de GBX. 55

Tabela III.10: Dados para obtenção do fator de resposta de BBzBr. 55

Tabela III.11: Absorbâncias para soluções alcoólicas de $\mathrm{HCl}$. 58

Tabela III.12: Dados para VML e VM+, em metanol/HCl. 58

Tabela III.13: $\quad$ Actinometria para as lâmpadas de mercúrio de baixa pressão. $\quad 59$

Tabela IV.1: Intensidades isotópicas relativas ao pico molecular. 73

Tabela IV.2: Tempos de retenção e respostas, relativos a $\mathrm{C}_{16} \mathrm{H}_{34}$.

Tabela IV.3: $\quad$ Irradiação de $\alpha$-bromo- $O$-xileno (MBX), em benzeno. 81

Tabela IV.4: $\quad$ Irradiação de $\alpha, \alpha$-dibromo- $o$-xileno (DBX), em benzeno. 81

Tabela IV.5: $\quad$ Irradiação de $\alpha, \alpha$-dibromo-o-xileno (GBX), em benzeno. $\quad 82$

Tabela IV.6: $\quad$ Irradiação de $\alpha, \alpha$ - $\alpha^{\prime}$-tribromo-o-xileno (TRBX), em benzeno. $\quad 82$

Tabela IV.7: Irradiação de $\alpha, \alpha, \alpha^{\prime}, \alpha^{\prime}$-tetrabromo-o-xileno (TBX), em benzeno. 83

Tabela IV.8: Rendimentos quânticos, de desaparecimento de reagente e de aparecimento do fotoproduto secundário em benzeno, em isooctano e em benzeno/ciclo-hexeno. 
Tabela IV.9: Tempos de vida triplete $\left(\tau_{\mathrm{T}}\right)$, em solução, à temperatura ambiente.

Tabela IV.10: Máximos de absorção $\mathbf{T}_{\mathbf{n}} \leftarrow \mathbf{T}_{1}$, para alguns compostos aromáticos, em ciclo-hexano.

Tabela IV.11: Máximos de absorção para os radicais benzila gerados nas fotólises por pulso de laser, em comparação a dados de literatura.

Tabela IV.12: Tempos de vida aparentes, para os transientes gerados na fotólise por pulso de laser.

Tabela IV.13: Máximos de absorção para difenilcarbenos e radicais benzidrila. 103

Tabela IV.14: Espectros de absorção devidos a cátions benzila. 105

Tabela IV.14: $\quad$ Espectros de absorção devidos a cátions di- e tri-fenil-benzila. 106 


\section{RESUMO}

O presente trabalho tem por objetivo o estudo da fotólise de uma série de brometos de benzila orto-substituídos em solventes apolares, visando contribuir para a elucidação, tanto dos mecanismos operativos após a homólise de ligações carbono-halogênio em sistemas benzilicos, como das espécies intermediárias envolvidas no processo.

Assim sendo, irradiaram-se soluções benzênicas dos compostos $\alpha$-bromo- $\alpha$ xileno (MBX), $\alpha, \alpha$-dibromo-o-xileno (GBX), $\alpha, \alpha^{\prime}$-dibromo-o-xileno (DBX), $\alpha, \alpha, \alpha^{\prime}$ tribromo- $\alpha$-xileno (TRBX) e $\alpha, \alpha, \alpha^{\prime}, \alpha^{\prime}$-tetrabromo-o-xileno (TBX) e soluções de MBX e DBX em iso-octano, utilizando-se uma lâmpada de vapor de mercúrio de baixa pressão $\left(\lambda_{\text {emissão }}=254 \mathrm{~nm}\right.$ ). Os produtos foram analisados e identificados por cromatografia gasosa acoplada a espectrometria de massas e confirmados por co-injeção de amostras autênticas, sintetizadas por via térmica. Os rendimentos quânticos dos produtos foram calculados, utilizando-se o leucocianeto de verde-malaquita como actinômetro.

A análise dos produtos revelou que a homólise da ligação $\mathrm{C}-\mathrm{Br}$ é seguida de uma série de reações de abstração de hidrogênio e recombinação de radicais resultando sempre em xilenos menos e mais bromados que o xileno de partida. Benzaldeídos, resultantes da hidrólise dos dibrometos geminais, também são formados, devido à presença de traços de água. Quando o solvente é iso-octano, o produto menos bromado aparece com maior rendimento quântico relativo, devido à abstração de hidrogênio do solvente pelo fotoproduto primário, um radical benzila; além disso, observa-se a formação de um novo produto: o 2-bromo-2,4,4-trimetil-pentano.

Os rendimentos quânticos de desaparecimento de substrato observados na fotólise de soluções benzênicas de MBX $(0,33)$ e $\mathbf{D B X}(0,52)$ foram superiores àqueles encontrados ao se utilizar iso-octano como solvente: 0,22 e 0,32 , respectivamente. Isto sugere que o benzeno excitado esteja intermediando o processo (i.e., agindo como sensibilizador), transferindo energia de excitação para o brometo de benzila.

Um intermediário bi-radicalar do tipo orto-quinodimetano (o-xilileno) era esperado em caso de: (i) fotólise do radical benzila formado (processo bifotônico) ou (ii) abstração de hidrogênio intramolecular. Entretanto, não se observaram produtos derivados de adição de Diels-Alder, quando ciclo-hexeno foi adicionado ao sistema. Também não se observou formação perceptível de brometo de hidrogênio, em nenhum dos sistemas investigados.

Foram feitos, também, estudos de fotólise por pulso de laser, em iso-octano, para os compostos MBX, DBX, GBX e TBX utilizando-se o 4 o harmônico de um laser de Nd:YAG $(\lambda=266 \mathrm{~nm})$. As soluções de trabalho foram desaeradas por, pelo menos, três ciclos de congelamento-degaseamento-descongelamento até $10^{-5} \mathrm{mmHg}$. A cinética de decaimento das absorções observadas foi analisada como sendo devida a duas espécies, isto é, os resultados são compativeis com um decaimento duplo-exponencial, 
cujos tempos de vida seriam da ordem de $\mu$ s e ms, para as espécies de tempos de vida curto e longo, respectivamente. Além disso, as distribuições espectrais observadas a 0,1 e $10 \mu$ s mostraram-se diferentes, indicando a presença de dois transientes.

A análise da cinética de decaimento das absorções transientes de MBX e DBX, além das distribuições espectrais obtidas para as transições $\mathbf{D}_{\mathbf{n}} \leftarrow \mathbf{D}_{\mathbf{0}}(\lambda=320 \mathrm{~nm}$ e $338 \mathrm{~nm}$, respectivamente) mostram que, na fotólise destes dois compostos, forma-se, inicialmente, um radical, de tempo de vida da ordem de microssegundos, por cisão homolítica da ligação C-Br: $o$-metil-benzila, no caso de $\mathbf{M B X}$ e $o$-(bromo-metil)benzila para DBX. Além destas espécies, formam-se cátions (detectáveis para todos os compostos estudados) que apresentam uma banda de absorção larga e desestruturada (de 330 a $360 \mathrm{~nm} ; \lambda_{\max }=347 \mathrm{~nm}$ ) e com tempo de vida da ordem de milissegundos nas condições de trabalho, a partir de um radical excitado, pela perda de um segundo elétron (Tokumura et alii 1989; 1991). Resultados análogos foram obtidos para a fotólise de DBX e TBX, em solução benzênica, empregando-se um laser de exímero de $\mathrm{XeCl}$ (308nm), tendo sido nestes experimentos que se detectou o radical gerado de TBX, o qual não é observável em iso-octano. Em benzeno observou-se, também, a formação do complexo $\mathrm{Br} * /$ benzeno $\left(\lambda_{\max }=550 \mathrm{~nm}\right)$, fato este que vem a reforçar a proposição de estarem-se gerando radicais nestes sistemas. 


\begin{abstract}
In the present work, the photolyses, in apolar solvents, of a series of bromoderivatives of $o$-xylene is investigated, aiming at attaining an improved understanding of the reaction mechanism and at the identification of the transient species formed after homolysis of the carbon-halogen bond.

$\alpha$-Bromo-o-xylene (MBX), $\alpha, \alpha$-dibromo-o-xylene (GBX), $\alpha, \alpha^{\prime}$-dibromo-oxylene (DBX), $\alpha, \alpha, \alpha^{\prime}$-tribromo- $o$-xylene and $\alpha, \alpha, \alpha^{\prime}, \alpha^{\prime}$-tetrabromo-o-xylene (TBX) were subjected to steady-state $254 \mathrm{~nm}$ irradiation in deaerated benzene and isoöctane. The products were identified by GC-MS and also by co-injection of authentic samples. The analysis of the products formed revealed that homolysis of $\mathrm{C}-\mathrm{Br}$ bond is followed by a series of hydrogen abstraction and radical recombination reactions, resulting in xylenes more and less brominated than the starting compound. Benzaldehydes are also formed from hydrolysis of the geminal dibromides, due to the presence of trace amounts of water. When isoöctane is the solvent, the less brominated products are formed with higher relative quantum yields, as the solvent undergoes hydrogen abstraction by the primary photoproduct, the $o$-methylbenzyl radical, a process also leading to the formation of 2-bromo-2,4,4-trimethylpentane. This notwithstanding, no trace of $\mathrm{HBr}$ was detected. The photolysis of MBX and DBX presented higher absolute quantum yields in benzene than in isoöctane, indicating sensitization by the solvent in the former case. A biradical intermediate, belonging to the orto-quinodimethane class, was expected on the occurrence of either (a) photolysis of the $o$-methylbenzyl radical formed (a biphotonic process) or (b) intramolecular hydrogen abstraction. However, in the presence of cyclohexene no Diels-Alder adduct was observed.

Laser flash-photolysis studies at $266 \mathrm{~nm}$ (quadrupled Nd:YAG) have been performed for MBX, DBX, GBX and TBX, using degassed isoöctane as solvent. The observed transient spectral and kinetic data indicates initial formation of a radical and of a cation, which present micro and millisecond lifetimes, respectively. Moreover, the spectral distributions were different at 0.1 and $10 \mu \mathrm{s}$, as expected for two different transients. Similar results were obtained from DBX, on $308 \mathrm{~nm}$ laser irradiation (XeCl eximer). For TBX, however, only in these latter conditions we were able to detect the $\alpha$-bromo-o-(dibromomethyl)benzyl radical (which half-life is too short in isoöctane to be detected by our apparatus). Both substracts also gave rise to the $\mathrm{Br} /$ /benzene complex $\left(\lambda_{\max }=550 \mathrm{~nm}\right)$, in the $308 \mathrm{~nm}$ photolyses, thus confirming the presence of $\mathrm{Br}$ • in the system under study.
\end{abstract}




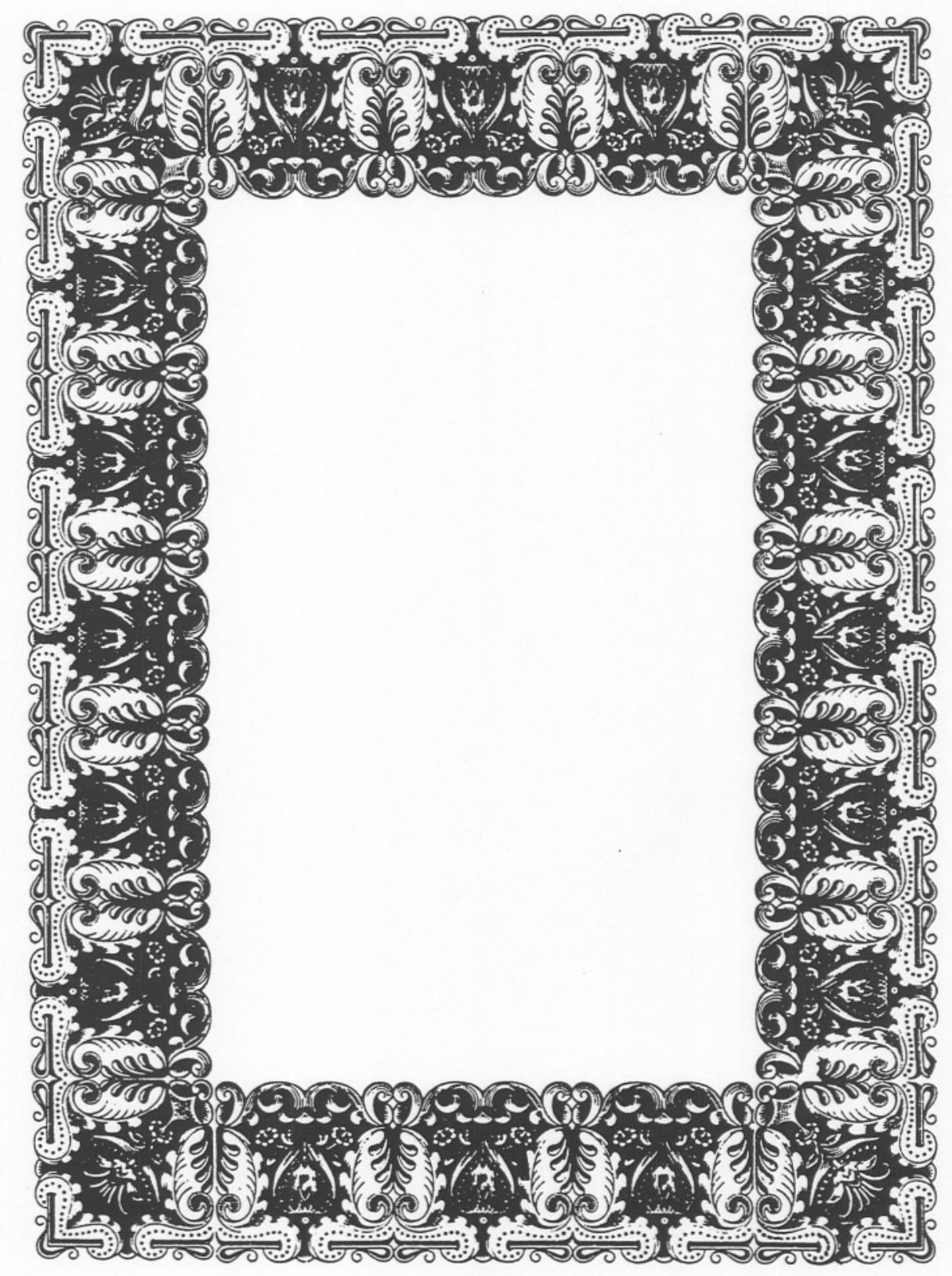

Figura 0 - Imagem de um elétron ampliada 10.000 vezes (observe que o elétron se estende para além da moldura, em todas as direções). 


\section{INTRODUÇÃO}

\section{I.1. Processos Fotoquímicos e Fotofísicos em Solução}

Atualmente, a fotoquímica orgânica abrange um campo de estudo bastante extenso. Neste contexto, o estudo dos processos fotofísicos - isto é, das transições, radiativas ou não-radiativas, que interconvertem os estados excitados de uma mesma espécie entre si, ou com o estado fundamental $\left(\mathbf{S}_{0}\right)$ - auxilia na compreensão mais detalhada dos mecanismos de reação envolvidos nos processos fotoquímicos. Estes últimos são aqueles processos onde as transições, a partir de um estado eletronicamente excitado, produzem estruturas diferentes da apresentada por $\mathbf{S}_{\mathbf{0}}$. A Figura $I_{\text {I. }}$ apresenta o esquema de uma rede que sumariza os principais processos fotofísicos e fotoquímicos (TURRO, 1978).

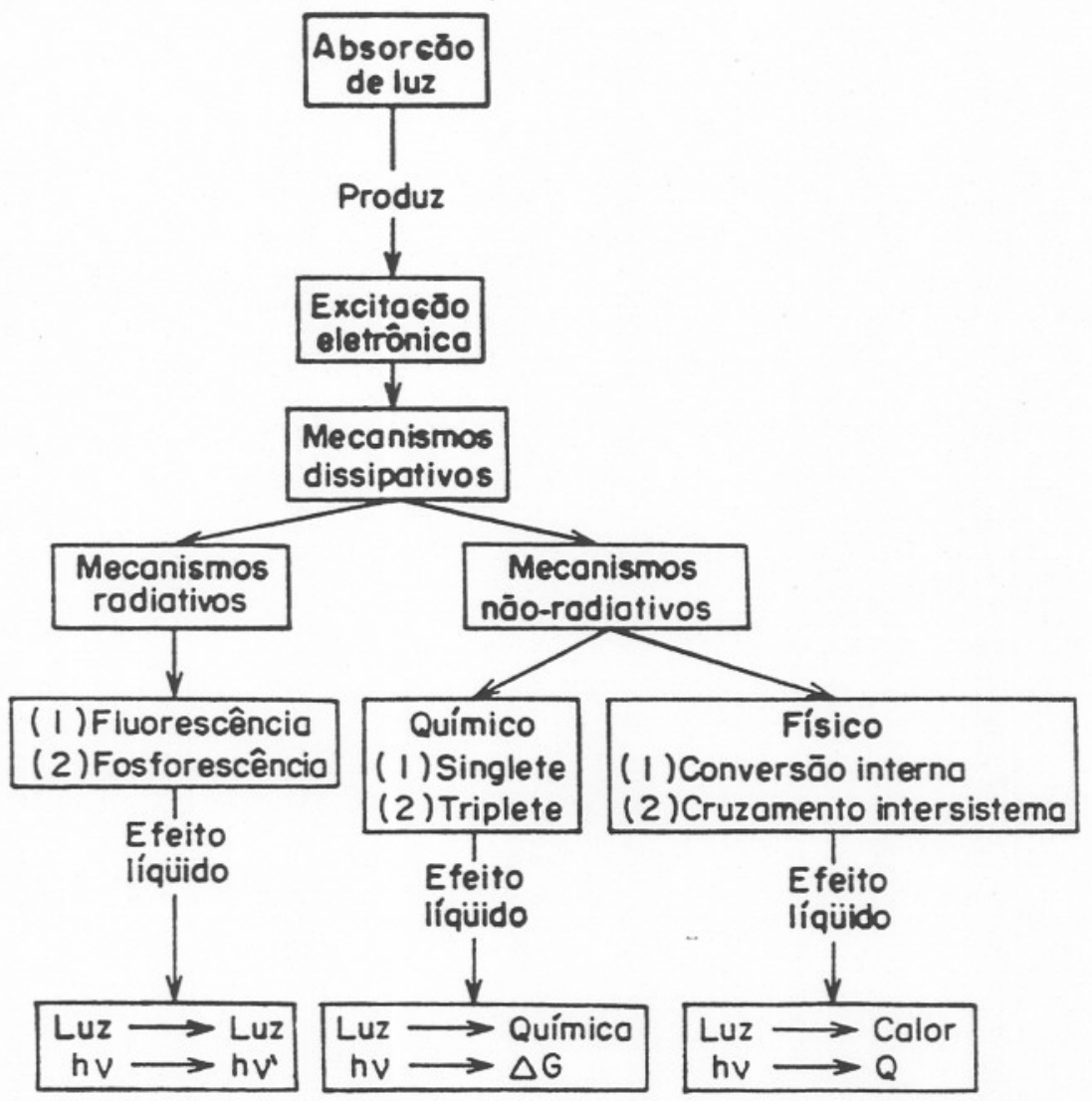

Figura I.1 - Processos que interessam a um fotoquímico (TURRO, 1978).

A promoção de uma molécula para um estado eletronicamente excitado pode ser induzida por radiação eletromagnética na região do visível ou do ultra-violeta, por radiação ionizante ou, ainda, através de reações químicas altamente exotérmicas. As características dos estados excitados criados podem variar, segundo a origem da excitação, quanto à proporção singlete-triplete, à geometria e aos conteúdos de energia eletrônica e vibracional (QUINA, 1982). Em fase condensada, estas diferenças 
são eliminadas como resultado de um equilíbrio térmico rápido (da ordem de picosegundos) das espécies excitadas criadas inicialmente. Estas espécies, sejam elas singlete $\left(\mathbf{S}_{\mathbf{n}}\right)$ ou triplete $\left(\mathbf{T}_{\mathbf{n}}\right)$, sofrem relaxação não-radiativa - conversão interna (ic) e relaxação vibracional (vr) - para os estados excitados de mesma multiplicidade, menor conteúdo energético e maior tempo de vida, $S_{1}$ ou $\mathbf{T}_{1}$ (TURRO et alii, 1978; WIESENFELD \& IPPEN, 1979; MORGANTE \& STRUVE, 1979; vide Figura I.2), ou seja, os processos fotoquímicos ou fotofísicos em solução envolvem, em geral, o decaimento de um - ou outro - destes estados excitados $\left(\mathbf{S}_{\mathbf{1}}\right.$ ou $\left.\mathbf{T}_{\mathbf{1}}\right)$.

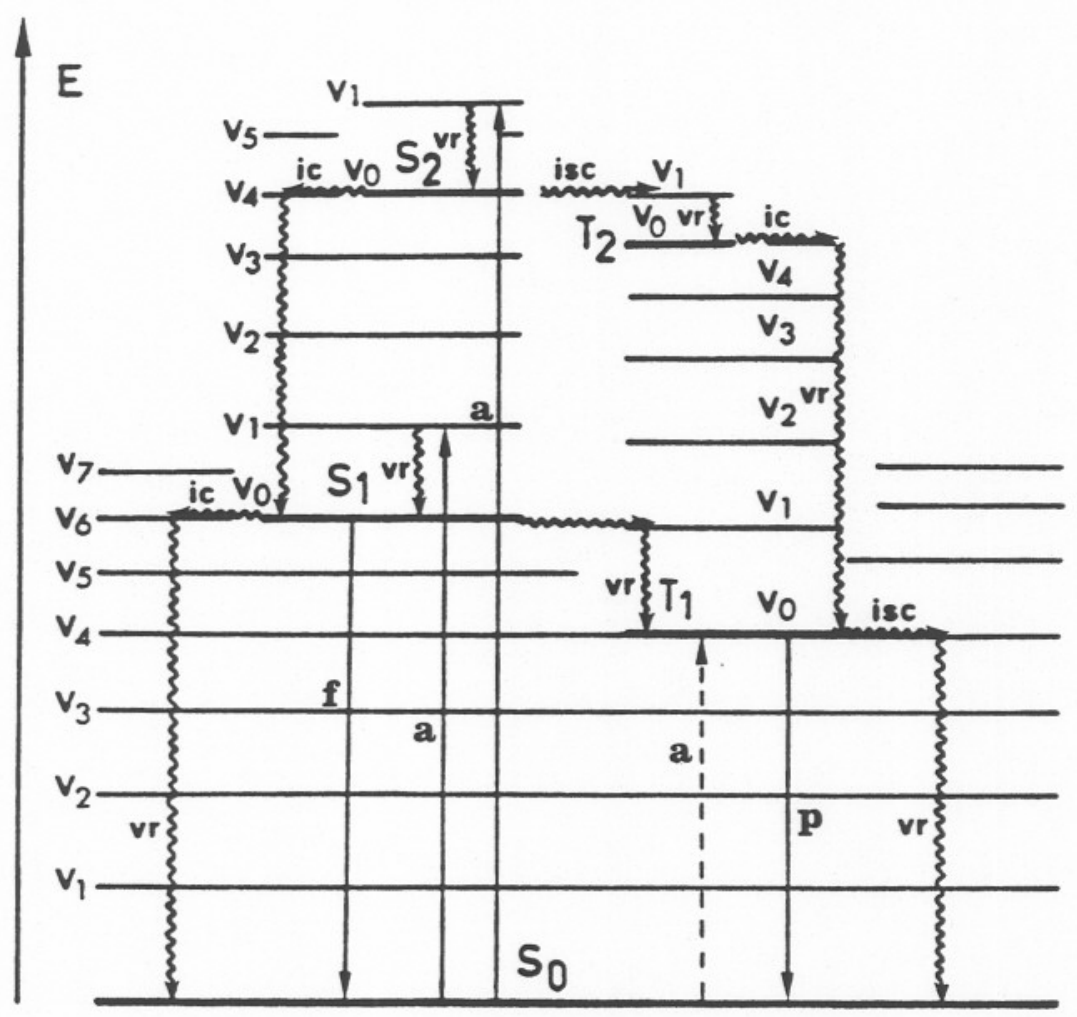

: transições não-radiativas

a: absorção

$\longrightarrow$ : transições radiativas

f: fluorescência

$----->$ : transições proibidas

p: fosforescência

ic: conversão interna

$\mathbf{v}_{\mathbf{n}}$ : níveis vibracionais

isc: cruzamento intersistema

$\mathbf{S}_{\mathbf{n}}$ : níveis eletrônicos singlete

vr: relaxação vibracional

$T_{\mathbf{n}}$ : níveis eletrônicos triplete

Figura I.2 - Diagrama de Jablonski (apud MARGARETHA, 1982). 
Dependendo da forma pela qual se encarem os processos "fotofisicos" e "fotoquímicos" fica evidente que a fronteira entre estes dois tipos de processos não é bem definida. Pensando genericamente, é possível dizer que a diferença entre estes processos está, essencialmente, no grau de alteração da geometria nuclear. De fato, podem-se descrever as transições não-radiativas, de maneira abrangente, como conversão de energia eletrônica em movimento nuclear. Assim, se a distorção com relação à geometria do estado fundamental não for muito grande, é possível que haja retomo à geometria original, por decaimento não-radiativo - conversão interna $\mathrm{e}$ relaxamento vibracional. Por outro lado, pequenas alterações na geometria internuclear relativa, para a direita da região de mínimo representada pelo "funil", tendem a conduzir a molécula para o estado fundamental com uma geometria que facilita a formação dos produtos (TURRO, 1978; vide Figura I.3).

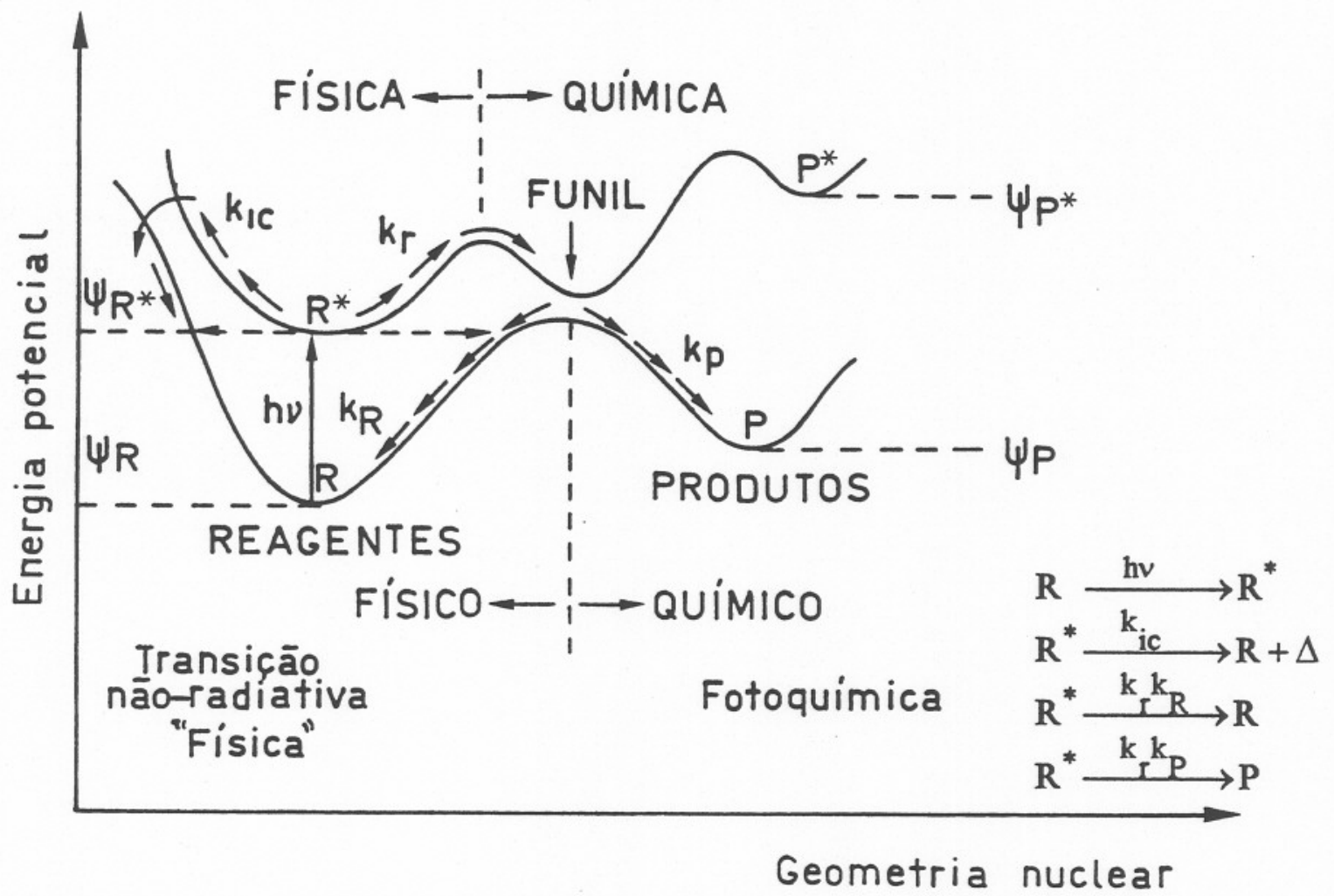

Figura I.3 - Descrição esquemática de superficies de energia, mostrando a relação entre processos fotofísicos não-radiativos e processos fotoquímicos (TURRO, 1978).

Os processos fotoquímicos primários nem sempre originam, diretamente, produtos estáveis, sendo mais comum a formação de intermediários reativos (possibilidades a e b, respectivamente, na Figura I.4), tais como radicais, bi-radicais ou íons, os quais dão origem ao produto final da reação através de processos secundários, térmicos. Neste último caso, o que se define como fotorreação envolve, além do passo de desativação do estado excitado (formado quando da absorção de luz), os subseqüentes passos térmicos, que conduzem ao fotoproduto (LAMOLA \& TURRO, 1977). A diferença entre estados de transição e intermediários é o fato destas últimas 
espécies encontrarem-se em um poço de energia potencial, enquanto os estados de transição correspondem a máximos, no corte da superficie de energia potencial definido ao longo da coordenada de reação. Para que os intermediários possam ser considerados como espécies "estáveis", a barreira energética para os passos de reação subseqüentes à sua formação deve ser tal que permita a sobrevivência do intermediário durante pelo menos uma vibração na direção da coordenada de reação (WENTRUP, 1984).

Um esquema simplificado desta seqüência de eventos, desde a excitação do substrato $\mathbf{R}$ até a obtenção de produtos, encontra-se na Figura I.4.

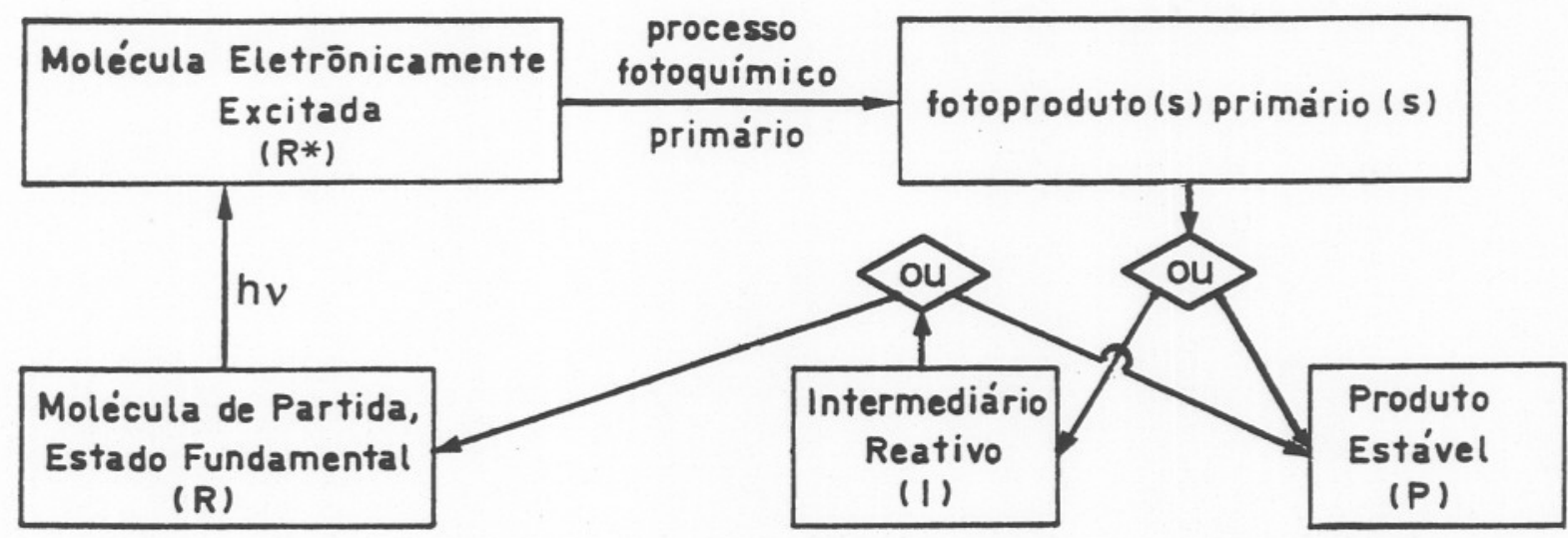

Figura I.4 - Eventos, em uma fotorreação (LAMOLA \& TURRO, 1977).

No caso de compostos benzílicos $\left(\mathrm{ArCH}_{2} \mathrm{Z}\right)$, ainda que a excitação se dê no cromóforo aromático, pode-se obter o radical benzila como fotoproduto primário, a partir da cisão homolítica da ligação sigma C-Z. A transferência de energia de excitação entre os estados $\pi, \pi^{*}$ e $\sigma, \sigma^{*}$ se dá através de um funil (i.e., de um cruzamento evitado), não envolvendo passos intermediários, como mostrado na Figura I.5 B (MICHL \& BONACIC-KOUTECKY, 1990).

Nas Figuras I.5 A e B estão apresentados os diagramas de correlação para os estados singlete do composto benzílico genérico $\mathrm{ArCH}_{2} \mathrm{Z}$. A Figura I.5 A apresenta o caso de ordem zero, isto é, considerando-se que o anel aromático e a ligação $\sigma \mathrm{C}-\mathrm{Z}$ se comportassem como duas sub-unidades independentes; na parte B, estão esboçadas as superficies de potencial obtidas quando se admitem interações entre estas duas subunidades, isto é, têm-se os diagramas de correlação de estados não-diabáticos (de primeira ordem). Analisando-se a Figura I.5 B é evidente que não há impedimento para a transformação de $\pi, \pi^{*}$ em $\sigma, \sigma^{*}$, havendo uma superficie de potencial contínua que permite a transferência de elétrons de $\pi$ para $\sigma$, alcançando-se uma geometria em $\sigma, \sigma^{*}$ que conduz à dissociação da ligaçao $\sigma$ nos radicais $\mathrm{ArCH}_{2}{ }^{\circ}$ e $\mathrm{Z}^{\circ}$. 
A

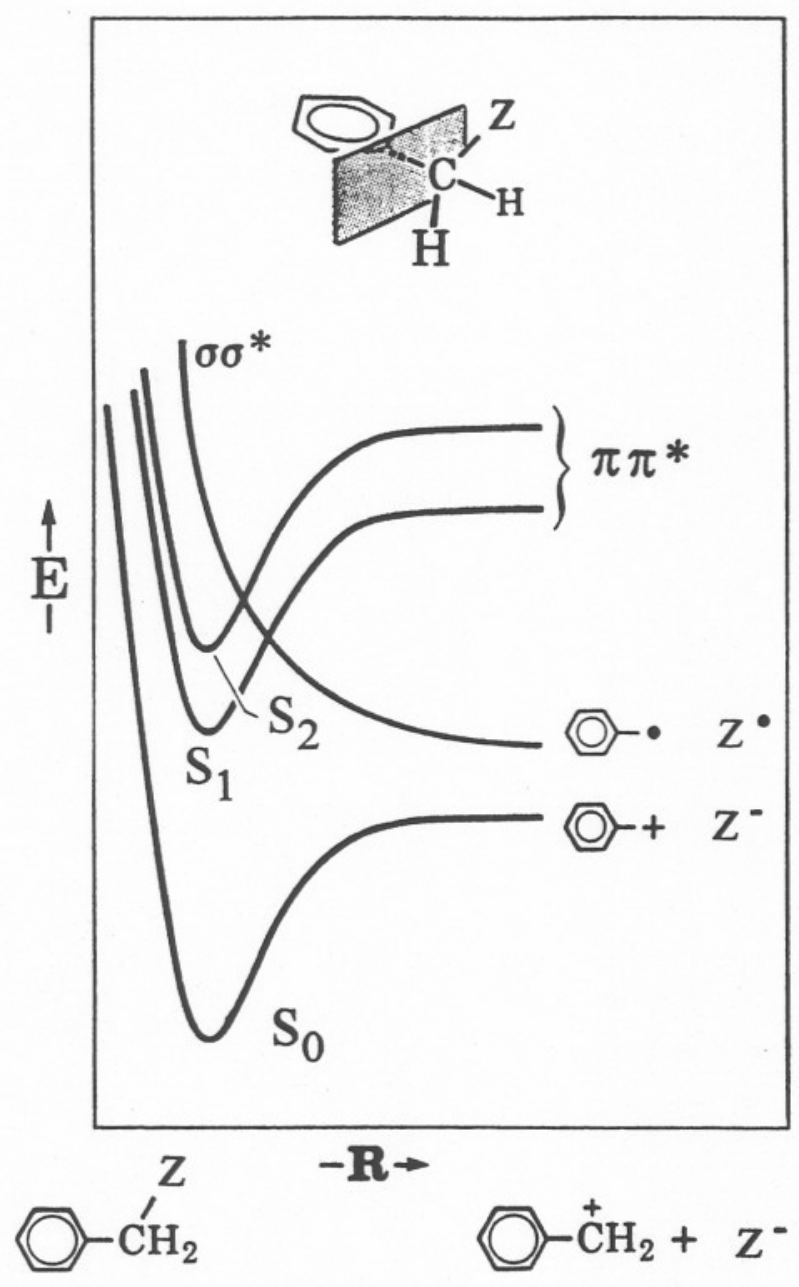

B

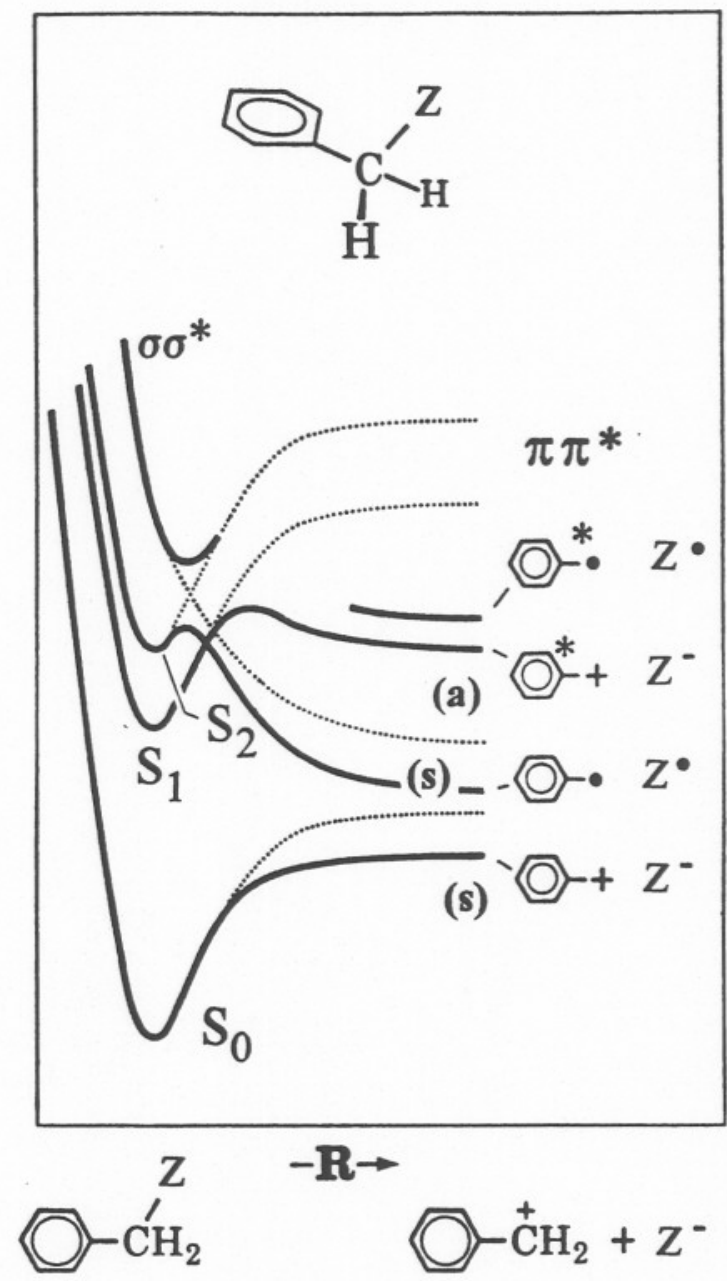

Figura L.5 - Dissociação da ligação $\sigma$, para um composto benzilico genérico. Diagrama de correlação de estados singlete antes (A) e depois (B) de se considerarem as interações entre as sub-unidades. As linhas pontilhadas indicam os cruzamentos evitados. $S_{2}$ e $S_{1}$ referem-se, respectivamente, aos estados singlete simétrico (s) e antisimétrico (a) com relação ao plano de simetria indicado em $A$. $S_{0}$ indica o estado fundamental. Os estados triplete $\pi, \pi^{*}$ não se encontram representados, para melhor visualização, mas as curvas seriam análogas às dos singletes, a menores energias. (MICHL \& BONACIC-KOUTECKY, 1990). 


\section{I.2. Fotólise por Pulso de Laser e Geração de Intermediários Radicalares}

Radicais e bi-radicais são intermediários reativos que podem ser obtidos através de vários métodos, como radiólise de pulso, fotólise por pulso (convencional ou de laser), ultra-som, ou ainda, a partir de outros radicais. O estudo da fotoquímica de intermediários reativos tem-se desenvolvido bastante nos últimos dez anos devido, entre outros motivos, à facilidade de se adquirirem, comercialmente, os componentes necessários para a execução de experimentos de fotólise por pulso de laser (SCAIANO, 1982; JOHNSTON, 1993). Em relação às lâmpadas de descarga convencionais, os lasers apresentam a característica de emitirem radiação monocromática de alta intensidade (1-100 mJ/pulso), além da luz emitida ser coerente, podendo ser focalizada em uma área pequena, o que gera uma concentração de estados excitados ou de intermediários (de pelo menos, $10^{-5} \mathrm{~mol} \cdot \mathrm{L}^{-1}$ ) mais alta do que a conseguida através da fotólise convencional (aproximadamente, $10^{-7} \mathrm{~mol} \cdot \mathrm{L}^{-1}$ ).

$\mathrm{Na}$ fotólise por pulso detectam-se, basicamente, as curvas de variação de absorbância $(\Delta \mathrm{A})$ versus tempo, a um comprimento de onda fixo, sendo o sinal obtido devido à absorbância do transiente. Além das informações cinéticas, obtidas através da análise da variação do sinal com o tempo, é possível obterem-se espectros de absorção dos transientes repetindo-se esta medida a diferentes comprimentos de onda e lendo-se a absorbância a um tempo fixo, determinado a partir do tiro do laser (SCAIANO, 1982).

A resolução temporal das fotólises por pulso, convencional e de laser, é limitada pela duração do pulso da fonte, sendo de alguns micro-segundos ( $\mu$ s) para o caso das lâmpadas de descarga e de nano-segundos (ns) a dezenas de femto-segundos (fs), no caso dos lasers. Assim, quando os lasers passaram a ser utilizados como fonte, tornouse possível obterem-se espectros de absorção para transientes, mesmo à temperatura ambiente, condição em que o tempo de vida destas espécies é bastante reduzido relativamente ao verificado em matrizes à baixa temperatura $(77 \mathrm{~K})$, caso em que, muitas vezes, o tempo de vida é tão longo que se podem utilizar técnicas convencionais para o estudo dos intermediários gerados. No caso do radical benzila, por exemplo, o tempo de vida de fluorescência (emissão $\mathbf{D}_{1} \rightarrow \mathbf{D}_{0}$ ) é menor do que 1 ns em solução, à temperatura ambiente, e de $1-1,5 \mu$ s em vidro a $77 \mathrm{~K}$ (JOHNSTON, 1993). 


\section{I.3. Radicais Benzila}

Dentre os vários métodos desenvolvidos para a geração fotoquímica de radicais (vide as equações a-d, que se seguem) e bi-radicais, tem-se utilizado, freqüentemente, a foto-homólise de ligações carbono-halogênio (equação a) para a geração de diferentes radicais aril-metila devido, tanto à facilidade com que se obtêm os precursores halogenados, como ao fato de sua fotoquímica ser razoavelmente simples, o que os torna bastante adequados como sistemas modelo (JOHNSTON, 1993). Por outro lado, a rota b não tem sido muito utilizada, embora o emprego de precursores como cetonas, ésteres ou sulfonas, na fotólise, apresente a vantagem de gerar dois radicais simultaneamente.

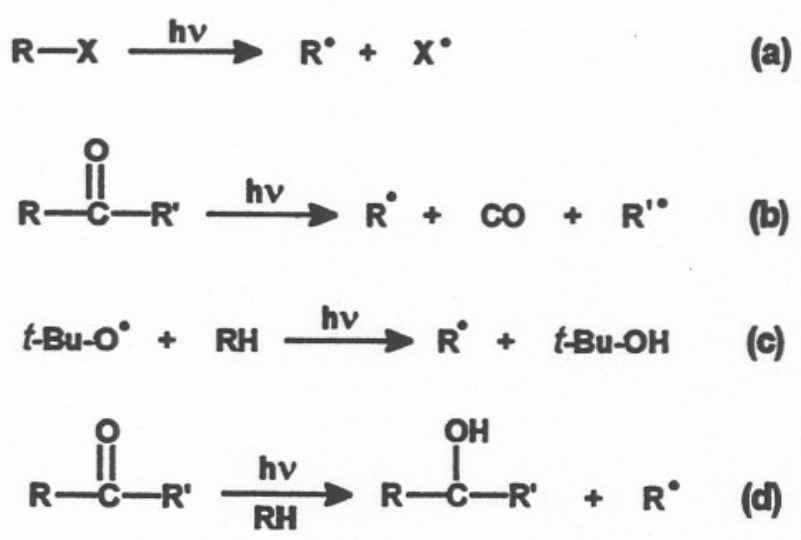

Existe uma gama razoável de trabalhos referentes às características espectroscópicas de radicais benzila pois, além da facilidade de serem gerados e de suas propriedades absortivas e emissivas serem adequadas para estudos de luminescência, 0 radical benzila, por ser considerado o protótipo de radicais alquil-aromáticos, tem sido objeto de vários trabalhos teóricos e experimentais, já há um certo tempo. Assim, em um estudo pioneiro, PORTER \& WRIGHT (1955) obtiveram o espectro de absorção para radicais benzila, em fase gasosa, com o objetivo de identificar a espécie produzida na fotólise de tolueno, etil-benzeno, cloreto de benzila, a-cloro-tolueno, benzil-amina e alguns outros derivados benzilicos. Na mesma época, BINDLEY \& WALKER (1955) e WATTS \& WALKER (1962) também obtiveram espectros de absorção para o radical benzila, gerado por descarga elétrica, em meio rarefeito. Subseqüentemente, obtiveram-se, para os radicais gerados por fotólise dos hidrocarbonetos correspondentes (tolueno, o-, $m$ - e $p$ - xileno), os espectros de absorção, na região do visível e do ultra-violeta, em matriz de EPA (PORTER \& STRACHAN, 1958), de metilciclo-hexano/isopentano (MI; BINDLEY et alii, 1962) e os espectros de emissão e de excitação de fluorescência (FRIEDRICH \& ALBRECHT, 1974; OKAMURA \& TANAKA, 1975; HIRATSUKA et alii, 1980) em matrizes de 3-metil-pențano (3-MP), de EPA e de etanol (EtOH), respectivamente, utilizando-se ou espectrômetros convencionais, ou um laser de corante, como analisador (OKAMURA \& TANAKA, 1975). Neste último trabalho, foram determinados tempos de vida de fluorescência $\left(\tau_{\mathrm{f}}\right)$ na faixa de de 0,5 a 
$3,0 \mu$ s para uma série de radicais benzila metil-substituidos, dados coincidentes com os determinados, posteriormente, por MEISEL et alii (1986).

Através do conjunto de dados obtidos ficou bem estabelecido que estes radicais exibem uma banda de absorção fraca e estruturada na região do visível (na faixa entre 460 e 500nm: 2,7 a 2,5eV), referente à primeira transição eletrônica dublete-dublete, além de uma banda forte na região do ultra-violeta próximo (vide Tabela I.1, p.10).

Após alguma controvérsia, os vários estados e transições eletrônicas responsáveis pelos espectros de absorção e de fluorescência do radical benzila puderam ser atribuídos. Esta atribuição foi dificultada por haver sobreposição de dois sistemas de bandas na região de menor energia $(2,68 \mathrm{eV} ; 463 \mathrm{~nm})$, os quais, além disso são relativamente pouco intensos. Considerando-se que o radical benzila pertença ao grupo de pontos $\mathrm{C}_{2 \mathrm{v}}$, seu estado fundamental e seus estados excitados de menor energia foram designados como sendo $\mathbf{1}^{2} \mathbf{B}_{2}, 1^{2} \mathbf{A}_{2}$ e $2^{2} \mathbf{B}_{2}$, respectivamente (COSSARTMAGOS \& LEACH, 1976; FRIEDRICH \& AIBRECHT, 1973), admitindo-se que o eixo y seja perpendicular ao plano da molécula, o eixo $\mathrm{z}$ seja coincidente com o eixo $\mathbf{C}_{2}$ e o plano $\mathbf{X Z}$ contenha o plano do anel, como é usual na literatura referente aos radicais benzila (vide Figura I.6A, p.9). Caso os eixos $\mathbf{x}$ e $\mathbf{y}$ fossem intercambiados de acordo com as recomendações apresentadas por MULLIKEN (1955), os estados $\mathbf{B}_{2}$ passariam a ser designados por $\mathbf{B}_{1}$ (e vice-versa), como indicado na Figura I.6A, a seguir. Embora a convenção de Mulliken seja, usualmente, a adotada na grande maioria dos trabalhos referentes a compostos aromáticos, inclusive naqueles sobre derivados monosubstituídos do benzeno, também pertencentes ao grupo $C_{2 v}$ (SANTIAGO et alii,1976), no caso de radicais benzila, por razões históricas, ela não é utilizada.

A partir dos dados de polarização de fluorescência obtidos por FRIEDRICH \& ALBRECHT (1974), COSSART-MAGOS \& LEACH (1976) demonstraram que a banda fraca ( $\approx \approx 10^{-3} \mathrm{eV}$ ) na região do visível $(463 \mathrm{~nm} ; 2,68 \mathrm{eV})$ pode ser atribuída não somente à transição $\mathbf{1}^{2} \mathbf{A}_{2} \leftarrow \mathbf{1}^{2} \mathbf{B}_{2}$, mas também, à $2^{2} \mathbf{B}_{2} \leftarrow \mathbf{1}^{2} \mathbf{B}_{2}$, até então não identificada, enquanto as bandas fortes observadas entre 4,1 e 3,9eV (305-321nm) e entre 4,8 e 4,7eV (258-264,5nm) devem-se, respectivamente, às transições $2^{2} \mathbf{A}_{2} \leftarrow \mathbf{1}^{2} \mathbf{B}_{2}$ e $\mathbf{4}^{\mathbf{2}} \mathbf{B}_{\mathbf{2}} \leftarrow$ $\mathbf{1}^{2} \mathbf{B}_{2}$, sofrendo, esta última, uma sobreposição de $3^{2} \mathbf{B}_{2} \leftarrow \mathbf{1}^{2} \mathbf{B}_{2}$, transição prevista como sendo menos intensa e de energia calculada de $4,6 \mathrm{eV}(269,6 \mathrm{~nm})$. O estado emissivo é o estado excitado de menor energia $\mathbf{1}^{2} \mathbf{A}_{2}$, tendo sido previsto por cálculos teóricos que o estado $\mathbf{2}^{\mathbf{2}} \mathbf{B}_{\mathbf{2}}$ - postulado por COSSART-MAGOS \& LEACH (1976) estaria em um nível ligeiramente acima daquele do estado $\mathbf{1}^{2} \mathbf{A}_{\mathbf{2}}(\Delta \mathrm{E} \leq 0,05 \mathrm{eV})$ e que a transição $2^{\mathbf{2}} \mathbf{B}_{2} \leftarrow \mathbf{1}^{\mathbf{2}} \mathbf{B}_{2}$ teria uma força de oscilador maior do que a transição $\mathbf{1}^{\mathbf{2}} \mathbf{A}_{\mathbf{2}} \leftarrow$ $\mathbf{1}^{2} \mathbf{B}_{2}$ (CHANG \& JAFFE, 1973). COSSART-MAGOS \& LEACH (1976) demonstraram que o acoplamento vibrônico entre estes dois estados é o principal motivo para a ausência de simetria especular observada nos espectros de absorção e de emissão do radical benzila, na região do visível $(2,68 \mathrm{eV})$. 


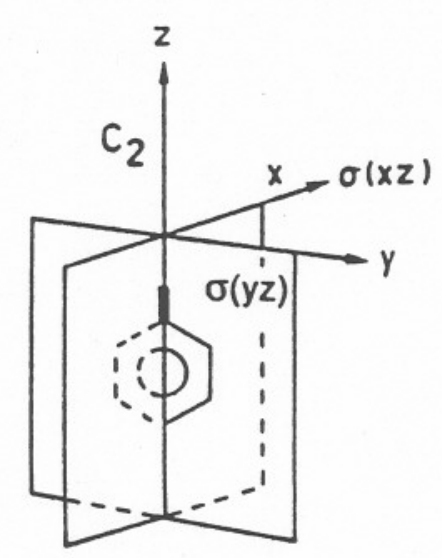

MULLIKEN

A:

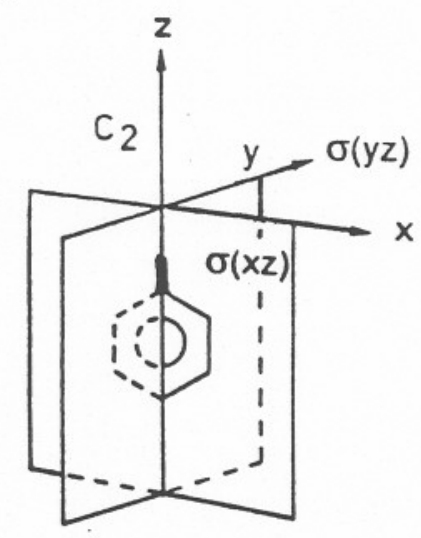

BENZILA

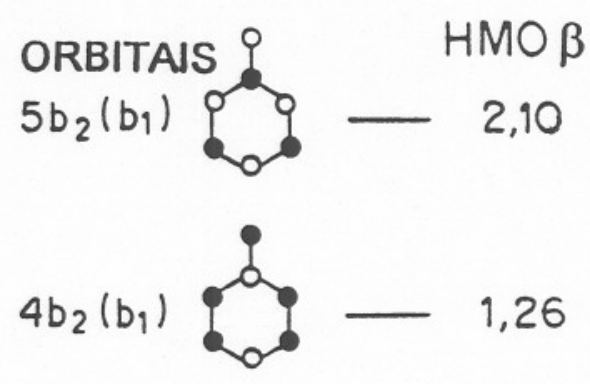

$2 a_{i} \int_{0}^{1}-1,00$<smiles>CC(C)C1COCCC1O</smiles><smiles>CC1CCCOOC1OO</smiles>

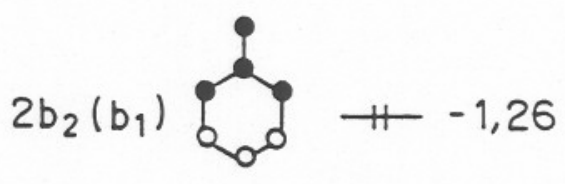
$1 b_{2}\left(b_{1}\right) \underbrace{a} a^{9}+-2,10$

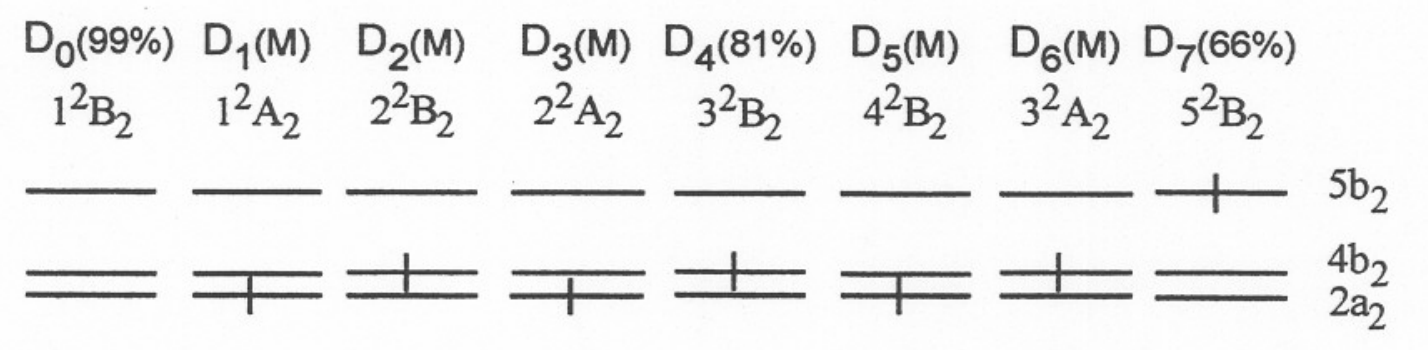

B:
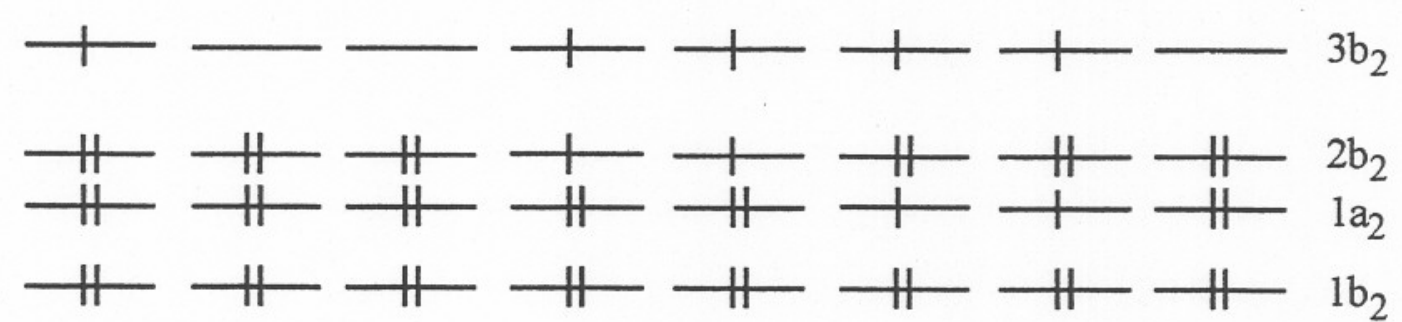

Figura I.6 - A: Orbitais moleculares (HMO), para o radical benzila, identificados segundo sua simetria e energia. Convenções para o sistema de coordenadas normais: a de MULLIKEN (1955) e a usualmente adotada para radicais benzila. B: Configurações de ordem zero correspondentes ao estado fundamental $\left(\mathbf{D}_{\mathbf{0}}\right)$ e aos estados excitados $\left(\mathbf{D}_{\mathbf{n}}\right)$ do radical benzila, também identificados pelas designações de simetria. As distâncias entre os níveis de energia, bem como sua organização seqüencial, correspondem a dados experimentais e/ou calculados por diversos métodos (ZIMMERMAN \& SANDEL, 1963; CHANG et alii, 1975; HIRATSUKA et alii, 1980; CLARIDGE \& FISCHER, 1983), diferindo da seqüência obtida por combinações lineares de orbitais (vide $\mathbf{A}$ ). $\mathrm{O}$ valor entre parênteses indica a pureza do estado (CI), segundo CHANG et alii (1975). 
Tabela I.1: Máximos de absorção $\left(\lambda_{0,0}\right)$ para radicais benzila em vários meios.

\begin{tabular}{|c|c|c|c|c|c|}
\hline Substituinte & $\begin{array}{l}\lambda_{\max }(\mathrm{nm}) \\
4^{2} \mathrm{~B}_{2} \leftarrow 1^{2} \mathrm{~B}_{2} \\
\left(D_{5} \leftarrow \mathrm{D}_{0}\right)\end{array}$ & $\begin{array}{l}\lambda_{\max }(\mathrm{nm}) \\
2^{2} \mathbf{A}_{2} \leftarrow 1^{2} \mathbf{B}_{2} \\
\left(\mathbf{D}_{3} \leftarrow \mathbf{D}_{0}\right)\end{array}$ & $\begin{array}{l}\lambda_{\max }(\mathrm{nm}) \\
2^{2} \mathrm{~B}_{2} \leftarrow 1^{2} \mathrm{~B}_{2} \\
1^{2} \mathrm{~A}_{2} \leftarrow 1^{2} \mathrm{~B}_{2} \\
\left(\mathrm{D}_{2} ; \mathrm{D}_{1} \leftarrow \mathrm{D}_{0}\right)\end{array}$ & Condiçōes & REF. \\
\hline$\overline{\mathrm{H}}$ & $\begin{array}{l}258 \\
260^{\mathrm{a}} \\
258,5^{\mathrm{a}} \\
259,3 \\
264,5 \\
260,3 \\
257 \\
258\end{array}$ & $\begin{array}{l}305,3 \\
318,7 \\
317,8 \\
318 \\
318,5^{\mathrm{a}} \\
321^{\mathrm{a}} \\
319,3 \\
320,9 \\
319,3 \\
318 \\
316 \\
315^{\mathrm{a}} \\
310 \\
312^{\mathrm{a}}\end{array}$ & $\begin{array}{l}462,5^{a} \\
463^{\mathrm{a}} \\
462,2 \\
462,2 \\
462,2 \\
463 \\
463\end{array}$ & $\begin{array}{l}\text { fase gasosa, t ambiente; Arco } \\
\text { matriz EPA } \\
\text { matriz MI, -196² C; Arco } \\
\text { matriz 3-MP, 77K; Arco } \\
\text { matriz 3-MP, 77K, excitação de fluorescência; Arco } \\
\text { matriz EPA, 77K, excitação de fluorescência; Arco } \\
\text { matriz 3-MH, excitação de fluorescência } \\
\text { matriz 2-MTHF, excitação de fluorescência } \\
\text { matriz EtOH, excitação de fluorescência } \\
\text { matriz EtOH, 77K, excitação fluorescência; Arco } \\
\text { ciclo-hexano, 260; FP } \\
\text { hexano, t ambiente; LFP } \\
\text { benzeno, t ambiente; LPF } \\
\text { hexano saturado com ar, t ambiente; LFP }\end{array}$ & $\begin{array}{r}1 \\
2 \\
3 \\
4 \\
5 \\
6 \\
7 \\
7 \\
7 \\
8 \\
9 \\
10 \\
11 \\
12\end{array}$ \\
\hline 2-Me & $\begin{array}{l}262 \\
261,5\end{array}$ & $\begin{array}{l}323 \\
322,6 \\
323 \\
321,5\end{array}$ & $\begin{array}{l}477 \\
475\end{array}$ & $\begin{array}{l}\text { matriz EPA } \\
\text { matriz MI, }-196^{\circ} \mathrm{C} \text {; Arco } \\
\text { matriz EtOH, } 77 \mathrm{~K} \text {, excitação de fluorescência; Arco } \\
\text { ciclo-hexano, } 26^{\circ} \mathrm{C} \text {; FP }\end{array}$ & $\begin{array}{l}2 \\
3 \\
8 \\
9\end{array}$ \\
\hline 3-Me & $\begin{array}{l}263 \\
263 \\
\end{array}$ & $\begin{array}{l}323 \\
322 \\
321 \\
\end{array}$ & $\begin{array}{l}473 \\
472 \\
\end{array}$ & $\begin{array}{l}\text { matriz EPA } \\
\text { matriz EtOH, } 77 \mathrm{~K} \text {, excitação de fluorescência; Arco } \\
\text { ciclo-hexano, } 26^{\circ} \mathrm{C} ; \mathrm{FP}\end{array}$ & $\begin{array}{l}2 \\
8 \\
9\end{array}$ \\
\hline 4-Me & $\begin{array}{l}266 \\
267^{a} \\
265 \\
257\end{array}$ & $\begin{array}{l}310 \\
323 \\
322,2 \\
322 \\
323^{\mathrm{a}} \\
323 \\
320 \\
319^{\mathrm{a}}\end{array}$ & $\begin{array}{l}466^{a} \\
466 \\
467\end{array}$ & $\begin{array}{l}\text { fase gasosa, t ambiente; Arco } \\
\text { matriz EPA } \\
\text { matriz MI, }-196^{\circ} \mathrm{C} \text {; Arco } \\
\text { matriz 3-MP, } 77 \mathrm{~K} \text {; Arco } \\
\text { matriz 3-MP, 77K, excitação de fluorescência; Arco } \\
\text { matriz EtOH, 77K, excitação de fluorescência; Arco } \\
\text { ciclo-hexano, } 26^{\circ} \mathrm{C} \text {; FP } \\
\text { hexano saturado com ar, t ambiente; LFP. }\end{array}$ & $\begin{array}{r}1 \\
2 \\
3 \\
4 \\
5 \\
8 \\
9 \\
12\end{array}$ \\
\hline 3,5-di-Me & 266,3 & 324 & 483 & matriz 3-MP, 77K; Arco & 4 \\
\hline 2,4,5-tri-Me & 272 & $\begin{array}{l}328 \\
331 \\
\end{array}$ & 488 & $\begin{array}{l}\text { matriz 3-MP, 77K; Arco } \\
\text { acetonitrila, t ambiente; LFP }\end{array}$ & $\begin{array}{l}4 \\
9 \\
\end{array}$ \\
\hline Penta-Me & 275 & 336 & & matriz 3-MP, 77K; Arco & 4 \\
\hline $2-n-\mathrm{Pr}$ & & 324,7 & & matriz MI, $-196^{\circ} \mathrm{C} ;$ Arco & 3 \\
\hline $3-n-\operatorname{Pr}$ & & 322,3 & & matriz MI, $-196^{\circ} \mathrm{C} ;$ Arco & 3 \\
\hline $4-n-\operatorname{Pr}$ & & 322,0 & & matriz MI, $-196^{\circ} \mathrm{C}$; Arco & 3 \\
\hline $3-i-\mathrm{Pr}$ & & 321,8 & & matriz MI, $-196^{\circ} \mathrm{C} ;$ Arco & 3 \\
\hline $4-i-\operatorname{Pr}$ & & 321,9 & & matriz MI, $-196^{\circ} \mathrm{C}$; Arco & 3 \\
\hline 2-OMe & 268 & 332 & 484 & ciclo-hexano, $26^{\circ} \mathrm{C}$; FP & 9 \\
\hline 3-OMe & 258 & 323 & $\sim 511$ & ciclo-hexano, $26^{\circ} \mathrm{C} ; \mathrm{FP}$ & 9 \\
\hline 4-OMe & $\begin{array}{l}283 \\
286^{\mathrm{a}} \\
283,3^{\mathrm{a}}\end{array}$ & $\begin{array}{l}321 \\
321^{\mathrm{a}} \\
316,7^{\mathrm{a}}\end{array}$ & 485 & $\begin{array}{l}\text { ciclo-hexano, } 26^{\circ} \mathrm{C} \text {; FP } \\
\text { hexano, } \mathrm{t} \text { ambiente; LFP } \\
\text { hexano saturado com ar, t ambiente; LFP }\end{array}$ & $\begin{array}{r}9 \\
12 \\
14\end{array}$ \\
\hline $4-\mathrm{F}$ & & $310^{\mathrm{a}}$ & & hexano saturado com ar, $\mathrm{t}$ ambiente; LFP & 12 \\
\hline $2-\mathrm{Cl}$ & 259 & 325 & 481 & ciclo-hexano, $26^{\circ} \mathrm{C}$; FP & 9 \\
\hline $3-\mathrm{Cl}$ & 261 & 324 & 478 & ciclo-hexano, $26^{\circ} \mathrm{C} ; \mathrm{FP}$ & 9 \\
\hline $4-\mathrm{Cl}$ & 269 & $\begin{array}{l}317 \\
314^{a} \\
\end{array}$ & 473 & $\begin{array}{l}\text { ciclo-hexano, } 26^{\circ} \mathrm{C} \text {; FP } \\
\text { hexano saturado com ar, t ambiente; LFP }\end{array}$ & $\begin{array}{r}9 \\
14 \\
\end{array}$ \\
\hline 2,4-di-Cl & 268 & 330 & $\sim 510$ & ciclo-hexano, $26^{\circ} \mathrm{C} ; \mathrm{FP}$ & 9 \\
\hline 2,6-di- $\mathrm{Cl}$ & 258 & 336,5 & $\sim 520$ & ciclo-hexano, $26^{\circ} \mathrm{C} ; \mathrm{FP}$ & 9 \\
\hline 4-Br & & 314 & & hexano saturado com ar, $t$ ambiente; LFP & 14 \\
\hline $4-\mathrm{CN}$ & $\begin{array}{l}270^{\mathrm{a}} \\
274\end{array}$ & $\begin{array}{l}315^{a} \\
317\end{array}$ & & $\begin{array}{l}\text { hexano, } \mathrm{t} \text { ambiente; LFP } \\
\text { hexano saturado com ar, } \mathrm{t} \text { ambiente; LFP }\end{array}$ & $\begin{array}{l}13 \\
14 \\
\end{array}$ \\
\hline $4-\mathrm{NO}_{3}$ & & 324 & & hexano satturado com ar, t ambiente; LFP & 15 \\
\hline
\end{tabular}

a: valores lidos diretamente da figura no trabalho original.

MI: metil-ciclo-hexano/isopentano; 3-MP: 3-metil-pentano; 3-MH: 3-metil-hexano; 2-MTHF: 2-metil-tetra-hidro-furano; EtOH: etanol; EPA: éter etilico + iso-pentano + etanol (5:5:2); LFP: fotólise por pulso de laser (laser flash photolysis); FP: fotólise por pulso de lâmpada (flash photolysis); Arco: lâmpadas de descarga convencionais.

1 - PORTER \& WRIGHT (1956); 2 - PORTER \& STRACHAN (1958); 3 - BINDLEY et alii (1962); 4 - JOHNSON \& ALBRECHT (1968); 5 - FRIEDRICH \& ALBRECHT (1974); 6 - OKAMURA \& TANAKA (1975); 7 - IRIE et alif (1976); 8 - HIRATSUKA et affi (1980);

9 - CLARIDGE \& FISCHER (1983); 10 - TOKUMURA ot alfi (1987); 11 - SCAIANO \& SUGAMORI (1988) 12 - TOKUMURA et afii (1990);

13 - TOKUMURA et alii (1989a); 14 - TOKUMURA et alii (1989); 15 - TOKUMURA et alii (1991); 
Em trabalhos mais recentes, foram obtidos dados sobre o radical benzila e radicais benzila substituídos, à temperatura ambiente (vide Tabela I.1, p.10). Estes dados são importantes para a compreensão da fotoquímica de radicais livres em solução já que, nesta condição, a reatividade dos intermediários é, freqüentemente, diferente da observada em matriz, nem sempre sendo fácil distinguir entre alterações reais na fotoquímica e simples efeito de matriz.

CLARIDGE \& FISCHER (1983) obtiveram os espectros de absorção para o radical benzila e para os radicais benzila metil-, cloro- e metóxi-substituídos, a partir da fotólise convencional das cetonas adequadas, enquanto TOKUMURA et alii (1987; 1989; 1990 ; 1991) os obtiveram para radicais benzila substituídos por grupos aceptores ou doadores de elétrons, gerados a partir de precursores halogenados, fotolisados tanto em meio saturado de oxigênio, como em meio desaerado. Em todos os casos, os espectros observados foram semelhantes àqueles obtidos em matriz (vide Tabela I.1, página 10).

Para estes mesmos sistemas, Tokumura e colaboradores determinaram, também, os primeiros espectros de emissão e de excitação de fluorescência em solução, à temperatura ambiente, para radicais benzila utilizando-se de dois lasers: o primeiro, para criar os radicais no estado fundamental e, o segundo, para excitá-los, técnica conhecida como fluorescência induzida por laser, em duas etapas (two-step laser induced fluorescence: TS LIF; TOKUMURA et alii, 1987; 1989a; 1989b; 1990; 1991). Estes autores verificaram que os tempos de vida de fluorescência $\left(\mathbf{D}_{0} \leftarrow \mathbf{D}_{1}\right)$, em solução, à temperatura ambiente, são da ordem de ns (p. ex. 14ns, p-metil-benzila; $81 \mathrm{~ns}, p$-cloro-benzila e $\leq 1 \mathrm{~ns}$, benzila; TOKUMURA et alii, 1987). Tempos de vida de fluorescência da mesma ordem de grandeza foram relatados, também, por TOKUMURA \& ITOH (1987), e WEIR et alii, (1988): 200ns, para $p$-fluoro-benzila, em hexano e 14ns, para $p$-fenil-benzila, em benzeno, respectivamente.

Como os dois estados excitados dublete de menor energia são quasedegenerados, há um significativo efeito de temperatura sobre a constante $\mathrm{k}_{\mathrm{nr}}$ de relaxação não-radiativa $\left(\tau_{\mathrm{f}}=1 / \Sigma \mathrm{k}_{\mathrm{i}}\right.$, onde $\left.\mathrm{k}_{\mathrm{i}}=\mathrm{k}_{\mathrm{r}}+\mathrm{k}_{\mathrm{nr}}+\mathrm{k}_{\mathrm{x}}\right)$, isto é, observa-se um decréscimo da ordem de $10^{3}$ nos tempos de vida de fluorescência, comparando-se dados obtidos em matriz àqueles determinados em temperatura ambiente (MEISEL et alii, 1986; TOKUMURA et alii, 1987). Os tempos de vida de emissão de fluorescência para os radicais benzila são consideravelmente mais longos do que os relatados para os compostos que os originam (vide Tabela I.2, à página 12), sugerindo que a transição $1^{2} \mathbf{B}_{2} \leftarrow \mathbf{1}^{2} \mathbf{A}_{2}$, contrariando as regras de seleção, seja menos permitida do que a transição fraca, mas permitida, que se verifica no caso do tolueno. Esta proposição é reforçada pela pequena força de oscilador calculada para esta transição ( $\leq 8 \times 10^{-4}$ ), por LAPOSA \& MORRISON (1974), a partir de dados de $\tau_{\mathbf{f}}$ ' Assim, a emissão de fluorescência, no caso dos radicais benzila, é um fenômeno comparável às emissões proibidas como, por exemplo, a fosforescência, sendo os tempos de vida para esta 
transição radiativa maiores dos que os esperados para uma transição entre estados de mesma multiplicidade.

Tabela I.2: Tempos de vida de emissão de fluorescência, em matriz e à temperatura ambiente.

\begin{tabular}{l||c|l|l|l|l|l}
\hline & $\tau_{\mathrm{o}} / \mathrm{ns}^{\mathbf{a}}$ & Radicais benzila & $\tau_{\mathrm{f}} / \mu \mathrm{s}^{\mathbf{b}}$ & $\tau_{\mathrm{f}} / \mu \mathrm{s}^{\mathbf{c}}$ & $\tau_{\mathrm{f}} / \mu \mathrm{s}^{\mathbf{d}}$ & $\tau_{\mathrm{f}} / \mathrm{ns}$ \\
\hline \hline tolueno & 173,8 & $\mathrm{H}$ & $1,28 \pm 0,08$ & 1,45 & 1,50 & $\leq 1 \mathrm{e}$ \\
tolueno-d8 & 192,3 & $\mathrm{~d} 7$ & $2,97 \pm 0,20$ & 3,65 & 3,69 & \\
$p$-xileno & 92,5 & $4-\mathrm{Me}$ & $1,21 \pm 0,09$ & & & $14 \mathrm{e}$ \\
$m$-xileno & 167,0 & $3-\mathrm{Me}$ & $0,75 \pm 0,04$ & & & \\
$o$-xileno & 153,4 & $2-\mathrm{Me}$ & $0,79 \pm 0,07$ & & & \\
mesitileno & 192,3 & $3,5-$ di-Me & $0,56 \pm 0,02$ & & & \\
dureno & - & $2,4,5$-tri-Me & $0,52 \pm 0,02$ & & & $5 \mathbf{f}$ \\
\hline
\end{tabular}

a: ciclo-hexano; BERLMAN (1951);

b: EPA; OKAMURA \& TANAKA (1975);

c: 3-MP; LAPOSA \& MORRISON (1974);

d: MeOH; LAPOSA \& MORRISON (1974);

e: ciclo-hexano, à temperatura ambiente; TOKUMURA et alii (1987);

f: tolueno; SCAIANO et alii (1988).

Estes tempos de vida são comparáveis, considerados os erros experimentais, aos determinados para a transição $\mathbf{D}_{\mathbf{n}} \leftarrow \mathbf{D}_{1}$, por Tokumura e colaboradores (TOKUMURA et alii, 1987; TOKUMURA et alii, 1989b), através da técnica conhecida como TS LIA (two step laser induced absorption), similar à TS LIF. Entretanto, como reflexo, primariamente, da dificuldade de se fazerem experimentos de absorção para espécies de tempo de vida tão curto, os espectros de absorção para o primeiro estado dublete excitado dos radicais foram obtidos em relativamente poucos casos, em contraste com a grande quantidade de dados de fluorescência disponíveis para estas espécies.

Em resumo, a análise dos dados apresentados nas Tabelas I.1 e I.2 mostra que, enquanto o máximo de absorção para a transição $\mathbf{D}_{\mathbf{3}} \leftarrow \mathbf{D}_{\mathbf{0}}$ do radical benzila é praticamente insensível ao meio e à temperatura, $\tau_{\mathrm{f}}$ é bastante influenciado pela temperatura $\mathrm{e}$ pela fase em que se encontram as soluções. A presença de substituintes desloca os máximos de absorção para comprimentos de onda maiores, sejam os grupos doadores ou aceptores de elétrons. A substituição na posição para do anel aromático causa efeitos mais significativos do que a presença de substituintes em outras posições. No caso dos $\tau_{\mathbf{f}}$, este efeito foi atribuído a ligeiras alterações dos níveis de energia e dos modos vibracionais dos estados excitados $\mathbf{1}^{\mathbf{2}} \mathbf{A}_{\mathbf{2}}$ e $\mathbf{2}^{\mathbf{2}} \mathbf{B}_{\mathbf{2}}$ o que contribui para diminuir a força de oscilador da transição $\mathbf{D}_{\mathbf{1}} \rightarrow \mathbf{D}_{\mathbf{0}}$, enquanto as substituições nas posições orto e meta têm menor efeito, por diminuir menos a força de oscilador da transição (OKAMURA \& TANAKA, 1975). Surpreendentemente, os $\tau_{\mathrm{f}}$ obtidos pela substituição de três ou cinco grupos metila apresentam valores de magnitude intermediária àqueles determinados para benzila e 4-metil-benzila. 
Nas fotólises por pulso de laser nas quais se utiliza somente um laser de síntese tem-se, em uma primeira etapa, um processo monofotônico, em solução, obtendo-se os radicais no estado fundamental $\mathbf{D}_{\mathbf{0}}$, a partir dos precursores adequados; subseqüentemente, a lâmpada de análise fornece energia para a transição $\mathbf{D}_{\mathbf{n}} \leftarrow \mathbf{D}_{\mathbf{0}}$, sendo registrada a cinética do decaimento de $\mathbf{D}_{\mathbf{0}}$ a produtos estáveis. A análise desta curva cinética fornece, portanto, o tempo de vida (ou o tempo de meia-vida) do estado fundamental do transiente $\left(\mathbf{D}_{\mathbf{0}}\right)$, que é maior do que os $\tau_{\mathbf{f}}$ (ou do que o tempo de vida determinado por TS LIA), que se referem ao estado $\mathbf{D}_{\mathbf{1}}$.

Várias investigações cinéticas mostraram que as reações radicalares de hidrocarbonetos, em solução, ocorrem muito rapidamente, com a magnitude esperada para difusão translacional. No caso dos radicais benzila, os dados obtidos, para uma larga faixa de solventes e de temperaturas (SCHUH \& FISCHER, 1976; 1978; LEHNI et alii, 1979; HUGGENBERGER \& FISCHER, 1981), são bem descritos pela equação de von Smoluchowski, para reações bi-moleculares de auto-terminação:

$$
\underset{\mathrm{r}}{2 \mathrm{k}^{\mathrm{D}}}=2\left(\frac{4 \cdot \pi \cdot \sigma \cdot \rho \cdot \mathrm{D} \cdot \mathrm{N}_{\mathrm{A}}}{1000}\right)
$$

sendo: $\mathbf{2} \mathbf{k}_{\mathbf{r}}$, a constante de velocidade referente ao desaparecimento de radicais e não, como usual, ao aparecimento de produto (k); como são necessários dois radicais para formar uma molécula de produto, o valor obtido para o desaparecimento de radicais será o dobro ( $2 \mathrm{k}$ ) daquele verificado para a formação de produto (k);

$\mathbf{N}_{\mathbf{A}}$, o número de Avogadro;

D, o coeficiente de difusão do radical, estimado pelo dos hidrocarbonetos correspondentes, $\mathrm{em} \mathrm{cm}^{2} \cdot \mathrm{s}^{-1}$;

$\rho$, o diâmetro colisional, estimado a partir do volume molecular ou molar, em $\mathrm{cm}$;

$\sigma$, o fator estatístico, considerado como $1 / 4$ pois somente colisões singlete entre pares radicais (HUGGENBERGER et alii, 1978) irão conduzir ao(s) produtos(s), no estado fundamental.

Como a terminação por recombinação radicalar é um processo cuja cinética é de segunda-ordem, o tempo de meia-vida do radical $\left(\tau_{1 / 2}\right)$ depende, intrinsecamente, da concentração inicial de espécies ativas - controlada, no caso de processos fotoquími$\cos$, pela intensidade de luz absorvida pelo substrato. Isto é, pode-se definir $\tau_{1 / 2}$ pela expressão:

$$
\tau_{1 / 2}=\frac{1}{2 \mathrm{k}_{\mathrm{r}} \cdot \mathrm{C}_{\text {molar }}}
$$

sendo, $\mathrm{C}_{\text {molar }}$ a concentração molar de espécies ativas geradas por pulso da fonte luminosa, isto é, $\mathrm{C}_{\text {molar }}=\mathrm{f}\left(\mathrm{I}_{0}\right)$. 
Através da análise desta expressão, é fácil perceber porque, ao invés de se compararem os tempos de meia-vida para o desaparecimento de radicais $\left(\tau_{1 / 2}\right)$, dependentes das condições experimentais, é mais freqüente, na literatura, a apresentação das constantes de segunda ordem $\left(\mathbf{2} \mathbf{k}_{\mathbf{r}}\right)$, referentes ao processo de desativação por recombinação de dois radicais. As constantes de auto-terminação $\left(2 \mathbf{k}_{\mathbf{r}}\right)$ para radicais benzila, em solução, à temperatura ambiente, são da ordem de $10^{9}$. Por exemplo, em benzeno, LÄUFER \& DREESKAMP (1984) obtiveram o valor de $7 \cdot 10^{9} \mathrm{M}^{-1} \mathrm{~s}^{-1}$, por CIDNP, a partir da fotólise por pulso de laser de cetonas benzílicas.

Na Tabela I.3, encontram-se dados de $\mathbf{2} \mathbf{k}_{\mathbf{r}}$, para radicais benzila substituídos.

Tabela I.3: Constantes de terminação para radicais benzila substituídos, em ciclohexano, a $22^{\circ} \mathrm{C}$ (apud CLARIDGE \& FISCHER, 1983).

$\begin{array}{llllll}\text { Substituinte } & \frac{\varepsilon_{\mathrm{r}}}{\mathrm{M}^{-1} \mathrm{~cm}^{-1}} & \frac{2 \mathrm{k}_{\mathrm{r}}^{\mathrm{a}}}{10^{9} \mathrm{M}^{-1} \mathrm{~s}^{-1}} & \frac{2 \mathrm{k}_{\mathrm{r}}^{\mathrm{D} b}}{10^{9} \mathrm{M}^{-1} \mathrm{~s}^{-1}} & \frac{\mathrm{D}^{\mathrm{c}}}{10^{-5} \mathrm{~cm}^{2} \mathrm{~s}^{-1}} & \frac{\rho^{\mathrm{d}}}{10^{-8} \mathrm{~cm}}\end{array}$

\begin{tabular}{crrrrr}
\hline $\mathrm{H}$ & $8800 \pm 600$ & $4,6 \pm 0,3$ & 3,74 & $1,68 \pm 0,05$ & 5,90 \\
$4-\mathrm{Me}$ & $7400 \pm 200$ & $3,7 \pm 0,1$ & 3,56 & $1,51 \pm 0,03$ & 6,48 \\
$3-\mathrm{Me}$ & $6800 \pm 800$ & $4,0 \pm 0,8$ & 3,27 & $1,39 \pm 0,05$ & 6,21 \\
$2-\mathrm{Me}$ & $10200 \pm 200$ & $4,4 \pm 0,1$ & 3,20 & $1,36 \pm 0,03$ & 6,22 \\
$4-\mathrm{Cl}$ & $7200 \pm 150$ & $3,7 \pm 0,3$ & 3,36 & $1,44 \pm 0,04$ & 6,17 \\
$3-\mathrm{Cl}$ & $7100 \pm 100$ & $3,8 \pm 0,6$ & 3,27 & $1,40 \pm 0,02$ & 6,17 \\
$2-\mathrm{Cl}$ & $8100 \pm 200$ & $2,1 \pm 0,2$ & 3,26 & $1,40 \pm 0,02$ & 6,15 \\
\hline
\end{tabular}

a: valores experimentais, em ciclo-hexano;

b: valores calculados, pela equação de von Smoluchowski;

c: valores experimentais para os coeficientes de difusão dos toluenos substituídos correspondentes;

d: valores apresentados para o volume molecular médio. 


\title{
I.4. Reações de foto-homólise: obtenção de radicais, bi-radicais e quinodimetanos
}

\author{
"Radicais livres têm, certamente, constituido parte do \\ arsenal mecanístico do químico orgânico há muito \\ tempo mas, só recentemente, as reações radicalares \\ passaram a ser exploradas com finalidades sintéticas." \\ Lennart Eberson \\ (EBERSON, 1987)
}

As reações mais prováveis para radicais, em solução, estão relacionadas a seu caráter eletrofilico, abrangendo abstração de hidrogênio, dimerização, desproporcionamento e adição a ligações duplas. Neste contexto, um dos motivos para que os fotoquímicos se interessassem em retomar o estudo de radicais é o fato das reações foto-iniciadas por lasers darem origem a produtos diferentes daqueles obtidos em irradiações convencionais - ou por envolverem concentrações maiores de intermediários reativos, ou pelo envolvimento de processos bifotônicos que gerem cátions ou biradicais.

Desde os trabalhos iniciais de Zimmerman e colaboradores (ZIMMERMAN \& SANDEL, 1963; ZIMMERMAN \& SOMASEKHARA, 1963) sobre a fotoclivagem de derivados benzílicos $\left(\mathrm{ArCH}_{2}-\mathrm{X} ; \mathrm{X}=\mathrm{Cl}, \mathrm{O}(\mathrm{C}=\mathrm{O}) \mathrm{R}\right)$ em solventes nucleofilicos, tem havido considerável interesse a respeito desse processo. Muitos dos estudos feitos centraram-se na competição entre clivagem homolítica e clivagem heterolítica, em função da multiplicidade do estado excitado (excitação direta versus sensibilização) e da natureza do grupo fotolábil $\left(\mathrm{ArCH}_{2}-\mathrm{X} ; \mathrm{X}=\mathrm{Cl}, \mathrm{Br}, \mathrm{I}, \mathrm{NR}_{3}{ }^{+}, \mathrm{SR}_{2}{ }^{+}, \mathrm{PR}_{3}{ }^{+}, \mathrm{O}(\mathrm{C}=0) \mathrm{R}\right.$, $\mathrm{SO}_{2} \mathrm{R}, \mathrm{OSO}_{2} \mathrm{R}$ ), tendo sido verificado que, através da seleção adequada, tanto do solvente, como dos grupos de partida, pode-se favorecer a formação de cátionsradicais, por foto-heterólise (vide, por exemplo, APPLETON et alii, 1977; 1980; CRISTOL \& GREENWALD, 1976; CRISTOL \& BINDEL, 1980; 1981; ARNOLD et alii, 1985 e referências de 7 a 19, ali citadas; ALONSO et alii, 1990; 1992 e referências 18 e 20 a 22, ali citadas).

Em contraste à quantidade significativa de estudos referentes a mono-radicais, além de existirem relativamente poucos bi-radicais para os quais a emissão tenha sido detectada, grande parte deles foi obtida e analisada somente em matrizes, a baixas temperaturas. Isto é, primariamente, um reflexo do curto tempo de vida destas espécies (JOHNSTON \& SCAIANO, 1989). Na maioria dos estudos, a obtenção dos biradicais envolve reações de clivagem de cetonas cíclicas ou azo-compostos (vide, por exemplo, de FONSEKA et alii, 1979; WINTGENS et alii, 1990). Já no caso dos quinodimetanos, de considerável utilidade para a síntese de anéis de sistemas policíclicos (OPPOLZER, 1978), têm sido amplamente estudados sistemas que conduzam à geração destes intermediários bi-radicalóides, altamente reativos. 
Apesar de restarem vários aspectos a serem aprofundados envolvendo, tanto a competição entre foto-homólise e foto-heterólise, como a possibilidade de serem gerados (dependendo do precursor selecionado) mono-radicais, bi-radicais ou quinodimetanos (o-xililenos, 2, ESQUEMA I.1), nesta revisão serão focalizados, essencialmente, trabalhos sobre a fotogeração de intermediários por homólise, sendo abordados, mais especificamente, estudos sobre a obtenção de espécies radicalares a partir de compostos aromáticos que contêm apenas um anel benzênico em sua estrutura.

Mesmo sendo muito instáveis, quinodimetanos e seus derivados têm sido utilizados em síntese há bastante tempo. Já no começo deste século, FINKELSTEIN (1910), a partir da redução de $\alpha, \alpha, \alpha^{\prime}, \alpha^{\prime}$-tetrabromo- $o$-xileno $\left(1 ; \mathrm{R}=\mathrm{R}^{\prime}=\mathrm{X}^{1}=\mathrm{X}^{2}=\mathrm{Br}\right.$ ), preparou 1,2-dibromo-benzo-ciclo-buteno $\left(4, \mathrm{R}=\mathrm{R}^{\prime}=\mathrm{Br}\right)$. Entretanto, o envolvimento de $o$-dibromo-quinodimetano $\left(2, \mathrm{R}=\mathrm{R}^{\prime}=\mathrm{Br}\right)$ somente foi reconhecido cerca de quarenta anos mais tarde, por Cava e colaboradores, através da captura deste intermediário por ciclo-adição a dienófilos típicos $Y^{1}=Y^{2}$ (CAVA et alii, 1959), como mostrado no ESQUEMA I.1.

\section{ESQUEMA I.1}

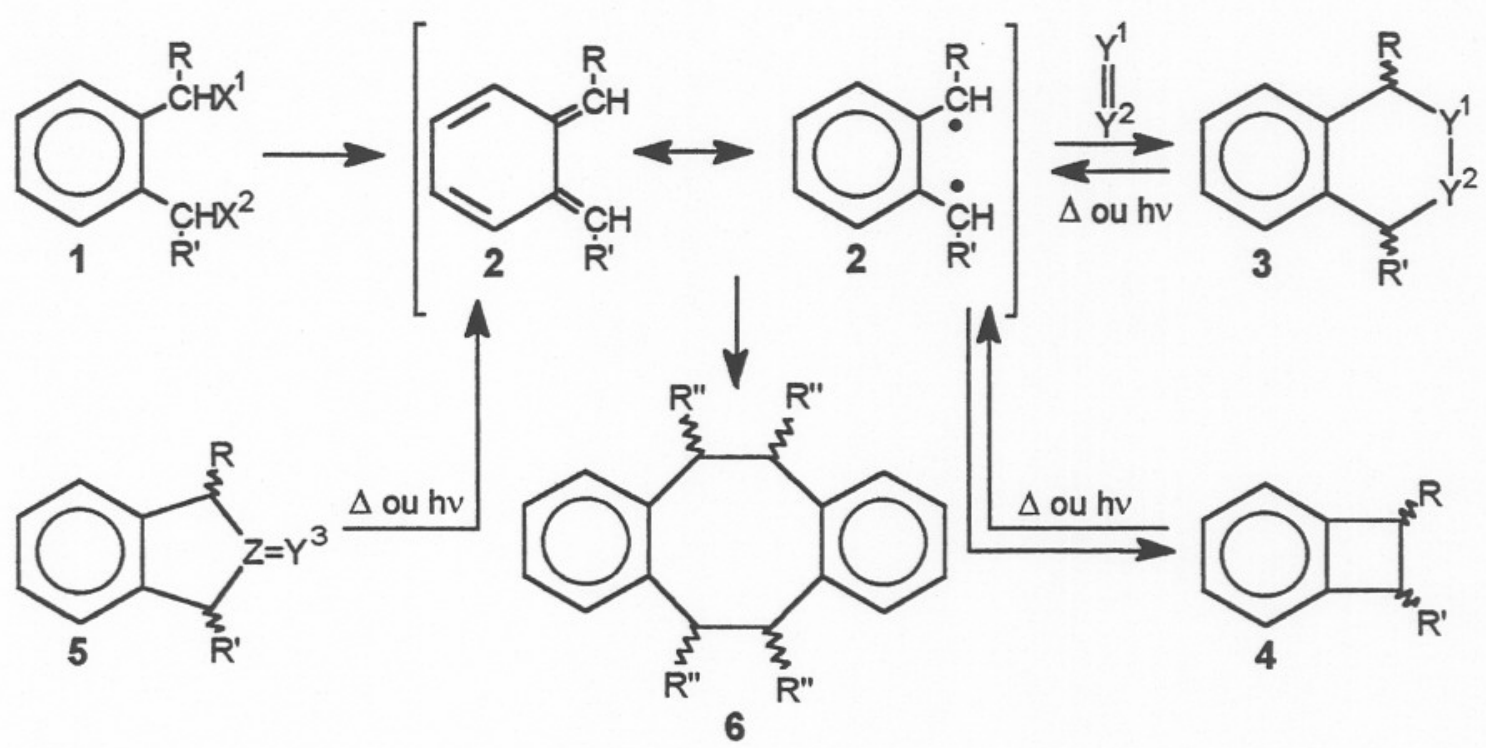

onde: $\mathbf{R}^{\prime \prime}=\mathbf{R}$ ou $\mathbf{R}^{\prime}$

Em trabalho independente, JENSEN \& COLEMAN (1958) também sugeriram a participação deste tipo de intermediário, ao estudarem adições térmicas de 1,2-difenilbenzo-ciclo-buteno $\left(4, \mathrm{R}=\mathrm{R}^{\prime}=\Phi\right)$ e de benzo-ciclo-buteno $\left(4, \mathrm{R}=\mathrm{R}^{\prime}=\mathrm{H}\right)$ a dienófilos $\mathrm{Y}^{1}=\mathrm{Y}^{2}$, originando o aduto 3 (ESQUEMA I.1). Enquanto a irradiação de benzo- 
ciclo-buteno, em pentano, conduziu a di-hidro-pentalenos, sugerindo que o intermediário fosse um pré-benzovaleno, ao invés de um quinodimetano (TURRO et alii, 1988), resultados diferentes foram obtidos por FLYNN \& MICHL (1974) que, ao irradiarem $4\left(R^{\prime}=R^{\prime}=H\right)$ em matriz de EPA, obtiveram o-quinodimetano $\left(2 ; R^{\prime}=R^{\prime}=H\right)$. Outros benzo-ciclo-butenos substituídos, quando submetidos à fotólise, também geraram o-quinodimetanos, por abertura eletrocíclica do anel de quatro membros (QUINKERT et alii, 1968). Estudos cinéticos e estereoquímicos sobre a reação de adição de 1,2-difenil-benzo-ciclo-buteno (HUISGEN \& SEIDL, 1964; QUINKERT et alii, 1966) indicam que há uma abertura conrotatória reversível do anel de quatro membros $(4 \rightarrow 2)$, seguida por uma reação de Diels-Alder entre o o-quinodimetano não-isolável e o dienófilo $(2 \rightarrow 3)$. Entretanto, a caracterização direta do o-quinodimetano (2, $\mathbf{R}^{\prime}=\mathbf{R}=\mathrm{H}$ ) só foi apresentada na década de 70 por Michl e colaboradores (FLYNN \& MICHL,1973; 1974; TSENG \& MICHL, 1977), tendo sido feita por espectroscopia no UV, em matriz rígida, a $-190^{\circ} \mathrm{C}\left(\lambda_{\max }=373 \mathrm{~nm}\right)$.

Foram desenvolvidos vários outros métodos para a geração de quinodimetanos, tais como: eliminação, térmica ou fotoquímica $(5 \rightarrow 2)$, de dióxido de enxofre (CAVA \& DEANA, 1959; OLIVER \& ONGLEY, 1965; FLYNN \& MICHL,1974), nitrogênio (BAKER et alii, 1961; CARPINO, 1962; 1966; 1969), telúrio (CUTHBERTON \& MACNICOL, 1975) ou monóxido de carbono (QUINKERT et alii, 1971; FLYNN \& MICHL,1974), além de reações tipo retro-Diels-Alder $(3 \rightarrow \mathbf{2})$ envolvendo perda de nitrogênio (SHABAROV et alii, 1961; FLYNN \& MICHL, 1974) ou dióxido de carbono (SPANGLER \& BECKMANN, 1976; SPANGLER et alii, 1977), processos de eliminação [1,4] $(1 \rightarrow 2)$, redutivos (MCOMIE \& PERRY, 1973) ou térmicos (HART et alii, 1966) e, ainda, partindo-se de $\alpha, \alpha^{\prime}$-dibromo-o-xilenos $\left(1, \mathrm{R}=\mathrm{R}^{\prime}=\mathrm{Br} ; \mathrm{X}^{1}=\mathrm{X}^{2}=\mathrm{H}\right)$ : teluro-desbromação por ariltelurolatos de sódio $(1 \rightarrow 2$; PETRAGNANI,1994), ou reação com zinco metálico, promovida por ultra-som (HAN \& BOUDJOUK, 1982). Os quinodimetanos obtidos podem ser capturados como adutos de Diels-Alder $(2 \rightarrow 3)$, utilizando-se diferentes dienófilos $\left(\mathrm{Y}^{1}=\mathrm{Y}^{2}\right)$, sofrer dimerização, gerando 6 , ou ainda, através de ciclização, formar ciclo-butenos $(2 \rightarrow 4)$.

Devido ao fato destes intermediários reativos atuarem como excelentes dienos em reações de Diels-Alder, com dienófilos intra- ou inter-moleculares, a geração fotoquímica de quinodimetanos interessou a um grande número de grupos de pesquisa, por permitir a construção de anéis de seis membros, fundidos a anéis benzênicos. Entretanto, quando existem caminhos alternativos para a desativação destes transientes, nem sempre é possível obterem-se adutos de Diels-Alder via quinodimetanos.

Assim, HORNBACK \& VADLAMANI (1980) observaram que, para o caso de 4-metil-isocromeno (7; ESQUEMA 1.2), a migração [1,5] de hidrogênio no xilileno (8), formado por irradiação na região do UV, é mais rápida do que a reação de DielsAlder, não sendo possível sua captura com dienófilos (vide ESQUEMA I.2), o que também havia sido observado (PADWA et alii, 1975; PADWA \& AU, 1976) na irradiação 
de soluções metanólicas de isocromanonas 3-substituídas (9; ESQUEMA 1.3), onde a ciclização aldólica intramolecular do intermediário 10 obtido, formando indanonas (11), impossibilitou a captura do quinodimetano com acetileno-dicarboxilato de dimetila (ESQUEMA I.3).

\section{ESQUEMA L.2}

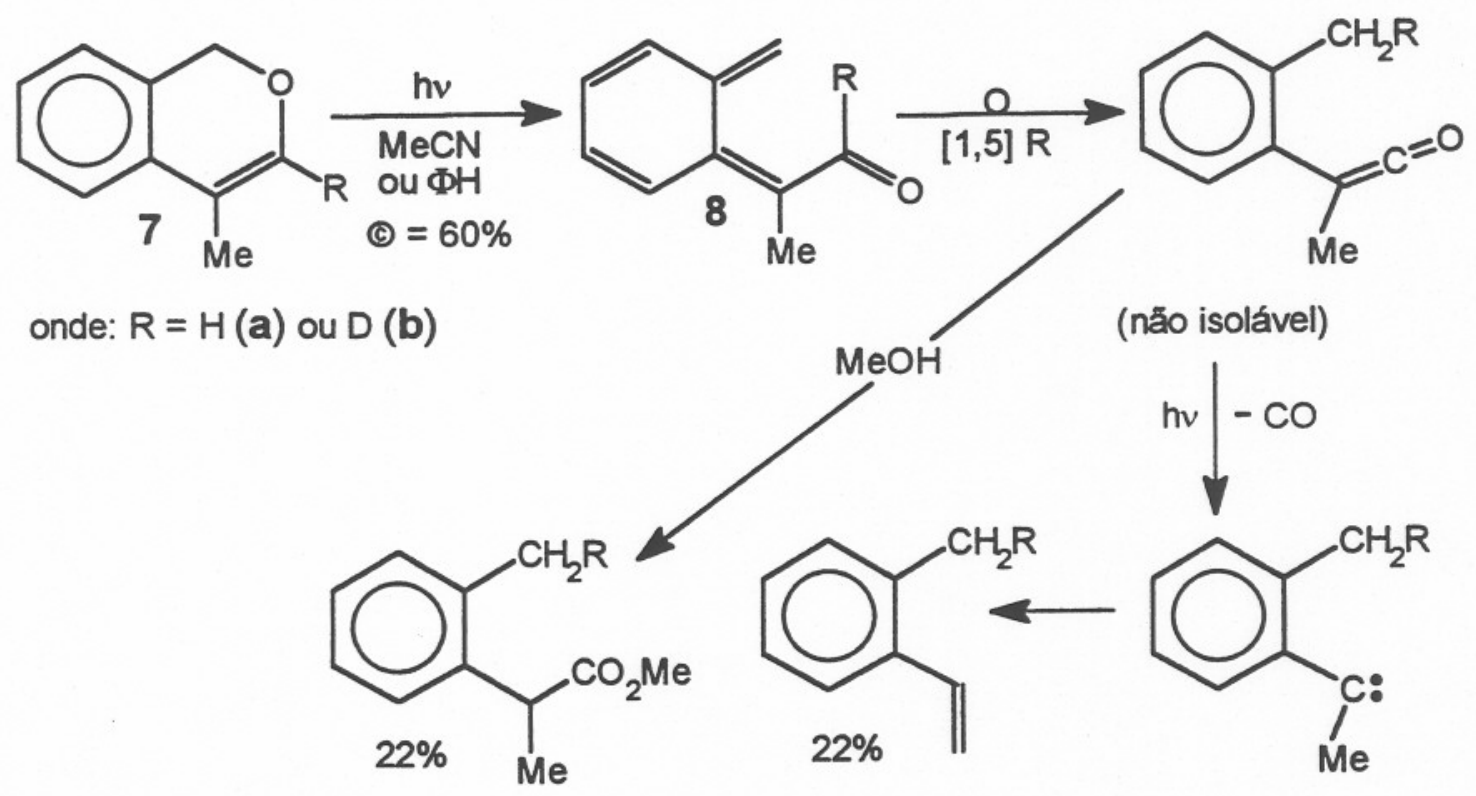

\section{ESQUEMA 1.3}
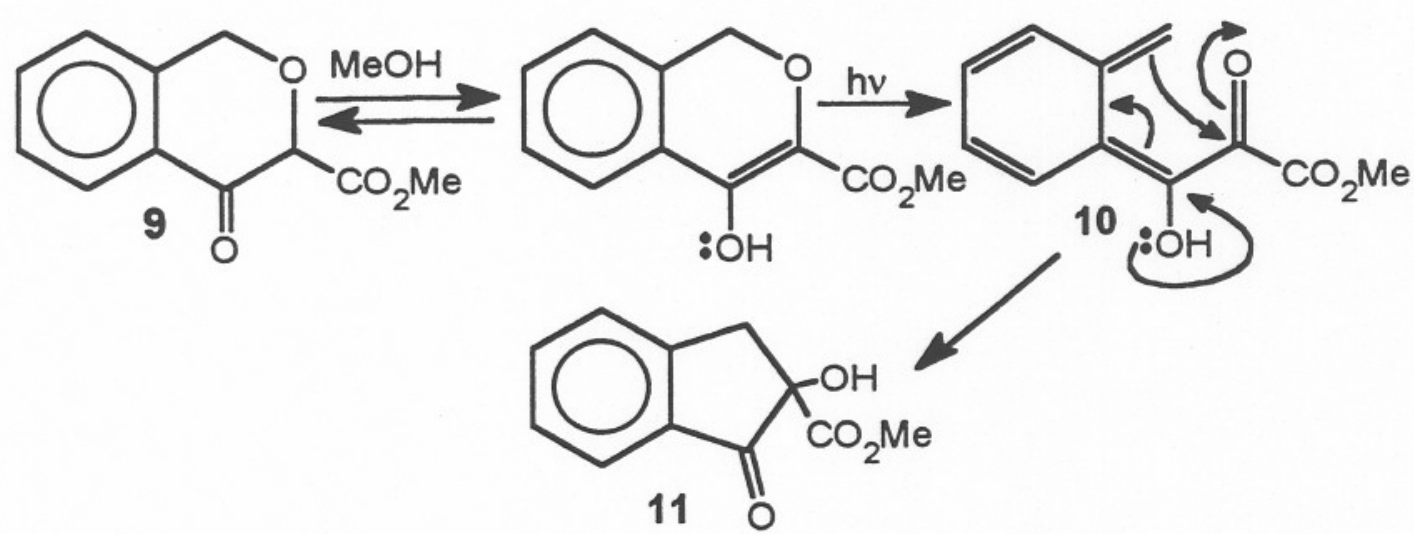

Em outros trabalhos (HORNBACK, 1976; HORNBACK \& BARROWS, 1982), foi possível a captura do intermediário formado, por meio de reação de Diels-Alder, utilizando-se ciclo-hexeno como dienófilo (ESQUEMA I.4). Este fato demonstra que, na etapa primária do processo, ocorre a geração fotoquímica de 0 -xililenos (13), a partir de derivados de $\sigma$-metil-estireno $\alpha$-substituídos, quer por fenila (12a), quer por metila (12b). É importante ressaltar que, sendo o quinodimetano muito reativo, mesmo um dienófilo relativamente ineficiente, como o ciclo-hexeno, é capaz de conduzir ao aduto 14, caso esta adição inter-molecular seja o caminho preferencial para 0 decaimento do transiente. 

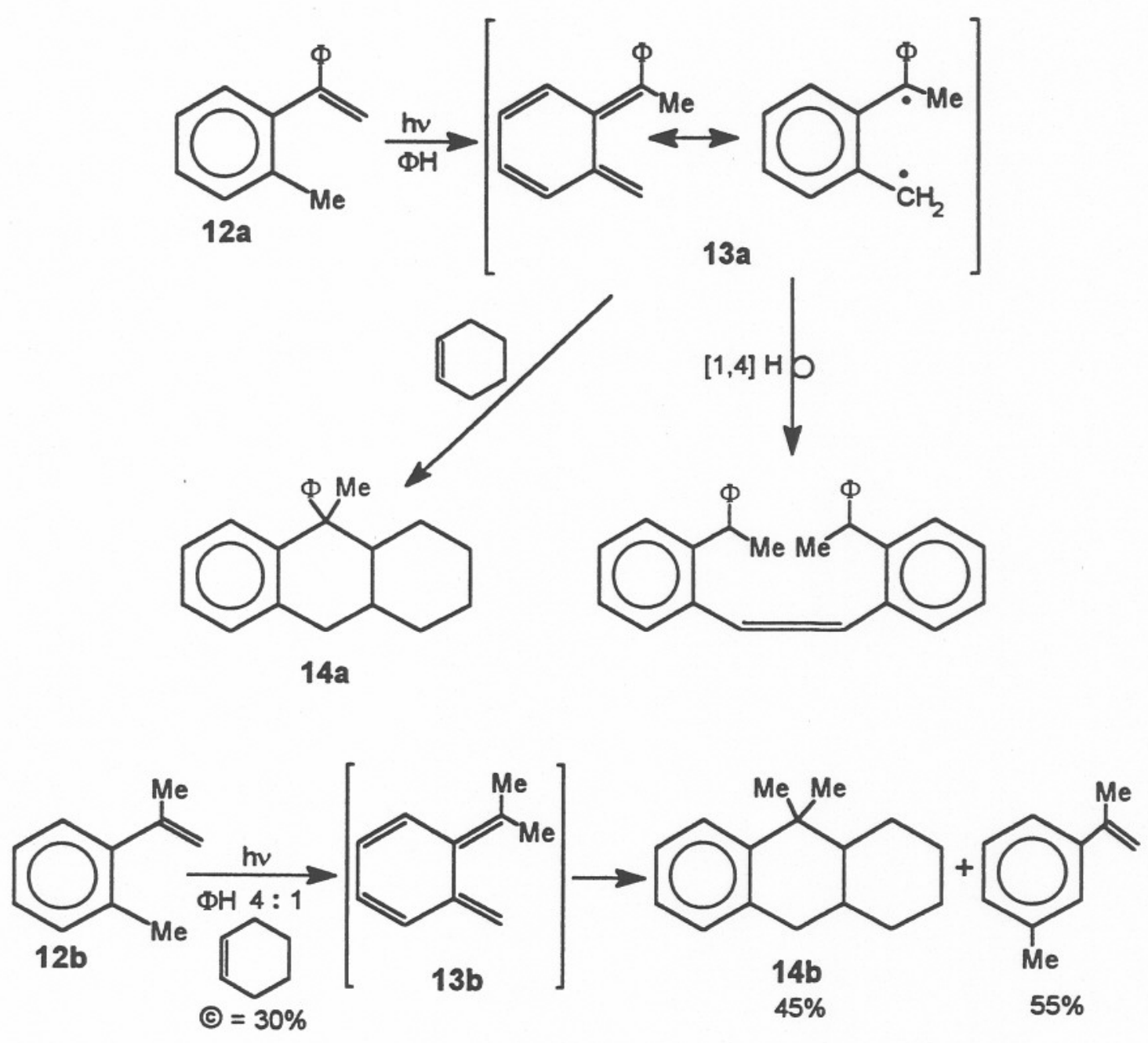

SAMMES (1976) havia verificado ser possível a obtenção de (E)-hidróxiquinodimetanos por fotoenolização do composto 15 , ou seja, pela indução de migração [1,5] de hidrogênio, após excitação eletrônica da carbonila, como representado no ESQUEMA I.5. No caso das isocromanonas 3-substituídas (9; vide ESQUEMA I.3), PADWA et alii (1975) e PADWA \& AU (1976) também propuseram que a enolização fosse o passo inicial para a formação dos quinodimetanos intermediários, sendo o enol a espécie precursora deste transiente.

\section{ESQUEMA 1.5}

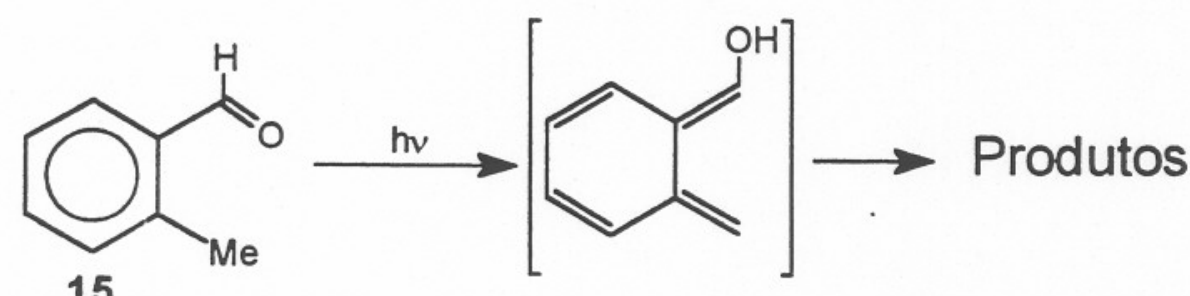


A migração [1,5] de hidrogênio, fotoinduzida ou não, foi observada, também, em outros sistemas. de FONSEKA et alii (1979) sugerem que os transientes gerados na fotólise-relâmpago de 2 -indanonas metiladas (16), em hexano, a $20^{\circ} \mathrm{C}$, sejam $o$-quinodimetanos (17) e apresentam os espectros de absorção obtidos em ciclopentano, a $-78^{\circ} \mathrm{C}$, para 7,7,8,8-tetrametil-o-xilileno $\left(17 \mathrm{a}, \lambda_{\max }=350 \mathrm{~nm}\right)$ e 7,7 -dimetil$o$-xilileno $\left(\mathbf{1 7 b}, \lambda_{\max }=360 \mathrm{~nm}\right)$. Os autores admitem que estes quinodimetanos decaiam termicamente através de migração sigmatrópica $[1,5]$ de hidrogênio, gerando alquilisopropenil-benzenos (18; ESQUEMA I.6). Evidências espectroscópicas (isto é, os máximos de absorção no UV de $17 \mathbf{a}$ e 17b, quando comparados ao $\lambda_{\max }=375 \mathrm{~nm}$, para $o$-xilileno) e cálculos teóricos simples (HMO) indicam que os transientes sejam torcidos ao redor das ligações simples (para uma representação do anel semelhante à da estrutura 17), sendo impedidos de adotar a geometria plana favorável para a migração suprafacial [1,5] de hidrogênio. Estas considerações e a fotolabilidade dos transientes sugerem que o decaimento térmico se dê através de uma migração antarafacial, mecanismo que ainda não havia sido proposto no caso de processos de estado fundamental. Também neste caso, foi impossível capturarem-se os transientes com dienófilos tais como anidrido malêico, tetraciano-etileno e $\alpha$-cloro-acrilonitrila. Este resultado deve-se, provavelmente, ao fato de o impedimento estérico exercido pelos grupos metila causar, além da distorção da geometria do intermediário, a diminuição da região espacial disponível para a aproximação de uma segunda molécula (ou seja, da "janela" de reação), dificultando a ocorrência de processos bimoleculares; prevalece, portanto, o decaimento intra-molecular, ainda que relativamente lento, que conduz à formação de 18.

\section{ESQUEMA I.6}

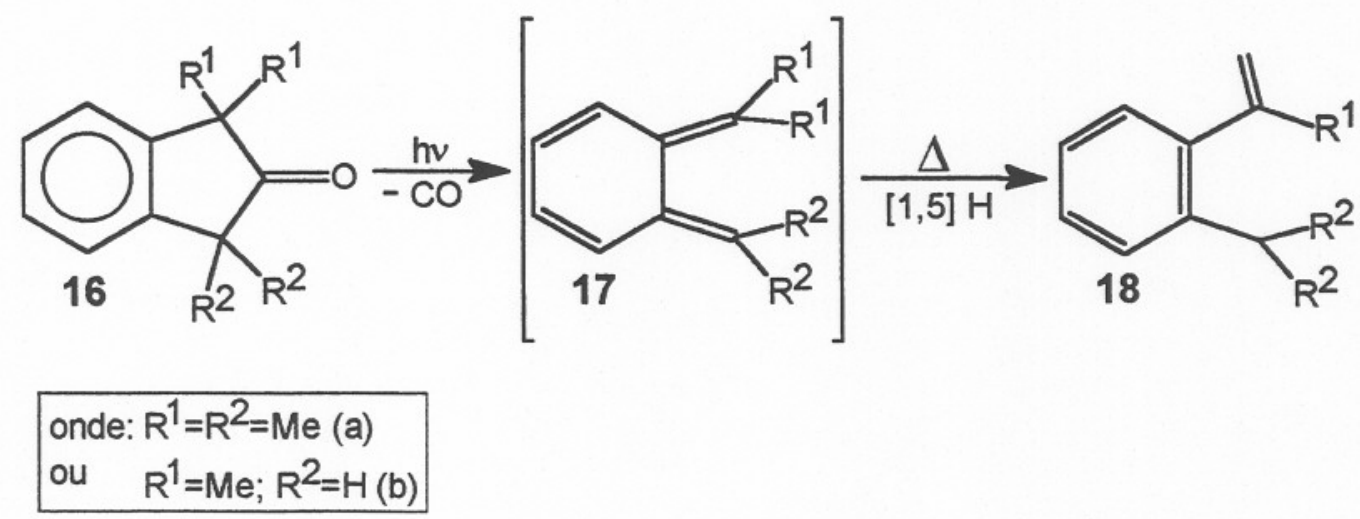

WINTGENS et alii (1990) também estudaram a fotodecomposição de 1,1,3,3tetrametil-2-indanona (16a; vide ESQUEMA I.6), em soluçạ̃o, à temperatura ambiente. $O$ estudo cinético por fotólise de pulso de laser mostrou, pela primeira vez, que há um transiente de tempo de vida de 580ns (em benzeno, à temperatura ambiente) envolvido 
na formação do o-quinodimetano. Através de dados de supressão por oxigênio e por $\beta$-caroteno, foi possível identificar esta espécie como sendo um bi-radical (19), idêntico ao estado triplete do quinodimetano 17a, como mostrado no ESQUEMA I.7.

Os autores apresentam, também, uma série de dados espectroscópicos, obtidos através de diferentes estratégias, para o transiente 17a gerado em solução: absorção no $\mathrm{UV}, \lambda_{\max }=358 \mathrm{~nm}$, através de fotólise por pulso de laser, em benzeno; $v=681 \mathrm{e}$ $1200 \mathrm{~cm}^{-1}$, por espectroscopia no infra-vermetho convencional, em tetracloreto de carbono ou ciclo-hexano; os dados de IV foram obtidos por diferença entre os espectros da solução irradiada (1000 tiros de laser, 308nm) e não-irradiada, graças ao tempo de vida surpreendentemente longo $(9,1 \mathrm{~min})$ determinado, em benzeno à temperatura ambiente, para este transiente, pela monitoração de seu decaimento por espectroscopia convencional no UV. Os dados espectroscópicos apresentados são coerentes com os determinados, em matriz, por FLYNN \& MICHL (1974), de FONSEKA et alii (1979) e MCMAHON \& CHAPMAN (1987), para os máximos de absorção no UV, e por TSENG \& MICHL (1977) e CHAPMAN et alii (1988), em matriz de argonio, para a região do infra-vermelho.

\section{ESQUEMA 1.7}

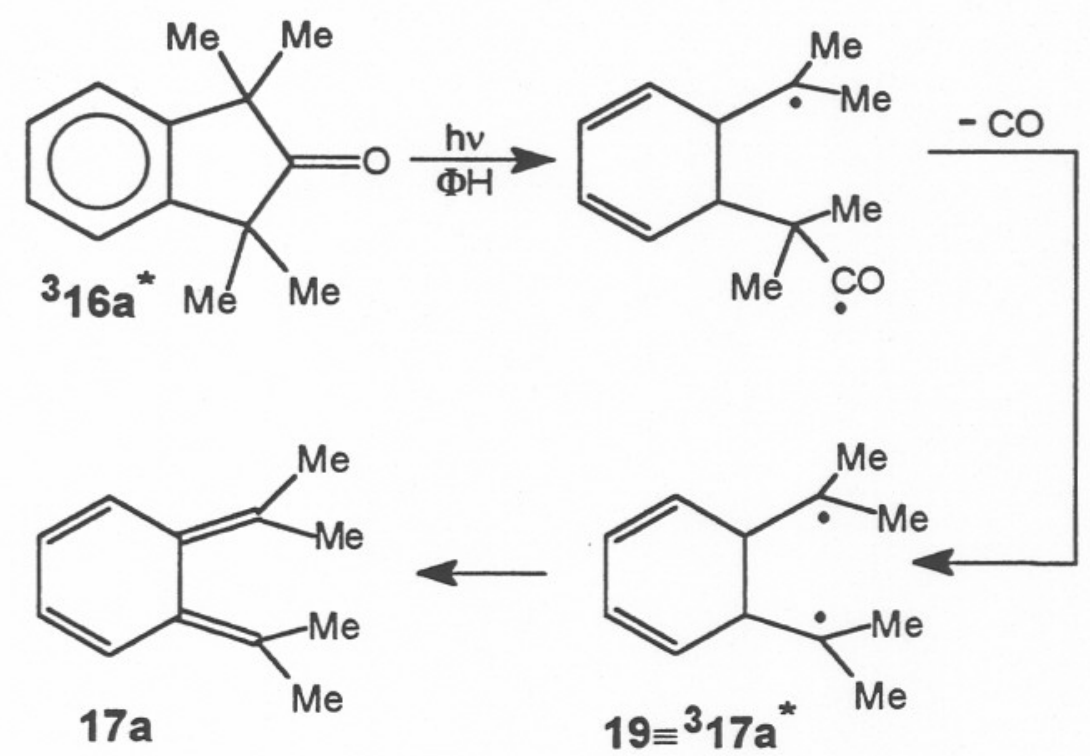

O estudo da fotólise de 16a utilizando a técnica de dois lasers mostrou que a transformação fotoquímica de 17a em 18a (vide ESQUEMA I.6) é muito rápida, ocorrendo em cerca de $8 \mathrm{~ns}$, sendo este tempo pelo menos 10 ordens de magnitude menor do que o observado no caso da desativação térmica; este dado corrobora a proposição da migração [1,5], tanto fotoquímica (permitida), como térmica (proibida), ser antarafacial, como sugerido por de FONSEKA et alii (1979).

MCMAHON \& CHAPMAN (1987) mostram que o estado triplete de o-tolilmetileno (21a), gerado fotoquimicamente a partir de o-tolil-diazo-metano (20a), decai 
termicamente para $o$-xilileno no estado fundamental singlete (2a), mesmo em matriz de argônio, a uma temperatura tão baixa quanto 4,6K (ESQUEMA I.8). Ambos transientes foram caracterizados através de dados espectroscópicos: 21, por UV e EPR; 2 , por UV(Ar,15K: $\lambda_{\max } ; \mathrm{nm}=403,395,389,384,379,376,367,362,347$, 342, 329, 326) e IV (Ar,15K: v; $\mathrm{cm}^{-1}=1575$ f; 1548 m; 1493 m; 1469 f; 869 F; 774 m; $754 \mathrm{~m} ; 635 \mathrm{~m} ; 436$ f). Este conjunto de dados espectroscópicos está de acordo com os apresentados por de FONSEKA et alii (1979) e WINTGENS et alii (1990). A migração [1,4] de hidrogênio, térmica e intramolecular, uma reação comum em carbenos, foi observada diretamente por espectroscopia de infravermelho, de ultravioleta e de EPR Como o rearranjo de 21a para 2a ocorre mesmo a baixas temperaturas, os autores sugerem que este processo se dê através de um mecanismo de tunelamento, o que é reforçado pelo fato de ter sido observada pouca dependência da velocidade de migração com a temperatura e pela não-linearidade dos parâmetros de Arrhenius. Em contraste, o carbeno deuterado (21b) é termicamente estável até 19K (a temperaturas mais altas, sofre dimerização). Entretanto, apesar do efeito isotópico ser bastante significativo $\left(\mathrm{k}_{\mathrm{H}} / \mathrm{k}_{\mathrm{D}} \geq 100\right)$, não é pronunciado o suficiente para que 0 mecanismo de tunelamento da migração de hidrogênio seja considerado inequívoco já que, na temperatura do experimento (20K), mesmo um efeito primário clássico deveria ser da ordem de $10^{12}$ (enquanto, a $298 \mathrm{~K}$, este valor seria igual a 7 ).

\section{ESQUEMA 1.8}
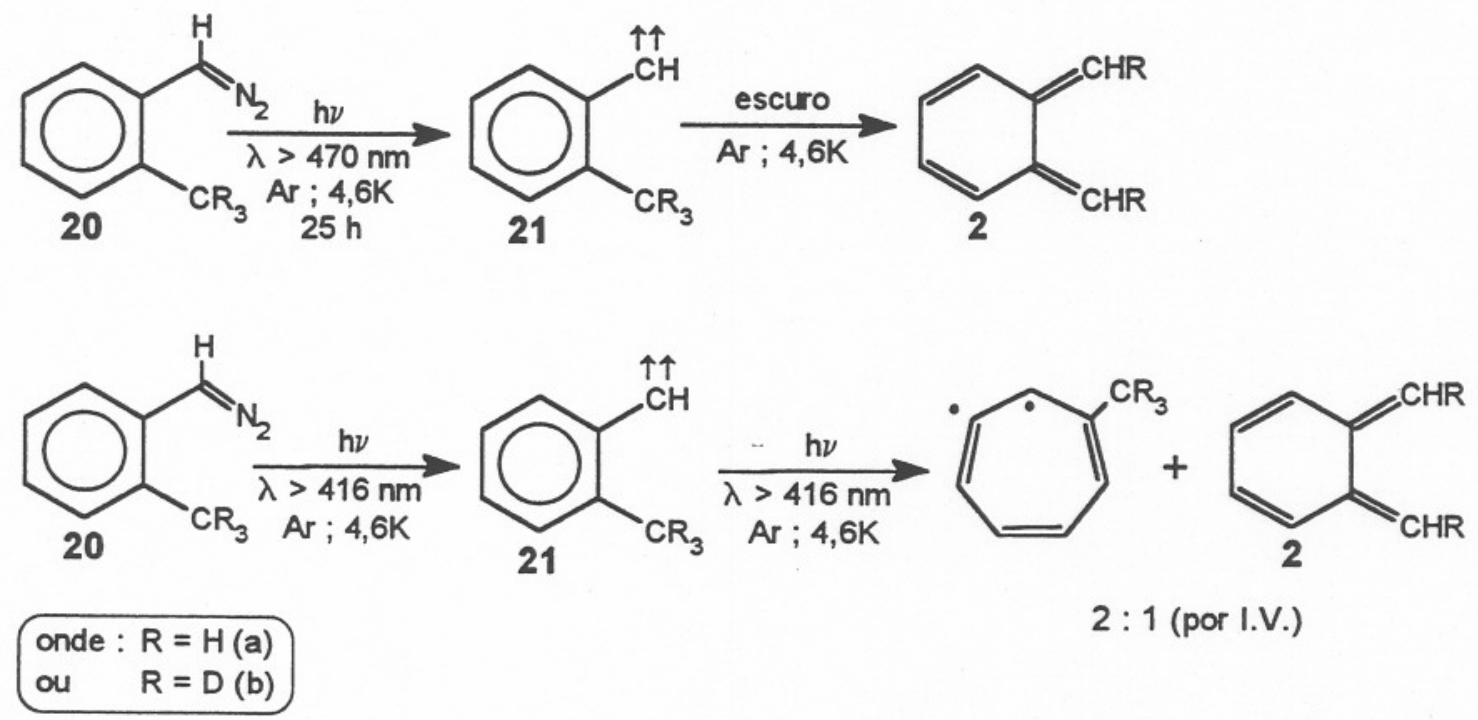

Os artigos apresentados a seguir referem-se, especificamente, a estudos sobre o comportamento fotoquímico de compostos benzilicos halo-substituídos sendo, portanto, mais diretamente relacionados ao tema abordado nesta Tese.

Platz e colaboradores (WRIGHT \& PLATZ, 1983; HAIDER et alii,198i8; 1990; HAIDER \& PLATZ, 1989) desenvolveram uma série de estudos sobre a geração de bi- 
radicais e o-quinodimetanos a partir de poli-metil- e di-halo-metil-benzenos. Assim, HAIDER et alii (1988) isolaram intermediários reativos bi-radicalares, em matriz de etanol, gerados por uma dupla clivagem homolítica da ligação $\mathrm{C}-\mathrm{Cl}$, na fotólise dos precursores fotoquímicos adequados, a $254 \mathrm{~nm}$ (vide ESQUEMA I.9). A partir de uma mesma amostra de $\alpha, \alpha^{\prime}$-dicloro-m-xileno (22), os autores obtiveram os espectros de fluorescência $\left(\lambda_{\max }=440 \mathrm{~nm}\right)$ e de EPR, para a espécie 23 , caracterizando o bi-radical obtido. Embora o espectro de fluorescência apresentado $\left(\lambda_{\max }=470 \mathrm{~nm}\right)$ indique, também, a presença do radical $m$-metil-benzila (28; vide ESQUEMA I.11), quando se fotolisam compostos diclorados a proporção do bi-radical 23 é bem maior do que aquela observada ao se utilizar $m$-xileno como precursor, caso em que 23 é detectado como uma impureza minoritária no espectro de fluorescência do mono-radical (MIGIRDICYAN, 1968; MIGIRDICYAN \& BAUDET, 1975; WRIGHT \& PLATZ, 1983; GOODMAN \& BERSON, 1985). Ao fotolisarem $\alpha, \alpha$-dicloro- $o$-xileno (24), HAIDER et alii (1988) obtiveram, ainda, o espectro de fluorescência para o intermediário 2 (ESQUEMA I.9), similar ao apresentado, anteriormente (MIGIRDICYAN, 1968; FLYNN \& MICHL, 1974), para $o$-xilileno (2, R=R'=H; ESQUEMA I.1).

\section{ESQUEMA I.9}<smiles>ClCc1cccc(CCl)c1</smiles>

22

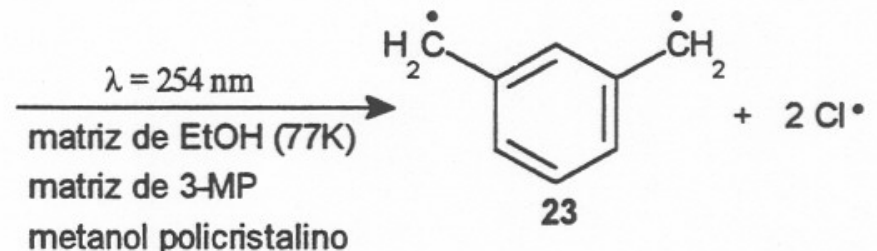

metanol policristalino<smiles>ClCc1ccccc1CCl</smiles><smiles>C=c1ccccc1=CC</smiles>

HAIDER et alii (1990) investigaram, também, o mecanismo de formação do biradical mesitilideno (27) a partir da fotólise de mesitileno (25) isolado em matriz, porque o bi-radical formado, neste caso, é mais facilmente detectável do que aquele derivado do $m$-xileno (vide ESQUEMA I.10). Como a fotólise de $m$-dimetil-benzenos com comprimentos de onda curtos produz uma mistura persistente de mono e biradicais, gerados pela quebra de ligações $\mathrm{C}-\mathrm{H}$ de um, ou dois, grupamentos metila do composto de partida (MIGIRDICYAN \& BAUDET, 1975; WRIGHT \& PLATZ, 1983; HAIDER et alii, 1988), a questão mecanística em foco referia-se à possibilidade do bi-radical ser formado, quer diretamente, quer por um mecanismo em etapas envolvendo a fotólise do mono-radical $m$-metil-benzila (26). Os dados obtidos para a fotólise de mesitileno sugeriam que o bi-radical 27 fosse formado em etapas, através da fotólise do radical 
$m$-metil-benzila (26), por serem estas espécies sempre detectadas simultaneamente nas amostras (por fluorescência, $\lambda_{\max }=487$ e $452 \mathrm{~nm}$, respectivamente). Entretanto, esta hipótese mecanística foi descartada por não se obter o bi-radical ao se irradiar o monoradical gerado por uma rota independente, partindo de peróxido de $\alpha$-( $m$-tolil) acetila. Assim, foi proposto um mecanismo alternativo - designado, pelos autores, como mecanismo de Berson- segundo o qual o hidrogênio nascente formado na etapa fotoquímica interage com o mono-radical 26, formando o bi-radical 27 ou, com a matriz, formando $\mathrm{H}_{2}$ (ESQUEMA I.10). Esta proposta mecanística foi testada através da diminuição da habilidade doadora de hidrogênio da matriz pois, neste caso, o rendimento de bi-radical (27), em relação ao de mono-radical (26), deveria aumentar, tendo-se observado, como esperado, que a razão $27 / 26$ era maior em matrizes de hidrocarboneto do que em matriz de $\mathrm{EtOH}$. Através da variação da velocidade de repetição do laser, os autores demonstraram, ainda, que a formação do mono-radical 26 envolvia um processo bifotônico, isto é, que dois fótons de $249 \mathrm{~nm}\left(115 \mathrm{kcal}^{\mathrm{mol}}{ }^{-1}\right)$ são necessários para a obtenção desta espécie. O primeiro dos fótons conduziria a molécula de mesitileno ao estado triplete excitado de menor energia $\left(80,3 \mathrm{kcal}_{\mathrm{mol}}{ }^{-1}\right.$; MUROV,1973) - caracterizado por seu espectro de absorção em 3-MP, à temperatura ambiente - enquanto o segundo fóton excitaria a molécula para níveis eletrônicos mais energéticos, de onde seria possível a quebra de uma ligação $\mathrm{C}-\mathrm{H}$ benzílica ( $88,2 \mathrm{kcal}_{\mathrm{mol}} \mathrm{m}^{-1}$, para tolueno; $87,8 \mathrm{kcal} \cdot \mathrm{mol}^{-1}$, para $m$-xileno; HAYASHIBARA et alii, 1986).

\section{ESQUEMA I.10}

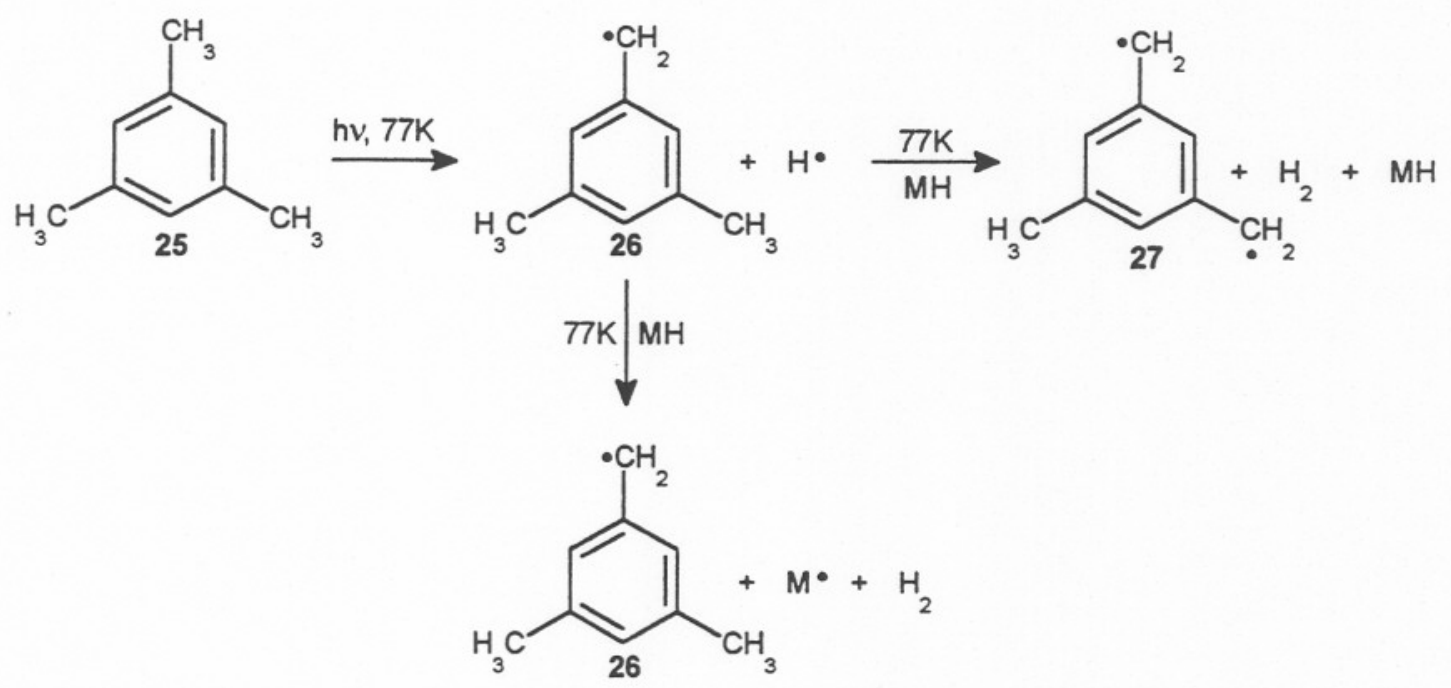

Nesse mesmo trabalho (HAIDER et alii, 1990), os autores apresentam novos dados sobre o comportamento de $\alpha, \alpha$-dicloro-m-xileno (22), em matriz e em solução, tendo verificado que a variação da velocidade de pulso do laser causava um efeito bastante diferente daquele observado para o caso dos precursores benzênicos metilados. Assim, dez pulsos rápidos de laser (freqüência $=5 \mathrm{~Hz}$, isto é, intervalos de 
0,2 s) produzem primariamente o bi-radical 23 , praticamente não se observando a formação do mono-radical 28 (vide ESQUEMA I.11). Quando a amostra é exposta a um número maior de pulsos (350 pulsos, $\lambda_{\text {exc }}=249 \mathrm{~nm}$ ) é possível detectar-se a formação de 28 , identificado por sua emissão de fluorescência $\left(\lambda_{\max }=471 \mathrm{~nm}\right.$, em matriz de EtOH), a qual aumenta de intensidade, paralelamente à do bi-radical, com 0 progresso da irradiação. $O$ incremento da razão entre as intensidades de fluorescência do mono- e do bi-radical deve-se, provavelmente, à fotólise secundária do $m$-xilileno (23) que conduza a uma reação fotoquímica lenta de transferência de hidrogênio entre o $m$-xilileno e a matriz, formando o mono-radical 28 (ESQUEMA I.11). Estes resultados contrastam com os dados obtidos no caso dos compostos benzênicos metilados, onde o mono-radical é a espécie absortiva majoritária, em matriz, mesmo para tempos de fotólise curtos e a razão mono/bi-radical é essencialmente independente do tempo, ao longo do experimento. Também em contraste ao observado para o caso de compostos não-halogenados, ao se utilizarem 50 pulsos de laser espaçados por 20 segundos de intervalo $(0,05 \mathrm{~Hz})$, formam-se 23 e radicais 28 , como no caso da repetição rápida. $O$ bi-radical deve, portanto, ser produzido a partir de $\alpha, \alpha^{\prime}$-m-dicloroxileno (22) em uma faixa de tempo compreendida na largura do pulso de laser de exímero (10ns).

ESQUEMA L.11
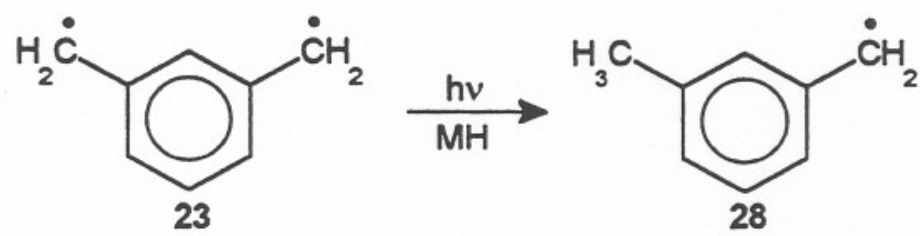

A primeira detecção espectroscópica direta de bi-radicais $m$-xilileno em solução, à temperatura ambiente, foi apresentada por Platz e colaboradores (HAIDER et alii, 1990). Este transiente foi gerado irradiando-se soluções do composto diclorado 22 e de $\alpha, \alpha$-dibromo-m-xileno com um único pulso de um laser de exímero $(\lambda=249 \mathrm{~nm}$, FWHM=10ns), que tanto dissocia o precursor como excita os radicais ou bi-radicais nascentes, tendo sido observados espectros de emissão de LIF semelhantes ao espectro de emissão de fluorescência detectado, em matriz, para $m$-xilileno. Entretanto, o mecanismo para a formação de 23 a partir deste precursor (22) não foi esclarecido pelos autores pois, na opinião destes, não era claro se um só fóton de $249 \mathrm{~nm}$ $(115 \mathrm{kcal} / \mathrm{mol})$ possuiria energia suficiente para a clivagem das duas ligações $\mathrm{C}-\mathrm{Cl}$ de 22, já que as energias para a quebra de ligação desta substância não eram conhecidas. Por outro lado, um mecanismo de dois fótons para a formação de $m$-xilileno (23) implicaria na existência de um intermediário sensível à luz conectando as espécies $22 \mathrm{e}$ 23. Com os dados disponíveis, os autores não puderam decidir entre o estado triplete de mais baixa energia do composto $m$-diclorado (22) e o radical $m$-(cloro-metil)-benzila (29), que seria formado pela rápida fragmentação de um estado excitado de 22 
(ESQUEMA I.12), pois este possível intermediário não foi detectado por espectroscopia de fluorescência após fotólise rápida de 22, seja com lâmpada de 254 $\mathrm{nm}$, seja com laser de exímero de $249 \mathrm{~nm}$, tanto em matriz (a 77K), como à temperatura ambiente. Por outro lado, embora fosse previsível que uma espécie de tempo de vida curto, como o triplete, não pudesse ser detectada ter-se-ia que admitir, neste caso, a ejeção simultânea de dois átomos de cloro, quando da absorção do segundo fóton.

\section{ESQUEMA I.12}

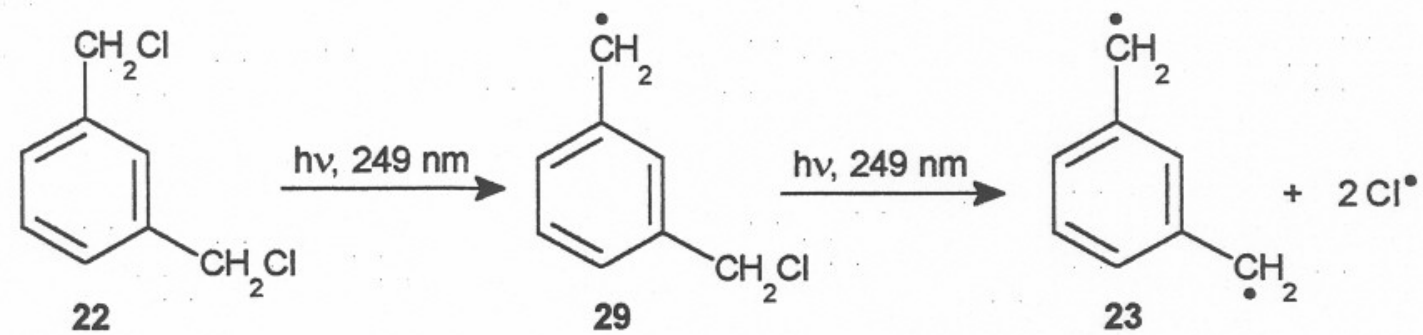

Efetivamente, admitindo-se que a energia necessária para a quebra de uma ligação $\mathrm{C}$-Cl de $\alpha$, $\alpha^{\prime}$-dicloro- $m$-xileno não deva diferir significativamente daquela determinada para o caso de cloreto de benzila ( $69 \mathrm{kcal}^{\mathrm{mol}}{ }^{-1}$; MUROV, 1973), um único fóton de $249 \mathrm{~nm}$ teria energia insuficiente para a quebra simultânea de duas ligações C-Cl. É de se supor, portanto, que a hipótese de estar envolvido um mecanismo bifotônico na formação do bi-radical 23, a partir do composto diclorado 22, seja, provavelmente, a correta, apesar dos autores não terem detectado a espécie intermediária 29 (ESQUEMA I.12).

Em outro trabalho, HAIDER \& PLATZ (1989) obtiveram difenil-carbeno (31; ESQUEMA I.13), ao estudarem, em analogia aos sistemas anteriores, a fotólise do dihaleto geminal 30, a $77 \mathrm{~K}$. Os autores propuseram que a fotodissociação ocorresse em dois passos, envolvendo, intermediariamente, a formação do radical difenil-cloro-metila (32), que pôde ser caracterizado por espectroscopia de fluorescência $\left(\lambda_{\max } \mathrm{de}\right.$ emissão $=522 \mathrm{~nm}$ ), em matriz de 2-metil-tetra-hidro-furano (2-MTHF).

\section{ESQUEMA I.13}<smiles>[2H]C([2H])(Cl)Cl</smiles>

30

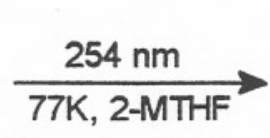
77K, 2-MTHF

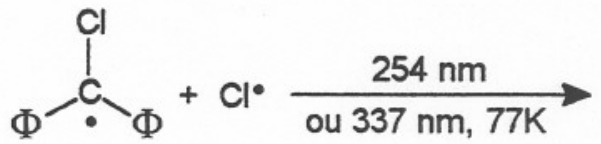

32<smiles>[O+][Co]</smiles>

31

McKenna e colaboradores (APPLETON et alii, 1977; 1980) mostram que, mesmo em solventes nucleofilicos polares, tais como álcoois, são obtidos produtos de homólise $(34,35)$ e de heterólise (33) na irradiação de haletos ou acetatos de benzila, tanto sensibilizada, como direta (ESQUEMA I.14), em contraste ao que se observa no caso de sais de trimetil-amônio benzílicos, para os quais só por sensibilização se obtêm produtos de foto-heterólise. 
ESQUEMA 1.14

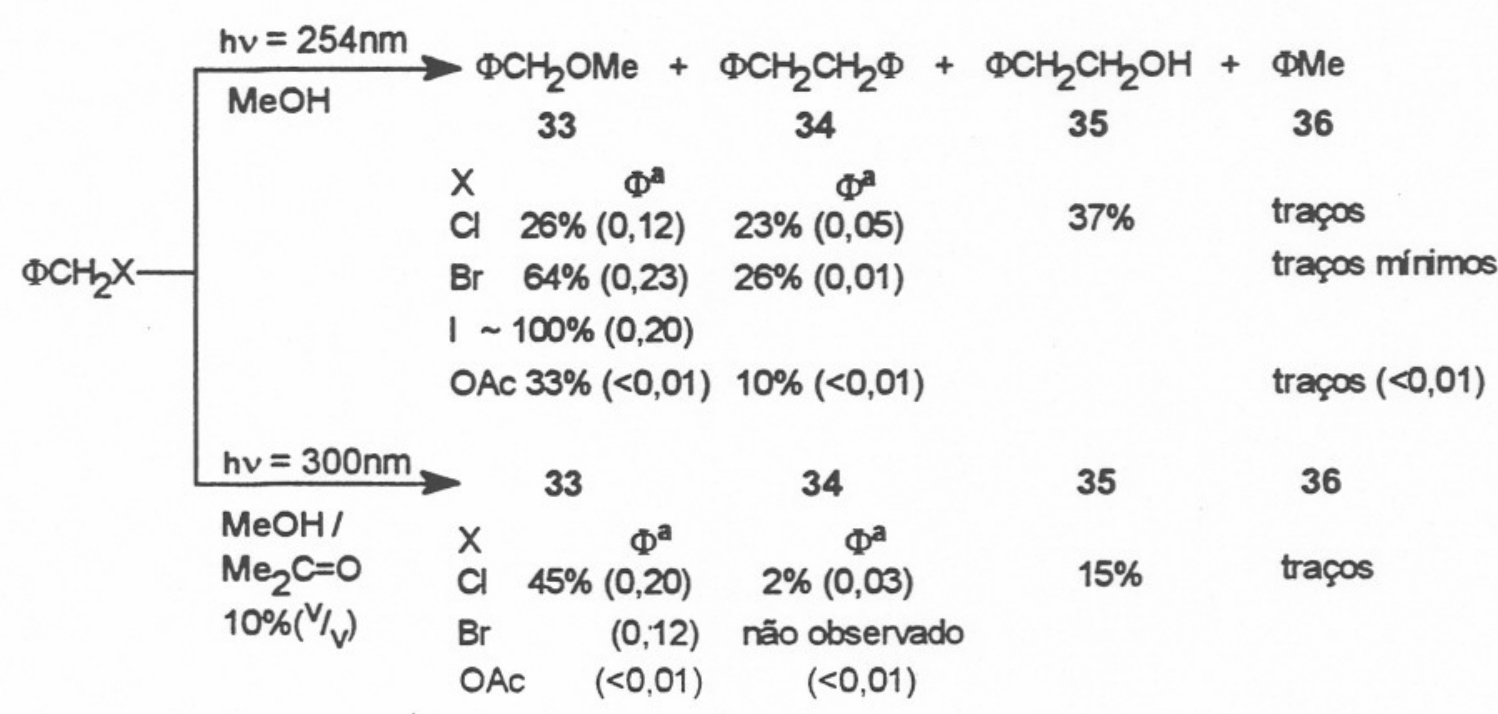

a: rendimentos quânticos determinados em t-butanol.

Entretanto, CRISTOL \& GREENWALD (1976) haviam obtido resultados discrepantes em relação aos relatados por McKenna e colaboradores, ao estudarem a fotólise de cloretos de benzila em metanol, tendo constatado somente a formação de produtos radicalares - bibenzila (34) e 2-fenil-etanol (35) - na irradiação direta (254nm), não tendo mencionado a presença de éter metil-benzílico, produto de heterólise, o qual, por outro lado, foi o único produto identificado na irradiação sensibilizada (por acetofenona, $\lambda_{\mathrm{irr}}=300 \mathrm{~nm}$ ). Em trabalhos posteriores, Cristol e colaboradores continuam apresentando dados discordantes daqueles publicados por McKenna e colaboradores. Assim, CRISTOL \& BINDEL (1980) mostram que cloretos de benzila substituídos, ao serem submetidos à irradiação direta (não-sensibilizada) em álcool tertbutílico, apresentam rendimentos quânticos de heterólise (foto-solvólise) menores do que os verificados para os produtos de homólise (radicais). Os mesmos autores, em artigo posterior (CRISTOL \& BINDEL, 1981), sugerem que dois estados triplete estejam envolvidos nos experimentos. Um, de vida curta e energia mais alta, que conduziria ao produto de solvólise e, outro, de menor energia e maior tempo de vida, que reverteria aos reagentes no estado fundamental.

Em um trabalho de abordagem fotoquímica mais clássica, com objetivo essencialmente preparativo, MITSUO et alii (1973), ao estudarem a redução fotoinduzida de compostos contendo grupos metila poli-halogenados, em tetra-hidro-furano, verificaram que a irradiação de tricloro-metil-benzeno (37) conduz a 1,1,2,2-tetracloro1,2-difenil-etano (38), como produto principal, praticamente não se formando o produto de redução 39 (ESQUEMA I.15). 


\section{ESQUEMA I.15}

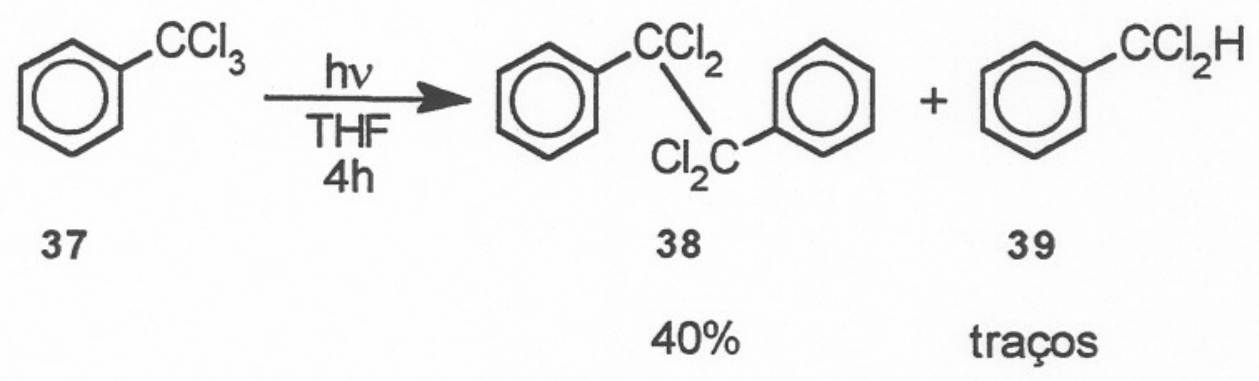

Este resultado contrasta com o observado para os compostos alquílicos estudados no mesmo trabalho, que forneceram, unicamente, produtos de redução. Este comportamento pode ser explicado levando-se em conta que o radical dicloro-benzila, mais estável que os radicais alquila, tenderia a sofrer dimerização, ao invés de abstrair hidrogênio do solvente, processo que, neste caso, deve ser endotérmico.

ABDEL-WAHAB et alii (1985) submeteram uma série de sete haletos de alquilarila (ESQUEMA I.16) à fotólise em tetracloreto de carbono, utilizando uma lâmpada de vapor de mercúrio de baixa pressão e concentrações de substrato relativamente altas $\left(2\right.$ mol. $\left.\mathrm{L}^{-1}\right)$. Foi observada a formação de vários produtos, provenientes de diferentes processos radicalares, tais como: dimerização, abstração de hidrogênio inter-molecular, eliminação de halogeneto de hidrogênio e ciclização intramolecular. Assim, os autores propuseram que a clivagem homolítica da ligação carbono-halogênio fosse o processo primário, nesta fotorreação.

\section{ESQUEMA I.16}

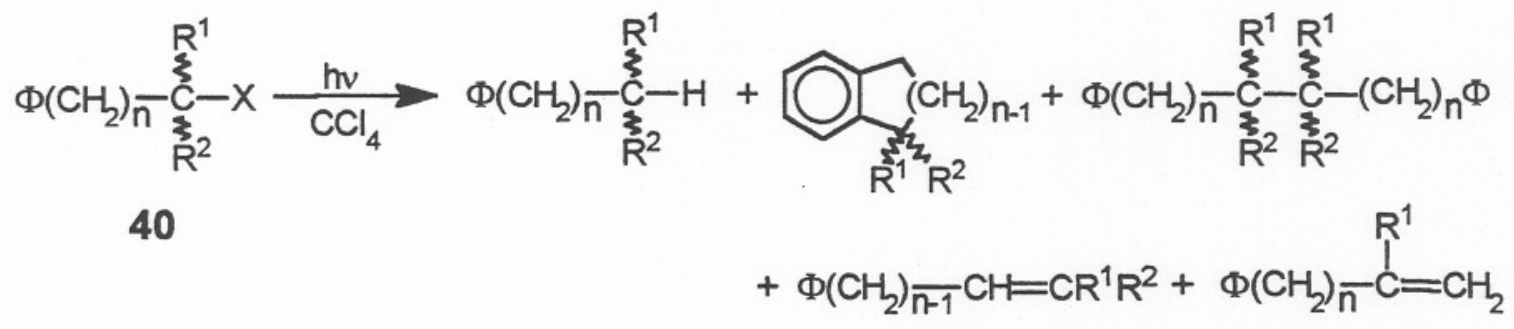

\begin{tabular}{|c|c|c|c|c|c|}
\hline Onde: & & & & $R^{1}$ & $\mathbf{R}^{2}$ \\
\hline$n R^{1}$ & $\mathbf{R}^{2}$ & X & d 3 & $\mathrm{H}$ & $\mathrm{H}$ \\
\hline a $0 \mathrm{H}$ & $\mathrm{H}$ & $\mathrm{Br}$ & e 2 & $\mathrm{Me}$ & $\mathrm{H}$ \\
\hline b $1 \mathrm{H}$ & $\mathrm{H}$ & $\mathrm{Br}$ & f 2 & $\mathrm{Me}$ & $M \epsilon$ \\
\hline c $2 \mathrm{H}$ & $\mathrm{H}$ & $\mathrm{Br}$ & g 3 & $\mathrm{Me}$ & $\mathrm{M}$ \\
\hline
\end{tabular}

Foram obtidos produtos de redução, resultantes de abstração inter-molecular de hidrogênio, em rendimentos de 12 a $30 \%$, na irradiação dos compostos 40 a-g. No caso dos compostos 40d-g, obtiveram-se, também, indanos ou tetralinas, devidos a ciclizações intramoleculares, com rendimentos de 12 a $20 \%$ e, para $40 \mathrm{c}-\mathrm{e}$, olefinas 
devidas à eliminação de haletos de hidrogênio, um processo competitivo, nestes casos, apresentando rendimentos de 11 a $26 \%$. Por outro lado, a dimerização só ocorreu em proporção significativa quando não havia possibilidade de ciclização intramolecular, ou quando este processo era desfavorecido (por exemplo, formação de indano, a partir de $40 c$, que não ocorre.).

Estes resultados podem ser melhor compreendidos caso se leve em conta 0 trabalho de TOURNIER et alii (1983). Estes autores estudaram a fotólise de cloreto de benzila, em meio apolar (decano), e propuseram que as constantes $\left(\mathbf{k}_{\mathbf{c}}\right)$ para reações de recombinação radicalar que ocorram dentro da gaiola de solvente sejam duas ordens de grandeza maiores do que a constante de difusão ( $\left.\mathbf{k}_{\text {dif }}\right)$, mesmo a $50^{\circ} \mathrm{C}$ :

$$
\beta=\left(\mathrm{k}_{\mathrm{c}} / \mathrm{k}_{\mathrm{dif}}\right)=110
$$




\section{OBJETIVOS}

Uma análise do conjunto de trabalhos sumarizados na revisão bibliográfica apresentada no item I.4 (capítulo I) mostra que persiste controvérsia a respeito dos processos de fotohomólise, tanto no que tange à reatividade, como sobre aspectos físico-químicos. Ainda, como muitos dos trabalhos que permitiram a caracterização dos intermediários envolvidos nesse tipo de reação foram efetuados em matriz, a baixas temperaturas, são necessárias mais informações sobre os mecanismos responsáveis pela reatividade em solução, à temperatura ambiente, pois as interações soluto/matriz podem alterar a reatividade do sistema, quando comparado ao que se observa em fase líqüida. Assim, com o objetivo de contribuir para a compreensão dos processos radicalares foto-induzidos em solução, consideramos ser de interesse desenvolver um estudo a respeito de alguns sistemas-modelo que pudessem, em princípio, gerar radicais e/ou quinodimetanos.

Dadas estas condições de contorno, iniciamos nossa pesquisa pela análise do comportamento de bromo-derivados do $o$-xileno (Figura II.1) em solventes apolares, meio este que deveria favorecer a foto-homólise. Na presente Tese, encontram-se relatados os resultados obtidos a partir destes compostos, os quais representam a primeira parte de uma investigação mais ampla do problema, ainda em andamento.

Compostos bromados com o esqueleto selecionado, além de serem de estrutura bastante simples - o que os torna adequados como sistemas-modelo - possuem um cromóforo que absorve em uma região de energia potencialmente suficiente $\left(254 \mathrm{~nm} ; 113 \mathrm{kcal}^{\mathrm{m}} \mathrm{mol}^{-1}\right)$ para a quebra simultânea de duas ligações $\mathrm{C}-\mathrm{Br}$, o que deveria possibilitar a geração de o-quinodimetanos, em solução, através de um processo monofotônico, já que são necessárias apenas 55kcal.mol-1 para o rompimento da ligação $\mathrm{C}-\mathrm{Br}$, no caso de brometo de benzila (MUROV, 1973).

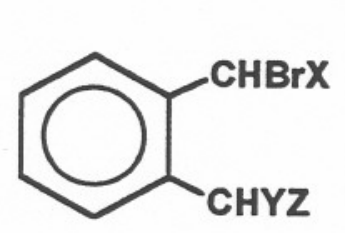

$$
\begin{aligned}
& \text { onde: } \mathrm{X}=\mathrm{Y}=\mathrm{Z}=\mathrm{H} \quad \text { (MBX); } \\
& \mathrm{X}=\mathrm{Y}=\mathrm{H} \text { e } \mathrm{Z}=\mathrm{Br} \quad \text { (DBX); } \\
& \mathrm{X}=\mathrm{Y}=\mathrm{Br} \text { e } \mathrm{Z}=\mathrm{H} \quad \text { (TRBX); } \\
& \mathrm{X}=\mathrm{Y}=\mathrm{Z}=\mathrm{Br} \quad \text { (TBX); } \\
& \mathrm{X}=\mathrm{Br} \text { e } \mathrm{Y}=\mathrm{Z}=\mathrm{H} \text { (GBX). }
\end{aligned}
$$

Figura II.1 - Bromo-derivados de o-xileno, utilizados no presente estudo.

Os objetivos do trabalho proposto desdobram-se em duas etapas: i) a primeira, a ser executada através de uma abordagem fotoquímica clássica, visa elucidar aspectos mecanísticos relacionados ao sistema-modelo e, também, estabelecer condições de contorno para o planejamento e obtenção de fotociclizações radicalares, em solução, sob temperatura e pressão ambientes, empregando lâmpadas convencionais; ii) a segunda, utilizando métodos rápidos, objetiva caracterizarem-se os intermediários transientes, a partir de dados cinéticos (tempos de vida) e espectroscópicos (absorção no UV), com a utilização de espectroscopia de fotóliserelâmpago. 


\section{MATERIAIS E MÉTODOS}

\section{III.1. Aparelhagem}

Os espectros de Ressonância Magnética Nuclear foram obtidos em um aparelho Bruker modelo AC-200-F de 4,71T $\left({ }^{1} \mathrm{H}\right.$, a $200 \mathrm{MHz}$ e ${ }^{13} \mathrm{C}$, a $\left.50 \mathrm{MHz}\right)$.

Os espectros de absorção no infravermelho foram obtidos utilizando-se o espectrômetro Perkin-Elmer 1750 FT.

Obtiveram-se os espectros de massas nos seguintes espectrômetros: (i) Finnigan MAT de captura de íons, modelo ITD 800 e Finnigan MAT, quadrupolar, INCOS 50, ambos acoplados a cromatógrafos a gás (Finnigan MAT e VARIAN, modelo 3400 , respectivamente) dotados de coluna capilar DB-5 (5\% fenil-, $95 \%$ polidimetil-silicone de $30 \mathrm{~m} \times 0,25 \mathrm{~mm} \times 0,25 \mu \mathrm{m}$ ); (ii) Hewlett Packard, quadrupolar, modelo 5988 A, acoplado a um cromatógrafo a gás HP, modelo 5890, dotado de uma coluna capilar HP-1 (poli-dimetil-silicone de $12 \mathrm{~m} \mathrm{x} \mathrm{0,25mm} \mathrm{x} \mathrm{0,25 \mu m).} O$ espectro de massas de alta resolução foi obtido em um espectrômetro Finnigan MAT, modelo MAT 90, dotado de um analizador magnético e um quadrupolar, em geometria reversa, utilizando-se injeção direta da amostra no "probe".

As cromatografias de partição líqüido-gás foram feitas em um cromatógrafo a gás Shimadzu GC-14-A, dotado de uma coluna capilar CBP-1 (poli-dimetil-silicone; $25 \mathrm{~m} \times 0,25 \mathrm{~mm} \times 0,22 \mu \mathrm{m}$ ), injetor com divisor de amostra (razão $43: 1$ ) e detector de ionização de chama, acoplado a um integrador/registrador computadorizado Shimadzu Chromatopac C-R4A, empregando-se hélio como gás de arraste (fluxo: $1,6 \mathrm{~mL} / \mathrm{min}$ ). Todos os cromatogramas foram obtidos nas seguintes condições: injetor, $230^{\circ} \mathrm{C}$; detector, $260^{\circ} \mathrm{C}$; coluna a temperatura programada $\left(80^{\circ} \mathrm{C}\right.$ durante 4 minutos, $30^{\circ} \mathrm{C}$ por minuto até $250^{\circ} \mathrm{C}, 250^{\circ} \mathrm{C}$ durante 2,7 minutos).

As medidas espectrofotométricas, nas regiões do visível e do ultravioleta, foram feitas em um espectrofotômetro Hitachi U-2000.

Para as medidas de fotólise-relâmpago, empregou-se um espectrômetro para cinética Applied Photophysics, com laser de Nd-YAG (largura do pulso, à meia altura, $\sim 15 \mathrm{~ns}, \lambda=1064,532,355$ e $266 \mathrm{~nm}$ ) e lâmpada de análise de xenônio, acoplado a um osciloscópio Tektroniks 2230 , selecionando-se $266 \mathrm{~nm}$ como comprimento de onda de excitação.

As determinações de massa foram efetuadas em balanças analíticas Mettler AE-260 e H20T ou em uma balança semi-analítica Marte A500.

Os pontos de fusão relatados foram obtidos em um aparelho Thomas Hoover, constituído por um microscópio Dynamics Optics AHT dotado de um bloco de Kofler.

As destilações bulbo-a-bulbo foram efetuadas em um destilador "kugelrohr" Büchi GKR-51.

Para as evaporações de solvente, empregou-se um evaporador rotativo Buchler PTFE-1GN, operando sob pressão reduzida por trompa de água pressurizada. 


\section{III.2. Materiais}

Os solventes de grau espectrocópico e os demais reagentes empregados neste trabalho, cuja purificação não esteja descrita a seguir, foram utilizados sem tratamento prévio.

- benzeno (Aldrich): grau espectroscópico.

- benzeno anidro: benzeno (P.A.) foi secado com sulfato de sódio anidro por uma noite. Filtrou-se e adicionaram-se fios de sódio, repetindo-se o procedimento a cada doze horas, até não mais haver evolução de hidrogênio. A seguir, destilouse 0 benzeno, mantido sobre fios de sódio, em atmosfera de argônio anidro, armazenando-se a porção central sobre novos fios de sódio, ainda em atmosfera inerte.

- ciclo-hexanona (P.A.): foi tratada com permanganato de potássio a refluxo e, a seguir, destilada por arraste a vapor; extraiu-se-a do destilado com benzeno, em presença de cloreto de sódio, roto-evaporando-se o extrato para eliminação do benzeno. A cetona foi, então, destilada e secada sobre sulfato de magnésio anidro.

- ciclo-hexeno (P.A.): foi tratado com solução ácida diluída de sulfato de ferro (II) - para eliminação de peróxidos - e destilado, sob argônio, segundo procedimento descrito na literatura (PERRIN et alii, 1966).

- clorofórmio anidro: clorofórmio (P.A.) foi refluxado durante uma hora sobre pentóxido de fósforo e destilado de sobre o secante, sendo, então, estocado sob atmosfera de argônio anidro, em frasco escuro.

- etanol anidro: preparado, a partir de etanol P.A., segundo o método do magnésio (LUND \& BJERRUM, 1931), sendo estocado sob argônio anidro.

- éter etílico seco: quatro litros de éter etílico P.A. foram agitados com ácido sulfúrico, sulfato de ferro (II) e água para eliminação de peróxidos, detectados por reação com dicromato de sódio. Após ter sido secado com sulfato de sódio e sódio metálico, segundo o procedimento já descrito para benzeno, o composto foi estocado em frasco âmbar.

- iso-octano (Merck ou Aldrich): grau espectroscópico.

- nafta $80-100^{\circ} \mathrm{C} ; 100-120^{\circ} \mathrm{C}$ e éter de petróleo $60-68^{\circ} \mathrm{C}$ : foram obtidos por fracionamento em coluna de Snyder, a partir de nafta ISSOL-60/120 (Ipiranga), previamente secada sobre sulfato de sódio.

- sulfato duplo de alumínio e potássio: foi dessecado em estufa a vácuo, a $140^{\circ} \mathrm{C}$, até massa constante (para $100 \mathrm{~g}$ de sal foram eliminados $42,94 \mathrm{~g}$ de água de hidratação).

- $\alpha, \alpha, \alpha^{\prime}, \alpha^{\prime}$-tetrabromo-o-xileno (TBX): foi recristalizado de éter de petróleo (faixa $80-100^{\circ} \mathrm{C}$ ), ou de hexano, por pelo menos três vezes, até que se obtivessem cristais brancos, em forma de agulhas, de ponto de fusão $116^{\circ} \mathrm{C}$ (115-116 ${ }^{\circ}$ C; BILL \& TARBELL, 1963); EM: vide Figura III.1, p.40.

- o-xileno (Aldrich, P.A.): foi utilizado sem tratamento prévio. 


\section{III.3. Obtenção dos Compostos Submetidos à Fotólise}

III.3.1: Preparação de $\alpha$-bromo-o-xileno, MBX (ATKINSON \& THORPE, 1907)<smiles>Cc1ccccc1C</smiles><smiles>CC(C)[Mg]</smiles><smiles>Cc1ccccc1CBr</smiles>

MBX

Aqueceram-se $36,0 \mathrm{~mL}$ de $o$-xileno $\left(32,4 \mathrm{~g} ; 30,6.10^{-2} \mathrm{~mol}\right)$ a $130^{\circ} \mathrm{C}$ e adicionaram-se, lentamente, sob a superficie do líqüido, $19,2 \mathrm{~mL}\left(57,6 \mathrm{~g} ; 36,0.10^{-2} \mathrm{~mol}\right)$ de bromo, mantendo-se a temperatura até, no máximo, $135^{\circ} \mathrm{C}$, irradiando-se a mistura reacional com uma lâmpada de $600 \mathrm{~W}$, de emissão na faixa do visível. Após o término da adição, a mistura reacional permaneceu em um dessecador contendo hidróxido de sódio, por uma noite e, a seguir, procedeu-se a uma destilação fracionada com coluna de Vigreux, à vácuo. Obtiveram-se $22,7 \mathrm{~g}\left(12,3.10^{-2} \mathrm{~mol}\right)$ de $\alpha$-bromo-o-xileno (MBX).

Rendimento: $40 \%$

P.E.: $104^{\circ} \mathrm{C} / 12 \mathrm{mmHg}\left(215-218^{\circ} \mathrm{C}\right.$; ATKINSON \& THORPE, 1907).

RMN de ${ }^{1} \mathrm{H}$, vide Tabelas III.1 e III.2, e de ${ }^{13} \mathrm{C}$, vide Tabela III.3, p. 36.

EM: vide Figura III.2, p. 42.

\section{III.3.2: Preparação de $\alpha, \alpha^{\prime}$-dibromo-o-xileno, DBX (STEPHENSON, 1963)}<smiles>Cc1ccccc1C</smiles>

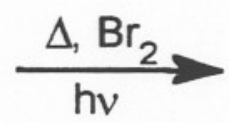<smiles>Cc1ccccc1CBr</smiles>

DBX

Adicionaram-se, lentamente, $117,5 \mathrm{~mL}\left(352,5 \mathrm{~g} ; 22,0.10^{-1} \mathrm{~mol}\right)$ de bromo, sob agitação mecânica, a $118,0 \mathrm{~mL}\left(106,2 \mathrm{~g} ; 10,0.10^{-1} \mathrm{~mol}\right)$ de $o$-xileno, mantido entre $127^{\circ}$ e $130^{\circ} \mathrm{C}$, irradiando-se a mistura reacional com uma lâmpada de $600 \mathrm{~W}$, de emissão na faixa do visível. Terminada a reação, adicionaram-se, ao meio reacional, $300 \mathrm{~mL}$ de éter de petróleo (de faixa $60-68^{\circ} \mathrm{C}$ ) a $60^{\circ} \mathrm{C}$ e, posteriormente, levou-se a mistura à geladeira, em erlenmeyer, durante $20 \mathrm{~h}$. Filtrou-se à vácuo, tendo sido obtidos $146,5 \mathrm{~g}$ $\left(55,5.10^{-2} \mathrm{~mol}\right)$ de material cristalizado, de cor marrom-escura.

Rendimento: $55 \%$.

P.F.: $93-95^{\circ} \mathrm{C}\left(89-94^{\circ}\right.$, STEPHENSON, 1963). 
Este material foi recristalizado em pequenas alíquotas, por pelo menos cinco vezes, ou de éter de petróleo (faixa $60-68^{\circ} \mathrm{C}$ ), ou de hexano, tomando-se o cuidado de manter o solvente a, no máximo, $60^{\circ} \mathrm{C}$. Após resfriamento à temperatura ambiente, filtração e secagem ao ar, obtem-se material de cor branca, em forma de longas agulhas.

P.F.: $95^{\circ} \mathrm{C}\left(89-94^{\circ} \mathrm{C}\right.$, STEPHENSON, 1963$)$.

$\mathrm{RMN}$ de ${ }^{1} \mathrm{H}$, vide Tabelas III.1 e III.2, e de ${ }^{13} \mathrm{C}$, vide Tabela III.3, p. 36.

EM: vide Figura III.3, p. 43.

III.3.3: Síntese de $\alpha, \alpha$-dibromo-o-xileno (GBX)
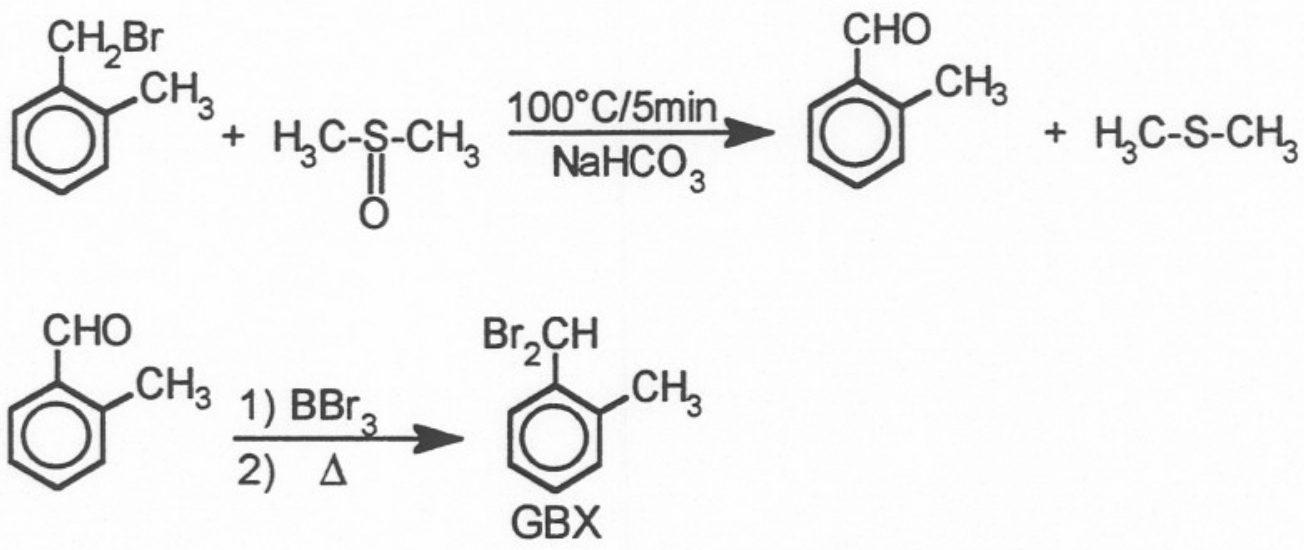

i. Preparação de $o$-metil-benzaldeído (KORNBLUM et alii, 1959): $\alpha$-bromo-o-xileno $\left(28,0 \mathrm{~g} ; 1,5.10^{-1} \mathrm{~mol}\right)$ foi adicionado a uma mistura, recém-preparada, de $300 \mathrm{~mL}$ de dimetil-sulfóxido e $100,0 \mathrm{~g}(1,2 \mathrm{~mol})$ de bicarbonato de sódio, aquecida previamente a $100^{\circ} \mathrm{C}$, através da qual se borbulhava argônio, em fluxo contínuo. Após cinco minutos de reação, verteu-se a mistura reacional sobre aproximadamente $500 \mathrm{~g}$ de gelo. $O$ produto foi extraído com éter, secado com sulfato de magnésio anidro e o solvente foi evaporado em um evaporador rotatório, sendo obtidos $9,2 \mathrm{~g}\left(7,7.10^{-2} \mathrm{~mol}\right)$ de material, de pureza cromatográfica igual a $90 \%$, que foi identificado como sendo $o$-metilbenzaldeído.

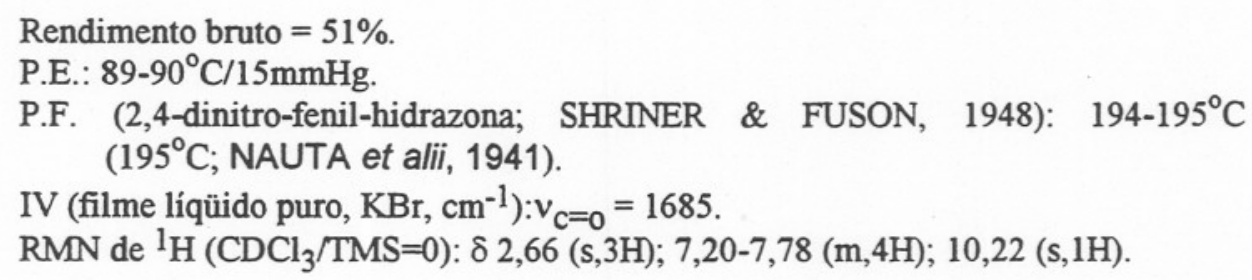

Este material foi destilado duas vezes, a vácuo, com coluna de Vigreux, tendo sido obtidos $8,10 \mathrm{~g}$ de material de pureza cromatográfica $97 \%$.

Rendimento $=45 \%$.

P.E.: $59^{\circ} \mathrm{C} / 1 \mathrm{mmHg}\left(199-200^{\circ} \mathrm{C}\right.$; BEILSTEIN H7,295).

ii. Transformação de $\boldsymbol{o}$-metil-benzaldeído em GBX (LANSINGER \& RONALD, 1979): Adicionaram-se $14,0 \mathrm{~mL}$ de tribrometo de boro $\left(37,1 \mathrm{~g} ; 1,5.10^{-1} \mathrm{~mol}\right)$, com seringa, a $8,10 \mathrm{~g}\left(6,8.10^{-2} \mathrm{~mol}\right)$ de $o$-metil-benzaldéído dissolvidos em $150 \mathrm{~mL}$ de clorofórmio anidro, após a solução ter sido purgada com argônio durante alguns minutos. 0 material, deixado em contacto durante $24 \mathrm{~h}$, adquiriu uma coloração avermelhada. 
Procedeu-se, então, à eliminação do solvente em um evaporador rotatório, em ausência de oxigênio e de umidade. O óleo escuro obtido foi pirolisado a $150^{\circ} \mathrm{C}(10 \mathrm{mmHg})$, sendo, concomitantemente, destilado bulbo-a-bulbo. Obtiveram-se 13,26g do composto dibromado geminal bruto. Rendimento bruto: $74,5 \%$. Este material foi destilado à vácuo, com uma coluna de Vigreux, tendo sido obtidos $10,20 \mathrm{~g}$ de um líqüido transparente, ligeiramente amarelado, de pureza cromatográfica $98 \%$, caracterizado como $\alpha, \alpha-$ dibromo-o-xileno. Não foram obtidos resultados de análise elementar para o composto, devido à sua rápida hidrólise por ação da umidade do ar.

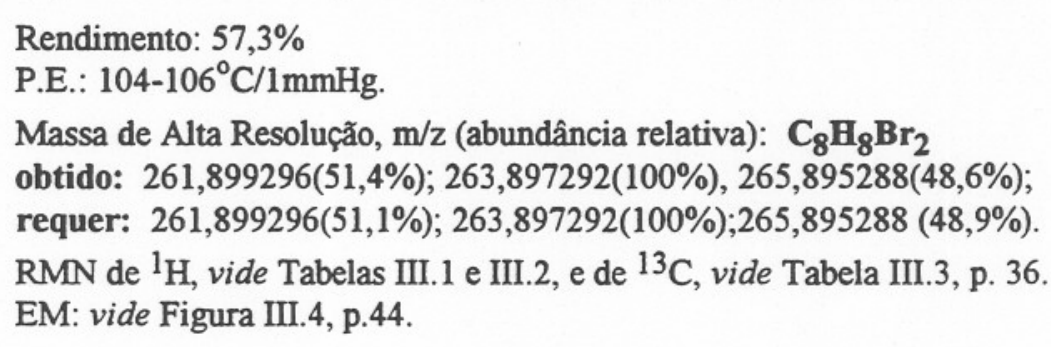
III.3.4: Preparação de $\alpha, \alpha, \alpha^{\prime}$-tribromo-o-xileno, TRBX (HALFORD \& WEISSMANN, 1953)<smiles>Cc1ccccc1CBr</smiles>
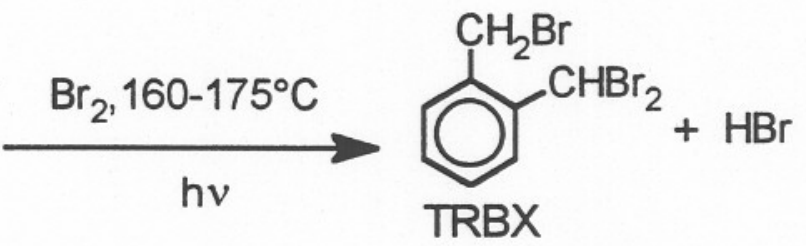

$2,2 \mathrm{~mL}$ de bromo $\left(6,55 \mathrm{~g} ; 4,09.10^{-2} \mathrm{~mol}\right)$ foram adicionados, lentamente e sob agitação, a $19,40 \mathrm{~g}\left(7,35.10^{-2} \mathrm{~mol}\right)$ de $\alpha, \alpha^{\prime}$-dibromo-o-xileno fundido, mantido entre 160 e $175^{\circ} \mathrm{C}$, de maneira que a adição ocorresse sob a superficie do líqüido. Utilizou-se uma lâmpada halógena de $110 \mathrm{~W}$ para manter o meio reacional sob irradiação. A mistura reacional, de cor marrom-escura, após ser resfriada e semeada com cristais de $\alpha, \alpha^{\prime}$-dibromo-o-xileno, forneceu um sólido que, depois de recristalizado de hexano, pôde ser identificado como sendo o composto dibromado de partida. $\mathrm{O}$ resíduo líqüido foi diluído com éter de petróleo/éter ( $5: 1 \mathrm{v} / \mathrm{v})$, ocorrendo a formação de alguns gramas de cristais de cor clara, também identificados como sendo o composto de partida. A fase líqüida remanescente foi roto-evaporada e, o óleo resultante, cristalizado de hexano/benzeno (9:1), tendo sido obtidos cristais de cor amarelo-clara na interface solução/ar, após 24 horas de repouso em freezer. Estes cristais, de pureza cromatográfica $80 \%$, foram recristalizados, novamente, de hexano/benzeno $(9: 1)$, fornecendo 2,5g de material tribromado, o qual apresentou purezas cromatográfica e de RMN de ${ }^{1} \mathrm{H}$ de $100 \%$ e $99,6 \%$, respectivamente.

Rendimento: $18 \%$.

P.F.: $42^{\circ} \mathrm{C}\left(40-41^{\circ} \mathrm{C}\right.$; HALFORD \& WEISSMANN, 1953).

$\mathrm{RMN}$ de ${ }^{1} \mathrm{H}$, vide Tabelas III.1 e III.2, e de ${ }^{13} \mathrm{C}$, vide Tabela III.3, p 36.

EM: vide Figura III.5, p. 46. 
III.3.5: Dados de RMN de ${ }^{1} \mathrm{H}$ e de ${ }^{13} \mathrm{C}$, para os compostos bromados<smiles>[X]C(=O)c1ccccc1Br</smiles>

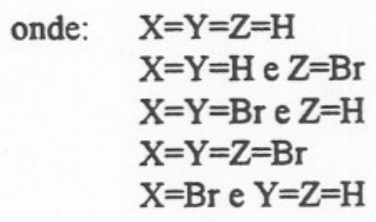

(MBX);

(DBX);

(TRBX);

(TBX);

(GBX).

Tabela III.1: Deslocamentos químicos de ${ }^{1} \mathrm{H}$, para bromo-derivados de $o$-xileno $\left(\delta / \mathrm{ppm} ; \mathrm{TMS}=0,00\right.$; solvente: $\mathrm{CDCl}_{3}$ ).

\begin{tabular}{ccccccc}
\hline Composto $^{\text {a }}$ & H-2 & H-3 & H-4 & H-5 & H-7 & H-8 \\
\hline MBX & 7,30 & 7,17 & 7,22 & 7,19 & 2,41 & 4,51 \\
DBX & 7,34 & 7,28 & 7,28 & 7,34 & 4,67 & 4,67 \\
TRBX & 7,92 & 7,38 & 7,25 & 7,22 & 4,55 & 7,09 \\
TBX & 7,65 & 7,36 & 7,36 & 7,65 & 7,14 & 7,14 \\
GBX & 7,80 & 7,18 & 7,24 & 7,06 & 2,38 & 6,86 \\
\hline
\end{tabular}

a: como apresentado na figura acima.

Tabela III.2: Constantes de acoplamento proton-proton, para bromo-derivados de $o$-xileno (J/Hz; Dados estimados por meio de simulações utilizando o programa LAOCOON 3).

\begin{tabular}{cccccccc}
\hline Composto $^{\mathbf{a}}$ & $\mathbf{J}_{2,3} \mathbf{b}$ & $\mathrm{J}_{2,4} \mathbf{b}^{\mathbf{b}}$ & $\mathrm{J}_{2,5} \mathbf{b}$ & $\mathrm{J}_{3,4} \mathbf{b}$ & $\mathrm{J}_{3,5} \mathbf{b}$ & $\mathrm{J}_{4,5} \mathbf{b}$ & $\begin{array}{c}\sigma^{\mathbf{c}} / \\
\mathrm{Hz}\end{array}$ \\
\hline MBX & $7,36 \pm 0,14$ & $1,26 \pm 0,13$ & $0,27 \pm 0,28$ & $7,62 \pm 0,12$ & $1,78 \pm 0,09$ & $7,86 \pm 0,13$ & 0,22 \\
DBX & $7,72 \pm 0,03$ & $1,32 \pm 0,02$ & $0,63 \pm 0,04$ & $7,64 \pm 0,04$ & $1,32 \pm 0,02$ & $7,72 \pm 0,03$ & 0,06 \\
TRBX & $7,87 \pm 0,03$ & $1,13 \pm 0,04$ & $0,31 \pm 0,04$ & $7,63 \pm 0,05$ & $1,21 \pm 0,06$ & $7,79 \pm 0,04$ & 0,07 \\
TBX & $7,89 \pm 0,01$ & $1,26 \pm 0,02$ & $-0,01 \pm 0,01$ & $7,31 \pm 0,02$ & $1,26 \pm 0,02$ & $7,89 \pm 0,01$ & 0,09 \\
GBX & $7,81 \pm 0,04$ & $1,19 \pm 0,04$ & $-0,06 \pm 0,04$ & $7,06 \pm 0,04$ & $1,09 \pm 0,04$ & $7,67 \pm 0,05$ & 0,23 \\
\hline
\end{tabular}

a: como apresentado na figura acima; b: \pm erro provável do dado; c: desvio-padrão global da simulação.

Tabela III.3: Deslocamentos químicos de ${ }^{13} \mathrm{C}$, para bromo-derivados de $o$-xileno $\left(\delta / \mathrm{ppm} ; \mathrm{TMS}=0,00 ;\right.$ solvente: $\left.\mathrm{CDCl}_{3}\right)$

\begin{tabular}{ccccccccc}
\hline Composto ${ }^{\text {a }}$ & C-1 & C-2 & C-3 & C-4 & C-5 & C-6 & C-7 & C-8 \\
\hline MBX & 135,40 & 129,66 & 126,06 & 128,60 & 130,43 & 136,86 & 18,41 & 32,18 \\
DBX & 136,47 & 131,01 & 129,36 & 129,36 & 131,01 & 136,47 & 29,98 & 29,98 \\
TRBX & 132,16 & 130,34 & 129,90 & 130,05 & 130,05 & 140,21 & 29,22 & 36,86 \\
TBX & 137,56 & 129,30 & 130,31 & 130,31 & 129,30 & 137,56 & 36,49 & 36,49 \\
GBX & 133,01 & 128,79 & 129,73 & 126,89 & 130,39 & 139,36 & 18,71 & 39,23 \\
\hline
\end{tabular}

a: como apresentado na figura acima. 


\section{III.4. Obtenção dos Padrões para a Caracterização dos Produtos de Fotólise}

\section{III.4.1: Síntese de 1,1'-biciclo-hexeno, DCHex(1,1')}

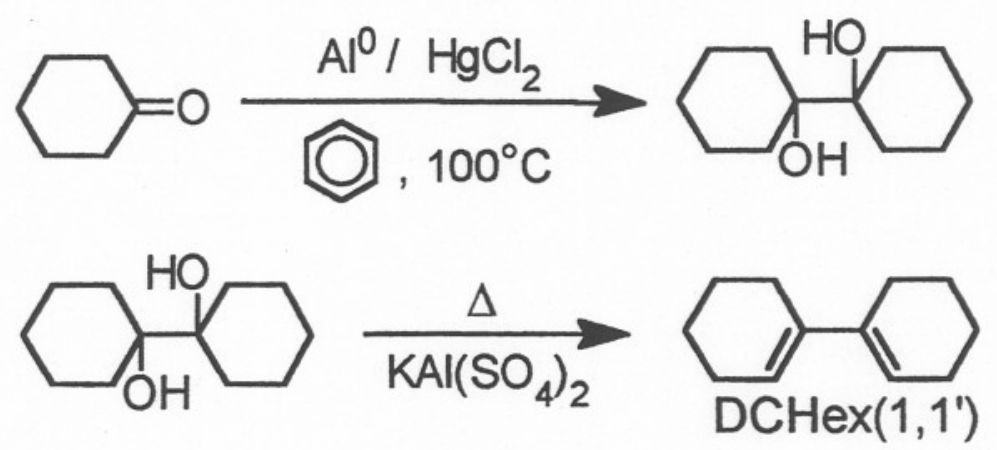

i. Preparação de 1,1'-di-hidróxi-1,1'-biciclo-hexano (BARNETT \& LAWRENCE, 1935): A $9,80 \mathrm{~g}(0,10 \mathrm{~mol})$ de ciclo-hexanona foram adicionados $1,75 \mathrm{~g}\left(6,48.10^{-2} \mathrm{~mol}\right)$ de fitas de alumínio, $0,70 \mathrm{~g}\left(2,57.10^{-3} \mathrm{~mol}\right)$ de cloreto de mercúrio (II) e $10,0 \mathrm{~mL}(8,7 \mathrm{~g}$; $1,1.10^{-1} \mathrm{~mol}$ ) de benzeno anidro. A mistura foi aquecida em banho-maria durante uma hora, sob agitação, sendo, então, acrescentados $10,0 \mathrm{~mL}$ de água e $15,0 \mathrm{~mL}$ de benzeno. Após mais três horas de aquecimento em banho-maria, filtrou-se a mistura, ainda quente, o sólido foi extraído com cerca de $20 \mathrm{~mL}$ de benzeno a ebulição e os filtrados, reunidos, foram secados com sulfato de magnésio anidro. Após roto-evaporação de parte do benzeno, adicionou-se éter de petróleo $\left(30-60^{\circ} \mathrm{C}\right)$ até se observar turvação, deixando-se esfriar lentamente. Foram obtidos $2,78 \mathrm{~g}$ de material cristalino, branco.

Rendimento: $14 \%$.

P.F.: $129-130^{\circ} \mathrm{C}\left(130^{\circ} \mathrm{C}\right.$; BARNETT \& LAWRENCE, 1935).

ii. Transformação do di-álcool em 1,1'-biciclo-hexeno (BARNETT \& LAWRENCE, 1935): O di-álcool obtido $(2,00 \mathrm{~g} ; 0,01 \mathrm{~mol})$ e $6,0 \mathrm{~g}$ de sulfato duplo de alumínio e potássio anidro foram misturados e aquecidos entre 140 e $160^{\circ} \mathrm{C}$, até que não mais houvesse eliminação de água (cerca de 4 horas). Destilou-se, bulbo-a-bulbo, sob vácuo, tendo sido obtidos cerca de $0,5 \mathrm{~g}$ de material oleoso bruto de p.e.: 110 $115^{\circ} \mathrm{C} / 10 \mathrm{mmHg}\left(245-251^{\circ} \mathrm{C}\right.$; BARNETT \& LAWRENCE, 1935). Este óleo foi secado com cloreto de cálcio anidro, em solução etérea. O éter foi removido por rotoevaporação e o óleo foi cristalizado, por três vezes, de etanol anidro, a $-40^{\circ} \mathrm{C}$, tendo sido obtidos $0,12 \mathrm{~g}$ de um líqüido levemente amarelado, altamente viscoso, à temperatura ambiente.

Rendimento: $7,0 \%$.

P.F.: $28-9^{\circ} \mathrm{C} ;\left(28^{\circ} \mathrm{C}\right.$; BARNETT \& LAWRENCE, 1935).

E.M.: vide Figura III.6, p. 47. 


\section{III.4.2: Síntese do brometo de o-benzil-benzila, $\mathrm{BBzBr}$}
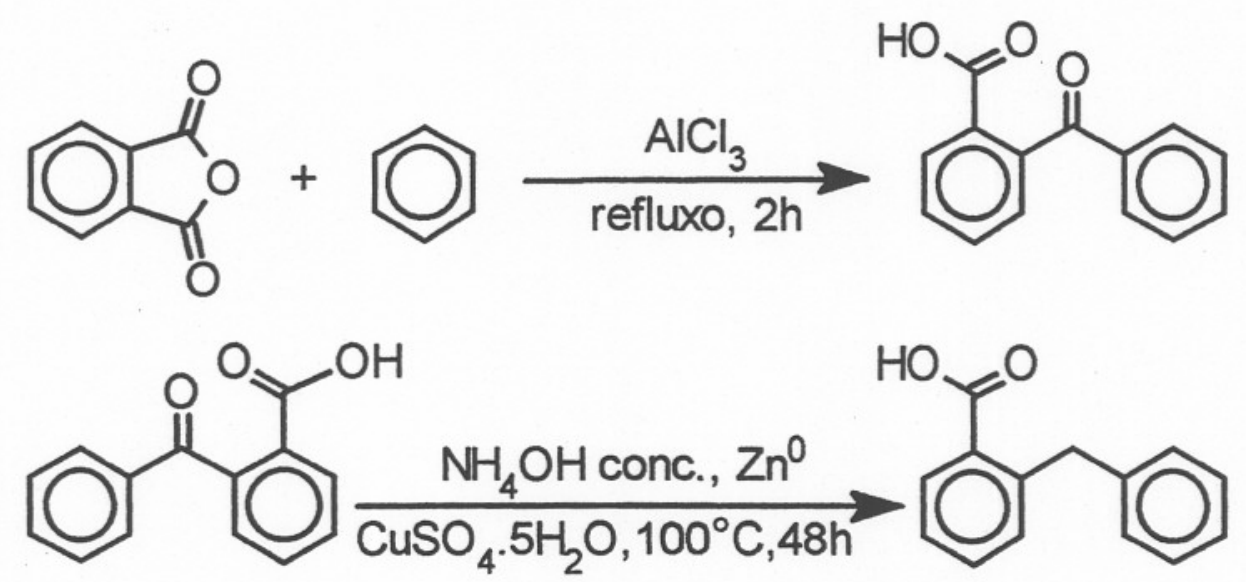<smiles>O=C(O)c1ccccc1Cc1ccccc1</smiles>

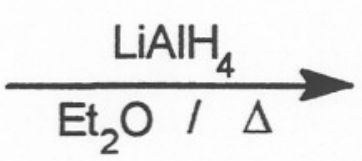<smiles>OCc1ccccc1Cc1ccccc1</smiles><smiles>OCc1ccccc1Cc1ccccc1</smiles>

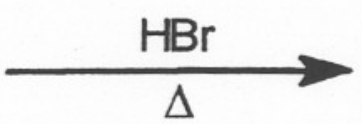<smiles>BrCc1ccccc1Cc1ccccc1</smiles>

$\mathrm{BBz} \mathrm{Br}$

i. Preparação do ácido o-benzoil-benzóico (VOGEL, 1967): A uma mistura de anidrido ftálico $(25,00 \mathrm{~g} ; 0,17 \mathrm{~mol})$ e $100 \mathrm{~mL}(\sim 1 \mathrm{~mol})$ de benzeno seco adicionaram-se, em quatro porções, $50,00 \mathrm{~g}\left(3,75.10^{-1} \mathrm{~mol}\right)$ de cloreto de alumínio anidro, sob agitação constante. Após ter-se completado a adição, aqueceu-se a mistura reacional em banhomaria e, finalmente, a refluxo, até que cessasse a evolução de gás. Adicionou-se, então, gelo moído suficiente para que a massa escura fosse completamente decomposta, adicionando-se solução concentrada de ácido clorídrico suficiente para clarear a solução. A solução foi roto-evaporada para eliminação do benzeno. Resfriou-se o resíduo obtido com gelo, filtrou-se e lavou-se o sólido obtido com água fria. $\mathrm{O}$ sólido foi dissolvido em cerca de $150 \mathrm{~mL}$ de solução morna de carbonato de sódio a $10 \%$. A solução foi filtrada e acidificada com solução concentrada de ácido clorídrico, até que o ácido-o-benzoil-benzóico se separasse, como uma fase oleosa, a qual cristalizou sob agitação e resfriamento. Filtrou-se e lavou-se com água. Recristalizou-se de benzeno/éter de petróleo $\left(60-80^{\circ} \mathrm{C}\right)$ e secou-se sobre parafina e pentóxido de fósforo, sob vácuo. Obtiveram-se $25,82 \mathrm{~g}$ de ácido $o$-benzoil-benzóico.

Rendimento: $67,2 \%$.

P.F.: $127-129^{\circ} \mathrm{C}\left(128^{\circ} \mathrm{C}\right.$; VOGEL, 1967$)$.

ii. Preparação do ácido o-benzil-benzóico (BARNETT et alii, 1927): $25,00 \mathrm{~g}$ de ácido $o$-benzoil-benzóico foram dissolvidos em cerca de $200 \mathrm{~mL}$ de solução concentrada de hidróxido de amônio diluídos em $50 \mathrm{~mL}$ de água. Acrescentaram-se alguns cristais de sulfato de cobre penta-hidratado e $50,00 \mathrm{~g}$ de zinco em pó, em diversas etapas, sob resfriamento. Aqueceu-se a reação em banho-maria durante 48 horas, quando uma amos- 
tra filtrada, depois de acidificada, forneceu um precipitado completamente solúvel em solução aquosa de carbonato de sódio, indicando o consumo completo do ftalídeo formado intermediariamente, insolúvel neste meio. Filtrou-se, lavou-se o sólido com água e acidulou-se o filtrado e as águas de lavagem com solução de ácido clorídrico. O precipitado obtido foi dissolvido em solução de carbonato de sódio, reprecipitado de ácido clorídrico e, finalmente, recristalizado de ácido acético/água. Repetiu-se este procedimento por mais duas vezes, tendo-se obtido $15,0 \mathrm{~g}$ de produto $97,7 \%$ puro por cromatografia.

Rendimento: $64 \%$.

P.F.: $114-115^{\circ} \mathrm{C}\left(113,3-114,2^{\circ} \mathrm{C}\right.$; BRADLOW \& VANDERWERF, 1947$)$.

$\mathrm{RMN}$ de ${ }^{1} \mathrm{H}\left(\mathrm{CDCl}_{3} / \mathrm{TMS}=0\right)$ :

$\delta 4,46(\mathrm{~s}, 2 \mathrm{H}) ; 7,20(\mathrm{~m}, 6 \mathrm{H}) ; 7,33\left(\mathrm{dd}, 1 \mathrm{H} ; \mathrm{J}=7,8 \mathrm{~Hz} ; \mathrm{J}^{\prime}=1,5 \mathrm{~Hz}\right)$;

$7,47\left(\mathrm{td}, 1 \mathrm{H} ; \mathrm{J}=7,5 \mathrm{~Hz} ; \mathrm{J}^{\prime}=1,6 \mathrm{~Hz}\right) ; 8,07\left(\mathrm{dd}, 1 \mathrm{H} ; \mathrm{J}=7,7 \mathrm{~Hz} ; \mathrm{J}^{\prime}=1,5 \mathrm{~Hz}\right)$.

$\mathrm{RMN}$ de ${ }^{13} \mathrm{C}\left(\mathrm{CDCl}_{3}=77,0 \mathrm{ppm}\right)$ :

$\delta 39,60\left(\mathrm{CH}_{2}\right) ; 125,98 ; 126,35 ; 128,35 ; 128,43 ; 129,06 ; 131,69 ; 131,75$;

132,$98 ; 140,71 ; 143,46 ; 173,03\left(\mathrm{CO}_{2} \mathrm{H}\right)$.

iii. Redução do ácido o-benzil-benzóico: A uma suspensão de $2,85 \mathrm{~g}\left(7,50.10^{-2} \mathrm{~mol}\right)$ de hidreto de lítio e alumínio em $100 \mathrm{~mL}$ de éter etílico anidro, sob intensa agitação e em atmosfera inerte de argônio anidro, adicionaram-se, lentamente, $5,30 \mathrm{~g}\left(2,50.10^{-2}\right.$ mol) de ácido $o$-benzil-benzóico dissolvidos em $50 \mathrm{~mL}$ de éter anidro. Ao final da adição refluxou-se por 45 minutos. Então, após adicionarem-se, lentamente, $20 \mathrm{~mL}$ de acetona, acrescentaram-se $25 \mathrm{~mL}$ de solução de ácido nítrico a $10 \%$ e $50 \mathrm{~mL}$ de solução concentrada de ácido nítrico/água ( $1: 1 \mathrm{v} / \mathrm{v})$, até que toda a massa branca formada fosse dissolvida. Separou-se a fase etereal, que se lavou com quatro porções de solução saturada de bicarbonato de sódio, verificando-se que o $\mathrm{pH}$ da fase aquosa da última lavagem alcançasse 8,5. A fase etereal foi, a seguir, secada com sulfato de magnésio anidro, filtrada e roto-evaporada. Obtiveram-se $3,86 \mathrm{~g}$ de um líqüido amarelo-claro, de pureza cromatográfica $99,7 \%$, identificado como sendo o álcool 2-benzil-benzílico.

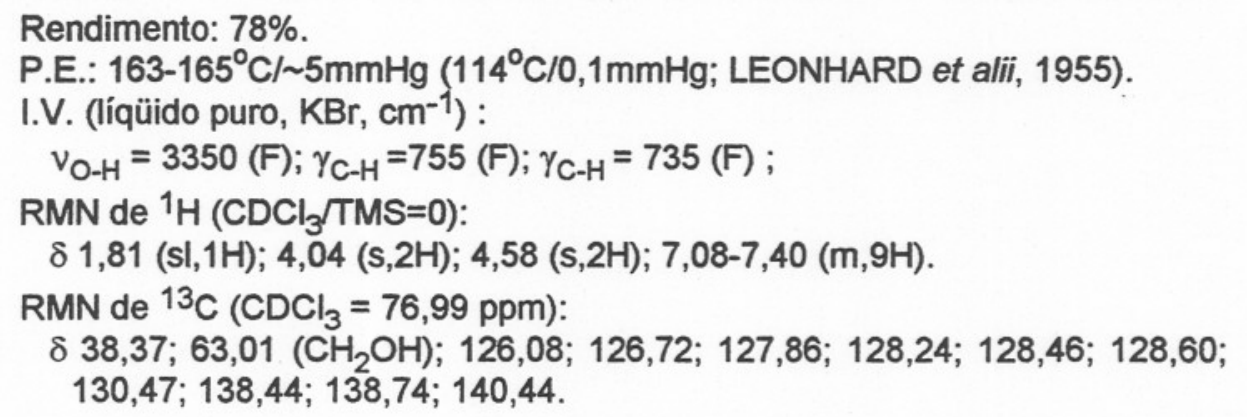

iv. Transformação do álcool 2-benzil-benzílico em brometo de 0 -benzil-benzila (LEONHARD et alii, 1955): Aqueceu-se, a refluxo, uma mistura de $1,57 \mathrm{~g}\left(7,93.10^{-3} \mathrm{~mol}\right)$ de álcool 2-benzil-benzílico e 5,5mL de uma solução aquosa $48 \%$ de ácido bromídrico $(\mathrm{d}=1,475)$, durante três horas. A mistura reacional foi resfriada e diluída até $20,0 \mathrm{~mL}$ com água, separando-se um óleo que foi extraído da fase aquosa com benzeno. $\mathrm{O}$ extrato orgânico foi lavado com água até $\mathrm{pH}$ neutro, sendo secado com sulfato de magnésio anidro. Após roto-evaporação do benzeno, obtiveram-se $1,80 \mathrm{~g}$ de material sólido (rendimento bruto de 87\%). Este material foi recristalizado de éter de petróleo (40$60^{\circ} \mathrm{C}$ ) tendo-se obtido $1,50 \mathrm{~g}$ de material, na forma de agulhas finas, de pureza cromatográfica $96 \%$.

Rendimento: $72 \%$.

P.F.: $46^{\circ} \mathrm{C}\left(45-45,5^{\circ} \mathrm{C}\right.$; LEONHARD et alii, 1955).

E.M.: vide Figura III.7, p. 49. 
III.5. Espectros de Massas Interpretados

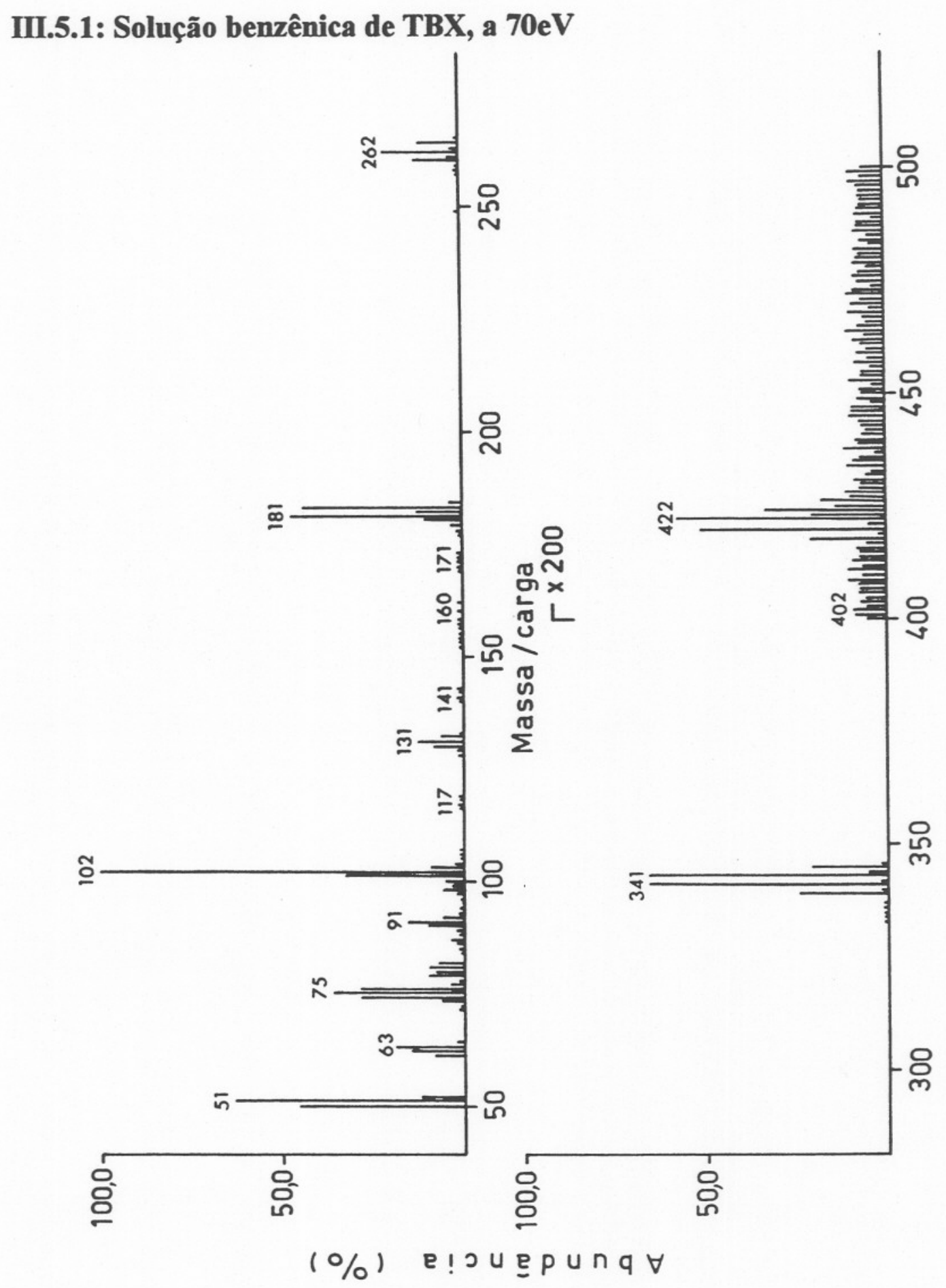

Figura III.1 - Espectro de massas de TBX, obtido no espectrômetro Finnigan MAT INCOS 50. 
ESQUEMA III.1 - Proposta de fragmentação para interpretação do espectro de massas de TBX.

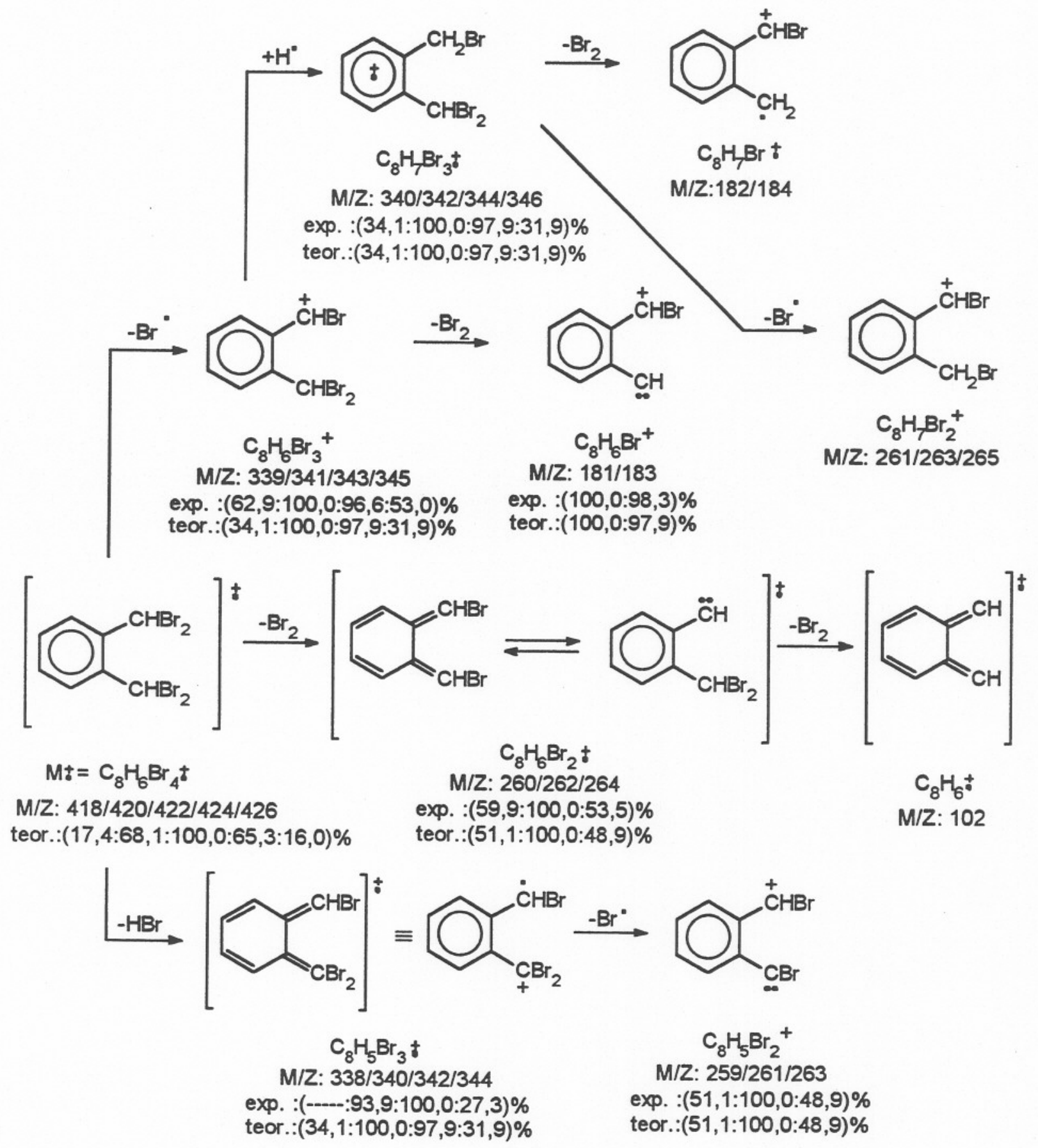




\section{III.5.2: Solução benzênica de MBX, a 70eV}

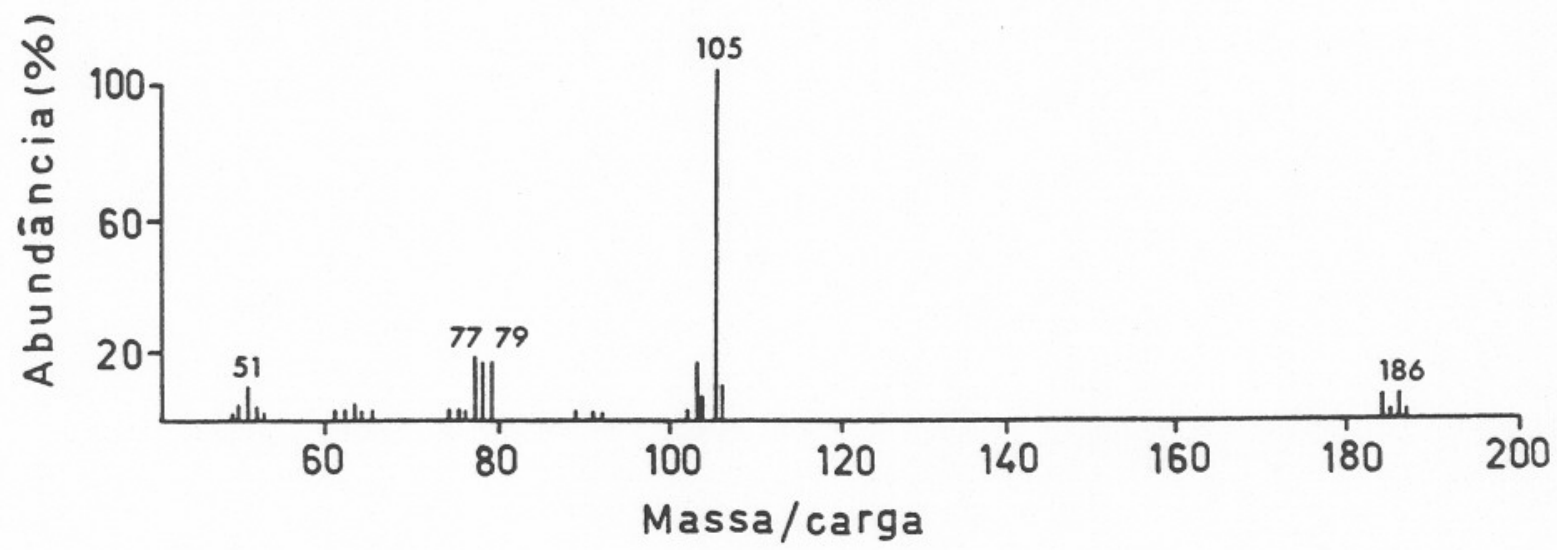

Figura III.2 - Espectro de massas para MBX, obtido no espectrômetro HewlettPackard 5988 A.

ESQUEMA III.2 - Proposta de fragmentação para interpretação do espectro de massas de MBX.

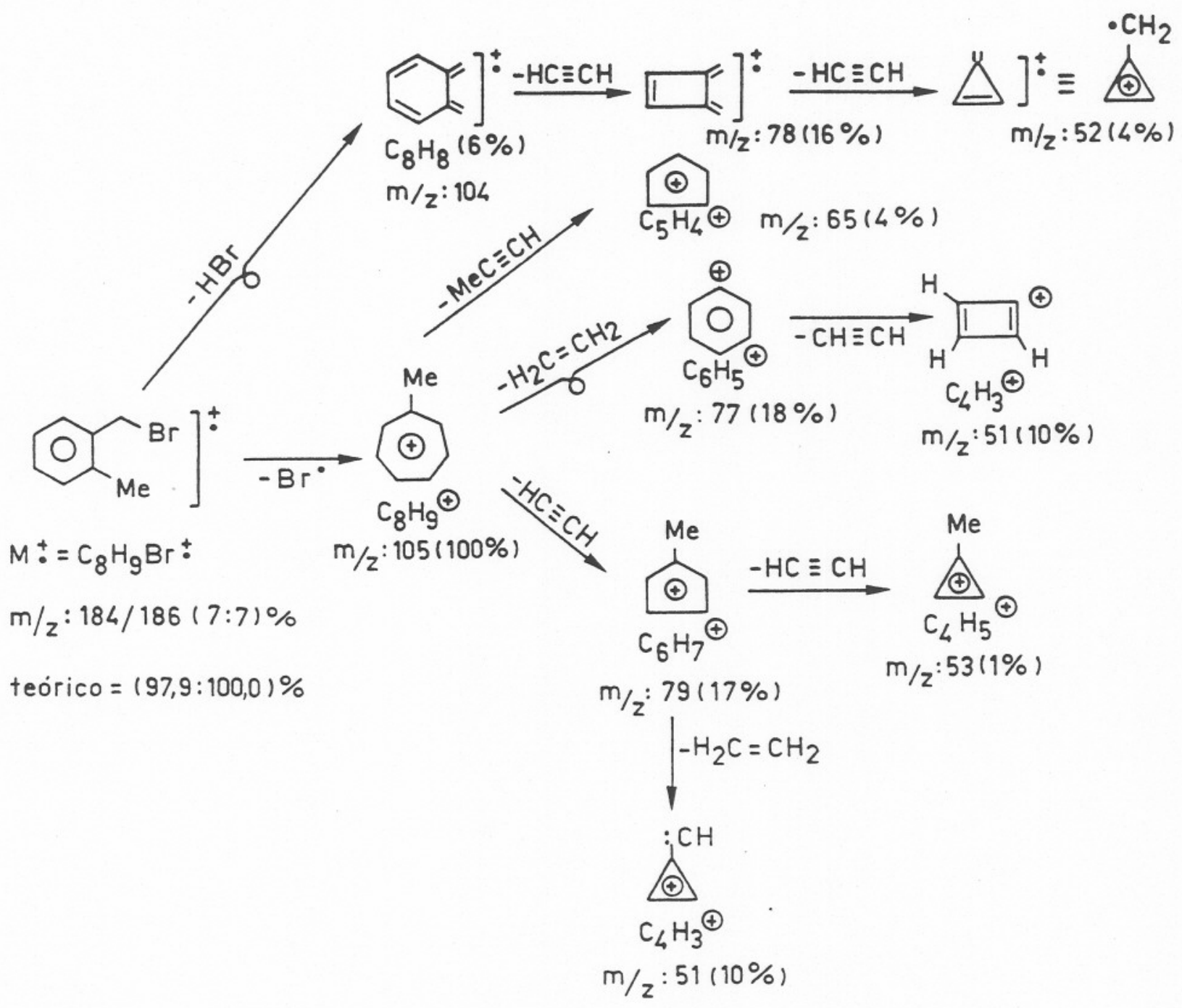


III.5.3: Solução benzênica de DBX, a $70 \mathrm{eV}$

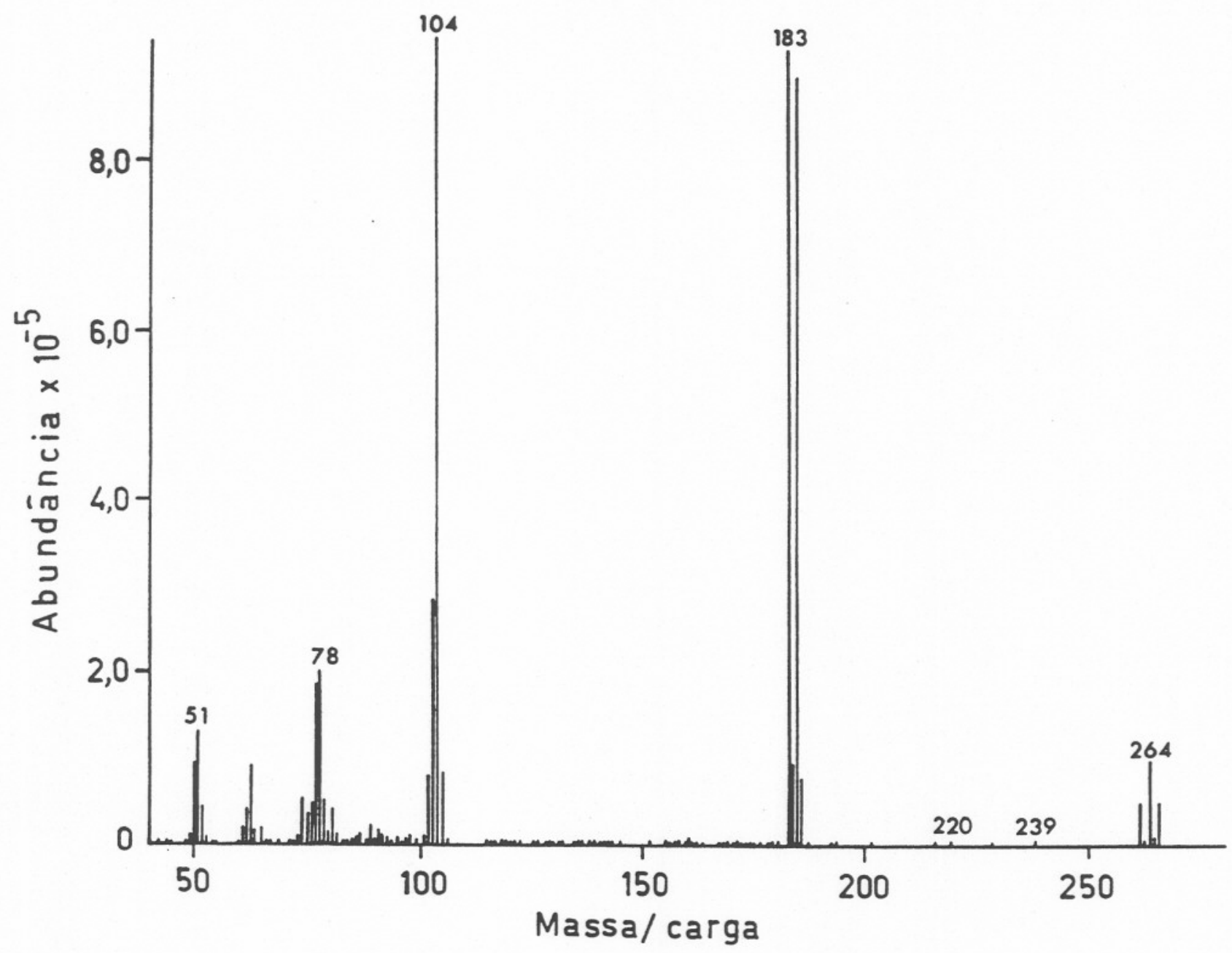

Figura III.3 - Espectro de massas para DBX, obtido no espectrômetro HewlettPackard 5988 A.

ESQUEMA II.3 - Proposta de fragmentação para interpretação do espectro de massas de DBX.

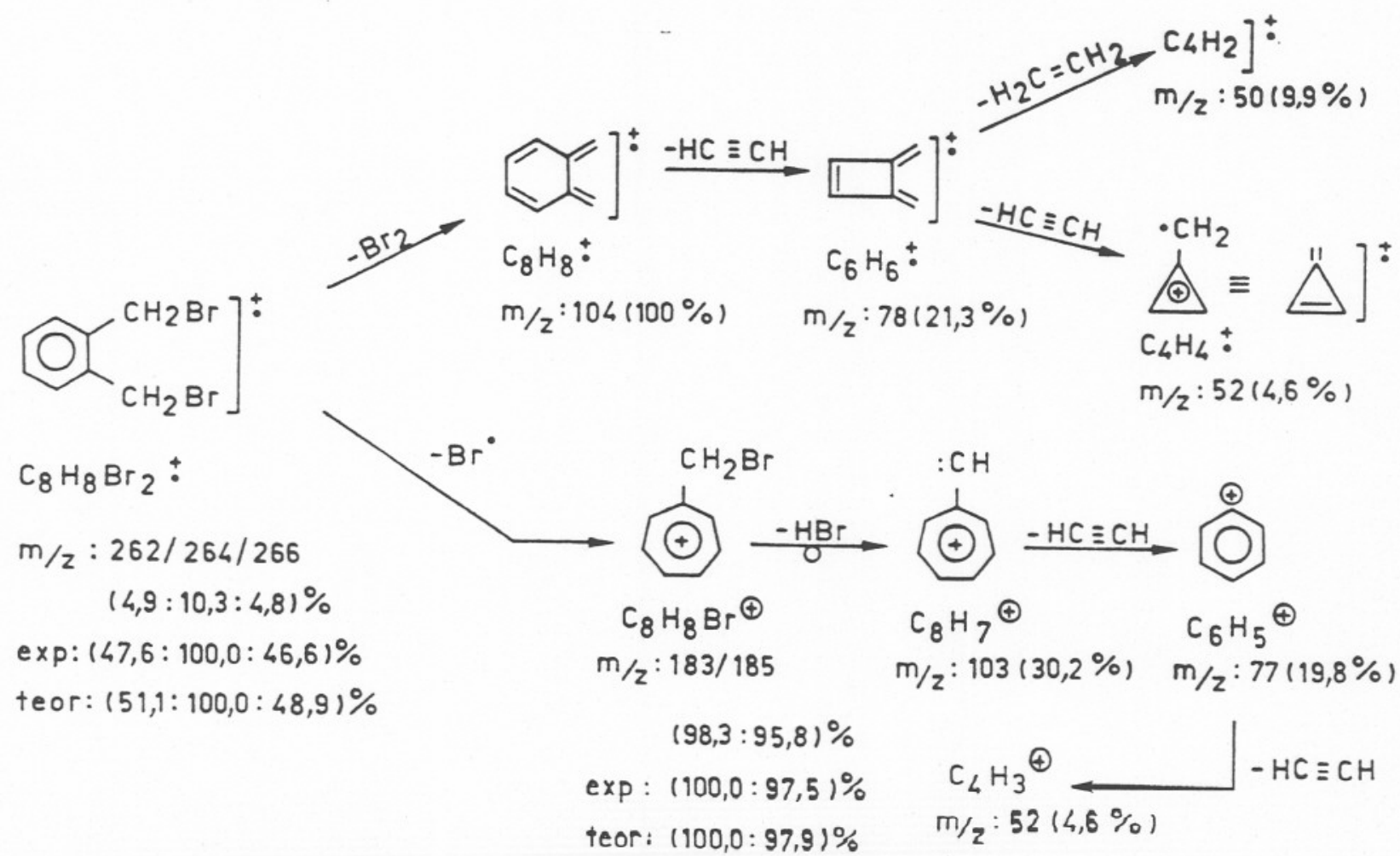


III.5.4: Solução benzênica de GBX, a $70 \mathrm{eV}$

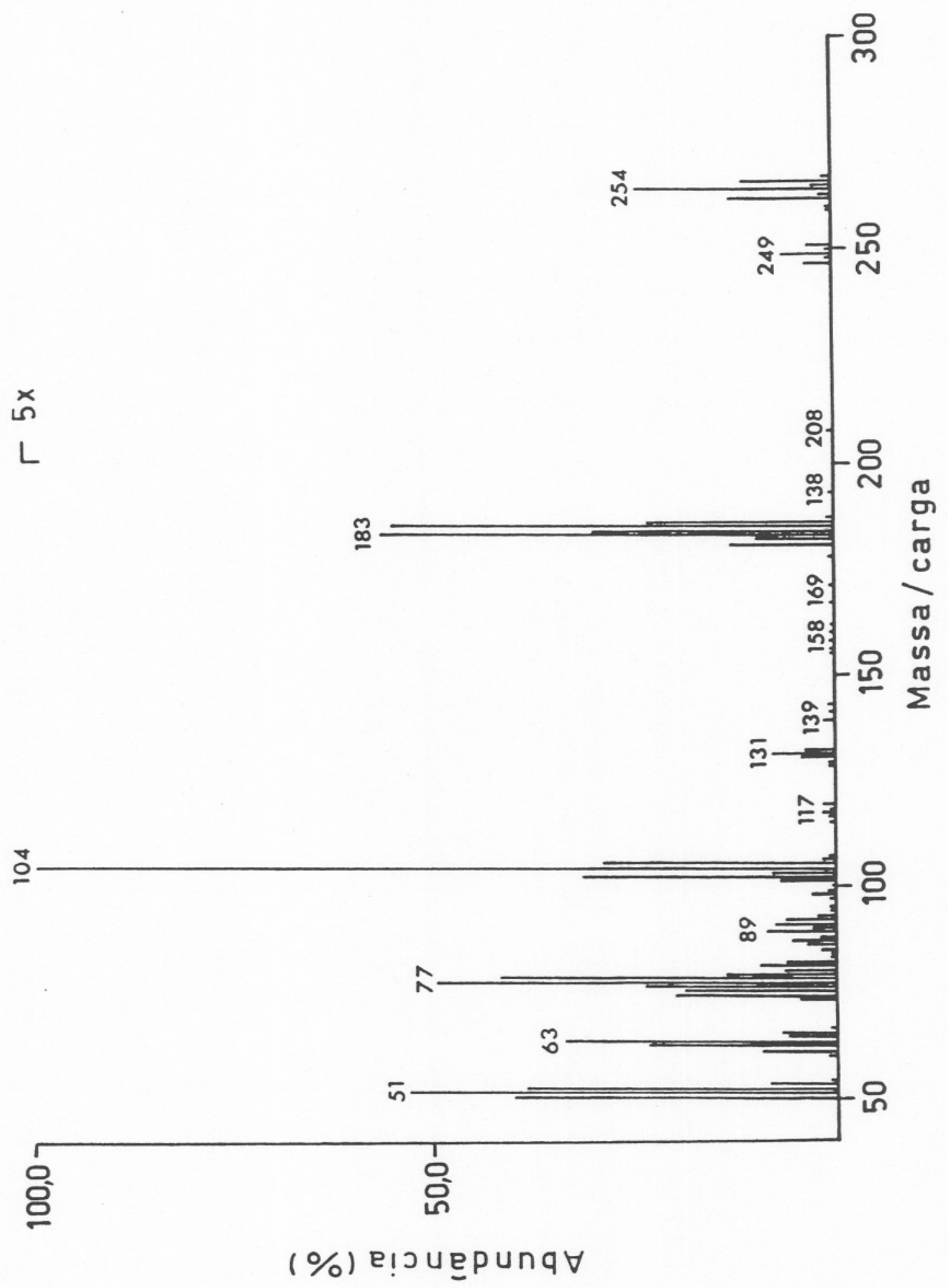

Figura III.4 - Espectro de massas para GBX, obtido no espectrômetro Finnigan Mat INCOS 50. 
ESQUEMA III.4 - Proposta de fragmentação para interpretação dos picos mais significativos do espectro de massas de GBX.

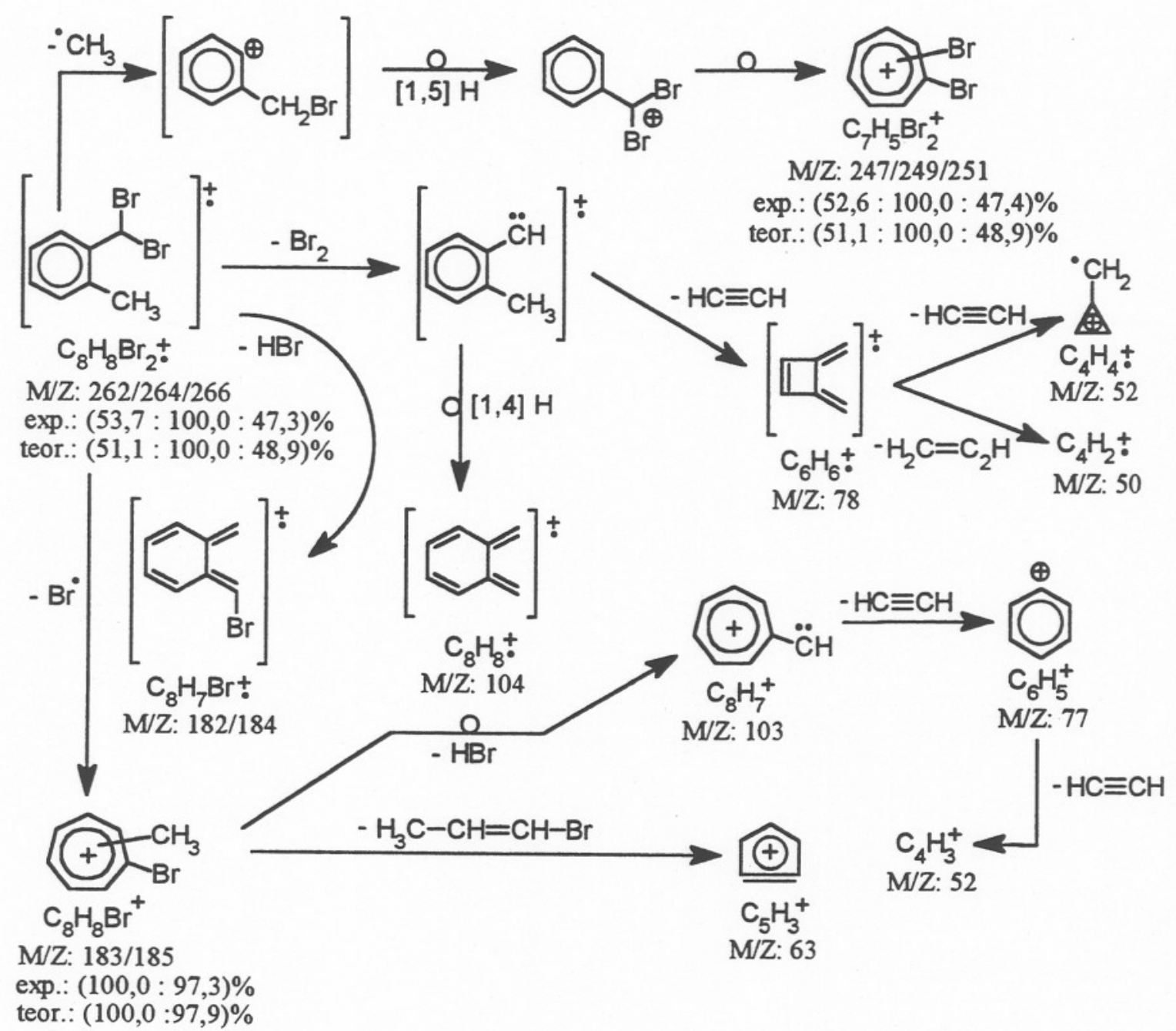


III.5.5: Solução benzênica de TRBX, a 70eV

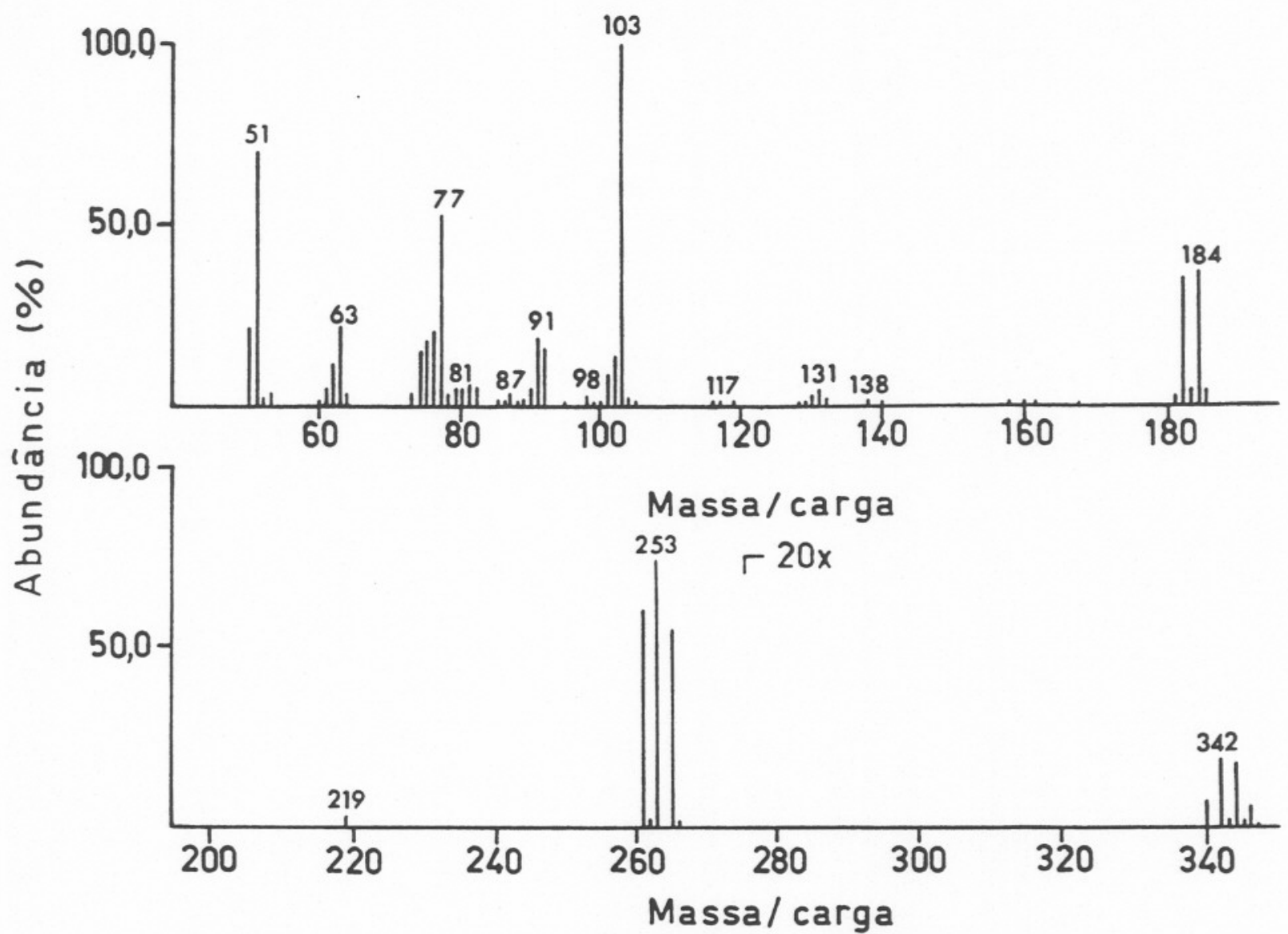

Figura III.5 - Espectro de massas para TRBX, obtido no espectrômetro Finnigan MAT INCOS 50.

ESQUEMA III.5 - Proposta de fragmentação para interpretação do espectro de massas de TRBX.

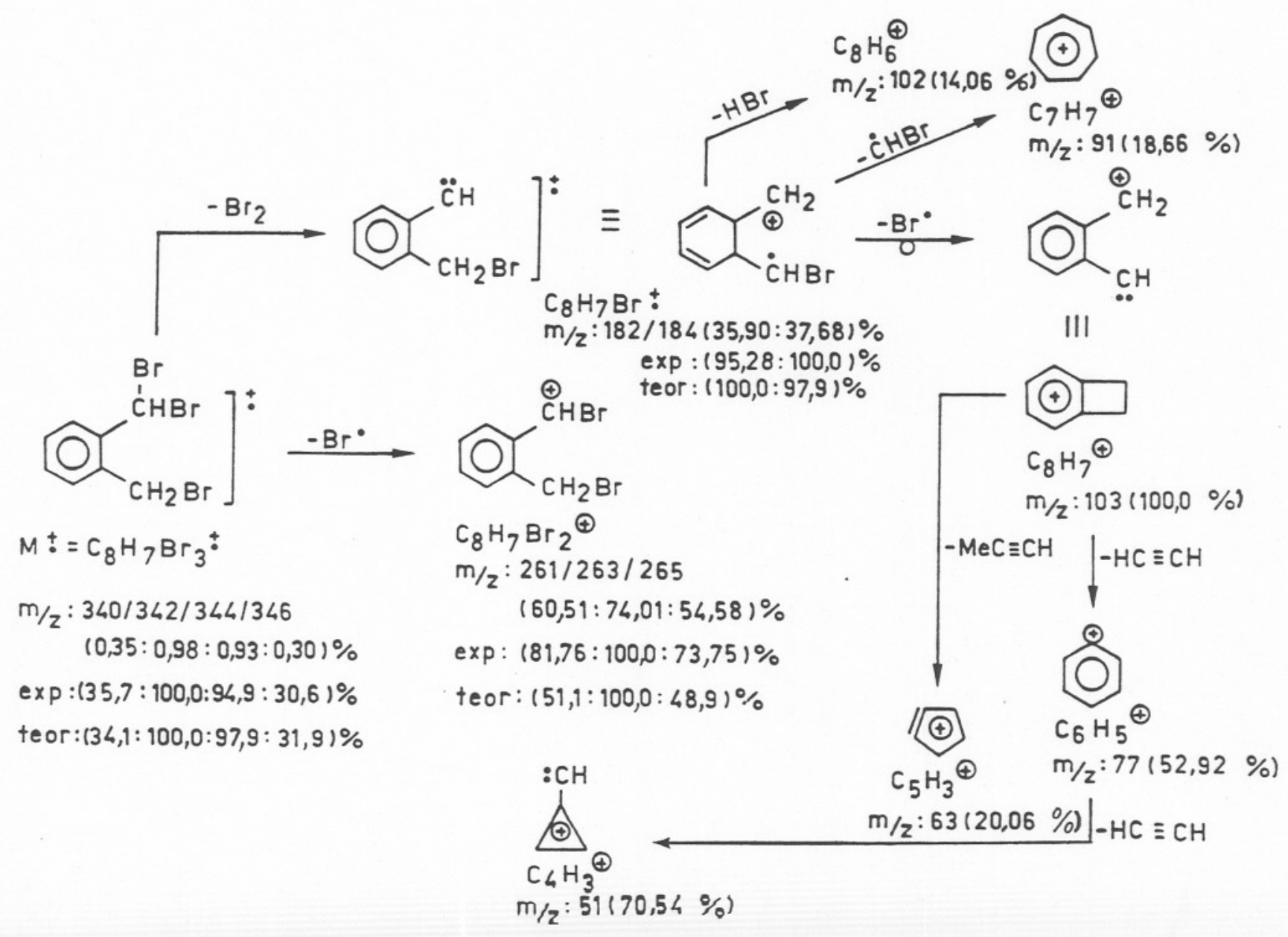


III.5.6: Solução benzênica de DCHex $\left(1,1^{\prime}\right)$, a $70 \mathrm{eV}$

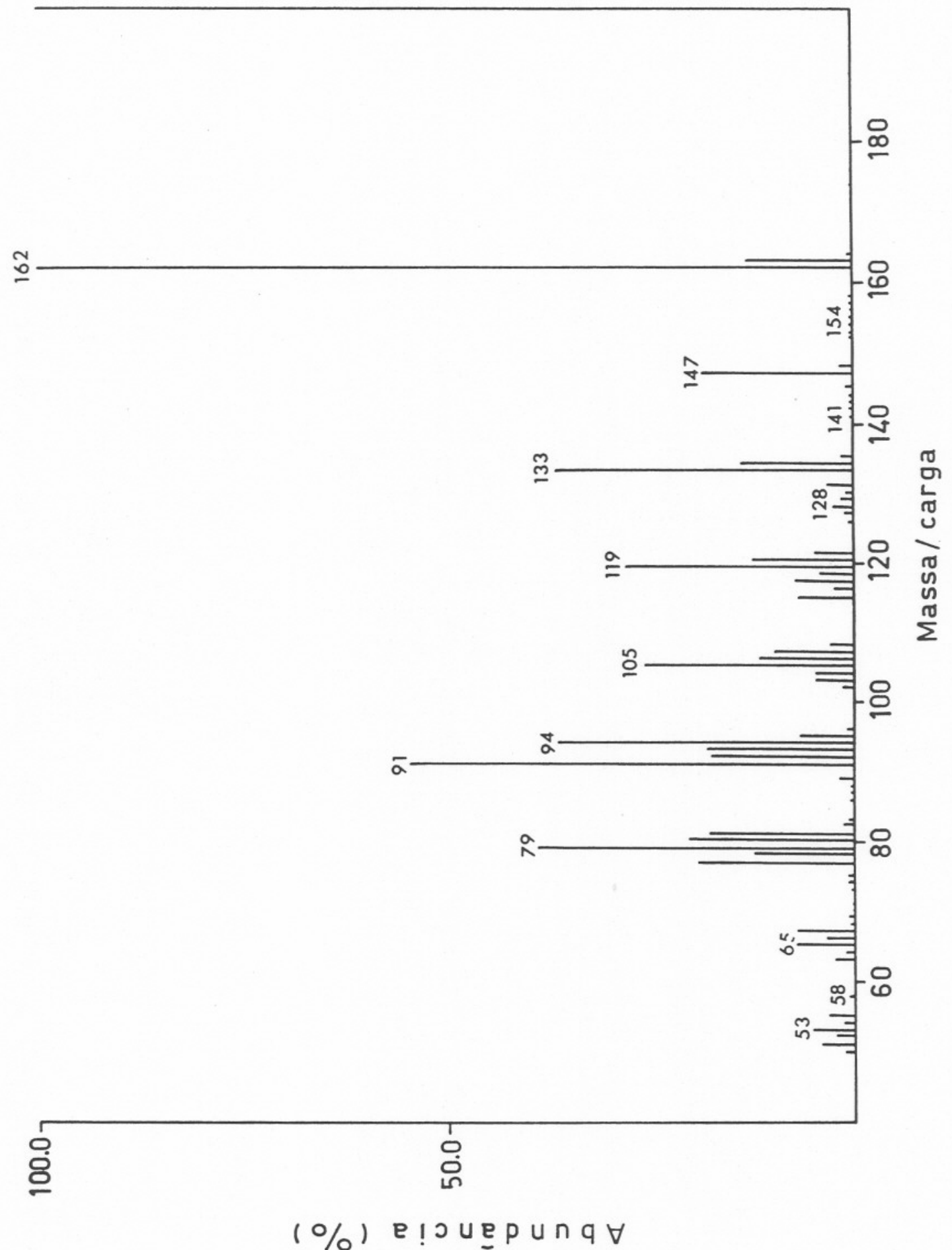

Figura II.6- Espectro de massas para DCHex (1,1'), obtido no espectrômetro Finnigan MAT INCOS 50. 
ESQUEMA III.6 - Proposta de fragmentação para a interpretação do espectro de massas de DCHex $\left(1,1^{\prime}\right)$.

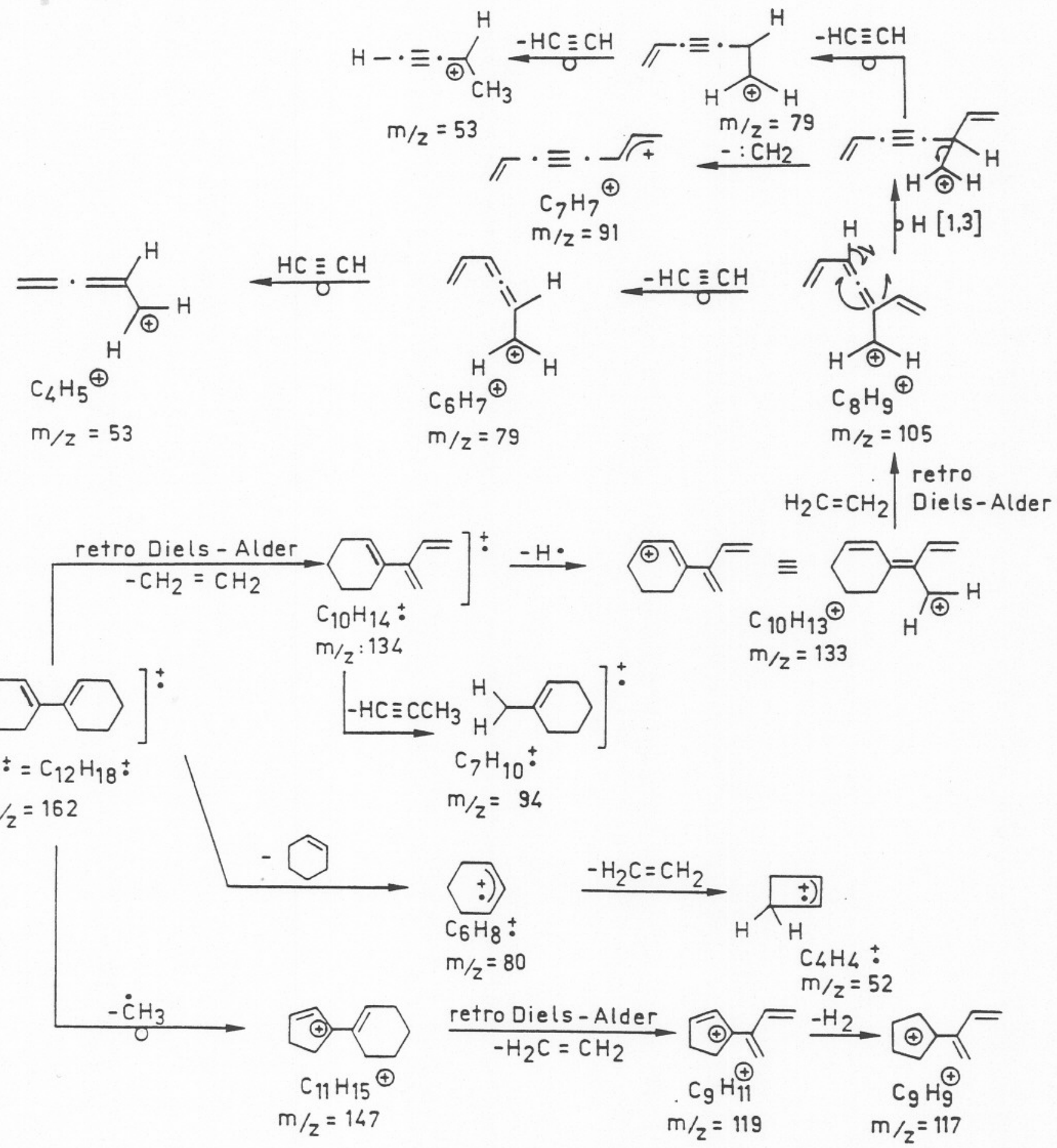


III.5.7: Solução benzênica de $\mathrm{BBzBr}$, a $70 \mathrm{eV}$

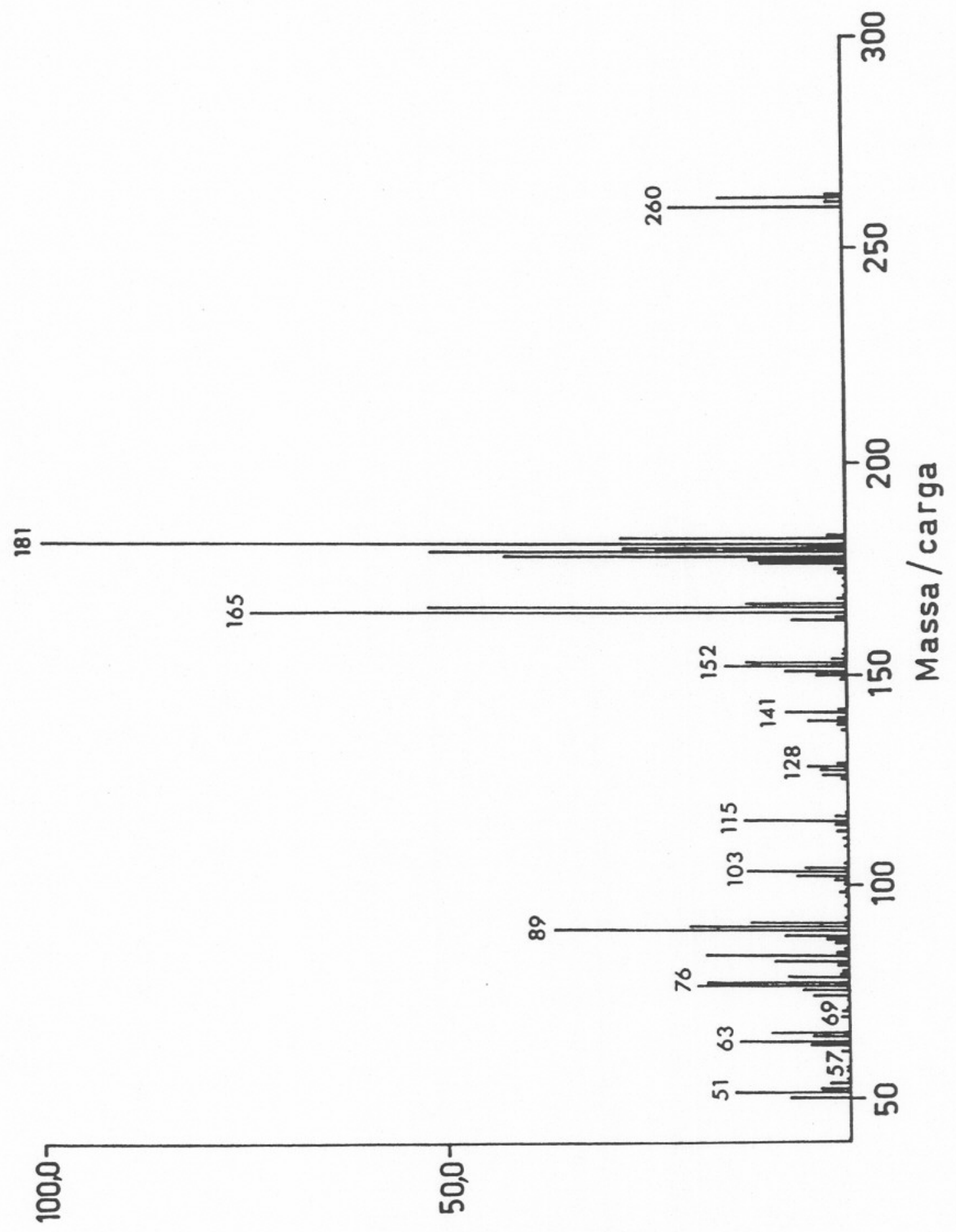

(\%) e! ougpunq

Figura III.7 - Espectro de massas para BBzBr, obtido no espectrômetro Finnigan MAT INCOS 50. 
ESQUEMA III.7 - Proposta de fragmentação para a interpretação do espectro de massas de $\mathbf{B B z B r}$.

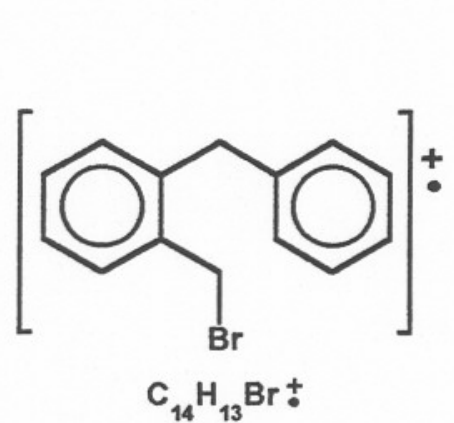

$\mathrm{m} / \mathrm{z}:$ 260/262

exp: $(100,0: 74,3) \%$

teo: $(100,0: 97,9) \%$

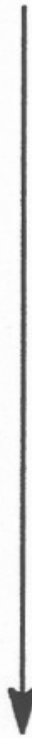

$\mathrm{HBr}$<smiles>Fc1ccccc1Cc1ccccc1</smiles>

$\mathrm{C}_{14} \mathrm{H}_{12} \mathbf{7}^{\circ}$ $\mathrm{m} / \mathrm{z}: 180$

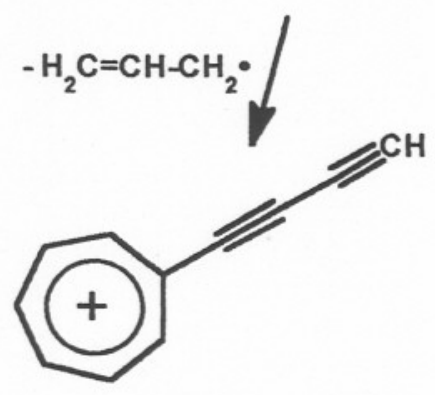

$$
\mathrm{C}_{11} \mathrm{H}_{7}+
$$

$\mathrm{m} / \mathrm{z}: 139$

Br॰<smiles>[3H]c1ccccc1Cc1ccccc1</smiles>

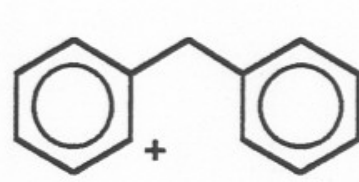

$$
\mathrm{C}_{13} \mathrm{H}_{11}+
$$

$\mathrm{m} / \mathrm{z}: 167$
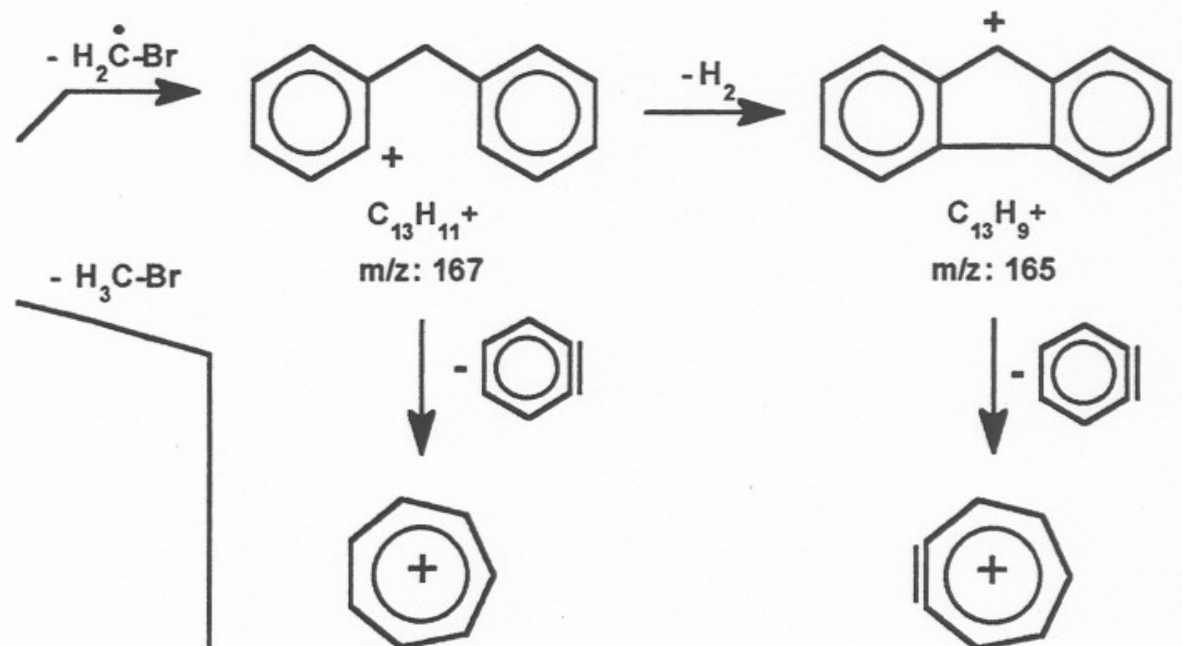

$\mathrm{m} / \mathrm{z}: 165$
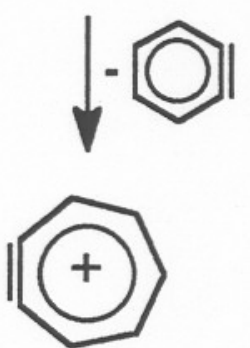

$\mathrm{C}_{7} \mathrm{H}_{7}+$

$\mathrm{C}_{7} \mathrm{H}_{5}+$

$\mathrm{m} / \mathrm{z}: 89$

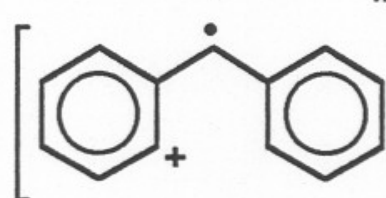

$\underset{\mathrm{C}_{13} \mathrm{H}_{10}^{+}}{\longrightarrow}$ $\mathrm{m} / \mathrm{z}: 166$

$$
\begin{aligned}
& \equiv \\
& \mathrm{C}_{14} \mathrm{H}_{13}+ \\
& \mathrm{m} / \mathrm{z}: 181
\end{aligned}
$$<smiles></smiles><smiles>c1ccccc1</smiles>
7<smiles>C[C+]c1ccccc1</smiles><smiles>CC1CC1</smiles>

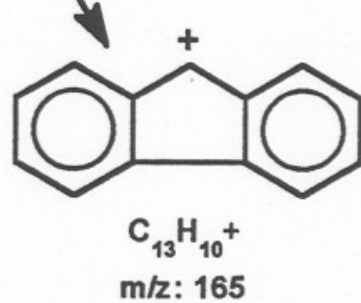

m/z: 165

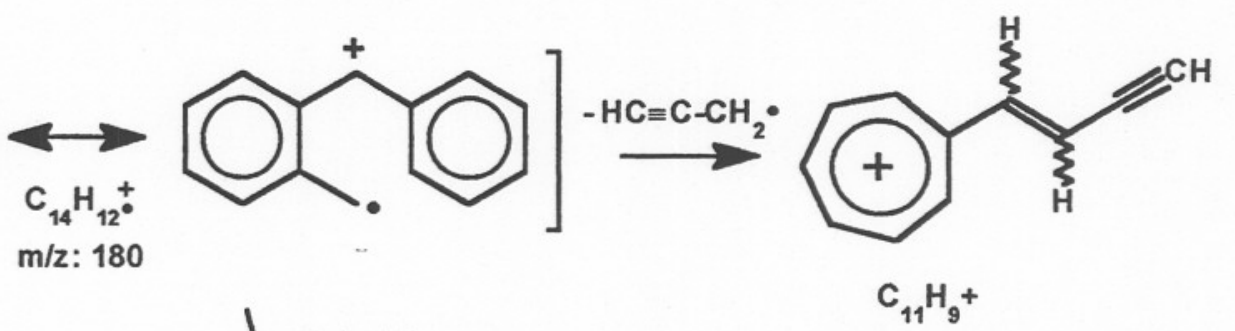

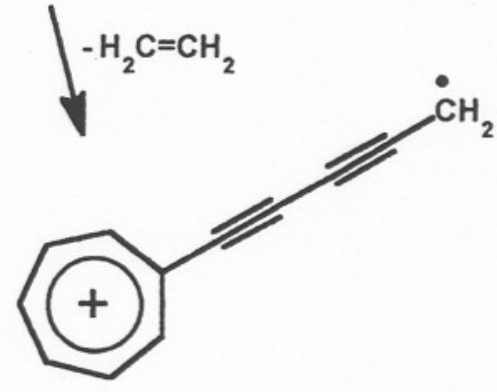

$\mathrm{C}_{12} \mathrm{H}_{80}+$

$\mathrm{m} / \mathrm{z}: 152$ $\mathrm{m} / \mathrm{z}: 141$

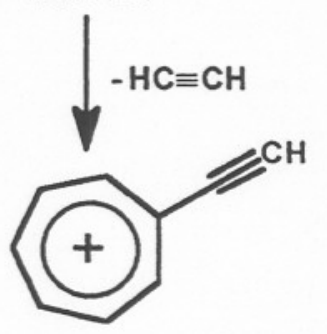

$\mathrm{C}_{9} \mathrm{H}_{7}+$

$\mathrm{m} / \mathrm{z}: 115$ 


\section{III.6. Fotólises Convencionais}

\section{III.6.1: Irradiações}

Soluções benzênicas $\left(25,0 \mathrm{~mL} ; 5,0.10^{-2} \mathrm{~mol}^{-1}\right)$ de cada um dos cinco compostos bromados (MBX, DBX, GBX, TRBX e TBX), contidas em um frasco cilíndrico de quartzo e desaeradas por corrente de argônio durante toda a irradiação, foram submetidas à fotólise em um sistema de irradiação PCQ - X1 da Ultraviolet Products, no qual se utilizam quatro lâmpadas de mercúrio de baixa pressão (tipo "biscoito"), de potência elétrica nominal total $72 \mathrm{~W}$ (18W por lâmpada) e $\lambda_{\text {emissão }}=254 \mathrm{~nm}$. Na aparelhagem utilizada, a potência elétrica experimental foi determinada como sendo de $68,8 \mathrm{~W}$ (17,2W por lâmpada).

Foram feitas, nas mesmas condições, irradiações de soluções benzênicas de MBX e DBX em presença de ciclo-hexeno $\left(1,97 \mathrm{~mol} . \mathrm{L}^{-1}\right)$, com o objetivo de se verificar o comportamento do sistema na presença de doadores de hidrogênio.

Mantendo-se o mesmo procedimento experimental, irradiaram-se, ainda, soluções de MBX e DBX, em iso-octano, com dois objetivos: em primeiro lugar, para se ter uma estimativa sobre a eficiência com que o benzeno atua, ao agir como sensibilizador na fotólise dos compostos bromados; em segundo lugar, havia a necessidade de se obterem parâmetros sobre a fotoquímica dos compostos bromados em iso-octano, por ter sido este o solvente selecionado para os estudos de fotólise por pulso de laser.

Todas as fotólises foram acompanhadas por cromatografia gasosa, recolhendo-se amostras de $1,0 \mathrm{~mL}$ do meio reacional, com seringa, a intervalos regulares, sem que se desligassem as lâmpadas. $\mathrm{Em}$ todas estas análises cromatográficas utilizou-se $n$-hexadecano como padrão-interno.

Comparando-se a série de cromatogramas referentes a uma mesma irradiação, verificou-se que os picos observados, a qualquer tempo até o término da irradiação, variaram apenas em intensidade, em cada uma das fotólises. Assim foi possível concluir que, pelo menos até $30 \%$ de conversão do reagente, não se formaram (ou não se detectaram) compostos resultantes de possíveis fotorreações dos produtos formados, para quaisquer das fotólises estudadas.

Os produtos obtidos nas fotorreações foram identificados através da interpretação dos espectrogramas de massa resultantes de análise por CG-EM. Quando necessário, sintetizaram-se padrões por via térmica para confirmação da identidade dos fotoprodutos, tanto pelo tempo de retenção (corrigido em função do padrão-interno), como pela comparação dos respectivos espectros de massas. Os espectrógrafos utilizados estão descritos no item III.1 (p.31) e os espectros de massas mais significativos encontram-se nas Figuras III.1 a III.7 (vide item III.5, p.40 a 46). 


\section{III.6.2: Quantificação dos fotoprodutos obtidos}

Soluções dos compostos bromados, em benzeno, ciclo-hexeno e iso-octano, foram irradiadas com o objetivo de se quantificarem os produtos obtidos. Neste caso, utilizou-se um carrossel com capacidade para seis tubos de $13 \times 100 \mathrm{~mm}$ e com diâmetro ligeiramente menor do que o das lâmpadas de irradiação, de maneira que o carrossel pudesse girar circundado pelos biscoitos. As soluções $\left(\sim 1.10^{-1} \mathrm{~mol}_{\mathrm{L}} \mathrm{L}^{-1}\right.$ ou $\sim 10^{-2}$ mol. $\mathrm{L}^{-1}$ ) foram degaseadas antes da irradiação, por passagem de corrente de argônio durante vinte minutos, tendo sido preparadas seis amostras por composto, transferindose $3,0 \mathrm{~mL}$ de solução para tubos de quartzo de $13 \times 100 \mathrm{~mm}$, com seringa, sob atmosfera de argônio. Os tubos foram tampados com rolhas de cortiça teflonizada, sendo retirados do carrossel, para análise, a intervalos regulares, sem que se desligassem as lâmpadas. A identificação e a quantificação dos produtos obtidos para cada uma das seis amostras irradiadas (e para as amostras controle, mantidas no escuro) foram feitas por CG-EM e por cromatografia gasosa, respectivamente. No caso das análises por cromatografia gasosa, utilizou-se o cromatógrafo Shimadzu descrito no item III.1 (p.31).

Para isso, foi necessário, em primeiro lugar, determinarem-se as respostas do detector de ionização de chama, para os diversos compostos em estudo. Assim, após ter-se escolhido $n$-hexadecano como padrão-interno e verificado que a técnica de injeção com agulha fria permitia maior reprodutibilidade, prepararam-se pelo menos cinco soluções benzênicas de concentrações diferentes em cada um dos compostos de interesse. Cada uma dessas soluções foi obtida por diluição de uma solução-estoque, acrescentando-se padrão-interno suficiente para que sua concentração fosse sempre a mesma em todas elas. Os dados obtidos estão apresentados nas Tabelas III.4 a III.10, tendo fornecido boas correlações lineares $(R=0,999$ a 0,993$)$, para as retas representadas pela equação: $\mathrm{Y}=\frac{\text { Área }_{\text {composto }}}{\text { Área }_{\text {padrão }}}=\mathrm{k} \frac{\mathrm{n}_{\text {composto }}}{\mathrm{n}_{\text {padrão }}}$.

Tabela III.4: Dados para a obtenção do fator de resposta do $o$-xileno.

\begin{tabular}{c|c|c|c|c|c}
\hline \multicolumn{2}{c|}{ o-xileno } & \multicolumn{2}{c|}{$\mathbf{C}_{16} \mathrm{H}_{34}$} & \multicolumn{2}{c}{ Razões } \\
\hline \hline Área & $\mathbf{n . 1 0 ^ { 1 0 }}(\mathrm{mol})$ & Área & $\mathbf{n . 1 0 ^ { 1 1 }}(\mathrm{mol})$ & $\frac{\text { Área }}{\text { Área }\left(\mathbf{C}_{16} \mathrm{H}_{34}\right)}$ & $\mathrm{n} / \mathbf{n}\left(\mathbf{C}_{16} \mathrm{H}_{34}\right)$ \\
\hline 12710 & 0,63 & 59113 & 14,60 & 0,22 & 0,43 \\
14785 & 0,74 & 67180 & 17,00 & 0,22 & 0,43 \\
13316 & 0,68 & 64699 & 15,80 & 0,21 & 0,43 \\
65970 & 1,58 & 56276 & 7,29 & 1,17 & 2,17 \\
61629 & 1,58 & 50774 & 7,29 & 1,21 & 2,17 \\
69476 & 1,97 & 59279 & 9,12 & 1,17 & 2,16 \\
22304 & 1,05 & 35818 & 9,72 & 0,62 & 1,08 \\
22946 & 1,05 & 38720 & 9,72 & $0,59$. & 1,08 \\
21088 & 0,85 & 34272 & 7,90 & 0,62 & 1,08 \\
\hline
\end{tabular}

Resultados de regressão linear:
Constante
$0 \quad$ № de Observações 9
Desvio-padrão de $Y \quad 0,023$ Graus de Liberdade 8
$\mathrm{R}^{2}$
0,997 R
R $\quad 0,999$
k
0,549 Desvio-Padrão de k 0,005 
Tabela III.5: Dados para a obtenção do fator de resposta de MBX.

\begin{tabular}{|c|c|c|c|c|c|}
\hline \multicolumn{2}{|r|}{ MBX } & \multicolumn{2}{|c|}{$\mathrm{C}_{16} \mathrm{H}_{34}$} & \multicolumn{2}{|c|}{ Razões } \\
\hline Área & $\mathrm{n} .10^{10}(\mathrm{~mol})$ & Área & $\mathrm{n} .10^{11}(\mathrm{~mol})$ & $\frac{\text { Área }}{\text { Área }\left(\mathrm{C}_{16} \mathrm{H}_{34}\right)}$ & $\mathrm{n} / \mathrm{n}\left(\mathrm{C}_{16} \mathrm{H}_{34}\right)$ \\
\hline 18416 & 0,92 & 59113 & 14,60 & 0,31 & 0,63 \\
\hline 21187 & 1,07 & 67180 & 17,00 & 0,32 & 0,63 \\
\hline 18716 & 1,00 & 64699 & 15,80 & 0,29 & 0,63 \\
\hline 95523 & 2,30 & 56276 & 7,29 & 1,70 & 3,16 \\
\hline 89303 & 2,30 & 50774 & 7,29 & 1,76 & 3,16 \\
\hline 101429 & 2,88 & 59297 & 9,12 & 1,71 & 3,16 \\
\hline 30317 & 1,53 & 35818 & 9,72 & 0,85 & 1,57 \\
\hline 32038 & 1,53 & 38720 & 9,72 & 0,83 & 1,57 \\
\hline 29734 & 1,25 & 34272 & 7,90 & 0,87 & 1,58 \\
\hline
\end{tabular}

Resultados de regressão linear:

$\begin{array}{llll}\text { Constante } & 0 & \text { № de Observações } & 9 \\ \text { Desvio-padrão de } Y & 0,031 & \text { Graus de Liberdade } & 8 \\ \mathrm{R}^{2} & 0,997 & \mathrm{R} & 0,999 \\ \text { k } & 0,542 & \text { Desvio-Padrão de k } & 0,005\end{array}$

Tabela III.6: Dados para obtenção do fator de resposta de DBX.

\begin{tabular}{|c|c|c|c|c|c|}
\hline \multicolumn{2}{|r|}{ DBX } & \multicolumn{2}{|c|}{$\mathrm{C}_{16} \mathrm{H}_{34}$} & \multicolumn{2}{|c|}{ Razões } \\
\hline Área & $\mathrm{n} .10^{11}$ (mol) & Área & $\mathrm{n} .10^{11}$ (mol) & $\frac{\text { Área }}{\text { Área }\left(\mathrm{C}_{16} \mathrm{H}_{34}\right)}$ & $n / n\left(C_{16} H_{34}\right)$ \\
\hline 12259 & 5,98 & 59113 & 14,60 & 0,21 & 0,41 \\
\hline 14151 & 6,98 & 67180 & 17,00 & 0,21 & 0,41 \\
\hline 12494 & 6,48 & 64699 & 15,80 & 0,19 & 0,41 \\
\hline 62140 & 15,00 & 56276 & 7,29 & 1,10 & 2,06 \\
\hline 58904 & 15,00 & 50774 & 7,29 & 1,16 & 2,06 \\
\hline 65947 & 18,70 & 59297 & 9,12 & 1,11 & 2,05 \\
\hline 19432 & 9,97 & 35818 & 9,72 & 0,54 & 1,03 \\
\hline 20883 & 9,97 & 38720 & 9,72 & 0,54 & 1,03 \\
\hline 18545 & 8,10 & 34272 & 7,90 & 0,54 & 1,03 \\
\hline
\end{tabular}

Resultados de regressão linear:
Constante
0
№ de Observações 9
Desvio-padrão de $Y$ $\mathrm{R}^{2}$
0,022
Graus de Liberdade 8
k
0,998
0,542 Desvio-Padrão de $\mathrm{k} \quad 0,006$ 
Tabela III.7: Dados para obtenção do fator de resposta de TRBX.

\begin{tabular}{|c|c|c|c|c|c|c|c|}
\hline \multirow{3}{*}{ Solução } & \multicolumn{3}{|c|}{ TRBX } & \multicolumn{2}{|c|}{$\mathrm{C}_{16} \mathrm{H}_{34}$} & \multicolumn{2}{|c|}{ Razões } \\
\hline & \multirow{2}{*}{ Área } & \multirow{2}{*}{$\begin{array}{c}C_{\text {molar }} \\
\left.\text { (mol. } L^{-1}\right)\end{array}$} & \multirow{2}{*}{ Área } & \multirow{2}{*}{$\begin{array}{c}C_{\text {molar }} \\
\left.\text { (mol. } L^{-1}\right)\end{array}$} & Área & \multirow{2}{*}{ Médias } & \multirow{2}{*}{$\frac{\mathrm{C}_{\text {molar }}}{\mathrm{C}_{\text {molar }}\left(\mathrm{C}_{\mathbf{1 6}} \mathrm{H}_{\mathbf{3 4}}\right)}$} \\
\hline & & & & & Área $\left(\mathrm{C}_{16} \mathrm{H}_{34}\right)$ & & \\
\hline \multirow{3}{*}{1} & 40175 & \multirow{3}{*}{$1,19.10^{-2}$} & 1762654 & \multirow{3}{*}{$2,13.10^{-1}$} & $2,28.10^{-2}$ & \multirow{3}{*}{$2,29.10^{-2}$} & \multirow{3}{*}{$5,59.10^{-2}$} \\
\hline & 31792 & & 1412888 & & $2,25.10^{-2}$ & & \\
\hline & 73388 & & 3119574 & & $2,35.10^{-2}$ & & \\
\hline \multirow{3}{*}{2} & 28295 & \multirow{3}{*}{$7,95.10^{-3}$} & 1927338 & \multirow{3}{*}{$2,16.10^{-1}$} & $1,47.10^{-2}$ & \multirow{3}{*}{$1,47.10^{-2}$} & \multirow{3}{*}{$3,68.10^{-2}$} \\
\hline & 27403 & & 1890868 & & $1,45.10^{-2}$ & & \\
\hline & 25790 & & 1739077 & & $1,48.10^{-2}$ & & \\
\hline \multirow{3}{*}{3} & 18354 & \multirow{3}{*}{$5,96.10^{-3}$} & 1711622 & \multirow{3}{*}{$2,13.10^{-1}$} & $1,07.10^{-2}$ & \multirow{3}{*}{$1,09.10^{-2}$} & \multirow{3}{*}{$2,79.10^{-2}$} \\
\hline & 20758 & & 1887016 & & $1,10.10^{-2}$ & & \\
\hline & 19972 & & 1801539 & & $1,11 \cdot 10^{-2}$ & & \\
\hline \multirow{3}{*}{4} & 13678 & \multirow{3}{*}{$4,77.10^{-3}$} & 1758496 & \multirow{3}{*}{$2,13.10^{-1}$} & $0,78.10^{-2}$ & \multirow{3}{*}{$0,84.10^{-2}$} & \multirow{3}{*}{$2,24.10^{-2}$} \\
\hline & 10367 & & 1109998 & & $0,93 \cdot 10^{-2}$ & & \\
\hline & 15033 & & 1883077 & & $0,80 \cdot 10^{-2}$ & & \\
\hline
\end{tabular}

Resultados de regressão linear:

$\begin{array}{llll}\text { Constante } & 0 & \text { № de Observações } & 4 \\ \text { Desvio-padrão de } Y & 0,005 & \text { Graus de Liberdade } & 3 \\ R^{2} & 0,994 & R & 0,997 \\ \text { k } & 0,402 & \text { Desvio-Padrão de k } & 0,006\end{array}$

Tabela III.8: Dados para obtenção do fator de resposta para TBX.

\begin{tabular}{c|c|c|c|c|c}
\hline \multicolumn{2}{c|}{ DBX } & \multicolumn{2}{c|}{$\mathrm{C}_{16} \mathrm{H}_{34}$} & \multicolumn{2}{c}{ Razões } \\
\hline \hline Área & $\mathrm{n} .10^{10}(\mathrm{~mol})$ & Área & $\mathrm{n} .10^{11}(\mathrm{~mol})$ & Área/Área $\left(\mathrm{C}_{16} \mathrm{H}_{34}\right)$ & $\mathrm{n} / \mathrm{n}\left(\mathrm{C}_{16} \mathrm{H}_{34}\right)$ \\
\hline 23514 & 1,36 & 59113 & 14,60 & 0,40 & 0,93 \\
27763 & 1,59 & 67180 & 17,00 & 0,41 & 0,94 \\
28233 & 1,47 & 64699 & 15,80 & 0,44 & 0,93 \\
57501 & 1,59 & 56276 & 7,29 & 1,02 & 2,18 \\
50571 & 1,59 & 50774 & 7,29 & 1,00 & 2,18 \\
59387 & 1,99 & 59297 & 9,12 & 1,00 & 2,18 \\
16319 & 1,06 & 35818 & 9,72 & 0,46 & 1,09 \\
18675 & 1,06 & 38720 & 9,72 & 0,48 & 1,09 \\
15543 & 0,86 & 34272 & 7,90 & 0,45 & 1,09 \\
\hline
\end{tabular}

Resultados de regressão linear:

$\begin{array}{llll}\text { Constante } & 0 & \text { № de Observações } & 9 \\ \text { Desvio-padrão de Y } & 0,026 & \text { Graus de Liberdade } & 8 \\ \mathrm{R}^{2} & 0,992 & \mathrm{R} & 0,996 \\ \mathrm{k} & 0,453 & \text { Desvio-Padrão de k } & 0,006\end{array}$


Tabela III.9: Dados para obtenção do fator de resposta de GBX.

\begin{tabular}{|c|c|c|c|c|c|c|c|}
\hline \multirow[b]{2}{*}{ Solução } & \multicolumn{2}{|c|}{ GBX } & \multicolumn{2}{|c|}{$\mathrm{C}_{16} \mathrm{H}_{34}$} & \multicolumn{3}{|c|}{ Razões } \\
\hline & Área & $\begin{array}{c}C_{\text {molar }} \\
\left(\text { mol.L } L^{-1}\right)\end{array}$ & Área & $\begin{array}{c}\mathrm{C}_{\text {molar }} \\
\left(\mathrm{mol} \cdot \mathrm{L}^{-1}\right)\end{array}$ & $\frac{\text { Área }}{\text { Área }\left(\mathrm{C}_{16} \mathrm{H}_{34}\right)}$ & Médias & $\frac{\mathrm{C}_{\text {molar }}}{\mathrm{C}_{\text {molar }}\left(\mathrm{C}_{16} \mathrm{H}_{34}\right)}$ \\
\hline 1 & $\begin{array}{l}54476 \\
41700 \\
95824 \\
\end{array}$ & $1,25.10^{-2}$ & $\begin{array}{l}1762654 \\
1412888 \\
3119574 \\
\end{array}$ & $2,13 \cdot 10^{-1}$ & $\begin{array}{l}3,09 \cdot 10^{-2} \\
2,95 \cdot 10^{-2} \\
3,07.10^{-2}\end{array}$ & $3,04.10^{-2}$ & $5,85.10^{-2}$ \\
\hline 2 & $\begin{array}{l}35861 \\
34934 \\
30498 \\
\end{array}$ & $8,32 \cdot 10^{-3}$ & $\begin{array}{l}1927388 \\
1890868 \\
1739077 \\
\end{array}$ & $2,16 \cdot 10^{-1}$ & $\begin{array}{l}1,86.10^{-2} \\
1,85.10^{-2} \\
1,75.10^{-2} \\
\end{array}$ & $1,82 \cdot 10^{-2}$ & $3,85.10^{-2}$ \\
\hline 3 & $\begin{array}{l}23898 \\
27475 \\
26793 \\
\end{array}$ & $6,24 \cdot 10^{-3}$ & $\begin{array}{l}1711622 \\
1887016 \\
1801539 \\
\end{array}$ & $2,13.10^{-1}$ & $\begin{array}{l}1,40.10^{-2} \\
1,46.10^{-2} \\
1,49.10^{-2}\end{array}$ & $1,45.10^{-2}$ & $2,92.10^{-2}$ \\
\hline 4 & $\begin{array}{l}18410 \\
12328 \\
20424 \\
\end{array}$ & $4,99 \cdot 10^{-3}$ & $\begin{array}{l}1758496 \\
1109998 \\
1883077 \\
\end{array}$ & $2,13.10^{-1}$ & $\begin{array}{l}1,05 \cdot 10^{-2} \\
1,11.10^{-2} \\
1,09.10^{-2} \\
\end{array}$ & $1,08.10^{-2}$ & $2,34.10^{-2}$ \\
\hline
\end{tabular}

Resultados de regressão linear:

Constante $\quad 0 \quad №$ de Observações 4

Desvio-padrão de Y 0,001 Graus de Liberdade 3

$\begin{array}{llll}\mathrm{R}^{2} & 0,985 & \mathrm{R} & 0,993\end{array}$

k $\quad 0,500$ Desvio-Padrão de $k \quad 0,013$

Tabela III.10: Dados para obtenção do fator de resposta de BBzBr.

\begin{tabular}{|c|c|c|c|c|c|c|c|}
\hline \multirow{3}{*}{ Solução } & \multicolumn{2}{|c|}{$\mathrm{BBzBr}$} & \multicolumn{2}{|c|}{$\mathrm{C}_{16} \mathrm{H}_{34}$} & \multicolumn{3}{|c|}{ Razões } \\
\hline & Área & $\mathrm{C}_{\text {molar }}$ & Área & $\mathrm{C}_{\text {molar }}$ & Área & Médias & $C_{\text {molar }}$ \\
\hline & & $\left(\mathrm{mol}^{-L^{-1}}\right)$ & & $\left(\mathrm{mol} . \mathrm{L}^{-1}\right)$ & Área $\left(\mathrm{C}_{16} \mathrm{H}_{34}\right)$ & & $\mathrm{C}_{\text {molar }}\left(\mathrm{C}_{16} \mathrm{H}_{34}\right)$ \\
\hline \multirow{3}{*}{1} & 82680 & & 1762654 & & $4,69.10^{-2}$ & & \\
\hline & 66267 & $1,26.10^{-2}$ & 1412888 & $2,13.10^{-1}$ & $4,69 \cdot 10^{-2}$ & $4,68 \cdot 10^{-2}$ & $5,89 \cdot 10^{-2}$ \\
\hline & 145424 & & 3119574 & & $4,66 \cdot 10^{-2}$ & & \\
\hline \multirow{3}{*}{2} & 60390 & & 1927338 & & $3,13 \cdot 10^{-2}$ & & \\
\hline & 59143 & $8,38 \cdot 10^{-3}$ & 1890868 & $2,16.10^{-1}$ & $3,13.10^{-2}$ & $3,17.10^{-2}$ & $3,88.10^{-2}$ \\
\hline & 56620 & & 1739077 & & $3,26 \cdot 10^{-2}$ & & \\
\hline \multirow{3}{*}{3} & 38249 & & 1711622 & & $2,24.10^{-2}$ & & \\
\hline & 40860 & $6,28 \cdot 10^{-3}$ & 1887016 & $2,13.10^{-1}$ & $2,17.10^{-2}$ & $2,22.10^{-2}$ & $2,95.10^{-2}$ \\
\hline & 40757 & & 1801539 & & $2,26.10^{-2}$ & & \\
\hline \multirow{3}{*}{4} & 30779 & & 1758496 & & $1,75.10^{-2}$ & & \\
\hline & 23638 & $5,03.10^{-3}$ & 1109998 & $2,13.10^{-1}$ & $2,13 \cdot 10^{-2}$ & $1,88.10^{-2}$ & $2,36 \cdot 10^{-2}$ \\
\hline & 32957 & & 1883077 & & $1,75 \cdot 10^{-2}$ & & \\
\hline
\end{tabular}

Resultados de regressão linear:

$\begin{array}{llll}\text { Constante } & 0 & \text { № de Observações } & 4 \\ \text { Desvio-padrão de Y } & 0,001 & \text { Graus de Liberdade } & 3 \\ R^{2} & 0,995 & R & 0,998 \\ \text { K } & 0,795 & \text { Desvio-Padrão de k } & 0,011\end{array}$




\section{III.6.3: Actinometria}

Pode-se definir o rendimento quântico $(\Phi)$ de um processo fotoquímico determinado como sendo a razão entre o número de moléculas (ou mols) que sofrem 0 processo e o número total de fótons (ou einsteins) absorvidos pelo substrato. Assim, considerando-se a reação fotoquímica genérica $\mathbf{R} \stackrel{h v}{\longrightarrow}$, onde $\mathbf{R}$ representa o reagente e P um fotoproduto, ambos no estado fundamental, o rendimento quântico para 0 desaparecimento de reagente $\left(\Phi_{R}\right)$, neste processo, seria definido como:

$$
\Phi_{\mathrm{R}}=\frac{\text { número de moléculas de } \mathrm{R} \text { que reagem }}{\text { número de fótons absorvido por } \mathrm{R}} ;
$$

e o rendimento quântico de aparecimento de fotoproduto $\left(\Phi_{\mathrm{P}}\right)$ seria dado por:

$$
\Phi_{\mathrm{P}}=\frac{\text { número de moléculas de produto } \mathrm{P} \text { formado }}{\text { número de fótons absorvidos por } \mathrm{R}}
$$

No caso de reações em solução, uma estratégia muito freqüente é a de se utilizarem concentrações de reagentes tais, que toda a luz seja absorvida durante o período de monitoração da reação.

Desde que o reagente $\mathbf{R}$ seja a única espécie a absorver luz, a intensidade de luz absorvida pelo substrato $\left(\mathrm{I}_{\mathrm{abs}}\right)$ é igual à intensidade da luz incidente $\left(\mathrm{I}_{\mathrm{o}}\right)$. Então, para a reação genérica em discussão, pode-se representar $\Phi_{R}$ como:

$$
\begin{aligned}
& -\frac{\mathrm{dn}_{\mathrm{R}}}{\mathrm{dt}}=\Phi_{\mathrm{R}} \mathrm{I}_{\mathrm{abs}}=\Phi_{\mathrm{R}} \mathrm{I}_{\mathrm{o}} \quad \text { ou, } \quad \text { se } \mathrm{n}_{\mathrm{R}}=[\mathrm{R}] . \mathrm{V}, \\
& -\frac{\mathrm{Vd}[\mathrm{R}]}{\mathrm{dt}}=\Phi_{\mathrm{R}} \mathrm{I}_{\mathrm{abs}}=\Phi_{\mathrm{R}} \mathrm{I}_{\mathrm{o}} \quad \mathrm{e}, \quad \text { se } \mathrm{t}_{\mathrm{o}}=0, \\
& \mathrm{~V}\left([\mathrm{R}]_{0}-[\mathrm{R}]_{\mathrm{t}}\right)=-\mathrm{V} \Delta[\mathrm{R}]=\Phi_{\mathrm{R}} \mathrm{I}_{\mathrm{O}} \mathrm{t} \quad \therefore \quad \quad \Phi_{\mathrm{R}}=\frac{-\mathrm{V} \Delta[\mathrm{R}]}{\mathrm{I}_{\mathrm{o}} \mathrm{t}} \text {, }
\end{aligned}
$$

Segundo estas definições, para se obter o rendimento quântico de um determinado processo é necessário determinarem-se duas quantidades, i.e., a quantidade de luz 
absorvida (normalmente, por actinometria convencional) e a quantidade de substrato que reagiu - ou de fotoproduto formado - utilizando-se algum método analítico como, por exemplo, espectrofotometria ou cromatografia. Na determinação da quantidade de luz absorvida pode-se utilizar um actinômetro químico, um sistema para determinação da huz de excitação baseado em um processo químico induzido por luz, cujo rendimento quântico seja conhecido. No caso do presente estudo selecionou-se, como actinômetro, o leucocianeto do verde-malaquita (CALVERT \& RECHEN, 1952), que apresenta a seguinte fotorreação:<smiles>CN(C)c1ccc(N(C)C(=O)c2ccc(C(C)(C)C)cc2)cc1</smiles>

Leucocianeto do Verde Malaquita

(VML) Incolor<smiles></smiles>

Cátion do Verde Malaquita

(VM+)

Azul Intenso

Para a determinação do fluxo de fótons emitido por lâmpadas de mercúrio de baixa pressão, o VML apresenta pelo menos duas vantagens em relação ao ferrioxalato de potássio, actinômetro clássico (HATCHARD \& PARKER, 1956), cuja faixa de absorção é muito extensa ( 250 a $500 \mathrm{~nm}$ ).

Em primeiro lugar, o VML, por não absorver na região do visivel (a região útil deste actinômetro está entre 225 e 289 nm, vide Figura III.8 à página 59), permite o manuseio das soluções fora de salas escuras. Em segundo lugar, como a região de absorção do VML está na mesma faixa da dos compostos halo-benzilicos em estudo, os eventuais erros causados por diferenças entre a capacidade absortiva do actinômetro e a quantidade de luz realmente absorvida pelo substrato são diminuídos, o que é importante no caso de se querer relacionar medidas actinométricas e de rendimento quântico feitas em condições policromáticas (i.e., para lâmpadas nuas).

Para se determinar o fluxo de fótons emitido pelo conjunto de lâmpadas utilizado neste trabalho, seguiu-se o procedimento descrito por JOHNS (1969), tendo sido necessário obterem-se os espectros de absorção completos para o VML e o $\mathrm{VM}^{+}$pois utilizaram-se soluções metanólicas, ao invés de etanólicas, como descrito por JOHNS (1969), o que desloca ligeiramente as curvas de absorção. O procedimento adotado está descrito, etapa por etapa, a seguir:

1. Adicionou-se, a metanol grau espectroscópico, ácido clorídrico suficiente para a preparação de uma solução $1,16 \times 10^{-3} \mathrm{molL}^{-1}$. Esta solução-estoque será designada como $S_{1}$. As absorbâncias de $S_{1}$ foram medidas (contra $\mathrm{H}_{2} \mathrm{O}$ ), tendo sido obtidos valores compatíveis com os da literatura (JOHNS, 1969) como apresentado na Tabela III.11. O ácido é adicionado para estabilizar o $\mathbf{V M}^{+}$, dificultando a hidrólise do cátion, processo este que diminuiria a absorbância da solução, segundo:

$$
\begin{aligned}
& \mathrm{VM}^{+}+\mathrm{H}_{2} \mathrm{O} \leftrightharpoons \mathrm{VMOH}+\mathrm{H}^{+} \\
& \text {(azol) } \\
& \text { (incolor) }
\end{aligned}
$$


Tabela III.11: Absorbâncias para soluções alcoólicas de $\mathrm{HCl}$.

\begin{tabular}{c|c|c}
\hline \multirow{2}{*}{$\begin{array}{c}\lambda \\
(\mathrm{nm})\end{array}$} & \multicolumn{2}{|c}{ Absorbåncias } \\
\cline { 2 - 3 } & experimental $^{\text {a }}$ & literatura $^{\text {b }}$ \\
\hline 220 & 0,19 & 0,17 \\
230 & 0,08 & 0,09 \\
240 & 0,03 & 0,035 \\
254 & 0,05 & $\overline{0,004}$ \\
260 & 0,00 & 0 \\
\hline
\end{tabular}

a. Metanol/ $\mathrm{HCl}\left(1,16 \cdot 10^{-3}\right.$ mol. $\left.\mathrm{L}^{-1}\right)$, contra $\mathrm{H}_{2} \mathrm{O}$.

b. Etanol/ $/ \mathrm{HCl}\left(10^{-3} \mathrm{~N}\right)$, contra $\mathrm{H}_{2} \mathrm{O}$ (JOHNS, 1969).

2. Preparou-se uma solução-estoque $\left(1,02.10^{-3} \mathrm{molL}^{-1}\right)$ de VML $\left(\mathbf{S}_{2}\right)$ acrescentandose, a $0,0363 \mathrm{~g}$ do actinômetro, solução $S_{1}$ suficiente para completar $100,00 \mathrm{~mL}$. A solução $S_{2}$ foi mantida congelada no freezer, em frasco escuro, sendo estável, nestas condições, por seis meses.

3. Dihuiu-se $S_{2} \operatorname{com} S_{1}$ para que a solução final apresentasse uma absorbância de cerca de 1,5 no comprimento de onda de interesse. Por exemplo, para $\lambda=254 \mathrm{~nm}$, $\left[\mathrm{S}_{3}\right]=1,55.10^{-4} \mathrm{mol.L} \mathrm{L}^{-1} ; \mathrm{A}=1,495$.

4. Obtiveram-se os espectros de absorção para $S_{3}$, em três dihuições diferentes (1:3, 1:5 e 1:10), a partir de $\left[S_{3}\right]=1,30.10^{-4} \mathrm{moll}^{-1}$, com o objetivo de se determinarem as curvas de absorção em $\varepsilon$ (ou $\log \varepsilon$ ), tendo sido obtida a curva apresentada na Figura III.8. Alguns dados importantes para os cálculos da intensidade da emissão das lâmpadas estão apresentados na Tabela III. 12, que se segue:

Tabela II.12: Dados para VML e VM ${ }^{+}$, em metanol/HCl $\left(1,16.10^{-3} \mathrm{moll}^{-1}\right)$.

\begin{tabular}{c|c|c|c|c}
\hline & \multicolumn{2}{|c|}{ VML } & \multicolumn{2}{c}{$\mathrm{VM}^{+}$} \\
\hline$\frac{\lambda}{\mathrm{nm}}$ & $\frac{\varepsilon}{10^{3} \mathrm{Lmol}^{-1} \mathrm{~cm}^{-1}}$ & $\log \left(\frac{\varepsilon}{\mathrm{L} \mathrm{mo}^{-1} \mathrm{~cm}^{-1}}\right)$ & $\frac{\varepsilon}{10^{3} \mathrm{Lmol}^{-1} \mathrm{~cm}^{-1}}$ & $\log \left(\frac{\varepsilon}{\mathrm{Lmo} \Gamma^{-1} \mathrm{~cm}^{-1}}\right)$ \\
\hline \hline 254 & 9,65 & 3,98 & 12,10 & 4,08 \\
266 & 14,30 & 4,16 & 9,47 & 3,98 \\
269 & 14,70 & 4,17 & 9,48 & 3,98 \\
297 & 3,03 & 3,48 & 11,80 & 4,07 \\
303 & 2,55 & 3,41 & 12,40 & 4,09 \\
313 & 2,05 & 3,31 & 13,90 & 4,14 \\
618 & - & - & 65,80 & 4,82 \\
619 & - & - & 65,80 & 4,82 \\
\hline
\end{tabular}

5. Irradiou-se a solução $S_{3}\left(\left[S_{3}\right]=1,04 \cdot 10^{-4} \mathrm{~mol}^{-1} \mathrm{~L}^{-1}\right)$ até conversão total do VML em $\mathrm{VM}^{+}$(80 minutos, $254 \mathrm{~nm}$ ) obtendo-se os espectros de absorção para $\mathbf{V M}^{+}$para soluções de três diferentes concentrações, preparadas por diluição de $S_{3} \operatorname{com} S_{1}(1: 5 ; 1: 10$; 1:15), com o objetivo de se determinar a curva de absorção do $\mathbf{V M}^{+}$em $\varepsilon$ (ou $\log \varepsilon$ ), apresentada na Figura III.8, que se segue. 


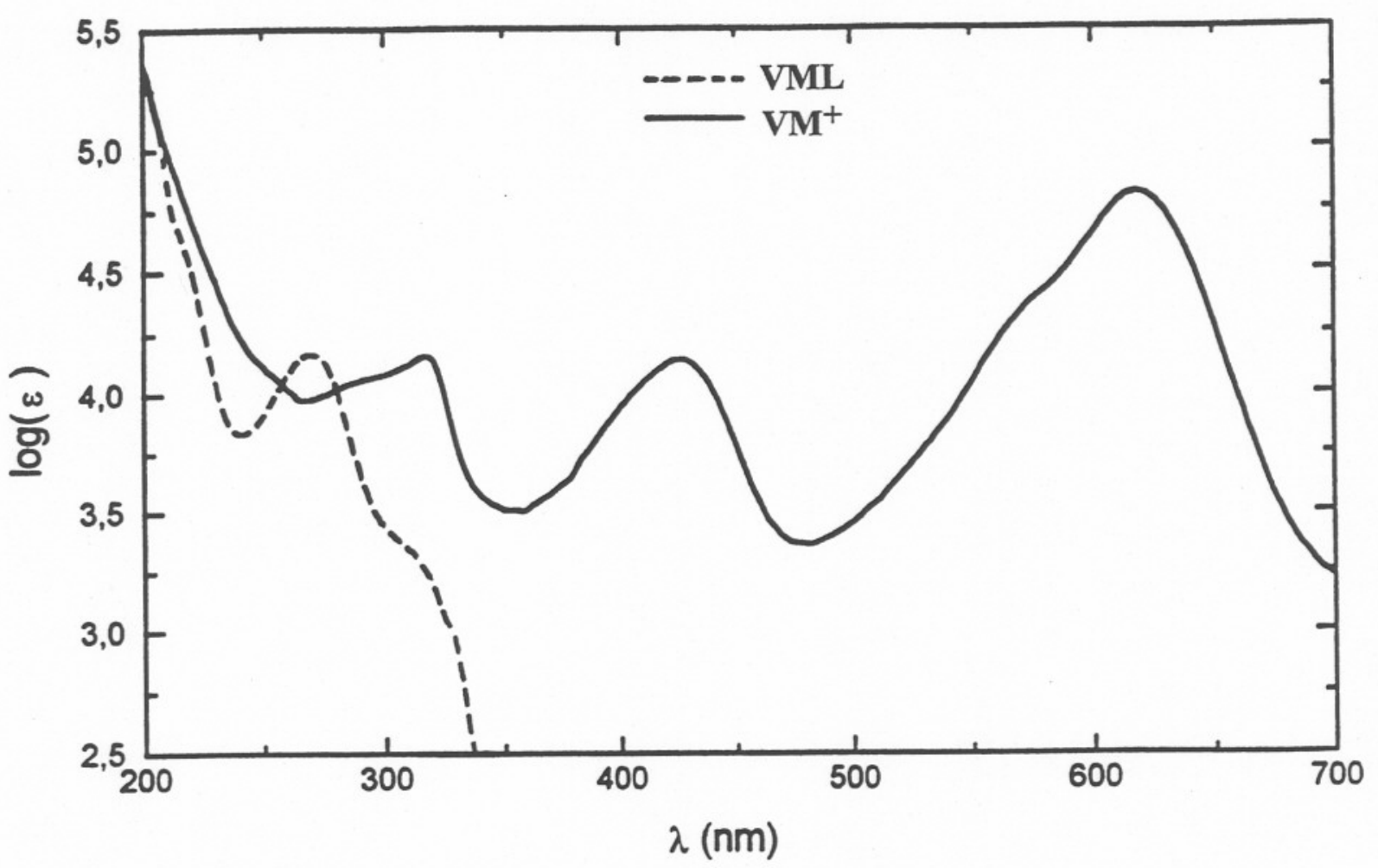

Figura III.8 - Espectros de absorção (em loge), para o VML (actinômetro) e para o fotoproduto $\mathbf{V M}^{+}$(curva cheia), em metanol/ácido clorídrico $\left(1,16.10^{-3} \mathrm{~mol} . \mathrm{L}^{-1}\right)$.

Conhecidos os espectros de absorção para o VML e o $\mathbf{V M}^{+}$, pôde-se passar às medidas actinométricas em si, consideradas duas condições de contorno: (i) que a solução de VML fosse concentrada o suficiente para não permitir a transmissão de luz através da amostra irradiada e (ii) que as medidas fossem feitas para uma conversão de VML na qual a variação das absorbâncias, a $618 \mathrm{~nm}$, obedecesse à linearidade.

Assim, irradiaram-se $3,00 \mathrm{~mL}$ de solução $\mathbf{S}_{\mathbf{3}}$, em um carrossel, cujas cavidades para o encaixe de tubos de 13 x 100mm são providas de fendas de $1 \mathrm{~mm}$ de largura (para minimizar os efeitos causados pela diferença de índice de refração dos solventes utilizados sobre o rendimento quântico observado; VESLEY, 1971). Foram obtidas, para alíquotas diluídas para a metade da concentração, as leituras que se encontram na Tabela III.13.

Tabela III.13: Actinometria para as lâmpadas de mercúrio de baixa pressão a

\begin{tabular}{c||c|c|c|c|c|c}
\hline $\begin{array}{c}\text { Tempo (s) } \\
\text { Absorbåncias } \\
(\mathbf{a} 618 \mathrm{~nm})^{\mathbf{b}}\end{array}$ & $0,00 \pm 0,01$ & $0,23 \pm 0,01$ & $0,44 \pm 0,01$ & $0,55 \pm 0,01$ & $0,75 \pm 0,01$ & $0,83 \pm 0,01$ \\
$\begin{array}{c}\text { Absorbåncias } \\
(\mathrm{a} 618 \mathrm{~nm})^{c}\end{array}$ & 0,00 & $0,47 \pm 0,01$ & $0,87 \pm 0,01$ & $1,10 \pm 0,01$ & $1,50 \pm 0,01$ & $1,67 \pm 0,01$ \\
\hline \hline
\end{tabular}

a. $\left[S_{3}\right]=1,55.10^{-3} \mathrm{~mol}^{-L^{-1}} ; A_{254}=1,495$.

b. absorbâncias medidas, para as alíquotas diluídas.

c. absorbâncias calculadas, para a solução $S_{3}$ irradiada: destes dados

obtem-se, por regressão linear, a equação: $\mathbf{A}=0,18 t ; \mathbf{r}=0,993$. 
Como, a $254 \mathrm{~nm}$, o VML e o fotoproduto absorvem, não se pode utilizar a expressão simplificada:

$$
I_{0}=\frac{k_{0} V}{\Phi}
$$

na qual se admite que $\mathrm{k}_{\mathrm{o}}$ seja uma constante cinética observada de ordem zero para 0 cálculo da intensidade de luz emitida $\left(\mathrm{I}_{0}\right)$. Assim, utilizou-se a equação proposta por BUNCE (1987):

$$
-\mathrm{V} \frac{\mathrm{d}[\mathrm{R}]_{\mathrm{t}}}{\mathrm{d}\left(\mathrm{I}_{\mathrm{o}} \cdot \mathrm{t}\right)}=\frac{\Phi \varepsilon_{\mathrm{R}}[\mathrm{R}]_{\mathrm{t}}\left(1-\exp \left[-2,303 \mathrm{~b}\left\{\varepsilon_{\mathrm{P}}[\mathrm{R}]_{\mathrm{o}}+\left(\varepsilon_{\mathrm{R}}-\varepsilon_{\mathrm{P}}\right)[\mathrm{R}]_{\mathrm{t}}\right\}\right]\right)}{\varepsilon_{\mathrm{P}}[\mathrm{R}]_{\mathrm{o}}+\left(\varepsilon_{\mathrm{R}}-\varepsilon_{\mathrm{P}}\right)[\mathrm{R}]_{\mathrm{t}}},
$$

onde:

b é o comprimento da cela, em cm;

$\varepsilon_{\mathrm{R}}$ é a absortividade molar do reagente, em L.mol ${ }^{-1} \cdot \mathrm{cm}^{-1}$, a $\lambda=254 \mathrm{~nm}$;

$\varepsilon_{\mathrm{P}}$ é a absortividade molar do produto, em L.mol ${ }^{-1} \cdot \mathrm{cm}^{-1}$, a $\lambda=254 \mathrm{~nm}$;

V é o volume irradiado, em $\mathrm{L}$;

$[R]_{0}$ é a concentração inicial, em mol. $\mathrm{L}^{-1}$;

$[R]_{t}$ é a concentração, no tempo t, em mol. $L^{-1} e$

$\Phi$ é rendimento quântico de desaparecimento do VML

Para o caso geral, esta equação diferencial não pode ser integrada analiticamente. Entretanto, pode-se integrá-la numericamente, por exemplo, pelo método de EULER, gerando-se dados suficientes, a partir dos experimentais, para que se tenham pelo menos 100 intervalos discretos de integração $(\Delta t=0,1 \mathrm{~s})$.

Como $\mathrm{A}=0,18 . \mathrm{t}$ e $\varepsilon_{618}=6,58 \cdot 10^{4} \mathrm{~L} \cdot \mathrm{mol}^{-1} \cdot \mathrm{cm}^{-1}$ (vide Tabela III.13, nota c, p. 59 e Tabela III.12, p. 58 , respectivamente), temos, pela Lei de Lambert-Beer, que:

$$
[R]_{i}=2,73 \cdot 10^{-6} \cdot \mathrm{i} \Delta \mathrm{t}
$$

Assim, se :

$I_{0}=\frac{V}{t} \sum_{i=1}^{100} \frac{\left([R]_{0}-[R]_{t}\right)\{f(i)+f(i+1)\}}{200 \Phi_{R} \varepsilon_{R}}$,

onde:

$f(i)=\frac{\left(\varepsilon_{R}-\varepsilon_{P}\right)+\varepsilon_{P}[R]_{0} /[R]_{i}}{1-\exp \left[-2,303 b\left\{\varepsilon_{P}[R]_{0}+\left(\varepsilon_{R}-\varepsilon_{P}\right)[R]_{i}\right\}\right]}$,

$[R]_{i}$ é a concentração do reagente no tempo (i $\left.\Delta \mathrm{t}\right) \mathrm{e}$ i $\in \mathbb{N}$.

tem-se, ao se proceder a integração numérica com $\mathrm{t}=\sum_{\mathrm{i}=1}^{100} \mathrm{i} \Delta \mathrm{t}=10 \mathrm{~s}$ e $\mathrm{V}=3 \mathrm{~mL}$, que $I_{0}=1,15 \cdot 10^{-8}$ einstein $/ \mathrm{s}$, ou seja:

$$
I_{0}=6,87 \cdot 10^{-7} \text { einstein } / \mathrm{min},
$$

para o sistema de irradiação utilizado nas fotólises convencionais (vide item III.6.1, à p. 51$)$. 


\section{III.7. Fotólises por Pulso de Laser}

O sistema utilizado para a realização dos experimentos de fotólise por pulso de laser é constituído, essencialmente, por quatro partes: (i) fonte de excitação, (ii) sistema de monitoração, (iii) sistema de detecção e (iv) recursos computacionais para o processamento dos sinais (SCAIANO, 1982). Nas fotólises por pulso de laser utilizamos o sistema descrito no item III.1 (p.31), cujo esquema simplificado encontra-se na Figura III.9, a seguir.

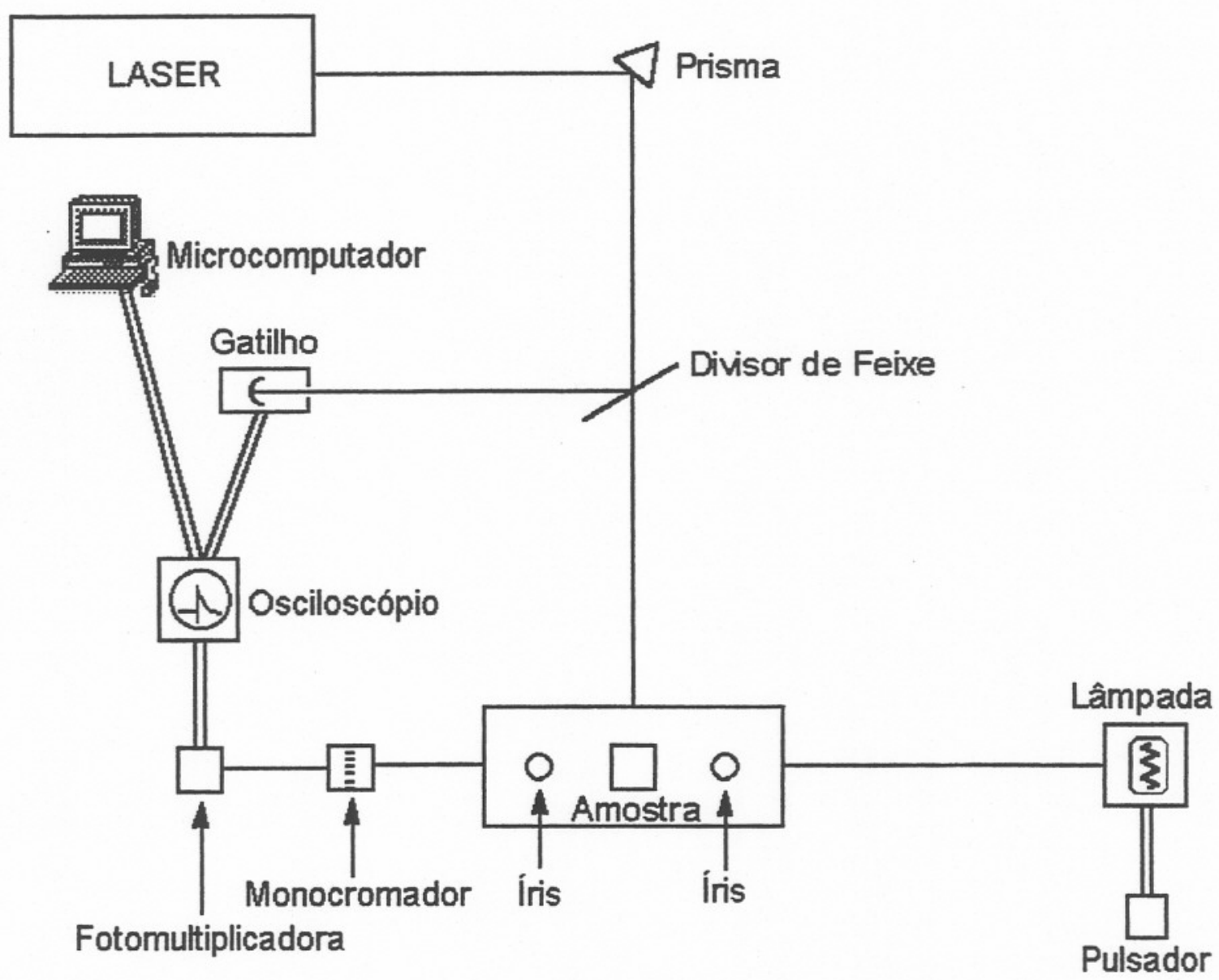

onde,

a fonte de excitação é um laser pulsado de Nd/YAG;

o sistema de monitoração é constituído por um monocromador, lentes, íris e uma lâmpada de xenônio, pulsada para aumentar a intensidade luminosa;

o sistema de detecção consiste em uma fotomultiplicadora e um osciloscópio rápido para captura das curvas de intensidade do transiente versus tempo;

o computador (IBM-PC/AT compativel) utilizado para o processamento dos sinais armazenados pelo osciloscópio emprega um software desenvolvido, para este laboratório, pelo Engo. Ricardo Furlan.

Figura III.9 - Esquema simplificado do sistema utilizado nas fotólises-relâmpago. 
Em nossos estudos, o laser foi operado com amplificadores de potência nominal igual a $1400 \mathrm{~V}$ (correspondendo a $6 \mathrm{~mJ} /$ pulso, i.e., $400 \mathrm{~kW}$ ), tendo-se selecionado o $4^{\circ}$ harmônico $(\lambda=266 \mathrm{~nm})$ como comprimento de onda de excitação. A largura do pulso (à meia altura) é, tipicamente, de $15 \mathrm{~ns}$ e, o diâmetro do feixe, de cerca de $1 \mathrm{~cm}$. A luz de excitação, em arranjo perpendicular ao feixe emitido pelo laser, é fornecida por uma lâmpada pulsada de xenônio de $450 \mathrm{~W}$.

Como não se poderiam utilizar soluções benzênicas neste comprimento de onda, selecionou-se, como solvente, um alcano cuja constante dielétrica fosse semelhante à do benzeno de forma que os resultados fossem obtidos em um meio de polaridade comparável à utilizada nas fotólises convencionais. Assim, soluções isooctânicas $\left(10^{-4}\right.$ mol. $\mathrm{L}^{-1}$; A na faixa de 0,6 a 0,8$)$ de quatro dos cinco compostos bromados (MBX, DBX, GBX e TBX), contidas em celas de quartzo de $1,00 \mathrm{~cm}$ de caminho óptico, providas de torneira de teflon, foram submetidas a experimentos de fotólise-relâmpago, após serem desaeradas, durante 20 minutos, por corrente de argônio ou por, pelo menos, quatro ciclos de congelamento-degaseamentodescongelamento (até cerca de $5.10^{-5} \mathrm{mmHg}$ ).

Para cada um destes compostos, foram obtidas as curvas cinéticas de decaimento das espécies geradas na fotólise, monitorando-se a absorbância destes transientes, em função do tempo. Tipicamente, a monitoração foi feita a vários comprimentos de onda, para cada uma das soluções, variando-se o monocromador de 5 em 5 (ou 10 em 10) nanômetros, para comprimentos de onda na faixa de 280 a $500 \mathrm{~nm}$. Em todos os casos, as curvas obtidas eram médias de uma série de pelo menos três tiros, dos quais havia sido subtraída a linha-base determinada para o sistema de fotólise.

Não houve necessidade de se utilizarem celas de fluxo porque a comparação dos espectros de absorção na região do ultra-violeta determinados, antes e após a execução das medidas, para cada uma das soluções em estudo, não indicou alterações significativas das características espectrais, a não ser no caso de GBX.

Com o objetivo de se identificarem os transientes gerados nestas fotólises, foram feitos vários experimentos adicionais para o caso de $\mathbf{D B X}$, em iso-octano. Assim, foram feitos estudos na presença de ciclo-hexeno, além de se investigar o efeito exercido por oxigênio sobre a cinética de decaimento das absorções transientes, através da comparação das curvas obtidas para uma mesma solução degaseada e após ter-se nela borbulhado oxigênio durante 20 minutos, sob ação de ultra-som. Foram, ainda, feitas medidas em iso-propanol, em presença e em ausência de cis-piperileno, em meio desaerado e em meio saturado de oxigênio.

Para se ter uma comparação mais imediata entre os resultados obtidos nas fotólises convencionais e os dados de espectroscopia por pulso de laser, efetuaram-se medidas para soluções de DBX e de TBX, em benzeno, utilizando-se um laser de exímero $(\lambda=308 \mathrm{~nm})$. As determinações em benzeno foram feitas, a nosso pedido, no laboratório da Dra. Cornelia Bohne (Universidade de Victoria, Victoria, B.C., Canadá).

A partir das curvas de decaimento cinético, construiram-se os espectros de absorção dos transientes detectados nas fotólises. Assim, para os decaimentos monitorados em cada um dos diferentes comprimentos de onda, obtiveram-se médias 
aritméticas dos valores de cinco pontos, ou seja: aquele observado no tempo de corte selecionado e os dois pontos que o antecedem e o sucedem. Analisando-se as curvas de decaimento, foi possível selecionar $5 \mu \mathrm{s}$ e $15 \mu \mathrm{s}$, a partir do início do decaimento, como tempos de amostragem típicos. O programa para este tratamento foi desenvolvido pelo Dr. Ivan Pérsio de Arruda Campos, pós-doutorando em nosso grupo de pesquisa. 


\section{RESULTADOS E DISCUSSÃO}

\section{IV.1 Fotólises Convencionais}

\section{IV.1.1: Em benzeno}

Na fotólise de DBX em solução benzênica foram obtidos, como produtos principais, $\alpha$-bromo-o-xileno (MBX) e $\alpha, \alpha, \alpha$-tribromo-o-xileno (TRBX) e, em menor quantidade, $\alpha, \alpha$-dibromo-o-xileno (GBX), conforme mostram os resultados apresentados na Tabela IV.4 (vide página 81). Detectaram-se, também, traços de brometo de $o$-benzil-benzila (BBzBr), produto proveniente do ataque, ao benzeno, do mono-radical o-(bromo-metil)-benzila (41) - formado na etapa fotoquímica primária pela quebra homolítica de uma ligação C-Br (vide ESQUEMA IV.1, p.65).

Nesta fotólise, o fotoproduto primário é o mono-radical 41, enquanto todos os processos subseqüentes são térmicos e podem ser compreendidos em termos de reações radicalares: o radical $\mathbf{4 1}$ gera MBX por abstração de um átomo de hidrogênio do substrato (DBX), analogamente ao observado por ABDEL-WAHAB et alii (1985) ao estudarem a fotólise de uma série de compostos halogenados (bromados ou clorados), em tetracloreto de carbono; a formação de TRBX envolve a combinação dos radicais bromo e $\alpha$-bromo-o-(bromo-metil)-benzila (42, gerado quando da formação de $\mathbf{M B X}$ ); finalmente, quanto à obtenção de GBX, admitindo-se que ocorra migração [1,4] de hidrogênio no radical 41, formar-se-ia um radical estabilizado pela presença de um substituinte bromo em ipso (43), o qual, ao combinar-se com um átomo de bromo, produziria GBX (ESQUEMA IV.1).

Como o solvente utilizado nesta irradiação é benzeno, o qual não é uma fonte adequada de radicais hidrogênio - $\mathrm{D}\left(\mathrm{C}_{6} \mathrm{H}_{5}-\mathrm{H}\right)=461 \mathrm{~kJ} \cdot \mathrm{mol}^{-1}$ (MUROV et alii,1993) a abstração de hidrogênio do próprio substrato (DBX), a recombinação e/ou a dimerização são os únicos caminhos disponíveis para a desativação dos radicais 41 e Br , formados na primeira etapa da fotorreação.

Entretanto, ao se irradiar DBX em benzeno, não se formaram, em quantidades detectáveis, quer dímeros, quer $\mathrm{HBr}$. Uma possível explicação para este comportamento seria estar-se formando um complexo benzeno/ $/ \mathrm{Br}^{\circ}$, pois este processo, ao estabilizar o radical bromo, torná-lo-ia menos reativo e mais seletivo, aumentando seu tempo de vida. A formação de complexos entre átomos de halogênio $(\mathrm{Cl}, \mathrm{Br}$ e I) e compostos aromáticos, tanto em solução, como em matrizes, está bem estabelecida na literatura (vide, por exemplo, BOSSY et alii, 1970; BÜHLER, 1972).

Considerando-se as energias de ligação de $\mathrm{HBr}$ e $o$-xileno $-\mathrm{D}(\mathrm{Br}-\mathrm{H})=$ $366 \mathrm{~kJ} \cdot \mathrm{mol}^{-1}$ (MUROV et alii, 1993); $\mathrm{D}\left(o-\mathrm{MeC}_{6} \mathrm{H}_{4} \mathrm{CH}_{2}-\mathrm{H}\right)=365 \mathrm{~kJ} \cdot \mathrm{mol}^{-1}$ (HAYASHIBA- 
RA et alii,1986) - conclui-se, facilmente, que a estabilização causada pela formação do complexo benzeno/ $/ \mathrm{Br}^{\bullet}$ desfavorece a retirada de $\mathrm{H}^{\bullet}$ do substrato (DBX) por tornar menos exotérmica esta abstração.

A diminuição da reatividade do radical bromo, devida à complexação com benzeno pode, ainda, contribuir para a formação do TRBX, um produto inesperado, pois o aumento do tempo de vida do radical favoreceria a ocorrência de encontros bimoleculares efetivos entre $\mathrm{Br}^{\circ} \mathrm{e}$ as demais espécies presentes no meio reacional, tornando menos provável a formação de dímeros, seja de 41, seja de 42 (os quais não foram detectatos).

ESQUEMA IV.1

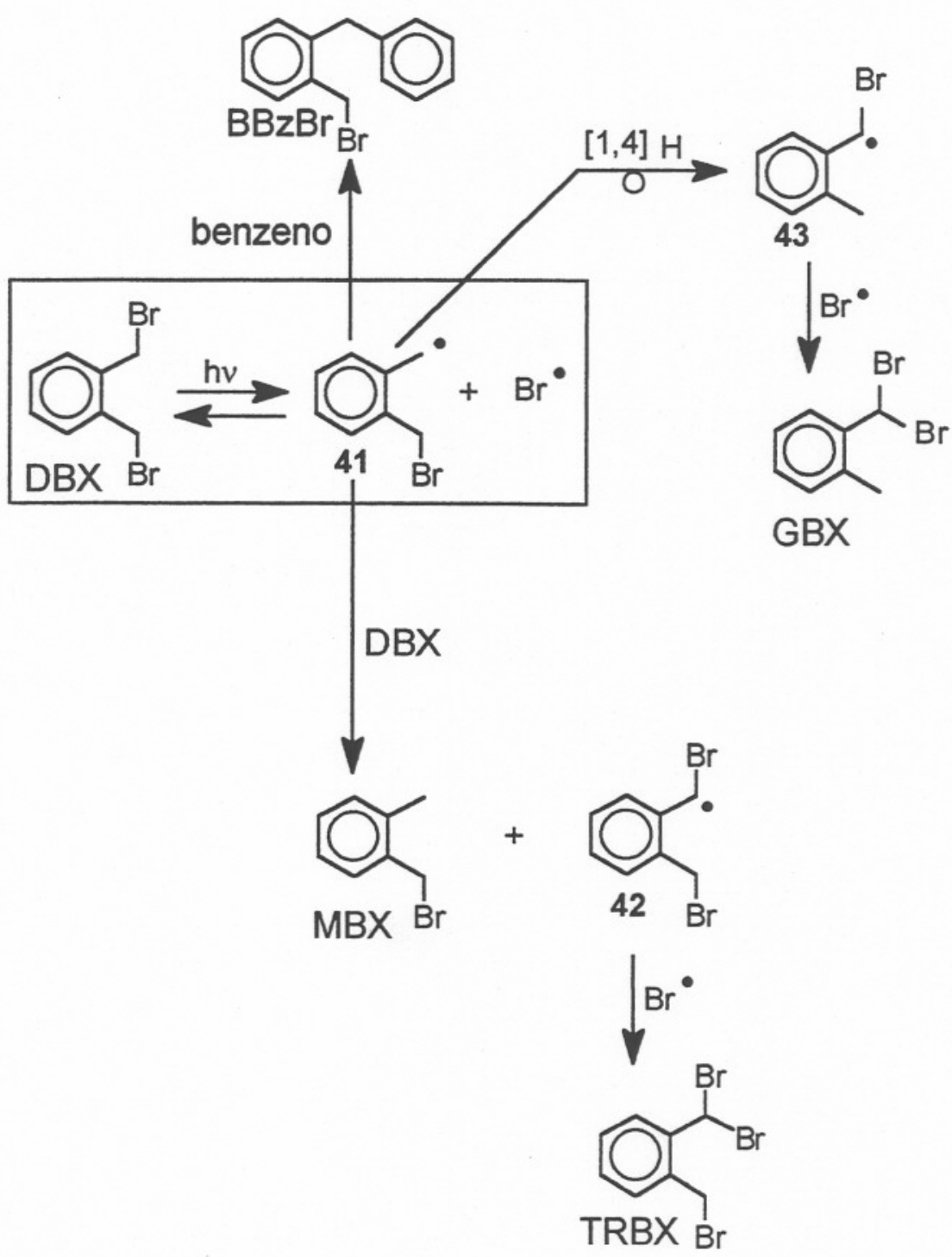

Com o objetivo de verificar a validade das hipóteses mecanísticas apresentadas no ESQUEMA IV.1, decidimo-nos a estudar o comportamento fotoquímico de uma série de compostos bromados cujo esqueleto carbônico fosse similar ao de DBX, enquanto o número de átomos de bromo presentes nos carbonos dos grupos metila seria variado. $\mathrm{O}$ estudo da fotoquímica dos demais $o$-xilenos bromados deveria permitir 
que se analisasse se o efeito de bromo no carbono ipso e/ou $\alpha$ ao radical 41 (vide ESQUEMA IV.1, p. 65) é significativo, mantendo-se a geometria dos intermediários envolvidos praticamente inalterada (vide Figura IV.1, p.68)

Assim, irradiaram-se, inicialmente, soluções benzênicas de MBX, nas condições descritas anteriormente (vide item III.6.1, p. 51). Nestas irradiações foram obtidos $o$-xileno e DBX, além de GBX e TRBX e seus respectivos produtos de hidrólise. A proposta mecanística simplificada para a obtenção destes fotoprodutos encontra-se sumarizada no ESQUEMA IV.2, a seguir.

ESQUEMA IV.2
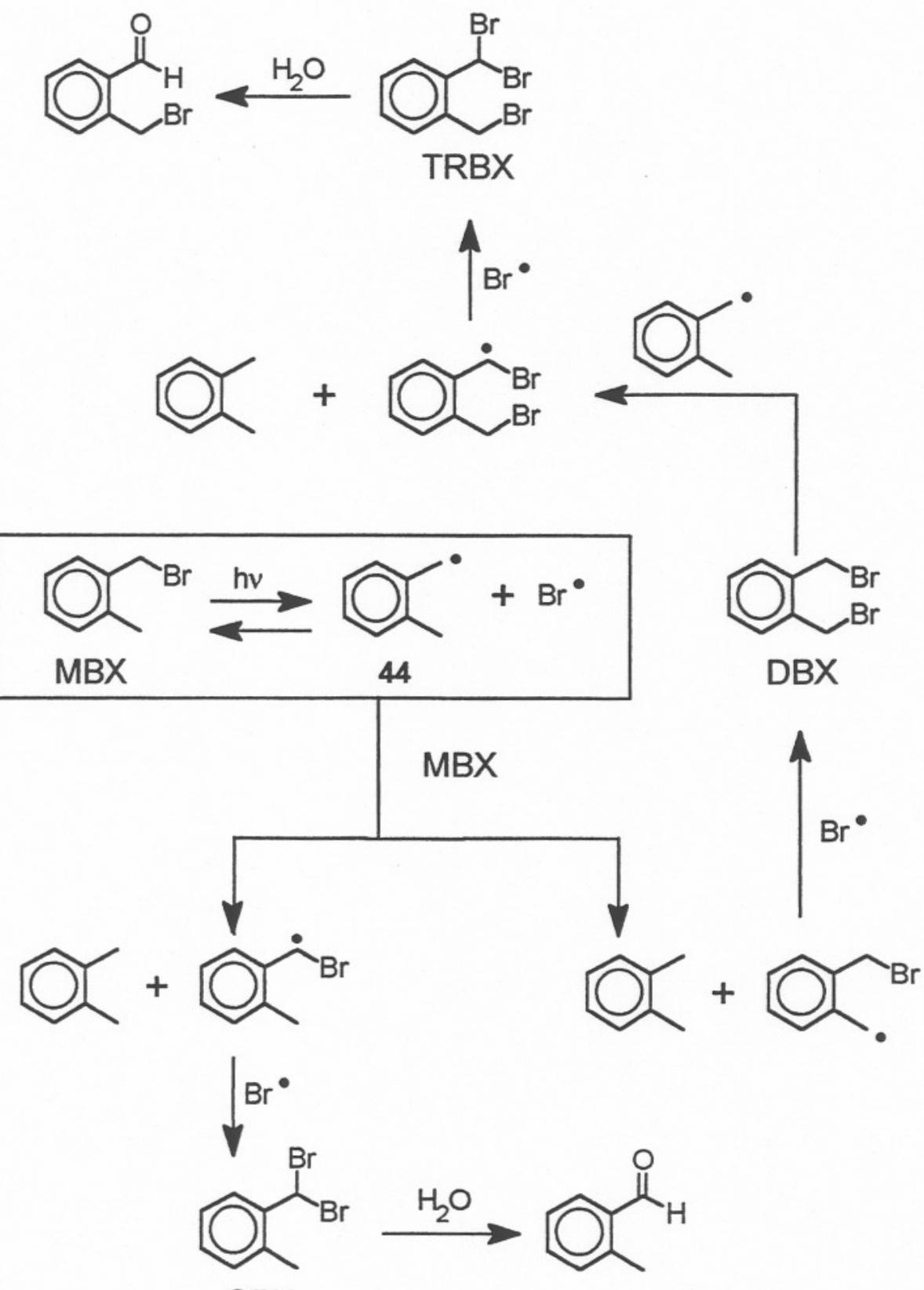

GBX 
A formação destes fotoprodutos, a partir de MBX, pode ser explicada utilizando-se raciocínios análogos aos desenvolvidos para o caso de DBX, o que fortalece a hipótese de estar operando o mecanismo de recombinação radicalar proposto nos ESQUEMAS IV.1e IV.2.

Mantendo-se, ainda, as mesmas condições de irradiação, estudou-se o comportamento de TBX, tendo sido identificados, além de TRBX, os produtos da hidrólise parcial e total de TBX (os aldeídos 45 e 46; vide ESQUEMA IV.3). Houve ainda, novamente, a formação de um composto inesperado, o $\alpha, \alpha, \alpha, \alpha^{\prime}$-tetrabromo$o$-xileno (47), observado apenas como seu produto de hidrólise (48; ESQUEMA IV.3).

\section{ESQUEMA IV.3}
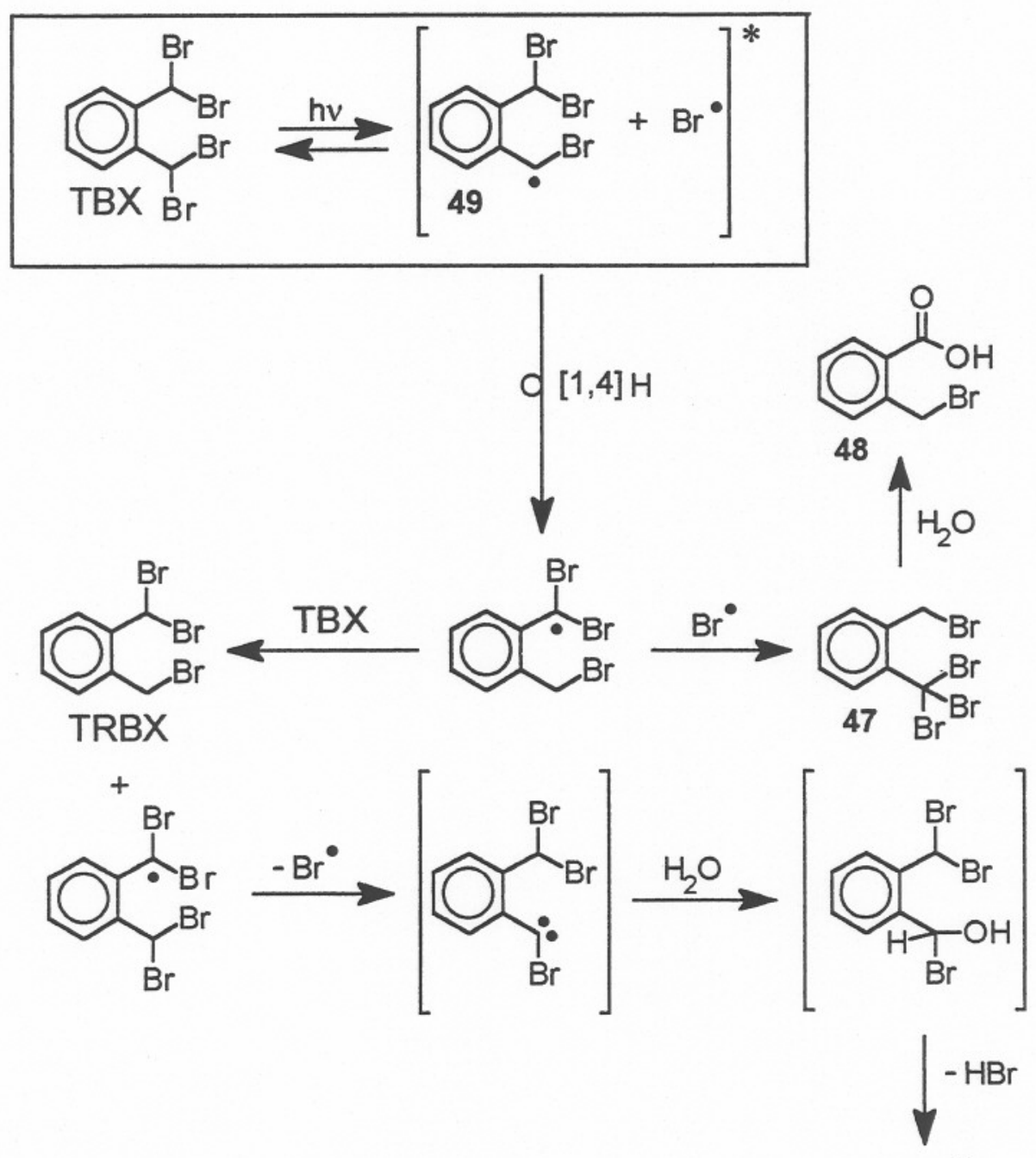<smiles>CC(Br)c1ccccc1C(Br)Br</smiles>

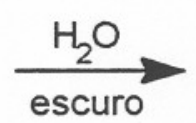<smiles>CCCCCCCC=O</smiles><smiles>CC(O)C1CCCC1</smiles><smiles>O=Cc1ccccc1C(Br)Br</smiles> 
A taxa de conversão de TBX em produtos é menor do que aquelas observadas para MBX e DBX. Pode-se imaginar que, na fotólise de TBX, a recombinação do par radicalar $\left(49 / \mathrm{Br}^{\circ}\right)$, regenerando o reagente de partida, tenha maior eficiência do que no caso dos dois sistemas anteriores. Este comportamento pode ser compreendido ao se considerar que o radical formado na etapa fotoquímica primária $(49$, vide ESQUEMA IV.3, p. 67) deva ter maior dificuldade para abstrair um átomo de hidrogênio do substrato (TBX), pois o impedimento estérico, neste caso, seria bem maior do que o existente nos sistemas anteriores (vide Figura IV.1).

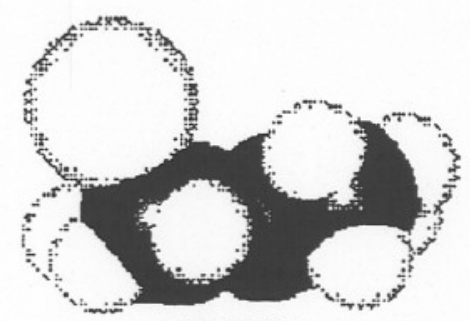

MBX
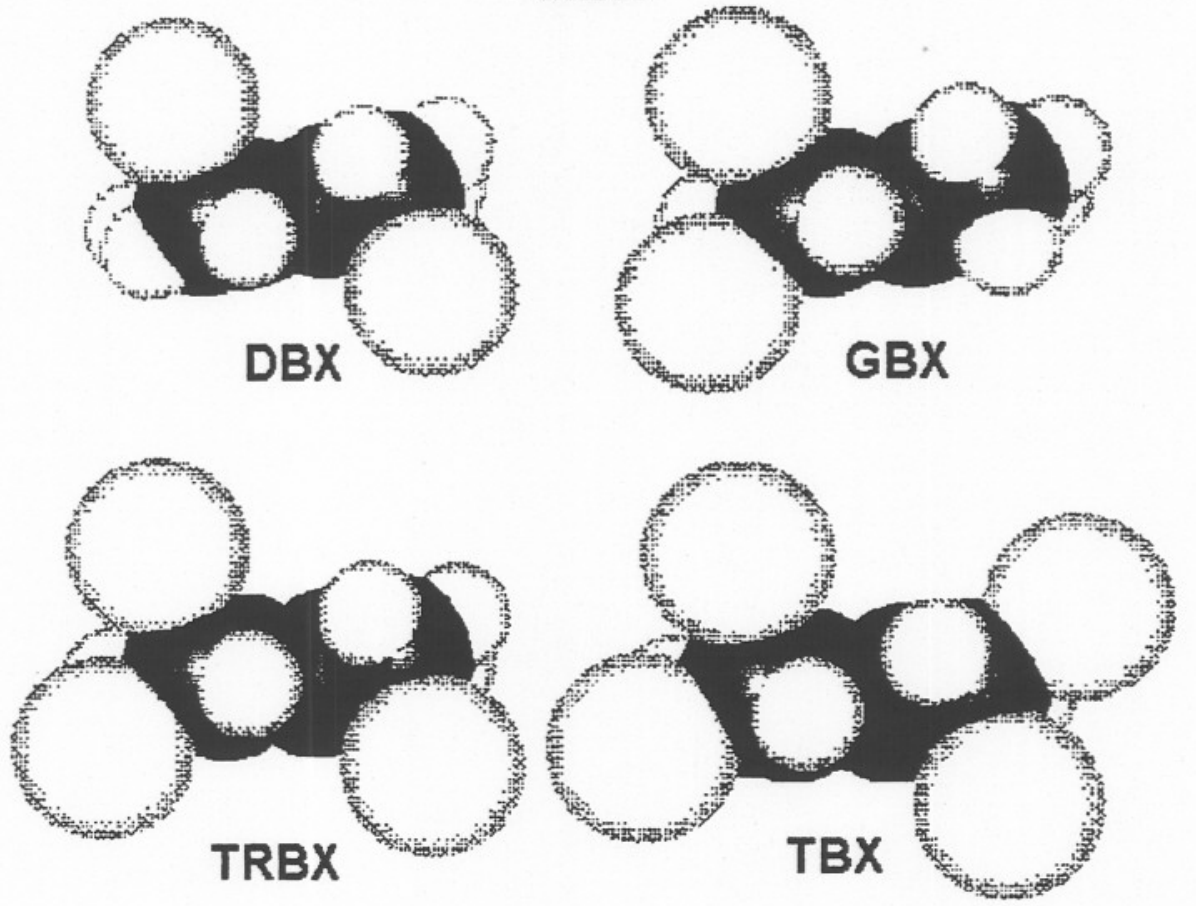

Figura IV.1 - Representações de modelos para confôrmeros de menor energia dos compostos bromados em estudo, de acordo com os volumes moleculares relativos, calculadas e traçadas pelo programa HyperChem. Nesta projeção, os anéis aromáticos encontram-se ocultos pelos substituintes e perpendiculares ao plano do papel. 
Irradiaram-se, ainda, soluções benzênicas de TRBX (vide ESQUEMA IV.4) e GBX (vide ESQUEMA IV.5, p.70), para verificar se estes derivados bromados apresentariam reatividades semelhantes às dos compostos já estudados, em reações de foto-homólise.

\section{ESQUEMA IV.4}

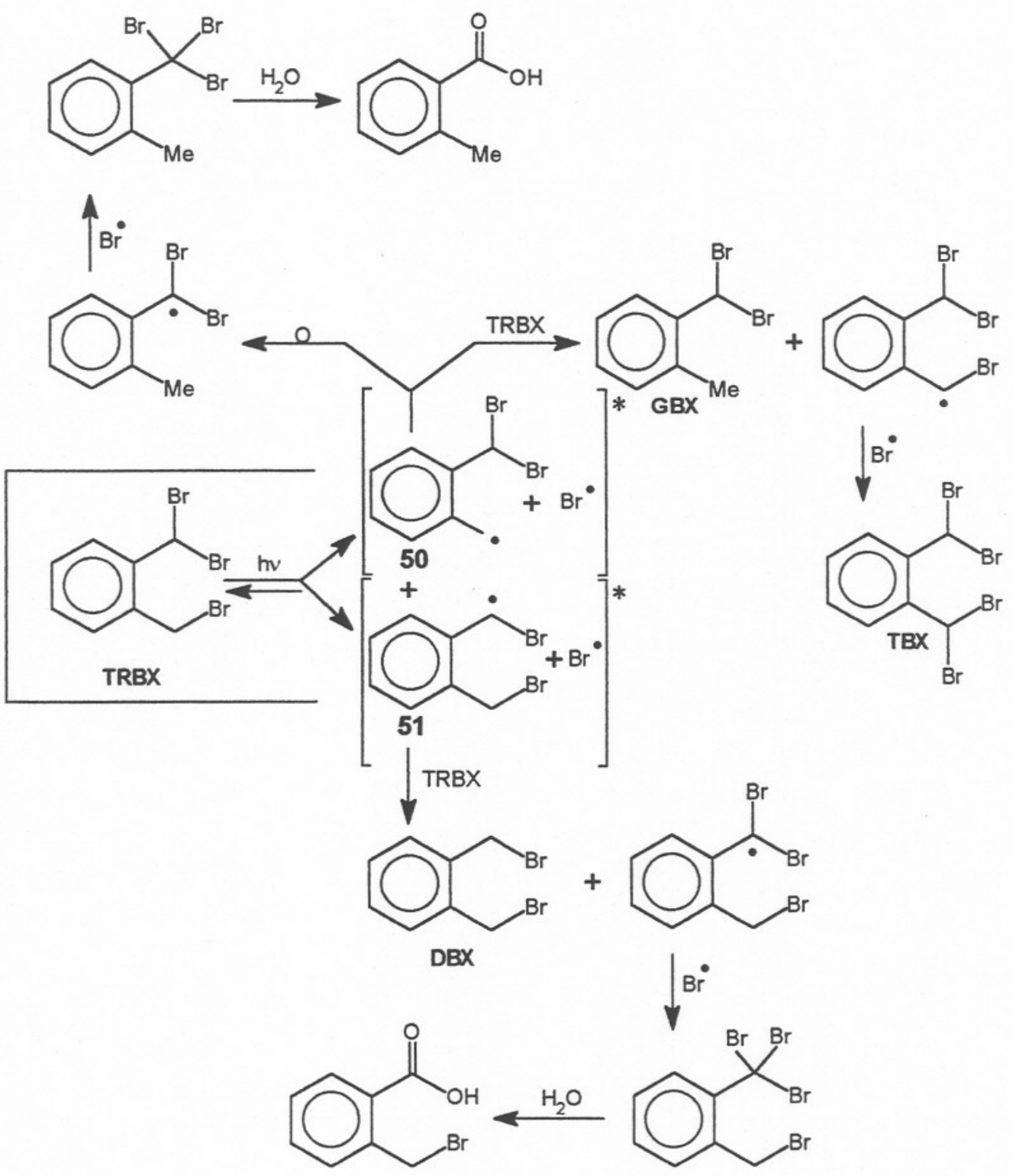

Supúnhamos que esses derivados geminais, TRBX e GBX, não tão impedidos estéricamente quanto TBX (vide Figura IV.1), fossem mais reativos do que os compostos MBX, DBX e TBX, pois a dificuldade para a obtenção de ambos derivados, por via térmica, indica que TRBX (ATKINSON \& THORPE, 1907) e GBX (o qual, aliás, não se encontra descrito na literatura: vide síntese à p. 34) não são os produtos preferenciais de uma bromação direta. Assim, seria de se esperar que estes compostos bromados fossem mais reativos do que MBX, DBX e TBX, por serem termodinamicamente menos estáveis. 

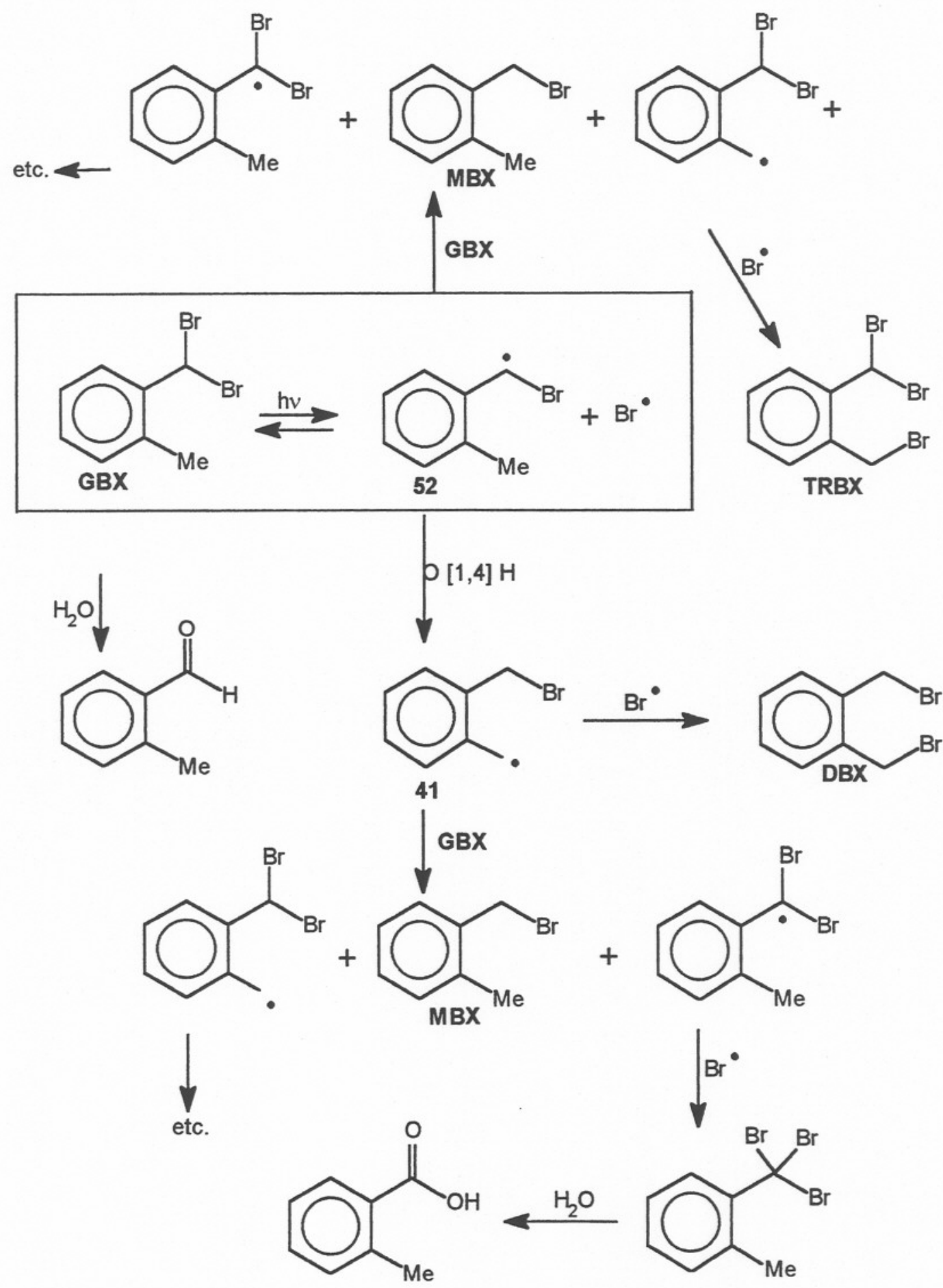

Obtiveram-se, entretanto, resultados surpreendentes, os quais não confirmaram nossa hipótese inicial: o composto TRBX mostrou-se menos susceptível à fotólise, nestas condições, do que MBX e DBX. Pode-se, portanto, presumir que, como no caso do TBX, a recombinação do par radicalar, regenerando o reagente de partida, tenha um papel significativo, também neste caso. Por outro lado, para uma conversão de cerca de $27 \%$, foi obtido um número de fotoprodutos maior do que o observado nos 
casos anteriores. A profusão de produtos observada nesta irradiação deve-se ao fato de se formarem dois diferentes tipos de radicais (50 e 51, vide ESQUEMA IV.4, p. 69), como fotoprodutos primários.

Já o composto dibromado GBX apresenta um comportamento análogo ao de DBX, quando submetido à fotólise em solução benzênica, embora apresente um maior número de reações do que seu isômero (ESQUEMA IV.5, p. 70), porque o radical 52, gerado na etapa fotoquímica primária, tem um substituinte bromo em ipso, o qual o estabiliza, aumentando a probabilidade de ocorrerem encontros bimoleculares; isto não ocorre no caso do radical 41 (p. 65, no ESQUEMA IV.1 e, também, p. 70, no ESQUEMA IV.5), o isômero de $\mathbf{5 2}$ formado quando da fotólise de DBX.

\section{IV.1.2: Em benzeno/ciclo-hexeno}

Foram feitas irradiações de soluções benzênicas dos compostos DBX, MBX e TBX, em presença de ciclo-hexeno $\left(1,97 \mathrm{~mol} . \mathrm{L}^{-1}\right)$, nas condições descritas no item III.6.1 (p.51), com dois objetivos: (i) verificar se o ciclo-hexeno serviria como fonte de radicais hidrogênio, desativando os fotoprodutos radicalares formados na etapa fotoquímica primária (vide ESQUEMAS IV.1 a IV.5); (ii) verificar se haveria formação de um intermediário bi-radicalar do tipo $o$-quinodimetano através de um processo monofotônico onde, à foto-homólise da ligação $\mathrm{C}-\mathrm{Br}$, se seguiria a abstração de um átomo de hidrogênio na posição $\gamma$, pelo mecanismo de Berson, (i. e., abstração interna ao par radicalar: vide HAIDER et alii, 1990 e, também, ESQUEMA I.10, p.24). Este intermediário seria capturado por ciclo-hexeno, que atuaria como um dienófilo, formando-se um aduto de Diels-Alder, como mostrado no ESQUEMA IV.6. Selecionou-se ciclo-hexeno, dentre os dienófilos disponíveis, porque este composto não apresenta absorção apreciável na região de $254 \mathrm{~nm}$, na concentração de trabalho.

\section{ESQUEMA IV.6}

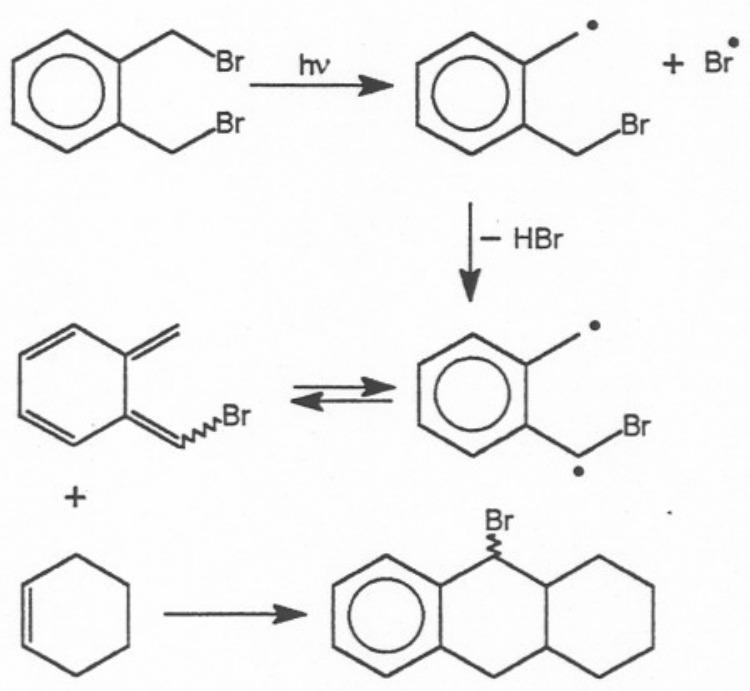


A hipótese de que o dienófilo fosse relativamente inerte é refutável: HAN \& BOUDJOUK (1982) compararam a eficiência de diferentes sequestradores frente ao $o$-quinodimetano gerado a partir de DBX, na presença de zinco em pó, por ação de ultra-som, mostrando que ciclo-hexeno é ativo perante este dieno; ciclo-hexeno foi utilizado, também com sucesso, para a captura de $o$-xilileno gerado fotoquimicamente, a partir de $o$-metil-estireno (HORNBACK \& BARROWS, 1982), tendo sido obtido o aduto de Diels-Alder correspondente (vide ESQUEMA I.1, p.16). Estes resultados mostram que, caso houvesse formação de $o$-quinodimetano durante a fotólise, ciclo-hexeno seria suficiente para seu sequestro.

Entretanto, nas fotólises em benzeno/ciclo-hexeno, identificaram-se, como produtos principais, apenas os compostos apresentados no ESQUEMA IV.7, produtos de reações radicalares, não se formando adutos de Diels-Alder.

\section{ESQUEMA IV.7}
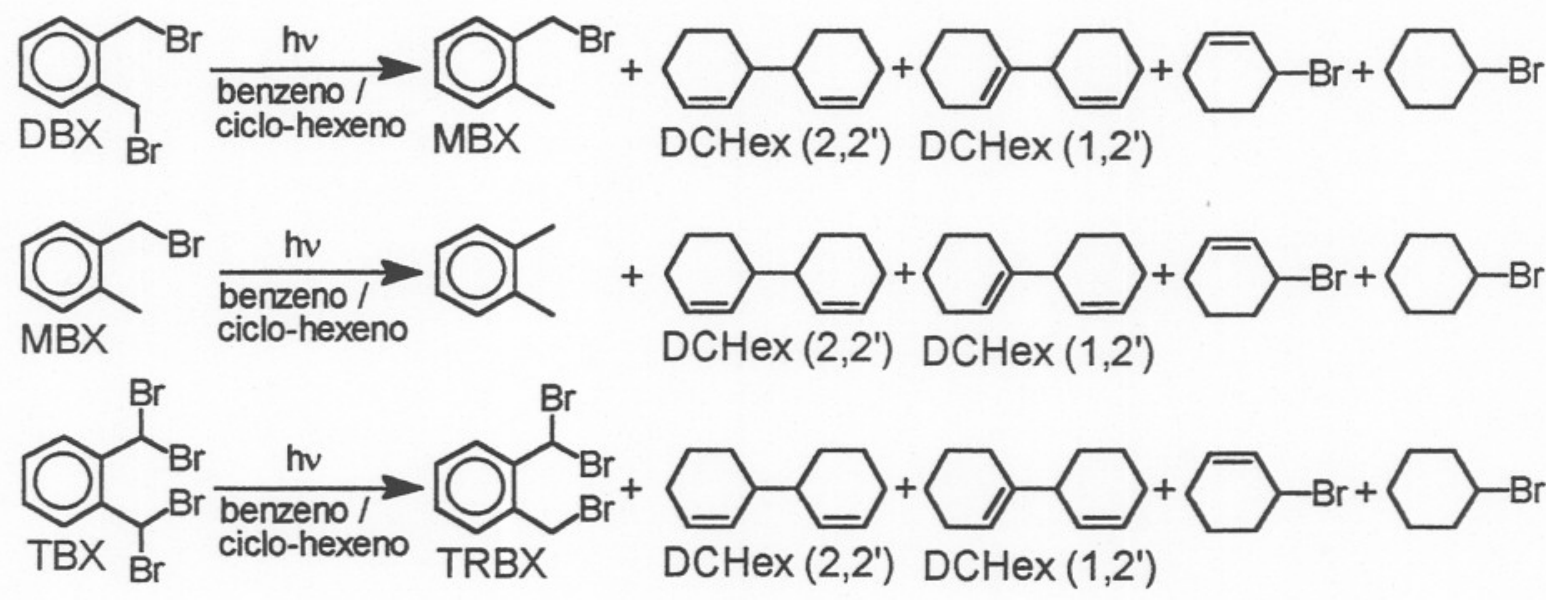

Os resultados obtidos reforçam o mecanismo proposto para as irradiações feitas em ausência de ciclo-hexeno, pois os principais produtos detectados, além dos dímeros de ciclo-hexeno (DCHex), foram os compostos MBX, o-xileno e TRBX, obtidos pela desativação dos radicais $\mathbf{4 1}, 44$ e 49 gerados na etapa fotoquímica primária, para cada um dos substratos irradiados (DBX, MBX e TBX, respectivamente). Assim, evidencia-se que a adição de um doador de hidrogênio melhor do que benzeno e do que o reagente de partida desativa várias das vias para a obtenção de produtos derivados de reações radicalares térmicas em cadeia, antes disponíveis $-\mathrm{D}\left(o-\mathrm{MeC}_{6} \mathrm{H}_{4} \mathrm{CH}_{2}-\mathrm{H}\right)=$ $365 \mathrm{~kJ} \cdot \mathrm{mol}^{-1}$ (HAYASHIBARA et alii, 1986); D (alila-H) $=362 \mathrm{~kJ} \cdot \mathrm{mol}^{-1} ; \mathrm{D}\left(\mathrm{C}_{6} \mathrm{H}_{5}-\mathrm{H}\right)=$ $461 \mathrm{~kJ}^{\mathrm{m}} \mathrm{mol}^{-1}$ (MUROV et alii, 1993). 
A formação dos dímeros de ciclo-hexeno (DCHex) pode ser explicada através das seguintes etapas: o radical ciclo-hexenila (53) formar-se-ia pelo ataque, ao ciclohexeno, quer do radical bromo, quer dos radicais 41, 44 ou 49 (ESQUEMAS IV.1, IV.2 e IV.3, respectivamente, às páginas 65, 66 e 67); o radical 53, ao interagir com o ciclo-hexeno, forma o radical 54, o qual, após perder $\mathrm{H}^{*}$ gera os dímeros $\operatorname{DCHex}\left(\mathbf{2}, \mathbf{2}^{\prime}\right)$ e DCHex(1,2'), como sumarizado no ESQUEMA IV.8, a seguir.

\section{ESQUEMA IV.8}
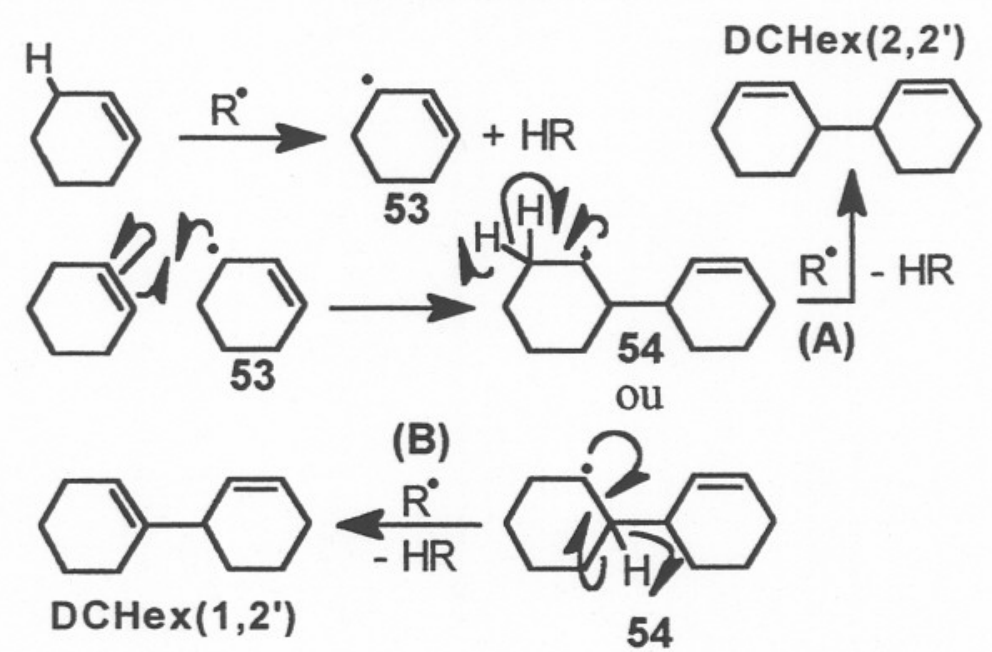

onde: $\mathrm{R}^{\circ}=41,42,43$ ou $\mathrm{Br}^{\circ}$

Embora, por via sintética não tenha sido possivel obterem-se os dímeros $\operatorname{DCHex}\left(1,2^{\prime}\right)$ e DCHex (2,2'), sua caracterização é convincente, devendo-se à série de argumentos que será exposta a seguir. Assim, para a caracterização dos dímeros DCHex, obtidos na fotólise, compararam-se:

(i) as proporções relativas entre os respectivos picos isotópicos ( $\mathrm{M}+1$ e $\mathrm{M}+2)$ e os picos moleculares (M), normalizados a $100 \%$; as intensidades relativas obtidas experimentalmente, quando comparadas aos valores teóricos para $\mathrm{C}_{12} \mathrm{H}_{18}$, são consistentes com a hipótese de serem estes três compostos dímeros de ciclo-hexeno, como mostram os dados obtidos dos respectivos espectrogramas de massas, os quais se encontram sumarizados na Tabela IV.1.

Tabela IV.1: Intensidades isotópicas relativas ao pico molecular.

\begin{tabular}{|c|c|c|c|c|c|c|c|c|c|c|c|}
\hline \multicolumn{3}{|c|}{ Térico } & \multicolumn{3}{|c|}{ DCHex $\left(1,1^{\prime}\right)^{a}$} & \multicolumn{3}{|c|}{ DCHex $\left(1,2^{\prime}\right)^{b}$} & \multicolumn{3}{|c|}{$\mathrm{DCHex}\left(2,2^{\prime}\right) \mathrm{C}$} \\
\hline Pico & $\overline{\mathrm{m} / \mathrm{z}}$ & $\begin{array}{l}\text { Irel }^{\mathbf{d}} \\
(\%)\end{array}$ & Pico & $\overline{\mathrm{m} / \mathrm{z}}$ & $\begin{array}{l}I_{\text {rel }}{ }^{\mathbf{d}} \\
(\%)\end{array}$ & Pico & $\overline{\mathrm{m} / \mathrm{z}}$ & $\begin{array}{l}\text { Irel }^{\mathbf{d}} \\
(\%)\end{array}$ & Pico & $\overline{m / z}$ & $\begin{array}{l}\text { Irel }^{\text {d }} \\
(\%)\end{array}$ \\
\hline $\mathrm{M}^{+}$ & 162 & 100,00 & $\mathrm{M}^{+}$ & 162 & 100,00 & $\mathrm{M}^{+}$ & 162 & 100,0 & $\mathrm{MH}^{+}$ & 163 & 100,0 \\
\hline$(M+1)^{ \pm}$ & 163 & 13,71 & $(M+1)^{+}$ & 163 & 13,46 & $(M+1)^{+}$ & 163 & 12,8 & $(\mathrm{M}+1) \mathrm{H}^{+}$ & 164 & 15,7 \\
\hline$(M+2)^{+}$ & 164 & 0,87 & $(M+2) !$ & 164 & 0,89 & $(M+2)^{ \pm}$ & 164 & 2,0 & & & \\
\hline
\end{tabular}

a- obtido no espectrômetro quadrupolar Finnigan MAT INCOS 50;

b- obtido no espectrômetro quadrupolar Hewlett Packard 5988A;

c- obtido no espectrômetro de captura de íons Finnigan MAT ITD 800;

d- intensidades relativas ao pico molecular, normalizado a $100 \%$. 
(ii) seus tempos de retenção cromatográficos (relativos a $\mathrm{C}_{16} \mathrm{H}_{34}$, padrão-interno) com o determinado para o isômero sintético $\operatorname{DCHex}\left(1,1^{\prime}\right)$ - vide síntese à página 37; a diferença de magnitude existente entre os tempos de retenção observados (vide Tabela IV.2, p.80) para os três compostos que se supunham ser isômeros está na faixa esperada: $9 \%$, tomando-se o dímero de th maior como referência, enquanto para $o$ - e $m$-xileno, por exemplo, esta diferença é de $17 \%$, nas mesmas condições cromatográficas.

(iii) o padrão de fragmentação observado nos espectrogramas de massas com o apresentado pelo isômero sintético adotado como referência para a identificação; o espectro de massas deste composto de referência - DCHex(1,1') - encontra-se à página 47 e o esquema proposto para as fragmentações que conduzem a seus picos mais significativos (ESQUEMA III.6) está apresentado à página 48, enquanto o do DCHex(1,2'), o dímero mais abundante obtido nas fotólises, está sumarizado no ESQUEMA IV.9 à página 75; o espectro de massas deste fotoproduto encontra-se na Figura IV.2, abaixo.

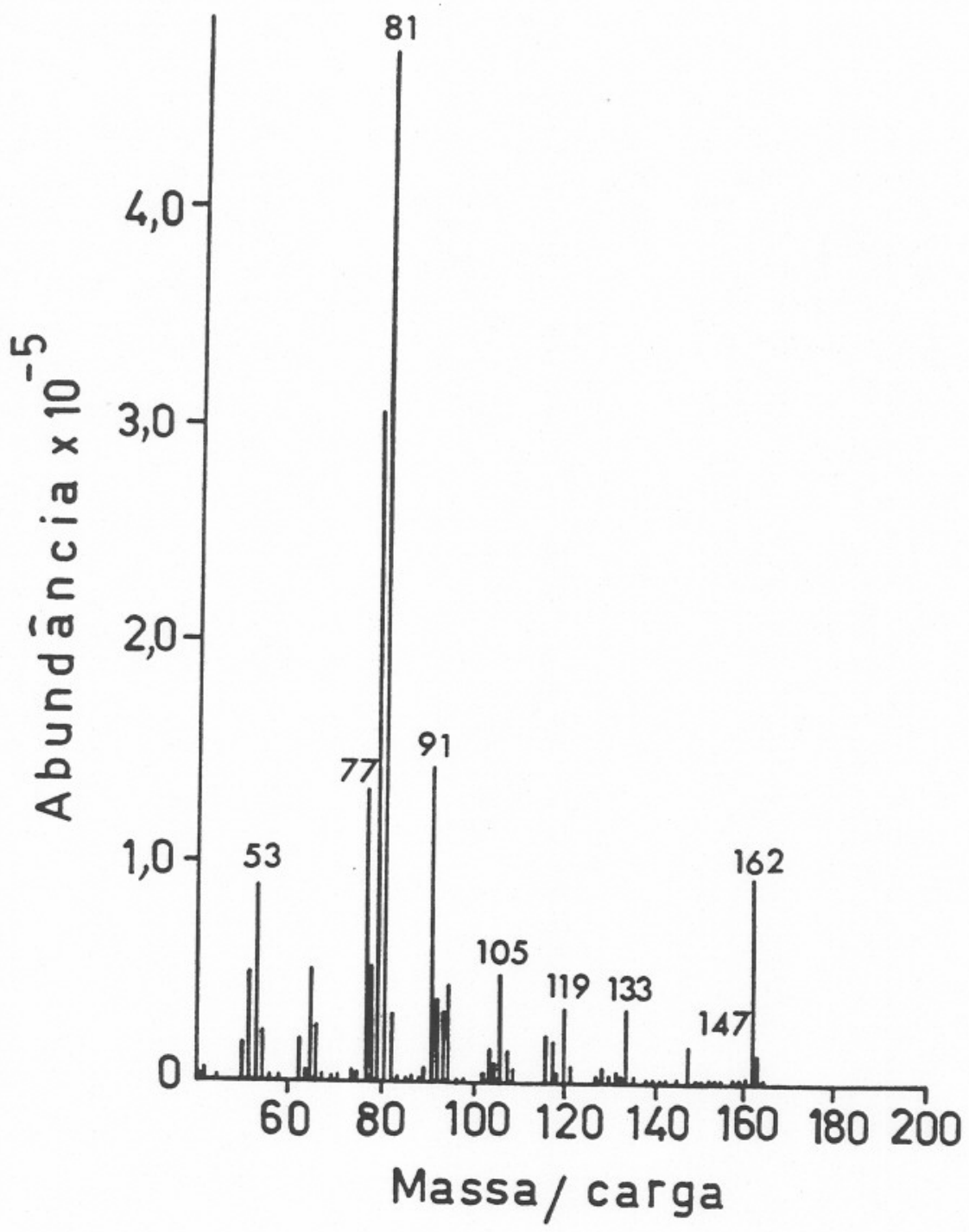

Figura IV.2 - Espectro de massas para DCHex(1,2'), obtido no espectrômetro quadrupolar Hewlett Packard 5988A. 
ESQUEMA IV.9 - Proposta de fragmentação para interpretação do espectro de massas de DCHex(1,2').

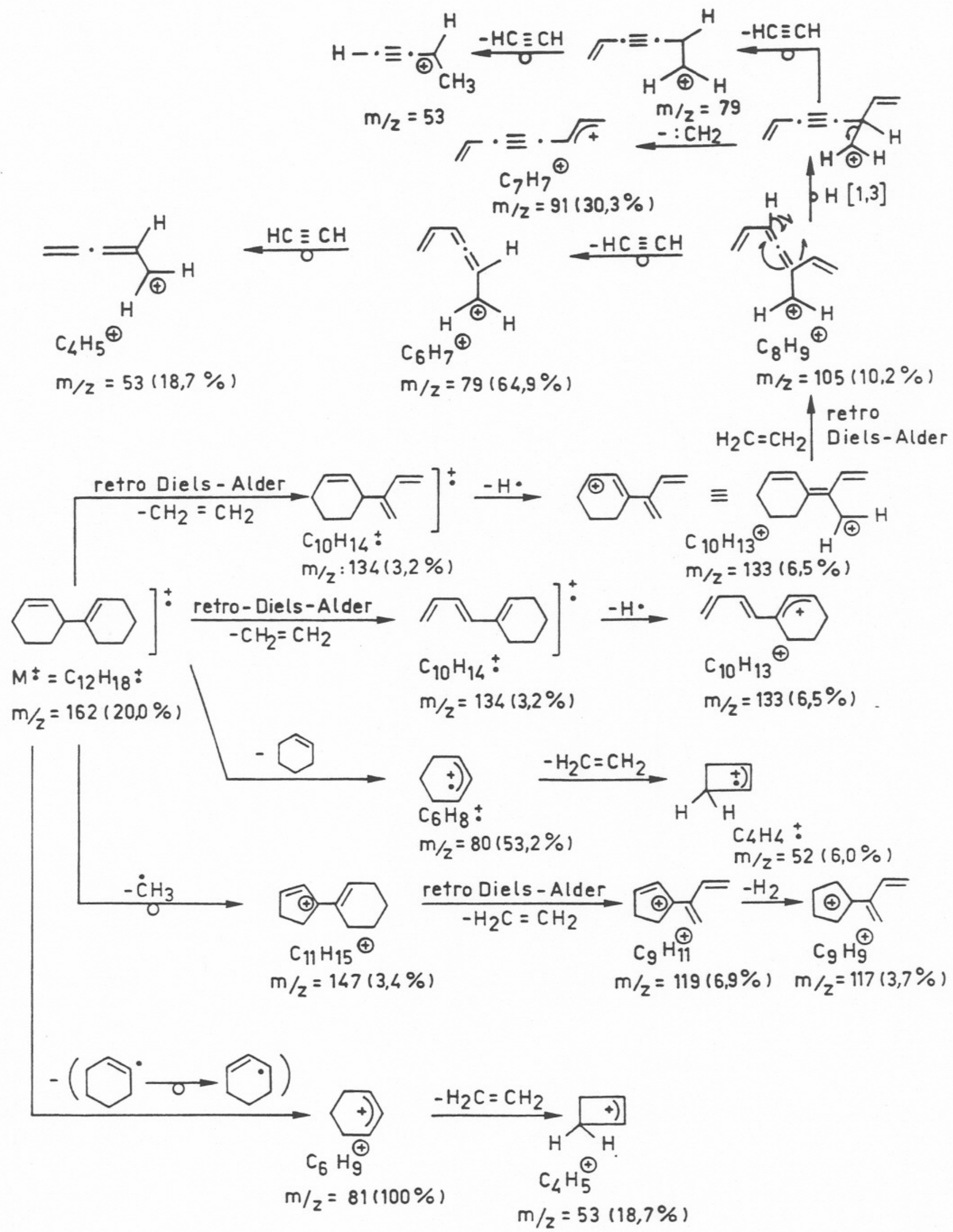


Embora existam algumas diferenças menores entre as relações de intensidades dos picos de massa observados nos espectros de massas destes três compostos, estas são facilmente explicáveis. De fato, os experimentos foram feitos em épocas diferentes e em diversos aparelhos. Existe, entretanto, uma diferença marcante observável nos espectrogramas de massas destes dímeros: no caso do dímero de ciclo-hexeno obtido por síntese, DCHex(1,1'), o pico-base do espectrograma é o pico molecular $(\mathrm{m} / \mathrm{z}=162)$, enquanto os outros dois dímeros têm, como pico-base, o de massa 81. Existe uma diferença estrutural significativa entre estes isômeros que, sendo a responsável por essa característica dos espectrogramas, permite diferenciá-los. 0 dímero sintético é um dieno conjugado, enquanto os obtidos por fotólise, $\operatorname{DCHex}\left(1,2^{\prime}\right)$ e $\operatorname{DCHex}\left(2,2^{\prime}\right)$, não o são. O dímero conjugado se rompe menos facilmente, necessitando de uma série de reações para formar o cátion alílico $(\mathrm{m} / \mathrm{z}=81)$; neste caso, o pico-base é o pico molecu$\operatorname{lar}(\mathrm{m} / \mathrm{z}=162)$. Já no caso dos fotoprodutos, o pico de massa 81 é o pico-base, sendo gerado diretamente a partir da cisão da ligação $\mathrm{C}-\mathrm{C}$ entre os dois anéis, além de também serem possíveis processos de fragmentação equivalentes aos acessíveis ao isômero $\left(1,1^{\prime}\right)$. Como, para os produtos de fotólise, o pico-base dos espectros de massas têm $\mathrm{m} / \mathrm{z}=81$, foi eliminada a hipótese de que um dos isômeros obtidos fosse um dímero com uma ligação dupla entre os anéis, pois, também neste caso, o pico 81 deveria ser pouco intenso, por razões análogas àquelas explicitadas no caso de DCHex $\left(1,1^{\prime}\right)$.

Tanto esta diferença marcante entre os padrões de fragmentação, como a verificada nos tempos de retenção cromatográficos, mostram que o isômero obtido por via sintética é diferente daqueles gerados por via fotoquímica. Por outro lado, o fato de vários dos outros fragmentos observados nos espectrogramas coincidirem, além de apresentarem intensidades relativas similares, fortalece a suposição de que os três compostos sejam dímeros isoméricos do ciclo-hexeno.

A hipótese de que o DCHex(1,2') seja o dímero mais abundante, dentre os dois obtidos nas fotólises em presença de ciclo-hexeno, está fundamentada em alguns argumentos clássicos: (i) a etapa de abstração de um átomo de hidrogênio do radical 54 (vide ESQUEMA IV.8, p.73) poder-se-ia dar, ou em um carbono secundário, ou em um carbono terciário (caminhos A ou B, ESQUEMA IV.8); (ii) para facilitar a discussão podem-se admitir, como modelos aproximados, as energias de ligação $\mathrm{C}-\mathrm{H}$ para ciclo-hexano, iso-butano e propano [ $\mathrm{D}\left(\right.$ ciclo- $\left.\mathrm{C}_{6} \mathrm{H}_{11}-\mathrm{H}\right)=400 \mathrm{~kJ} \cdot \mathrm{mol}^{-1}, \mathrm{D}(t$-butil$\mathrm{H})=385 \mathrm{~kJ} \cdot \mathrm{mol}^{-1}$ e D (iso-propil-H) $=398 \mathrm{~kJ} \cdot \mathrm{mol}^{-1}$ (MUROV et alii, 1993)]: analisandose estas energias de ligação, conclui-se que a abstração de um átomo de hidrogênio terciário é favorecida, em cerca de $13 \mathrm{~kJ} \cdot \mathrm{mol}^{-1}$ (ou $3,1 \mathrm{kcal} . \mathrm{mol}^{-1}$ ), em relação à abstração de um atomo secundário; (iii) essa diferença de energia é de uma ordem de grandeza suficiente para que haja seletividade no processo de abstração, favorecendo a retirada do hidrogênio do carbono terciário (BENSON, 1976). 
Pode-se estimąr facilmente a predominância deste processo no equilíbrio reacional, pelas seguintes razões termodinâmicas:

A distribuição estatísticamente mais provável em um sistema é aquela de equilíbrio. Considerando-se que a probabilidade termodinâmica de as moléculas atingirem uma certa distribuição seja expressa por $\mathrm{W}$, número de configurações possíveis, distingüiveis entre si, que a espécie possa apresentar, tem-se a relação de Boltzmann entre entropia (S) e probabilidade:

$$
\mathrm{S}=\mathrm{k} \cdot \ln \mathrm{W}
$$

onde $\mathrm{k}=(\mathrm{R} / \mathrm{N})$ é a constante de Boltzmann, sendo $\mathrm{R}$ a constante dos gases ideais e $\mathrm{N}$ o número de Avogadro.

Pode-se, portanto, expressar a energia livre $(\Delta \mathrm{G})$, envolvida em um dado processo, pela expressão:

$$
\Delta \mathrm{G}=\Delta \mathrm{H}-\mathrm{RT} \cdot \ln \mathrm{W}
$$

sendo $\Delta \mathrm{H}$ a variação de entalpia do sistema e, $\mathrm{T}$, a temperatura em Kelvin.

Admitindo-se que, para o caminho $\mathbf{A}, \mathrm{W}=2$ e, para o caminho $\mathbf{B}, \mathrm{W}=1$, devido ao número de hidrogênios disponíveis em cada uma dessas vias (vide ESQUEMA IV.8, p.73), tem-se que:

$$
\Delta(\Delta \mathrm{G})=\Delta(\Delta \mathrm{H})-\mathrm{RT} \cdot \ln 2
$$

Substituindo-se adequadamente as variáveis, obtém-se o valor para a diferença entre os $\Delta \mathrm{Gs}$, para os dois caminhos competitivos:

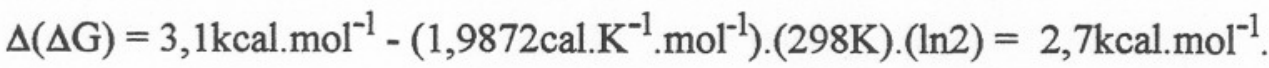

$$
\begin{aligned}
& \text { E, como } \\
& \exp \left(-\frac{\Delta \mathrm{G}}{\mathrm{RT}}\right)=\mathrm{K}=\frac{[\mathrm{B}]}{[\mathrm{A}]},
\end{aligned}
$$

obtém-se, para a constante de equilibrio $\mathrm{K}$, o seguinte valor:

$$
\exp \left(\frac{2,7 \cdot 10^{3} \mathrm{cal} \cdot \mathrm{mol}^{-1}}{1,9872 \cdot 298 \mathrm{cal} \cdot \mathrm{K}^{-1} \cdot \mathrm{mol}^{-1} \cdot \mathrm{K}}\right)=\mathrm{K}=\frac{[\mathrm{B}]}{[\mathrm{A}]}=1,1 \cdot 10^{-2}
$$

Assim, conclui-se que, se

$$
\mathrm{x}_{\mathrm{B}}=\frac{[\mathrm{B}]}{[\mathrm{A}]+[\mathrm{B}]}
$$

expressa a fração molar da espécie B no equilíbrio, e admitindo-se que [A] $>[B]$, então:

$$
\mathrm{x}_{\mathrm{B}} \approx \mathrm{Ke} \mathrm{x}_{\mathrm{A}} \approx(1-\mathrm{K}),
$$

isto é, ao final da reação dever-se-iam ter formado cerca de $1 \%$ do isômero DCHex (2,2') e $99 \%$ do DCHex (1,2'). 
Os dados quantitativos extraídos dos cromatogramas obtidos durante as fotólises são coerentes com esta análise, tendo-se determinado uma proporção experimental média de $97,4 \%$ para o isomero mais abundante de DCHex, nas fotólises de MBX $(96,7 \%)$ e DBX $(98,1 \%)$ em benzeno/ciclo-hexeno. Assim sendo, consideramos que o isômero mais abundante seja DCHex(1,2'), ao comparar os valores experimentais acima aos calculados por argumentos termodinâmicos.

\section{IV.1.3: Em iso-octano}

Foram irradiadas soluções de MBX e DBX, em iso-octano, para: (i) avaliar a eficiência com que ocorre a transferência de energia de excitação entre benzeno e os substratos, pela comparação das velocidades relativas de reação nestes dois solventes; (ii) obterem-se dados sobre a fotoquímica em iso-octano, que fornecessem subsídios para os estudos cinéticos de fotólise por pulso de laser, feitos em iso-octano porque, no comprimento de onda disponivel para a excitação do substrato $(\lambda=266 \mathrm{~nm})$, não se podem utilizar soluções benzênicas. Selecionou-se iso-octano para estes estudos comparativos por ser este um solvente similar a benzeno, quando se comparam os valores de suas constantes dielétricas $\left(\varepsilon=1,940\right.$ e 2,284 , a $20^{\circ} \mathrm{C}$, para iso-octano e para benzeno, respectivamente; CRC, 1973) e de suas viscosidades [a $20^{\circ} \mathrm{C}: 0,652 \mathrm{cP}$, para benzeno, CRC (1973); 0,507cP, para iso-octano, BEILSTEIN (EIV1, 439)], além de ser transparente na região de trabalho.

Irradiando-se a solução iso-octânica de $\mathbf{M B X}$ durante $4,3 \mathrm{~h}$ obtiveram-se os fotoprodutos apresentados no ESQUEMA IV.10, para uma conversão de $13 \%$ do substrato. O comportamento de DBX, quando irradiado em iso-octano, é semelhante, tendo-se identificado os fotoprodutos apresentados no ESQUEMA IV.11, à página 79 .

\section{ESQUEMA IV.10}

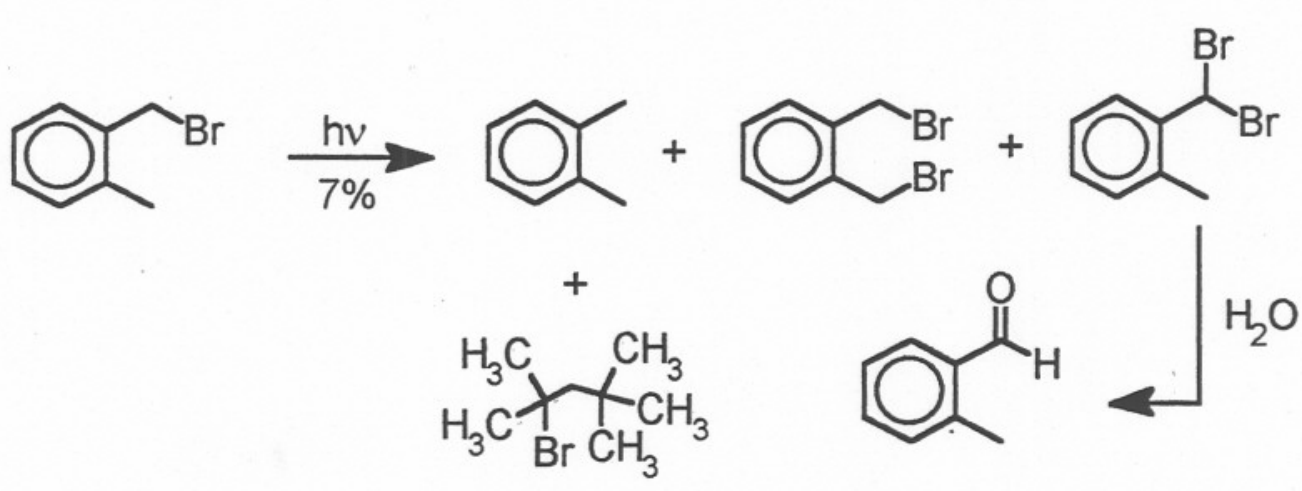




\section{ESQUEMA IV.11}

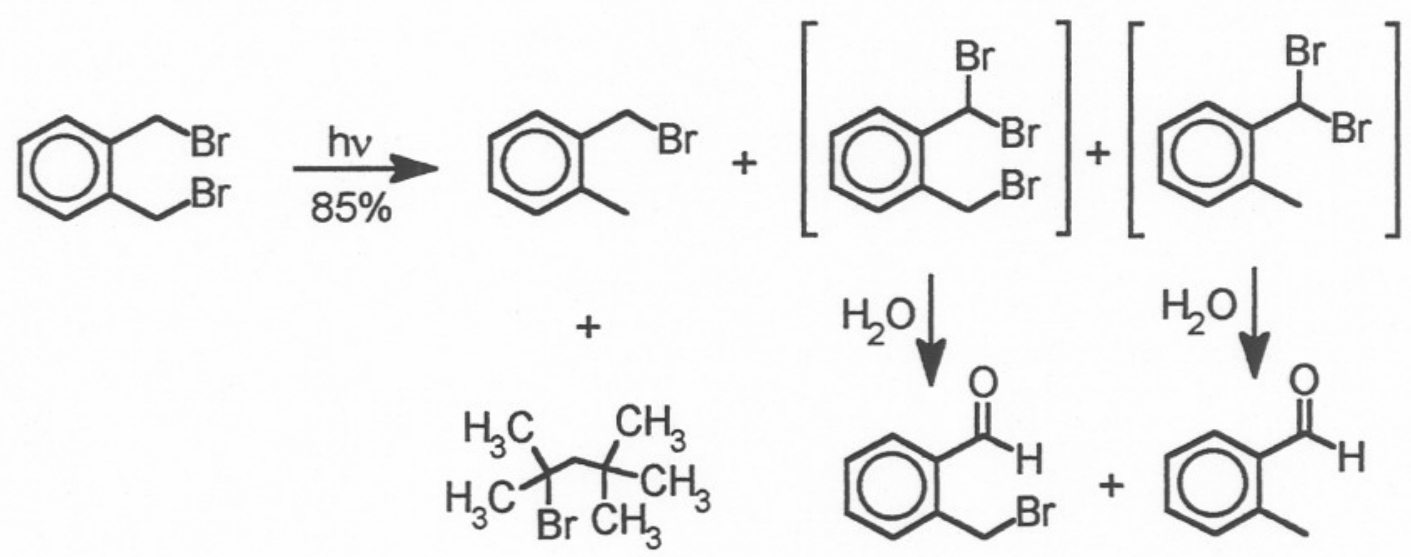

Estes resultados mostram que a fotoquímica em iso-octano e em benzeno não apresenta diferenças relevantes, a não ser quanto à reatividade: no caso de $\mathbf{M B X}$, para um tempo de irradiação aproximadamente igual $(4,3 \mathrm{~h}$, em iso-octano; $4,8 \mathrm{~h}$, em benzeno) as conversões foram de $13 \%$ e $18 \%$, respectivamente (vide Figuras IV.3, à p. 83 e IV.10, à p.87), o que indica que a reatividade em benzeno é cerca de uma vez e meia maior do que a verificada em iso-octano; para DBX, novamente, a fotoquímica observada é bastante semelhante àquela que se verifica em benzeno, sendo que, neste caso, não se identificaram os fotoprodutos GBX e TRBX, mas somente seus produtos de hidrólise (vide ESQUEMA IV.10, p.78). Quanto à reatividade, em comparação a benzeno, para uma irradiação de 3,3h, a conversão de DBX, em iso-octano, foi de $90 \%$, enquanto em benzeno, após $5,3 \mathrm{~h}$ de irradiação, a conversão foi de $41 \%$. Considerando-se que a concentração inicial de DBX na irradiação em iso-octano era de $1,6.10^{-2}$ mol. $\mathrm{L}^{-1}$ (por limite de solubilidade) e, em benzeno, era 5,4 vezes maior $\left(8,7.10^{-2}\right.$ mol.L $\left.{ }^{-1}\right)$, pode-se admitir que a conversão de DBX em iso-octano foi favorecida porque o fator limitante nestas reações unimoleculares é a luz. Desta forma, tratando-se o sistema como se de pseudo-ordem zero, poder-se-ia estimar uma conversão de aproximadamente $27 \%$ em iso-octano, para $41 \%$ em benzeno, por normalização das concentrações e dos tempos de irradiação, a partir das correlações lineares apresentadas nas Figuras IV.4 (p. 84) e IV.11 (p. 87); estes dados confirmam o observado para a irradiação de MBX, isto é, a irradiação em benzeno é cerca de uma vez e meia mais eficiente do que em iso-octano. 


\section{IV.2. Quantificação dos Principais Produtos Obtidos nas Fotólises Convencionais}

Foi feita a quantificação dos produtos para todas as fotólises utilizando-se cromatografia líqüido-gás, como descrito anteriormente (vide item III.6.2, p.52). Na Tabela IV.2 encontram-se sumarizados os fatores de resposta determinados para os diferentes compostos em estudo, em relação a $n$-hexadecano (padrão-interno). Utilizando-se estes fatores de resposta, quantificaram-se os fotoprodutos de interesse e determinou-se a conversão do composto de partida, para cada uma das irradiações.

Para as irradiações em benzeno obtiveram-se os dados apresentados nas Tabelas IV.3 a IV.7, nas quais constam todos os produtos identificados, tendo sido considerados apenas os tempos inicial e final de cada uma das irradiações. Por outro lado, as curvas de concentração em função do tempo para o desaparecimento de substrato e para o aparecimento dos fotoprodutos principais das fotólises de MBX, DBX, GBX, TRBX e TBX, encontram-se, respectivamente, nas Figuras IV.3 a IV.7. De maneira geral, as retas obtidas apresentaram boas correlações lineares, como indicado em cada uma das figuras.

Para as fotólises feitas em benzeno/ciclo-hexeno e em iso-octano, os perfis cinéticos das irradiações estão apresentados nas Figuras IV.8 e IV.9 (p. 86) e nas Figuras IV.10 e IV.11 (p. 87), respectivamente.

Tabela IV.2: Tempos de Retenção e Respostas ${ }^{\mathrm{a}}$, relativos a $\mathrm{C}_{16} \mathrm{H}_{34}$

\begin{tabular}{|c|c|c|c|}
\hline $\begin{array}{c}\text { Tempo de Retenção } \\
\text { (tr) }\end{array}$ & COMPOSTO & $\begin{array}{c}\text { Respostas Relativas } \\
\text { (para FID) }\end{array}$ & $\begin{array}{c}\text { Respostas Teóricas } \\
(\mathrm{nC} / 16)\end{array}$ \\
\hline $\begin{array}{l}2,55 \\
3,02 \\
4,53\end{array}$ & $\begin{array}{l}m \text {-xileno } \\
\text { o-xileno } \\
t-\mathrm{C}_{8} \mathrm{H}_{17} \mathrm{Br}\end{array}$ & $\begin{array}{l}0,552 \\
0,549 \\
0,493\end{array}$ & $\begin{array}{l}0.500 \\
0.500 \\
0.500\end{array}$ \\
\hline $\begin{array}{l}5,33 \\
5,93\end{array}$ & $\begin{array}{l}\text { o-tolualdeído } \\
\mathrm{C}_{6} \mathrm{H}_{5} \mathrm{CH}_{2} \mathrm{Br}\end{array}$ & $\begin{array}{l}0,442 \\
0,432\end{array}$ & $\begin{array}{l}0.500 \\
0.438\end{array}$ \\
\hline 6,97 & $p-\mathrm{Me}-\mathrm{C}_{6} \mathrm{H}_{4} \mathrm{CH}_{2} \mathrm{Br}$ & $(0,542) b$ & 0.500 \\
\hline $\begin{array}{l}7,05 \\
7,59\end{array}$ & $\begin{array}{l}\mathrm{MBX} \\
\mathrm{o}-\mathrm{ClCH}_{2} \mathrm{C}_{6} \mathrm{H}_{4} \mathrm{CH}_{2} \mathrm{Br}\end{array}$ & $\begin{array}{l}0,542 \\
(0,542) \text { b }\end{array}$ & $\begin{array}{l}0.500 \\
0.500\end{array}$ \\
\hline $\begin{array}{l}7,77 \\
7,82\end{array}$ & $\begin{array}{l}\text { DCHex }\left(2,2^{\prime}\right) \\
\text { DCHex }\left(1,1^{\prime}\right)\end{array}$ & $\begin{array}{l}0,785 \\
0,785\end{array}$ & $\begin{array}{l}0.750 \\
0.750\end{array}$ \\
\hline 7,92 & ácido o-tolúico & 0,334 & 0.500 \\
\hline 8,38 & $\alpha$-bromo-o-tolualdeído & $(0,435)$ b & 0.500 \\
\hline 8,54 & $\mathrm{DCHex}\left(1,2^{\prime}\right)$ & 0,785 & 0.750 \\
\hline 8,60 & GBX & 0,500 & 0.500 \\
\hline 9,00 & Ácido $\alpha$-bromo-o-tolúico & $(0,327)$ b & 0.500 \\
\hline 9,07 & DBX & 0,542 & 0.500 \\
\hline 9,48 & $0-\mathrm{Me}-\mathrm{C}_{6} \mathrm{H}_{4} \mathrm{CBr}_{3}$ & $(0,402)$ b & 0.500 \\
\hline 9,69 & $\mathrm{C}_{16} \mathrm{H}_{34}$ & 1,000 . & 1,000 \\
\hline $\begin{array}{r}9,94 \\
102,24\end{array}$ & $\alpha, \alpha$-dibromo-o-tolualdeído & $(0,428) b$ & 0.500 \\
\hline $\begin{array}{l}10,24 \\
10,85\end{array}$ & $\begin{array}{l}\text { TRBX } \\
\mathrm{RR}>\mathrm{Rr}\end{array}$ & 0,402 & 0.500 \\
\hline 11,36 & $\begin{array}{l}\text { BBzBr } \\
\text { TBX }\end{array}$ & $\begin{array}{l}0,795 \\
0,453\end{array}$ & $\begin{array}{l}0.875 \\
0.500\end{array}$ \\
\hline
\end{tabular}

a. FID, detector de ionização de chama; b. valores estimados. 
Tabela IV.3: Irradiação de $\alpha$-bromo-o-xileno (MBX),em benzeno ${ }^{a}$.

\begin{tabular}{|c|c|c|c|c|c|c|}
\hline \multirow[b]{2}{*}{ Compostos } & \multicolumn{2}{|c|}{$\begin{array}{c}\text { Antes } \\
\text { da irradiação } \\
\end{array}$} & \multicolumn{2}{|c|}{$\begin{array}{l}\text { Depois da } \\
\text { irradiaçãa }{ }^{b}\end{array}$} & \multicolumn{2}{|c|}{$\begin{array}{c}\text { Variação do } \\
\text { no de mols }\end{array}$} \\
\hline & $\begin{array}{c}t_{R} \\
(\mathrm{~min})\end{array}$ & $\begin{array}{c}\text { Conc.molar } \\
\left(\mathrm{mol} . \mathrm{L}^{-1}\right)\end{array}$ & $\begin{array}{c}t_{R} \\
(\min )\end{array}$ & $\begin{array}{l}\text { Conc.molar } \\
\left(\mathrm{mol} . \mathrm{L}^{-1}\right)\end{array}$ & $\begin{array}{c}\text { Conc.molarc } \\
\left(\mathrm{mol} . \mathrm{L}^{-1}\right)\end{array}$ & $\% \mathrm{e}$ \\
\hline o-xileno & 3,28 & $5,8 \cdot 10^{-5}$ & 3,28 & $8,4.10^{-3}$ & $8,3.10^{-3}$ & 37,2 \\
\hline o-tolualdeído & -- & -- & 5,72 & $3,5.10^{-3}$ & $3,5.10^{-3}$ & 15,7 \\
\hline$p-\mathrm{Me}-\mathrm{C}_{6} \mathrm{H}_{4} \mathrm{CH}_{2} \mathrm{Br}$ & 6,96 & $7,5.10^{-4}$ & 6,97 & $4,1 \cdot 10^{-4}$ & $(-) 3,4.10^{-4 d}$ & $45,3^{f}$ \\
\hline MBX & 7,13 & $1,2.10^{-1}$ & 7,14 & $9,8.10^{-2}$ & $(-) 2,2.10^{-2 d}$ & $18,3^{f}$ \\
\hline$\alpha$-bromo-o-tolualdeído & - & - & 8,38 & $2,1.10^{-3}$ & $2,1.10^{-3}$ & 9,4 \\
\hline GBX & 8,62 & $6,1 \cdot 10^{-4}$ & 8,62 & $1,7.10^{-3}$ & $1,1.10^{-3}$ & 4,9 \\
\hline DBX & 9,07 & $6,8 \cdot 10^{-4}$ & 9,08 & $3,1.10^{-3}$ & $2,4.10^{-3}$ & 10,8 \\
\hline $\mathrm{C}_{16} \mathrm{H}_{34}$ & 9,69 & $6,8 \cdot 10^{-3}$ & 9,69 & $6,8.10^{-3}$ & \multicolumn{2}{|c|}{ padrão-interno } \\
\hline
\end{tabular}

a. conversão $=18,3 \%$

b. $\lambda_{\text {irr }}=254 \mathrm{~nm} ; t_{\text {irr }}=4,77 \mathrm{~h}$ (286 minutos)

c. total de mols de fotoprodutos : $1,74.10^{-2}$ mol. $\mathrm{L}^{-1}$, correspondendo a $78 \%$ da quantidade de substrato convertida.

d. quantidade de mols do substrato convertidos em fotoprodutos: $2,23 \cdot 10^{-2} \mathrm{~mol} \cdot \mathrm{L}^{-1}$.

e. $\%$, em relação à quantidade total de mols convertida.

f. $\%$ do substrato convertida em fotoprodutos.

Tabela IV.4: Irradiação de $\alpha, \alpha^{\prime}$-dibromo-o-xileno (DBX), em benzeno ${ }^{a}$.

\begin{tabular}{|c|c|c|c|c|c|c|}
\hline \multirow[b]{2}{*}{ Compostos } & \multicolumn{2}{|c|}{$\begin{array}{c}\text { Antes da } \\
\text { irradiação }\end{array}$} & \multicolumn{2}{|c|}{ Depois da irradiaçãob } & \multicolumn{2}{|c|}{$\begin{array}{l}\text { Variação do } \\
\text { no de mols }\end{array}$} \\
\hline & $\begin{array}{c}t_{R} \\
(\mathrm{~min})\end{array}$ & $\begin{array}{c}\text { Conc.molar } \\
\left(\mathrm{mol}^{-1} \mathrm{~L}^{-1}\right)\end{array}$ & $\begin{array}{c}t_{R} \\
(\mathrm{~min})\end{array}$ & $\begin{array}{c}\text { Conc.molar } \\
\left(\mathrm{mol} . \mathrm{L}^{-1}\right)\end{array}$ & $\begin{array}{c}\text { Conc.molarc } \\
\left(\mathrm{mol}^{-1} \mathrm{~L}^{-1}\right)\end{array}$ & $\% e$ \\
\hline $\mathrm{C}_{6} \mathrm{H}_{5} \mathrm{CH}_{2} \mathrm{Br}$ & - & --- & 6,08 & $4,0.10^{-4}$ & $4,0.10^{-4}$ & 1,1 \\
\hline MBX & - & -- & 7,13 & $6,1.10^{-3}$ & $6,1 \cdot 10^{-3}$ & 16,9 \\
\hline $\mathrm{o}-\mathrm{ClCH}_{2} \mathrm{C}_{6} \mathrm{H}_{4} \mathrm{CH}_{2} \mathrm{Br}$ & 7,59 & $1,7.10^{-5}$ & -- & $\cdots$ & $(-) 1,7.10^{-5 d}$ & $100,0 f$ \\
\hline GBX & -- & - & 8,67 & $1,2.10^{-3}$ & $1,2.10^{-3}$ & 3,3 \\
\hline DBX & 9,13 & $8,7.10^{-2}$ & 9,11 & $5,1.10^{-2}$ & $(-) 3,6 \cdot 10^{-2 d}$ & $41,4^{f}$ \\
\hline $\mathrm{C}_{16} \mathrm{H}_{34}$ & 9,69 & $5,0.10^{-2}$ & 9,69 & $5,0.10^{-2}$ & \multicolumn{2}{|c|}{ padrāo-interno } \\
\hline TRBX & --- & -- & 10,21 & $7,4.10^{-3}$ & $7,4.10^{-3}$ & 20,6 \\
\hline $\mathrm{BBzBr}$ & $\cdots$ & - & 10,72 & $2,1.10^{-3}$ & $2,1.10^{-3}$ & 5,8 \\
\hline
\end{tabular}

a. conversão $=41,4 \%$

b. irr $_{\text {in }}=254 \mathrm{~nm} ; \mathrm{t}_{\mathrm{irr}}=5,33 \mathrm{~h}$ ( 320 minutos).

c. total de mols de fotoprodutos : $1,72.10^{-2} \mathrm{~mol} \cdot \mathrm{L}^{-1}$, correspondendo a $47,8 \%$ da quantidade de substrato convertida.

d. quantidade de mols do substrato convertidos em fotoprodutos : $3,60.10^{-2} \mathrm{~mol}^{-L^{-1}}$.

e. $\%$, em relação à quantidade total de mols convertida.

f. $\%$ do substrato convertida em fotoprodutos. 
Tabela IV.5: Irradiação de $\alpha, \alpha$-dibromo-o-xileno (GBX), em benzeno ${ }^{a}$.

\begin{tabular}{|c|c|c|c|c|c|}
\hline & & $\begin{array}{c}\text { Não- } \\
\text { irradiado }\end{array}$ & Irradiadob & \multicolumn{2}{|c|}{$\begin{array}{l}\text { Variação do } \\
\mathrm{n} \underline{\mathrm{o}} \text { de mols }\end{array}$} \\
\hline Compostos & $\begin{array}{c}t_{R} \\
(\mathrm{~min})\end{array}$ & $\begin{array}{l}\text { Conc.molar } \\
\left(\mathrm{mol}^{-1} \mathrm{~L}^{-1}\right)\end{array}$ & $\begin{array}{l}\text { Conc.molar } \\
\left(\mathrm{mol.L} \mathrm{L}^{-1}\right)\end{array}$ & $\begin{array}{c}\text { Conc.molare } \\
\left(\mathrm{mol} \cdot \mathrm{L}^{-1}\right)\end{array}$ & $\% \mathrm{e}$ \\
\hline o-tolualdeído & 5,54 & $1,8.10^{-4}$ & $9,2.10^{-4}$ & $7.4 .10^{-4}$ & 1,8 \\
\hline MBX & 6,98 & $7,6.10^{-4}$ & $2,7.10^{-3}$ & $1,9.10^{-3}$ & 4,5 \\
\hline Ácido o-tolúico & 7,57 & - & $7,7.10^{-3}$ & $7,7.10^{-3}$ & 18,3 \\
\hline GBX & 8,63 & $9,2.10^{-2}$ & $5,0.10^{-2}$ & $(-) 4,2 \cdot 10^{-2} \mathrm{~d}$ & $45,7^{f}$ \\
\hline $\mathrm{DBX}$ & 9,05 & 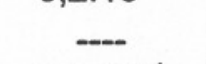 & $1,8.10^{-3}$ & $1,8.10^{-3}$ & 4,3 \\
\hline $\mathrm{o}-\mathrm{Me}-\mathrm{C}_{6} \mathrm{H}_{4} \mathrm{CBr}_{3}$ & 9,48 & $2,3.10^{-4}$ & $2,4.10^{-3}$ & $2,2.10^{-3}$ & 5,2 \\
\hline $\mathrm{C}_{16} \mathrm{H}_{34}$ & 9,69 & $6,1.10^{-3}$ & $6,1.10^{-3}$ & \multicolumn{2}{|c|}{ padrão-interno } \\
\hline TRBX & 10,21 & - & $1,0.10^{-2}$ & $1,0.10^{-2}$ & 23,8 \\
\hline
\end{tabular}

a. conversão $=45,7 \%$.

b. $\lambda_{\text {irr }}=254 \mathrm{~nm} ; \mathrm{t}_{\text {irr }}=6,17 \mathrm{~h}(370,2$ minutos $)$.

c. total de mols de fotoprodutos : $2,43 \cdot 10^{-2} \mathrm{~mol}$. $\mathrm{L}^{-1}$, correspondendo a $58,0 \%$ da quantidade de substrato convertida.

d. quantidade de mols do substrato convertidos em fotoprodutos: $4,2 \cdot 10^{-2} \mathrm{~mol} \cdot \mathrm{L}^{-1}$.

e. \%, em relação à quantidade total de mols convertida.

f. $\%$ do substrato convertida em fotoprodutos.

Tabela IV.6: Irradiação de $\alpha, \alpha, \alpha^{\prime}$-tribromo-o-xileno (TRBX), em benzenoa .

\begin{tabular}{|c|c|c|c|c|c|}
\hline & & $\begin{array}{c}\text { Não- } \\
\text { irradiado }\end{array}$ & Irradiado b & \multicolumn{2}{|c|}{$\begin{array}{l}\text { Variação do } \\
\text { no de mols }\end{array}$} \\
\hline Compostos & $\begin{array}{c}t_{R} \\
(\mathrm{~min})\end{array}$ & $\begin{array}{l}\text { Conc.molar } \\
\left(\mathrm{mol} \cdot \mathrm{L}^{-1}\right)\end{array}$ & $\begin{array}{l}\text { Conc.molar } \\
\left(\mathrm{mol} . \mathrm{L}^{-1}\right)\end{array}$ & $\begin{array}{l}\text { Conc.molarc } \\
\left(\mathrm{mol} \cdot \mathrm{L}^{-1}\right)\end{array}$ & $\% \mathrm{e}$ \\
\hline o-tolualdeído & 5,89 & -- & $1,1.10^{-3}$ & $1,1.10^{-3}$ & 5,8 \\
\hline Ácido o-tolúico & 7,88 & - & $6,7.10^{-4}$ & $6,7.10^{-4}$ & 3,5 \\
\hline GBX & 8,60 & -- & $5,0.10^{-4}$ & $5,0.10^{-4}$ & 2,6 \\
\hline DBX & 9,07 & $5,3 \cdot 10^{-4}$ & $1,2.10^{-3}$ & $6,7.10^{-4}$ & 3,5 \\
\hline $\mathrm{O}-\mathrm{Me}-\mathrm{C}_{6} \mathrm{H}_{4} \mathrm{CBr}_{3}$ & 9,51 & $-\ldots$ & $2,1.10^{-3}$ & $2,1.10^{-3}$ & 11,1 \\
\hline $\mathrm{C}_{16} \mathrm{H}_{34}$ & 9,69 & $6,1 \cdot 10^{-3}$ & $6,1.10^{-3}$ & \multicolumn{2}{|c|}{ padräo-interno } \\
\hline TRBX & 10,27 & $7,0.10^{-2}$ & $5,1.10^{-2}$ & $(-) 1,9.10^{-2} \mathrm{~d}$ & $27,1^{f}$ \\
\hline TBX & 11,40 & $3,6.10^{-3}$ & $6,1.10^{-3}$ & $2,5.10^{-3}$ & 13,2 \\
\hline
\end{tabular}

a. conversão $=27,1 \%$.

b. $\lambda_{\text {irr }}=254 \mathrm{~nm} ; t_{\text {irr }}=5,38 \mathrm{~h}(322,6$ minutos $)$.

c. total de mols de fotoprodutos : $7,54.10^{-3}$ mol.L. ${ }^{-1}$, correspondendo a $39,7 \%$ da quantidade de substrato convertida.

d. quantidade de mols do substrato convertidos em fotoprodutos: $1,90.10^{-2} \mathrm{~mol}^{\mathrm{L}} \mathrm{L}^{-1}$.

e. $\%$, em relação à quantidade total de mols convertida.

f. \% do substrato convertida em fotoprodutos. 
Tabela IV.7: Irradiação de $\alpha, \alpha, \alpha^{\prime}, \alpha^{\prime}$-tetrabromo-o-xileno (TBX), em benzenoa .

\begin{tabular}{|c|c|c|c|c|c|c|}
\hline \multirow[b]{2}{*}{ Compostos } & \multicolumn{2}{|c|}{$\begin{array}{l}\text { Antes da } \\
\text { irradiação }\end{array}$} & \multicolumn{2}{|c|}{$\begin{array}{l}\text { Depois da } \\
\text { irradiação }\end{array}$} & \multicolumn{2}{|c|}{$\begin{array}{l}\text { Variação do } \\
\mathrm{n}^{\mathrm{o}} \text { de mols }\end{array}$} \\
\hline & $\begin{array}{c}t_{R} \\
(\mathrm{~min})\end{array}$ & $\begin{array}{l}\text { Conc.molar } \\
\left(\mathrm{mol} . \mathrm{L}^{-1}\right)\end{array}$ & $\begin{array}{c}\mathrm{t}_{\mathrm{R}} \\
(\mathrm{min})\end{array}$ & $\begin{array}{l}\text { Conc.molar } \\
\left(\mathrm{mol}^{-1}\right)^{-1}\end{array}$ & $\begin{array}{l}\text { Conc.molarc } \\
\left(\mathrm{mol} \cdot \mathrm{L}^{-1}\right)\end{array}$ & $\% e^{e}$ \\
\hline o-tolualdeído & -- & - & 5,98 & $5,0.10^{-4}$ & $5,0.10^{-4}$ & 3,6 \\
\hline Ácido $\alpha$-bromo-o-tolúico & -- & $\cdots$ & 9,00 & $1,7.10^{-3}$ & $1,7.10^{-3}$ & 12,1 \\
\hline$p$-TBX & 9,45 & $2,0.10^{-4}$ & 9,45 & $9,0.10^{-5}$ & $(-) 1,1 \cdot 10^{-4} d$ & 0,6 \\
\hline $\mathrm{C}_{16} \mathrm{H}_{34}$ & 9,69 & $6,8 \cdot 10^{-3}$ & 9,69 & $6,8 \cdot 10^{-3}$ & \multicolumn{2}{|c|}{ padrāo-interno } \\
\hline$\alpha, \alpha$-dibromo-o-tolualdeído & - & -- & 9,94 & $3,5.10^{-4}$ & $3,5.10^{-4}$ & 2,5 \\
\hline TRBX & 10,17 & $8,9.10^{-5}$ & 10,19 & $1,3.10^{-3}$ & $1,2.10^{-3}$ & 8,6 \\
\hline TBX & 11,79 & $1,2.10^{-1}$ & 11,87 & $1,1.10^{-1}$ & $(-) 1,4 \cdot 10^{-2} \mathrm{~d}$ & $11,7^{f}$ \\
\hline
\end{tabular}

a. conversão $=11,7 \%$

b. $\lambda_{\text {irr }}=254 \mathrm{~nm} ; \mathrm{t}_{\mathrm{irr}}=7,38 \mathrm{~h}$ ( 470 minutos).

c. total de mols de fotoprodutos : $3,75.10^{-3} \mathrm{~mol}^{-\mathrm{L}^{-1}}$, correspondendo a $26,8 \%$ da quantidade de substrato convertida.

d. quantidade de mols do substrato convertidos em fotoprodutos : $1,41.10^{-2} \mathrm{~mol}_{\mathrm{L}} \mathrm{L}^{-1}$.

e. \%, em relação à quantidade total de mols convertida.

f. $\%$ do substrato convertida em fotoprodutos.

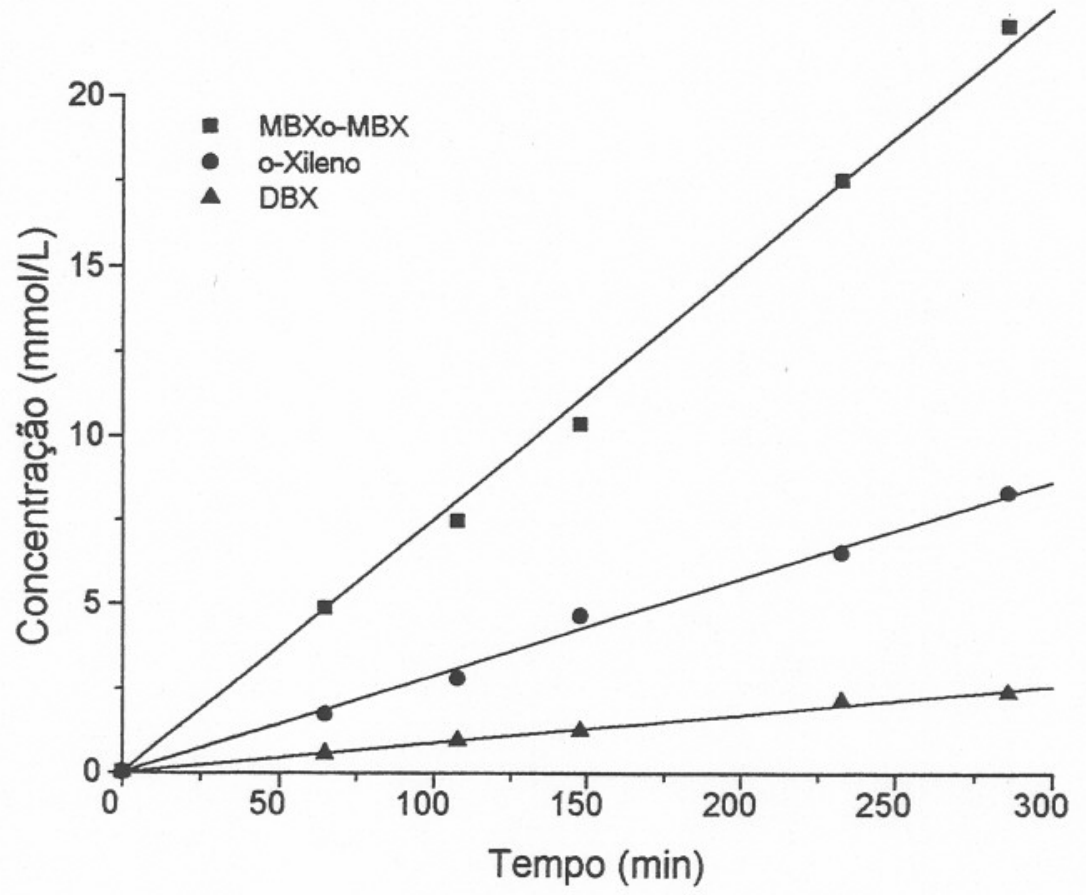

\begin{tabular}{|c|c|c|c|c|}
\hline Composto & $\begin{array}{l}\text { Conc. Inicial } \\
\left(\mathrm{Co} / \mathrm{mol}^{-1} \mathrm{~L}^{-1}\right)\end{array}$ & 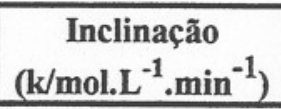 & Desvio Padrão (s) & $\begin{array}{l}\text { Coeficiente de } \\
\text { Correlação (r) }\end{array}$ \\
\hline MBXo - MBX & $1,2.10^{-1}$ & $7,50 \cdot 10^{-5}$ & $1,20.10^{-6}$ & 0,998 \\
\hline$o$-Xileno & $5,8.10^{-5}$ & $2,88 \cdot 10^{-5}$ & $5,83 \cdot 10^{-7}$ & 0,997 \\
\hline DBX & $6,8 \cdot 10^{-4}$ & $8,57 \cdot 10^{-6}$ & $1,79.10^{-7}$ & 0,997 \\
\hline
\end{tabular}

Figura IV.3 - Perfil cinético da irradiação de MBX, em benzeno. 


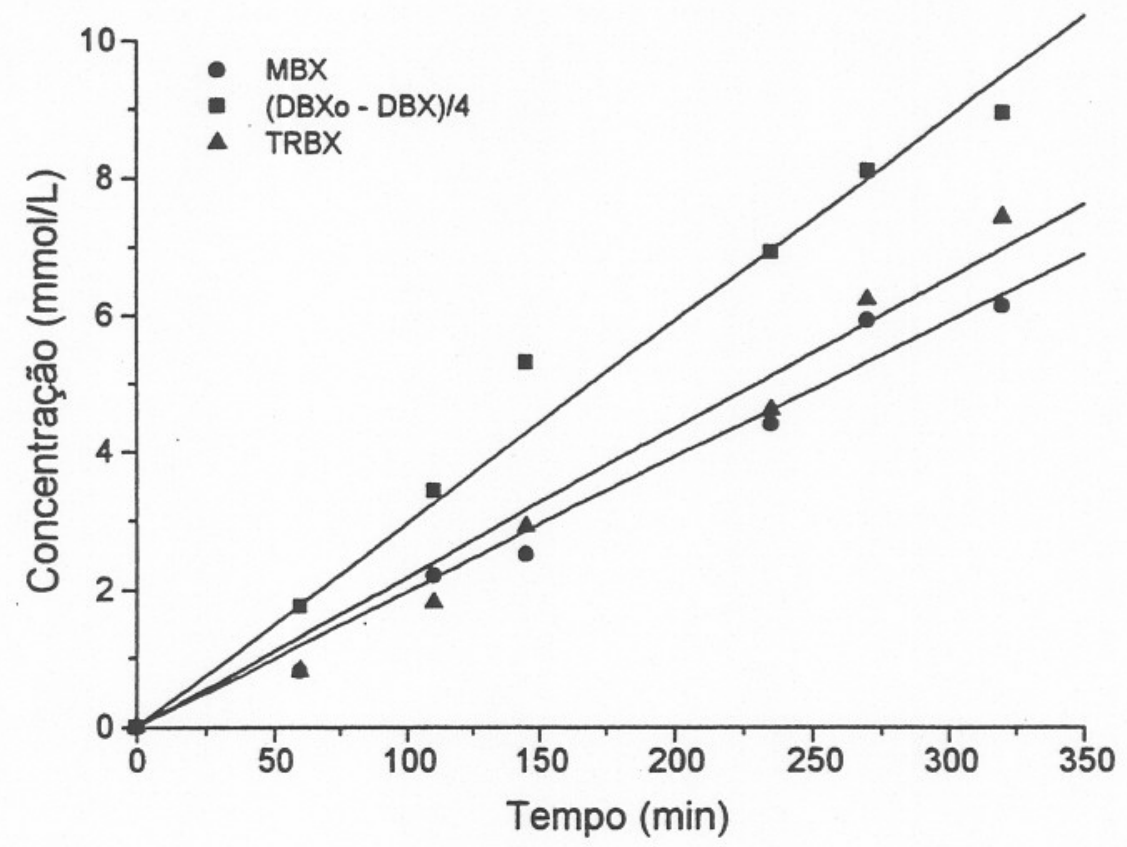

\begin{tabular}{|c|c|c|c|c|}
\hline Composto & $\begin{array}{l}\text { Conc. Inicial } \\
\left(\mathrm{Co} / \mathrm{mol}^{-L^{-1}}\right)\end{array}$ & $\begin{array}{c}\text { Inclinação } \\
\left(\mathrm{k} / \mathrm{mol}^{-\mathrm{L}^{-1}} \cdot \mathrm{min}^{-1}\right)\end{array}$ & Desvio Padrão (s) & $\begin{array}{l}\text { Coeficiente de } \\
\text { Correlação (r) }\end{array}$ \\
\hline MBX & 0 & $1,96 \cdot 10^{-5}$ & $6,62 \cdot 10^{-7}$ & 0,990 \\
\hline DBXo - DBX & $8,7 \cdot 10^{-2}$ & $1,18 \cdot 10^{-4}$ & $3,71 \cdot 10^{-6}$ & 0,990 \\
\hline TRBX & 0 & $2,17 \cdot 10^{-5}$ & $8,76 \cdot 10^{-7}$ & 0,987 \\
\hline
\end{tabular}

Figura IV.4 - Perfil cinético da irradiação de DBX, em benzeno.

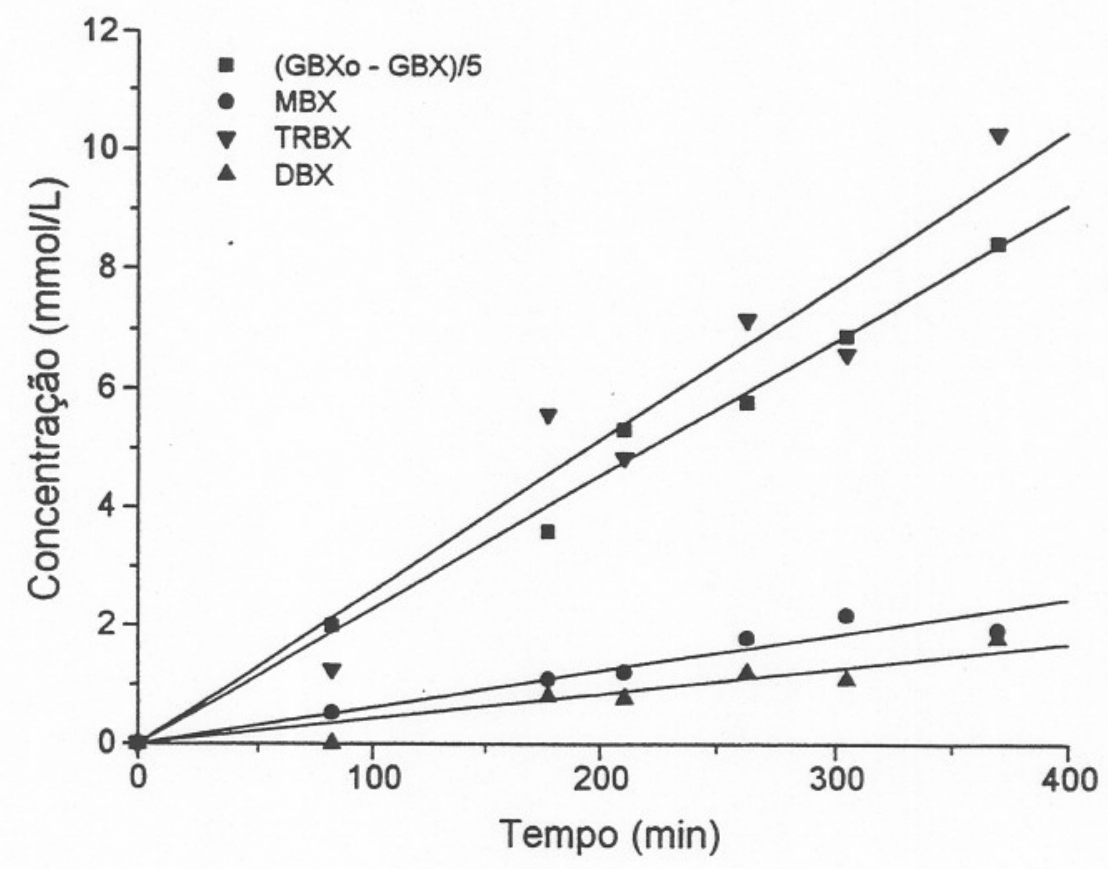

\begin{tabular}{|c|c|c|c|c|}
\hline Composto & $\begin{array}{l}\text { Conc. Inicial } \\
\left(\mathrm{Co} / \mathrm{mol}^{\left.-\mathrm{L}^{-1}\right)}\right.\end{array}$ & $\begin{array}{c}\text { Inclinação } \\
\left(\mathrm{k} / \mathrm{mol}^{-1} \mathrm{~L}^{-1} \cdot \mathrm{min}^{-1}\right)\end{array}$ & Desvio Padrão (s) & $\begin{array}{l}\text { Coeficiente de } \\
\text { Correlação (r) }\end{array}$ \\
\hline GBXo - GBX & $9,2 \cdot 10^{-2}$ & $1,13 \cdot 10^{-4}$ & $2,36 \cdot 10^{-6}$ & 0,995 \\
\hline MBX & $7,6.10^{-4}$ & $6,09 \cdot 10^{-6}$ & $3,34 \cdot 10^{-7}$ & 0,965 \\
\hline TRBX & 0 & $2,56 \cdot 10^{-5}$ & $1,39 \cdot 10^{-6}$ & 0,970 \\
\hline DBX & 0 & $4,19 \cdot 10^{-6}$ & $3,19 \cdot 10^{-7}$ & 0,951 \\
\hline
\end{tabular}

Figura IV.5 - Perfil cinético da irradiação de GBX, em benzeno. 


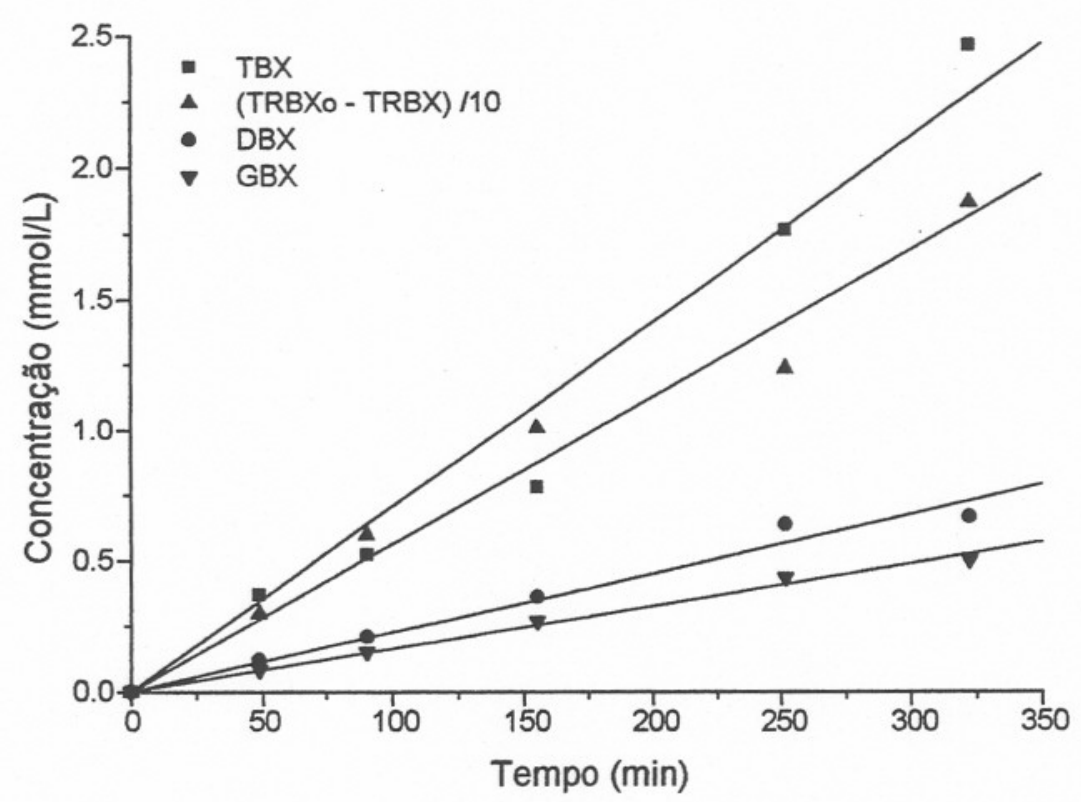

\begin{tabular}{|c|c|c|c|c|}
\hline Composto & $\begin{array}{l}\text { Conc. Inicial } \\
\left(\mathrm{Co} / \mathrm{mol}^{-1} \mathrm{~L}^{-1}\right) \\
\end{array}$ & $\begin{array}{c}\text { Inclinação } \\
\left(\mathrm{k} / \mathrm{mol}^{-1} \mathrm{~L}^{-1} \cdot \mathrm{min}^{-1}\right) \\
\end{array}$ & Desvio Padrão (s) & $\begin{array}{l}\text { Coeficiente de } \\
\text { Correlação (r) } \\
\end{array}$ \\
\hline TBX & $3,6.10^{-3}$ & $7,04 \cdot 10^{-6}$ & $3,84 \cdot 10^{-7}$ & 0,983 \\
\hline TRBXo - TRBX & $7,0.10^{-2}$ & $5,62 \cdot 10^{-5}$ & $2,47.10^{-6}$ & 0,986 \\
\hline DBX & $5,3 \cdot 10^{-4}$ & $2,25 \cdot 10^{-6}$ & $9,26 \cdot 10^{-8}$ & 0,988 \\
\hline GBX & 0 & $1,63.10^{-6}$ & $3,71.10^{-8}$ & 0,996 \\
\hline
\end{tabular}

Figura IV.6 - Perfil cinético da irradiação de TRBX, em benzeno.

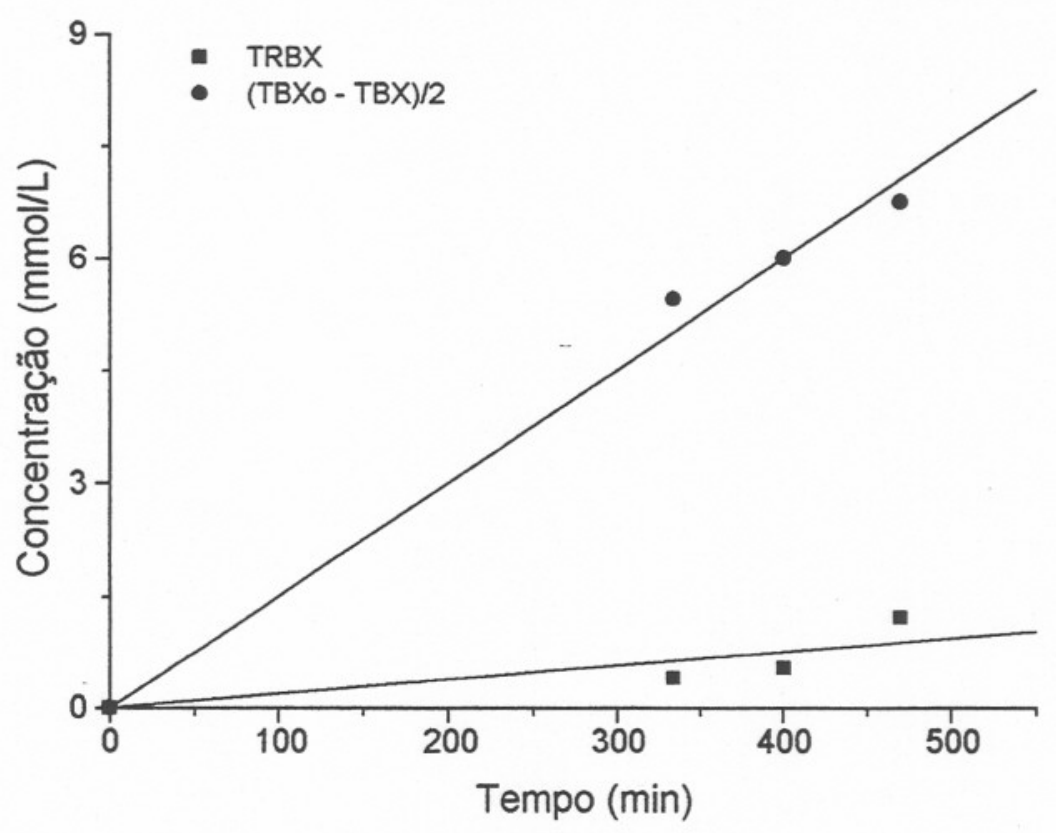

\begin{tabular}{|c|c|c|c|c|}
\hline Composto & $\begin{array}{l}\text { Conc. Inicial } \\
\left(\mathrm{Co} / \mathrm{mol}^{-\mathrm{L}^{-1}}\right)\end{array}$ & $\begin{array}{c}\text { Inclinação } \\
\left(\mathrm{k} / \mathrm{mol}^{-1} \mathrm{~L}^{-1} \cdot \min ^{-1}\right)\end{array}$ & Desvio Padrão (s) & $\begin{array}{l}\text { Coeficiente de } \\
\text { Correlação (r) }\end{array}$ \\
\hline TRBX & $8,9 \cdot 10^{-5}$ & $1,88 \cdot 10^{-6}$ & $3,84 \cdot 10^{-7}$ & 0,851 \\
\hline TBXo - TBX & $1,2.10^{-1}$ & $3,00 \cdot 10^{-5}$ & $8,76.10^{-7}$ & 0,995 \\
\hline
\end{tabular}

Figura IV.7 - Perfil cinético da irradiação de TBX, em benzeno. 


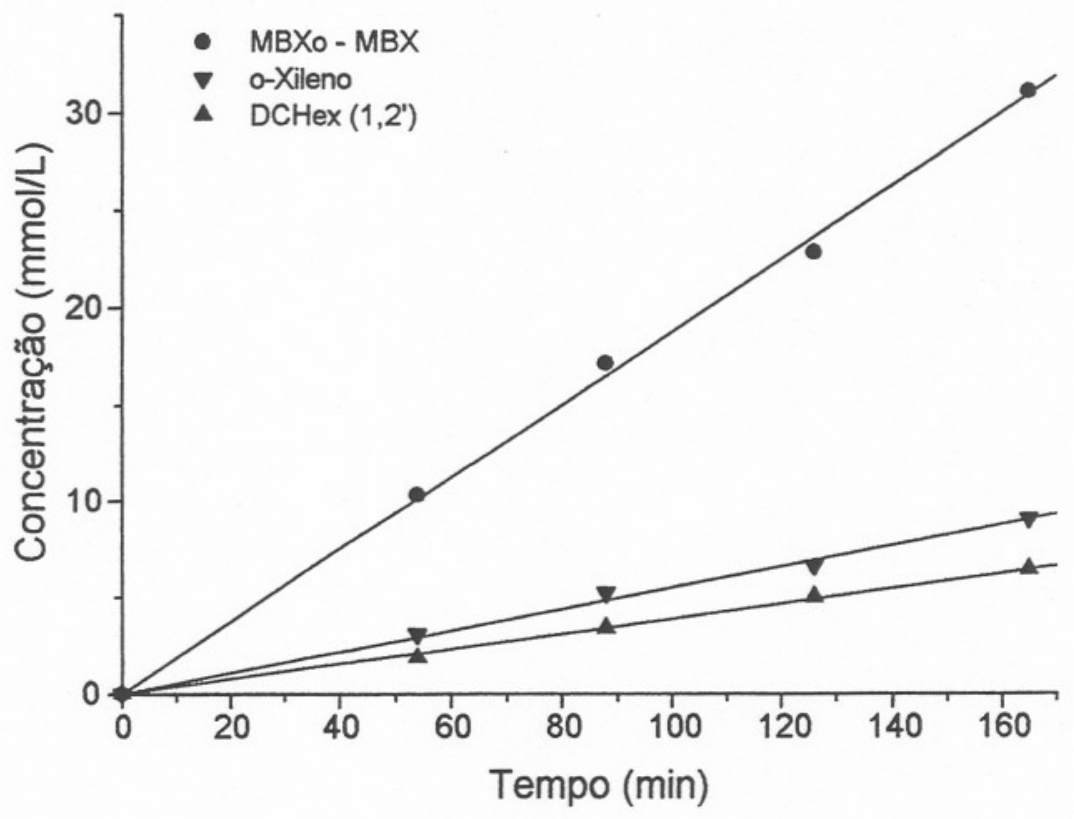

\begin{tabular}{|c|c|c|c|c|}
\hline Composto & $\begin{array}{l}\text { Conc. Inicial } \\
\left(\mathrm{Co} / \mathrm{mol.L}^{-1}\right)\end{array}$ & 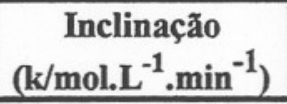 & Desvio Padrão (s) & $\begin{array}{l}\text { Coeficiente de } \\
\text { Correlação (r) } \\
\end{array}$ \\
\hline$o$-Xileno & $4,8 \cdot 10^{-5}$ & $5,47 \cdot 10^{-5}$ & $1,09 \cdot 10^{-6}$ & 0,997 \\
\hline MBXo - MBX & $1,0.10^{-1}$ & $1,87 \cdot 10^{-4}$ & $2,22 \cdot 10^{-6}$ & 0,999 \\
\hline DCHex $\left(1,2^{\prime}\right)$ & 0 & $3,88 \cdot 10^{-5}$ & $4,85 \cdot 10^{-7}$ & 0,999 \\
\hline
\end{tabular}

Figura IV.8 - Perfil cinético da irradiação de MBX, em benzeno/ciclo-hexeno.

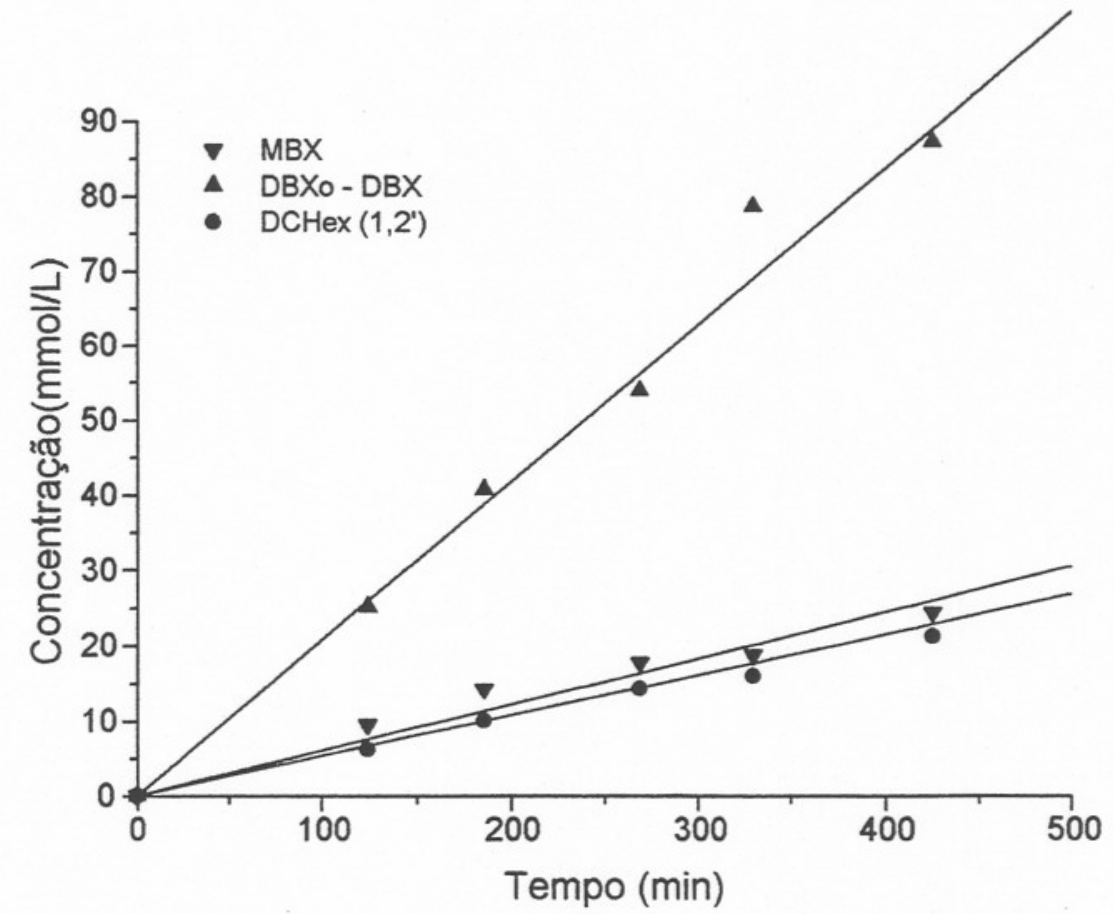

\begin{tabular}{|c|c|c|c|c|}
\hline Composto & $\begin{array}{c}\text { Conc. Inicial } \\
\left(\text { Co/mol.L } \mathbf{L}^{\mathbf{1}}\right)\end{array}$ & $\begin{array}{c}\text { Inclinação } \\
\left(\mathbf{k} / \mathbf{m o l}^{-\mathbf{1}} \cdot \mathbf{m i n}^{-1}\right)\end{array}$ & Desvio Padrão (s) & $\begin{array}{c}\text { Coeficiente de } \\
\text { Correlação (r) }\end{array}$ \\
\hline MBX & 0 & $6,12.10^{-5}$ & $2,98 \cdot 10^{-6}$ & 0,974 \\
DBXo - DBX & $5,3.10^{-2}$ & $2,09.10^{-4}$ & $8,27.10^{-6}$ & 0,986 \\
DCHex (1,2') & 0 & $5,06.10^{-5}$ & $8,88.10^{-7}$ & 0,997 \\
\hline
\end{tabular}

Figura IV.9 - Perfil cinético da irradiação de DBX, em benzeno/ciclo-hexeno. 


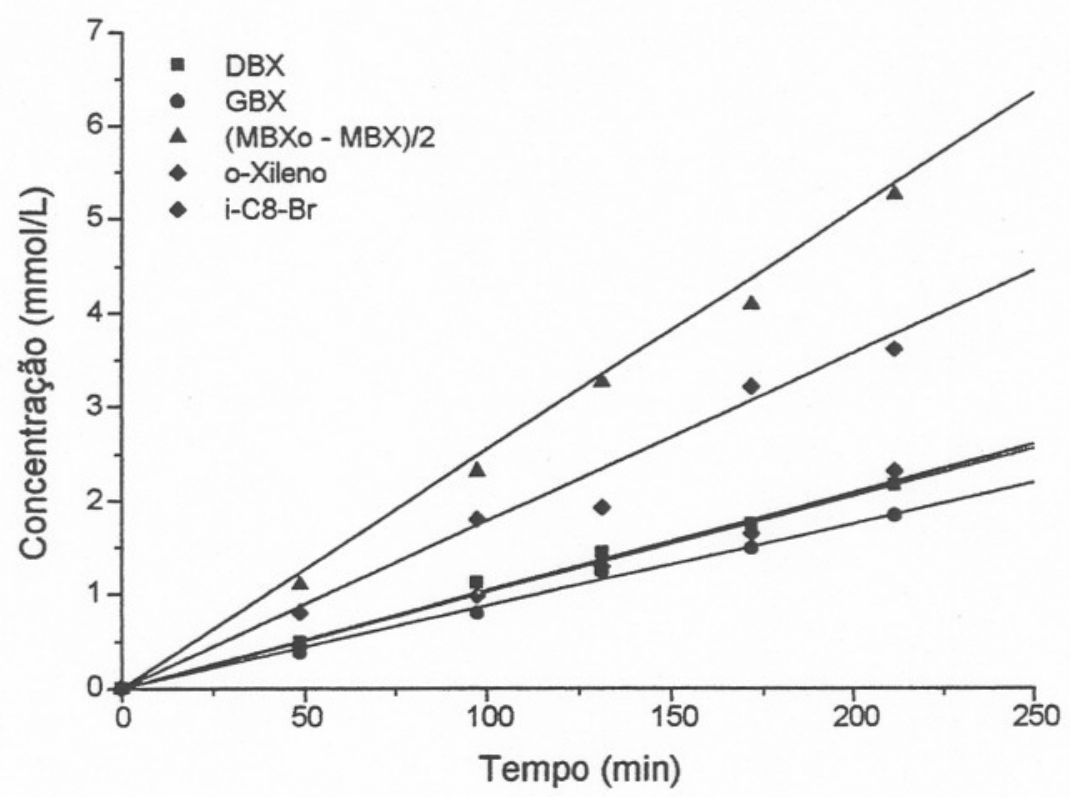

\begin{tabular}{|c|c|c|c|c|}
\hline Composto & $\begin{array}{c}\text { Conc. Inicial } \\
\left(\mathbf{C o} / \text { mol. }^{-1}\right)\end{array}$ & $\begin{array}{c}\text { Inclinação } \\
\left(\mathbf{k} / \mathbf{m o l}^{-1} \mathbf{L}^{-1} \cdot \mathbf{m i n}^{-1}\right)\end{array}$ & Desvio Padrão (s) & $\begin{array}{c}\text { Coeficiente de } \\
\text { Correlação (r) }\end{array}$ \\
\hline$o$-Xileno & $4,8 \cdot 10^{-5}$ & $1,78 \cdot 10^{-5}$ & $6,15 \cdot 10^{-7}$ & 0,990 \\
MBXo- MBX & $1,0.10^{-1}$ & $5,07 \cdot 10^{-5}$ & $1,47.10^{-7}$ & 0,993 \\
GBX & 0 & $8,74 \cdot 10^{-6}$ & $1,60.10^{-7}$ & 0,997 \\
DBX & $5,7.10^{-4}$ & $1,04 \cdot 10^{-5}$ & $1,88.10^{-7}$ & 0,997 \\
$t-\mathrm{C}_{8} \mathrm{H}_{17}-\mathrm{Br}$ & 0 & $1,02 \cdot 10^{-5}$ & $2,72 \cdot 10^{-7}$ & 0,994 \\
\hline
\end{tabular}

Figura IV.10 - Perfil cinético da irradiação de MBX, em iso-octano.

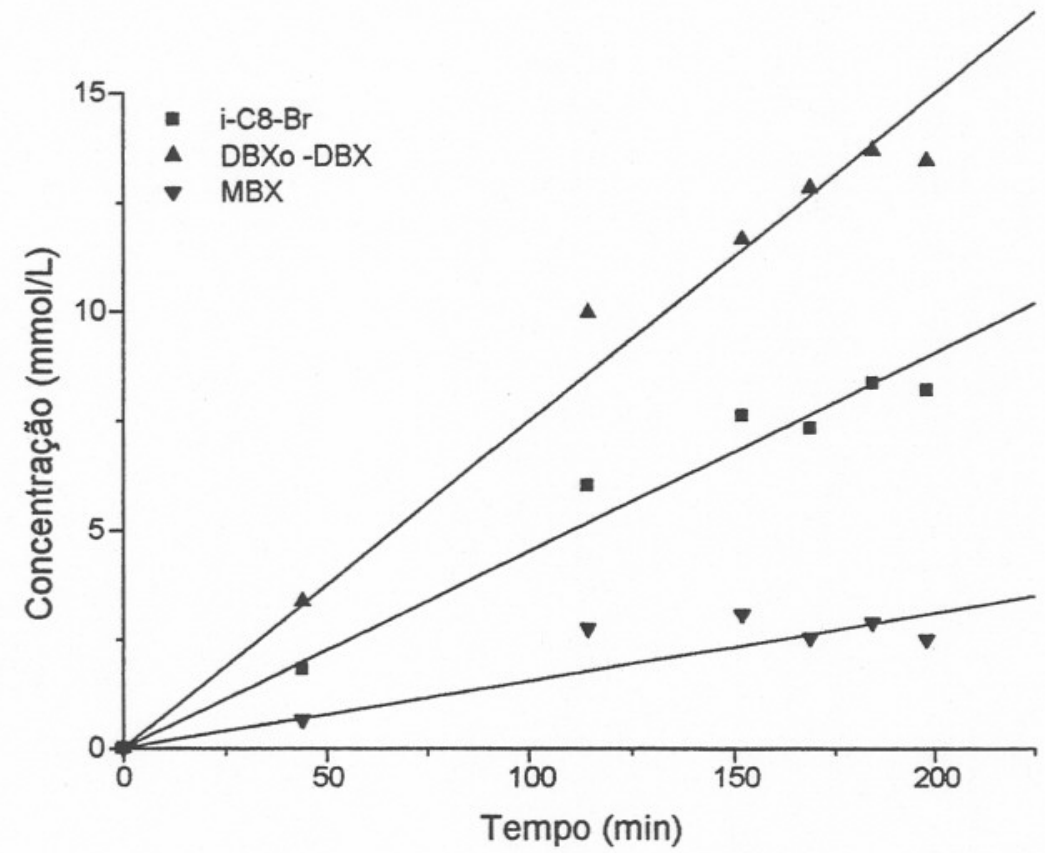

\begin{tabular}{|c|c|c|c|c|}
\hline Composto & $\begin{array}{c}\text { Conc. Inicial } \\
\left(\mathbf{C o} / \text { mol. }^{-\mathbf{1}}\right)\end{array}$ & $\begin{array}{c}\text { Inclinação } \\
\left(\mathbf{k} / \mathbf{m o l}^{-1} \cdot \mathbf{m i n}^{-1}\right)\end{array}$ & Desvio Padrão (s) & $\begin{array}{c}\text { Coeficiente de } \\
\text { Correlação (r) }\end{array}$ \\
\hline MBX & 0 & $1,62 \cdot 10^{-5}$ & $1,43 \cdot 10^{-6}$ & 0,898 \\
DBXo - DBX & $1,6 \cdot 10^{-2}$ & $7,43 \cdot 10^{-5}$ & $2,17 \cdot 10^{-6}$ & 0,989 \\
$t$ - $\mathrm{C}_{8} \mathrm{H}_{17}-\mathrm{Br}$ & 0 & $4,52 \cdot 10^{-5}$ & $1,51 \cdot 10^{-6}$ & 0,986 \\
\hline
\end{tabular}

Figura IV.11 - Perfil cinético da irradiação de DBX, em iso-octano. 


\section{IV.3. Rendimentos Quânticos, nas Fotólises Convencionais}

A partir dos perfis cinéticos, para cada uma das fotólises, e do valor de $\mathrm{I}_{0}$ determinado para o sistema de lâmpadas, é possível calcularem-se os rendimentos quânticos para as foto-irradiações estudadas. Cabem, entretanto, algumas considerações prévias:

Todas as irradiações foram efetuadas em condições tais que a absorbância inicial das soluções empregadas fosse considerável, a $254 \mathrm{~nm}$ :

(i) no caso das soluções benzênicas, contendo ou não ciclo-hexeno, toda a luz deve ser inicialmente absorvida pelo solvente, havendo posterior transferência de excitação para o substrato investigado. Neste caso, como benzeno puro tem uma concentração de 11,2 mol. $L^{-1}$ e $\varepsilon_{254}=200$, a absorbância da solução seria $A \approx 2200$..

(ii) no caso das soluções iso-octânicas, considerando-se que $\mathbf{M B X}$ apresenta $\varepsilon_{254} \approx 2000$, e que $\varepsilon_{254}(\mathbf{M B X}) \approx \varepsilon_{254}(\mathbf{D B X})$, teríamos $\mathrm{A}_{254}(\mathbf{M B X}) \approx 150 \mathrm{e}$ $\mathrm{A}_{254}(\mathbf{D B X}) \approx 32$, para as concentrações iniciais empregadas (vide Figuras IV.10 e IV.11, p. 87).

Se admitirmos que, em todos os casos, $\varepsilon_{254}$ (reagentes) $\approx \varepsilon_{254}$ (produtos), teremos o caso actinométrico denominado "isosbéstico" por BUNCE (1987).

Assim sendo, nestas condições $\left(A_{254} \geq 4\right.$ e $\left.\varepsilon_{254}(\mathbf{R}) \approx \varepsilon_{254}(\mathbf{P})\right)$, a equação actinométrica geral (vide Equação III.2, p. 60) se reduz a:

$$
-\mathrm{V} \frac{\mathrm{d}[\mathrm{R}]_{\mathrm{t}}}{\mathrm{d}\left(\mathrm{I}_{\mathrm{o}} \cdot \mathrm{t}\right)}=\Phi \frac{[\mathrm{R}]_{\mathrm{t}}}{[\mathrm{R}]_{\mathrm{o}}}
$$

que, integrada, se torna:

$$
\Phi=\frac{\mathrm{V}}{\mathrm{I}_{\mathrm{o}} \cdot \mathrm{t}} \cdot[\mathrm{R}]_{0} \ln \left(\frac{[\mathrm{R}]_{0}}{[\mathrm{R}]_{\mathrm{t}}}\right) .
$$

Isto implica que, a tempos longos, o desaparecimento de reagente de partida deva ser descrito por uma curva exponencial. Entretanto, a tempos suficientemente curtos, esta curva tende a uma reta limite, i. e., se $[\mathrm{R}]_{\mathrm{t}}=[\mathrm{R}]_{0}-\mathrm{k}_{\mathrm{o}} \mathrm{t}$, então:

$$
\lim _{[R]_{t} \rightarrow[R]_{0}}\left\{[R]_{0} \ln \left(\frac{[R]_{0}}{[R]_{t}}\right)\right\}=\lim _{[R]_{t} \rightarrow[R]_{0}}\left\{-[R]_{0} \ln \left(1-\frac{k_{0} t}{[R]_{0}}\right)\right\}=k_{0} \cdot t
$$

ou seja:

$$
\Phi=\frac{\mathrm{k}_{0} \cdot \mathrm{V}}{\mathrm{I}_{\mathrm{o}}},
$$

que pode ser reconhecida como a Equação III.1 (vide p. 60).

Portanto, fica demonstrado que, apesar de, neste caso não se estar investigando um sistema onde o(s) fotoproduto(s) formado(s) não absorve(m) luz, dada a linearidade observada experimentalmente, tanto do desaparecimento do reagente de partida, como da formação de produtos, é lícito que utilizemos aqui a Equação III.1 para calcularmos os rendimentos quânticos! Na Tabela IV.8, abaixo, encontram-se os resul- 
tados que obtivemos para as diversas irradiações efetuadas, utilizando os valores de $\mathrm{k}_{\mathrm{o}}$ (vide Figuras IV.3 a IV.11, p.83-87) e $\mathrm{I}_{\mathrm{o}}$ (vide $\mathrm{p}$. 60) obtidos anteriormente, e $\mathrm{V}=3 \mathrm{~mL}$.

TABELA IV.8: Rendimentos quânticos, de desaparecimento de reagente $\left(\Phi_{\mathrm{RBr}}\right)$ e de aparecimento do fotoproduto secundário $\left(\Phi_{\mathrm{RH}}\right)$ em benzeno, em iso-octano e em benzeno/ciclo-hexeno.

\begin{tabular}{|c|c|c|c|c|}
\hline Reagente & $\Phi_{\mathbf{R B r}}$ & Produto & $\Phi_{\mathbf{R H}}$ & Solvente \\
\hline MBX & 0,33 & $o$-Xileno & 0,13 & benzeno \\
\hline DBX & 0,52 & MBX & 0,09 & benzeno \\
\hline GBX & 0,49 & MBX & 0,03 & benzeno \\
\hline \multirow[t]{2}{*}{ TRBX } & 0,25 & DBX & 0,01 & benzeno \\
\hline & & GBX & 0,01 & benzeno \\
\hline TBX & 0,13 & TRBX & 0,01 & benzeno \\
\hline MBX & 0,22 & $o$-Xileno & 0,08 & iso-octano \\
\hline DBX & 0,32 & MBX & 0,07 & iso-octano \\
\hline MBX & 0,82 & $o$-Xileno & 0,24 & $\begin{array}{l}\text { benzeno + } \\
\text { ciclo-hexeno }\end{array}$ \\
\hline DBX & 0,91 & MBX & 0,27 & $\begin{array}{l}\text { benzeno + } \\
\text { ciclo-hexeno }\end{array}$ \\
\hline
\end{tabular}

Optamos por analisar apenas o comportamento do desaparecimento do reagente de partida e da formação do produto reduzido, pois estes são dados suficientes para se avaliar o comportamento geral dos sistemas fotoquímicos em estudo.

Inicialmente, pode-se verificar que os rendimentos quânticos de desaparecimento de reagente de partida são cerca de $50 \%$ maiores em benzeno, do que em isooctano, o que indica que o benzeno sensibiliza esta reação. por outro lado os rendimentos quânticos de formação de produto reduzido apresentam comportamento diferenciado: enquanto para MBX também ocorre aumento de ca. 50\%, no caso de DBX parece não haver diferença entre os dois solventes. Isto se deve, provavelmente, ao fato de haver maior disponibilidade de doadores de hidrogênio (no caso o hidrogênio metínico do solvente), quando em iso-octano, o que contribuiria para uma formação mais eficiente do produto reduzido, neste solvente. No caso de benzeno + ciclo-hexeno, cuja eficiência como doador de hidrogênio é ainda maior, ambos os rendimentos quânticos são fortemente exacerbados. Em todos os casos considerados, o aparecimento de produto reduzido representa $29 \%$, em média, do desaparecimento de reagente de partida, pois este não é o único processo operante nestes sistemas, como já discutimos amplamente até aqui.

Por outro lado, nos casos de GBX, TRBX e TBX, em benzeno, o aparecimento de produto reduzido representa menos de $10 \%$ do desaparecimento de reagente de partida, sendo que, aqui, a hidrólise dos brometos geminais, foto-induzida ou não, desempenha um papel relevante como contribuidora para o desaparecimento de reagente de partida. 


\section{IV.4. Fotólises por Pulso de Laser}

Finalmente, investigou-se o comportamento de MBX, DBX, GBX e TBX, quando submetidos à fotólise por pulso de laser, com o objetivo de identificar quais seriam os transientes envolvidos na etapa fotoquímica primária, de maneira a verificar o modelo mecanístico proposto a partir dos dados obtidos no estudo fotoquímico clássico. Assim, soluções iso-octânicas desses compostos bromados foram submetidas à ação do $4^{\underline{0}}$ harmônico de um laser pulsado de Nd:YAG $\left(\lambda_{\text {exc }}=266 \mathrm{~nm}\right)$, sistema já descrito mais detalhadamente no Capítulo referente a Materiais e Métodos (item III.7, página 61).

Os decaimentos cinéticos obtidos nestes experimentos podem ser classificados em dois grupos: no primeiro, discriminam-se claramente duas regiões na curva experimental, atribuíveis a duas espécies transientes, uma de tempo de vida significativamente mais curto que a outra, como mostram as Figuras IV.12 e IV.13 (vide p.91), referentes às fotólises de MBX e DBX; no outro, abrangendo os dados obtidos para GBX e TBX, o sinal detectado deve-se a apenas uma espécie, cujo tempo de vida é longo o suficiente $\left(\mathrm{k}\right.$ da ordem de $10^{2} \mathrm{~s}^{-1}$ ) para que, na maior janela de tempo possível de ser utilizada no sistema, não se observasse qualquer decaimento (vide Figuras IV.14 e IV.15, à página 92).

Este conjunto de resultados sugere que, no caso de GBX e TBX, a espécie de tempo de vida mais curto seja menos estável do que a gerada pela fotólise de MBX e de DBX (não sendo, portanto, detectável pelo nosso equipamento). Alternativamente, poder-se-ia admitir que esta espécie fosse de natureza diferente daquelas detectáveis pois, tanto GBX, como TBX, por apresentarem carbonos ligados a dois substituintes bromo geminais, poderiam favorecer uma rota alternativa (i.e. clivagem $\alpha$ ) para a desativação do transiente, pela obtenção de um carbeno: um intermediário distinto daquele observado nos casos de MBX e de DBX.

As curvas escolhidas para serem apresentadas nas Figuras IV.12 a IV.15 são representativas dos perfis cinéticos de decaimento observados para a absorção das espécies transientes em cada série individual de medidas efetuadas com MBX, DBX, GBX e TBX (em soluções iso-octânicas), tendo sido selecionadas aquelas nas quais o comprimento de onda de monitoração correspondesse ao máximo de emissão do transiente, em cada caso, o que maximiza a relação sinal/ruído.

Analisando-se, por regressão não-linear (MARQUARDT,1963; PRESS et alii, 1986), a componente rápida das curvas medidas para MBX e DBX, obtiveram-se os tempos de vida aparentes das espécies menos estáveis, admitindo-se que o processo dominante nestes decaimentos obedecesse a uma cinética de pseudo-primeira ordem. Os resultados encontrados para o melhor ajuste estão apresentados entre parênteses nas legendas das Figuras IV.12 e IV.13 (média de dez valores, para MBX e de cinco valores, para DBX). As distribuições de resíduos mostradas como inserte nestas duas figuras demonstram que há um bom ajuste entre a curva experimental e uma mono-expo- 
nencial, pois o espalhamento da distribuição de resíduos é estatístico e não tendencioso, embora evidencie a existência de um ruído multi-senoidal de baixa freqüência ( 100 $\mathrm{kHz}$ ), intrínseco ao arranjo experimental utilizado.

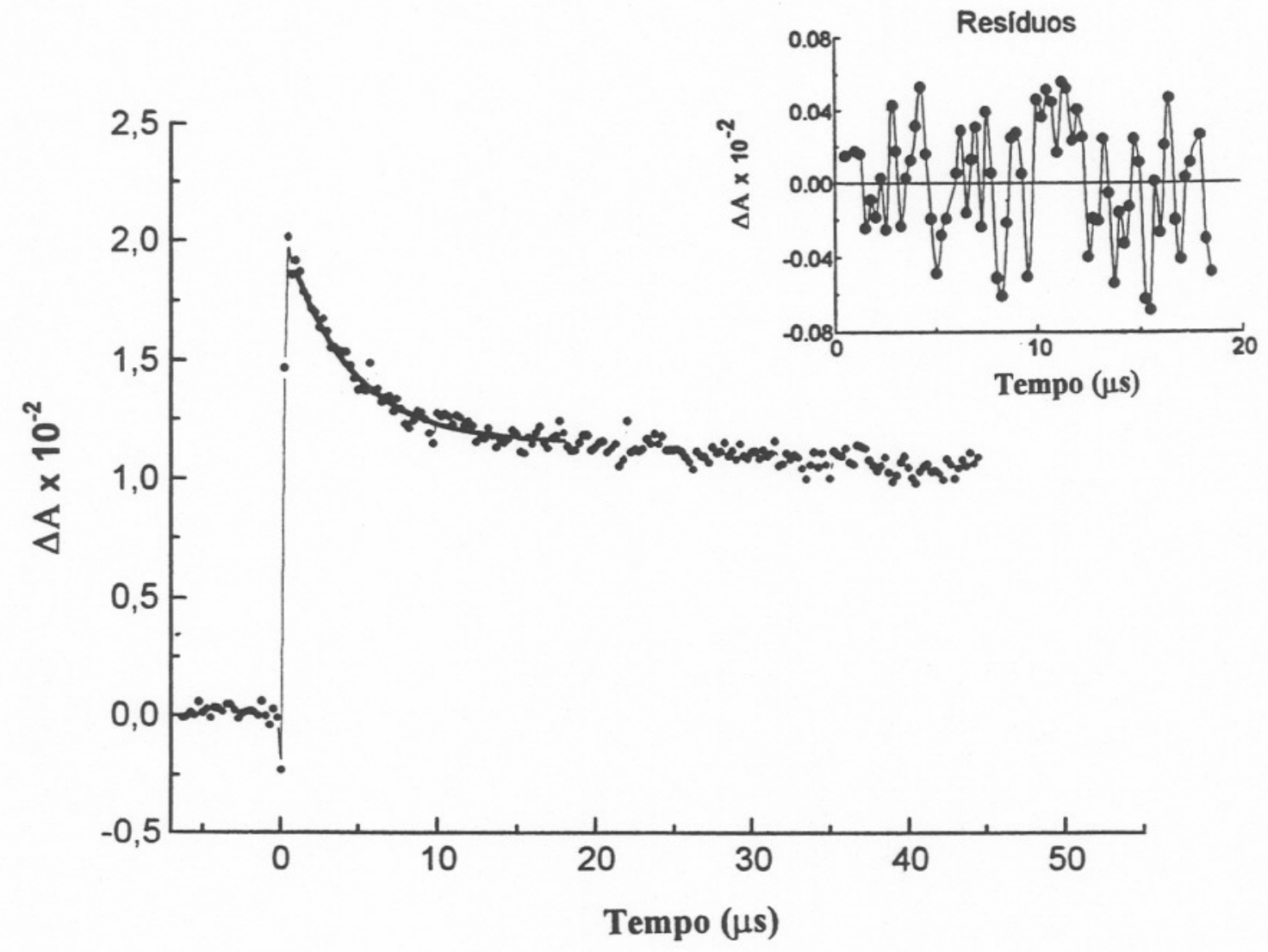

Figura IV.12 - Decaimento, monitorado a 320nm, para uma solução de MBX $\left(\mathrm{A}_{266}=0,468\right)$, em iso-octano; $\tau=(4,0 \pm 0,5) \cdot 10^{-6} \mathrm{~s}$.

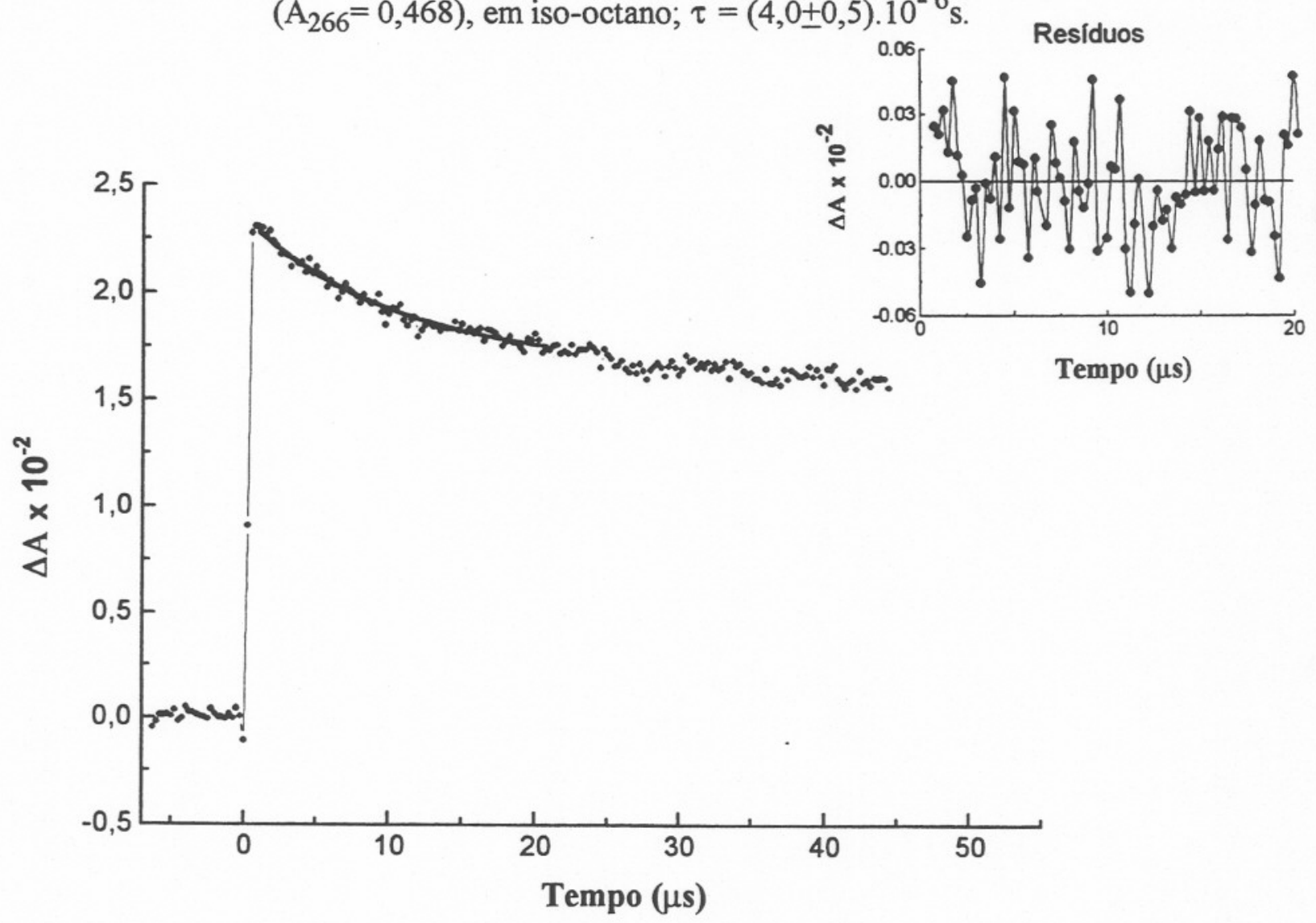

Figura IV.13 - Decaimento, monitorado a 340nm, para uma solução de DBX $\left(A_{266}=0,783\right)$, em iso-octano; $\tau=(8,8 \pm 0,5) \cdot 10^{-6}$ s. 


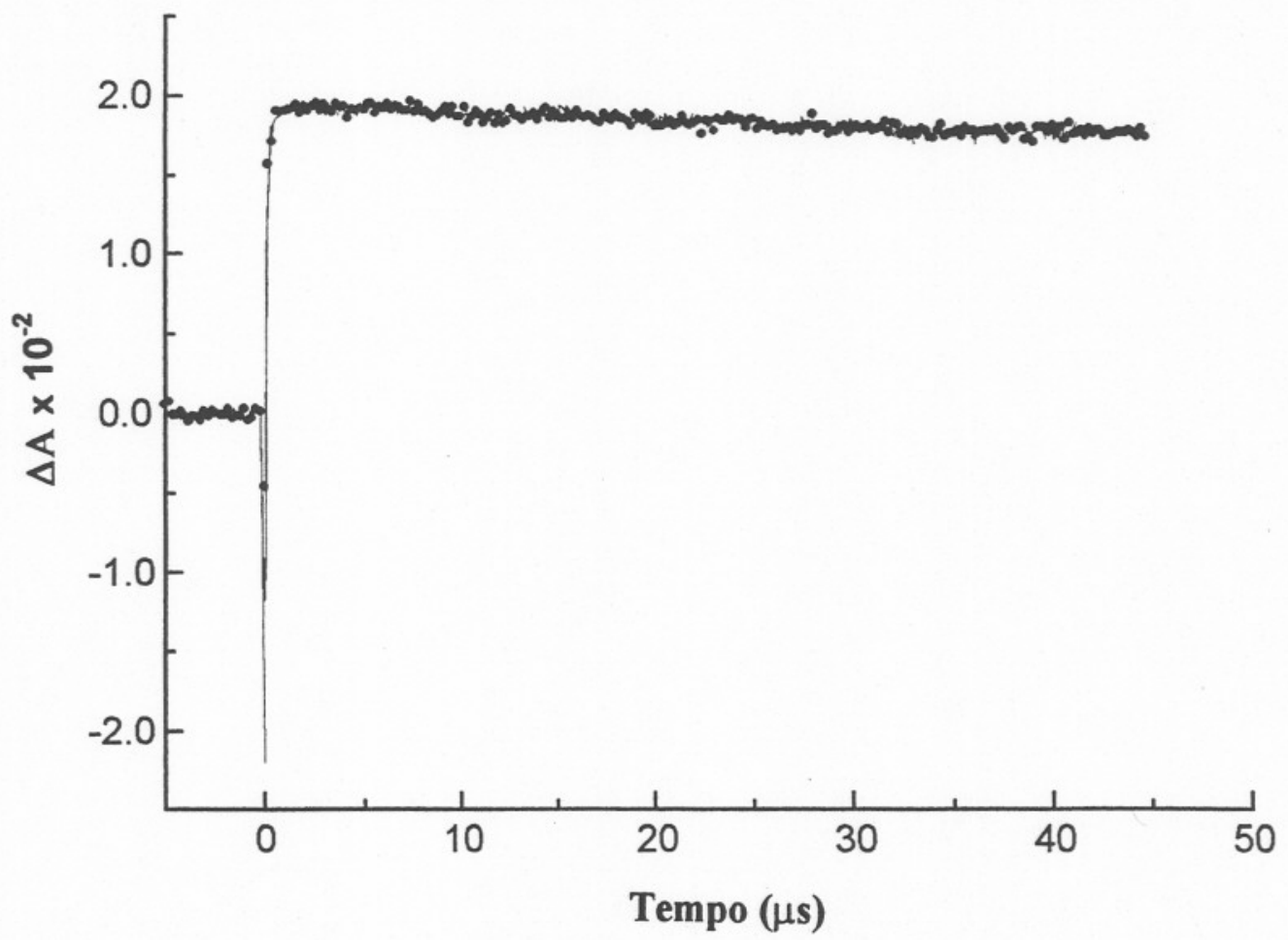

Figura IV.14 - Decaimento, monitorado a 310nm, para uma solução de GBX $\left(A_{266}=0,857\right)$, em iso-octano.

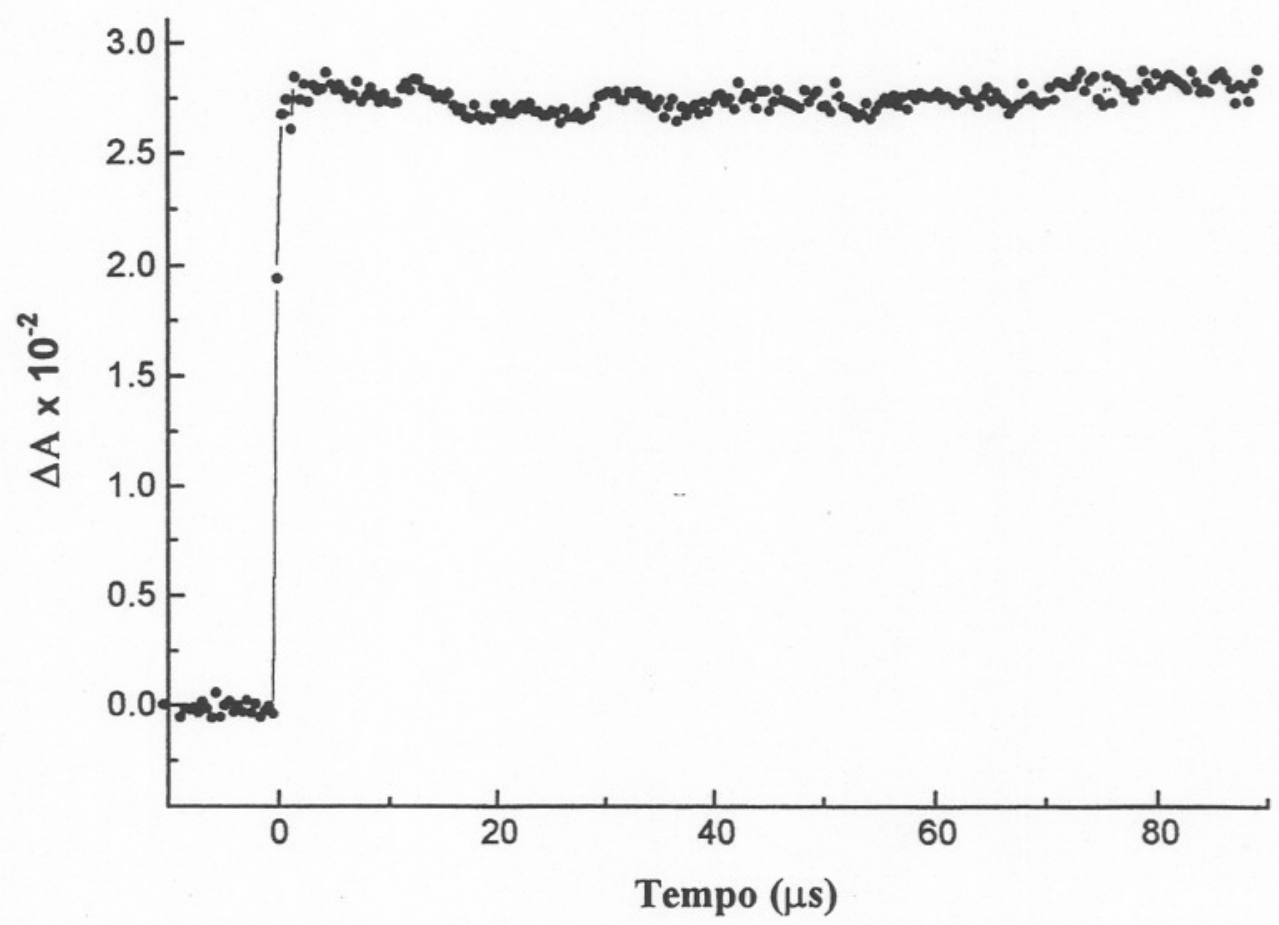

Figura IV.15 - Decaimento, monitorado a 315nm, para uma solução de TBX $\left(A_{266}=0,804\right)$, em iso-octano. 
Em princípio, poder-se-iam admitir dois modelos alternativos para a compreensão do conjunto de dados obtidos nestas fotólises-relâmpago: em um dos casos, a espécie de tempo de vida mais curto seria atribuída ao primeiro estado triplete excitado do substrato e, a de vida mais longa, ao radical gerado pela homólise da ligação $\mathrm{C}-\mathrm{Br}$; no outro, o transiente de vida mais curta seria o radical, enquanto a espécie de maior tempo de vida seria o cátion benzílico a ele correspondente (DORFMAN et alii, 1976; TOKUMURA et alii, 1989a; 1991).

Entretanto, comparando-se os dados apresentados na Tabela IV.9, para o decaimento de estados triplete, em solução, com aqueles apresentados na Tabela I.3 (vide p.14), para as constantes de auto-terminação $\left(2 \mathrm{k}_{\mathrm{r}}\right)$ de radicais benzila (admitindo-se que a concentração das espécies geradas pelo laser seja da ordem de $10^{-5} \mathrm{~mol} . \mathrm{L}^{-1}$ ), conclui-se que, em ambos os casos, a cinética de decaimento do transiente se daria em uma escala de micro-segundos. Por este motivo, exclui-se de per se a hipótese de as espécies detectadas serem, respectivamente, triplete e radical, pois os decaimentos observados apresentam tempos de vida com uma diferença de magnitude da ordem de $10^{3}$.

Tabela IV.9: Tempos de vida triplete $\left(\tau_{\mathrm{T}}\right)$, em solução, à temperatura ambiente.

\begin{tabular}{l||c|l}
\hline \multicolumn{1}{c||}{ COMPOSTO } & $\tau_{\mathrm{T}}(\mu \mathrm{s})$ & \multicolumn{1}{c}{ Referência } \\
\hline \hline$o$-xileno & $\sim 1$ & CUNDALL et ali, 1973-1974 \\
tolueno & 3 & CARMICHAEL \& HUG, 1987 \\
cloro-benzeno & 1,6 & PREVITALI \& EBBESEN,1984 \\
\multicolumn{1}{c|}{} & 2 & LOEFF et alli, 1970 \\
$o$-dicloro-benzeno & 2,22 & ALFASSI \& PREVITALI, 1985 \\
$m$-dicloro-benzeno & 2,70 & $"$ \\
$p$-dicloro-benzeno & 4,35 & $"$ \\
fluoro-benzeno & 0,67 & LOEFF et alli, 1970 \\
anisol & 3,3 & BENT \& HAYON, 1975 \\
\hline
\end{tabular}

A caracterização da espécie de tempo de vida curto pode, ainda, ser feita através do espectro de absorção do transiente para MBX e DBX, casos em que foi possível a deteç̧ão do componente rápido, em iso-octano. A curva de absorção da espécie transiente foi obtida subtraindo-se o espectro gerado para as leituras dos perfis cinéticos (para os vários comprimentos de onda de monitoração) a $10 \mu$ s daquele determinado para os pontos a $0,5 \mu \mathrm{s}$ (curva a-b, Figuras IV.16 e IV.17, a seguir). Este procedimento foi adotado porque a curva obtida para a amostragem a um tempo menor (curva a, Figuras IV.16 e IV.17) se deve à somatória das absorções dos dois transientes, o de tempo de vida curto e o de tempo de vida longo; enquanto a obtida para o tempo maior (curva b, Figuras IV.16 e IV.17) resulta principalmente do $\Delta \mathrm{A}$ do transiente de tempo de vida mais longo. Estes espectros de absorção são os apresentados, a seguir. 


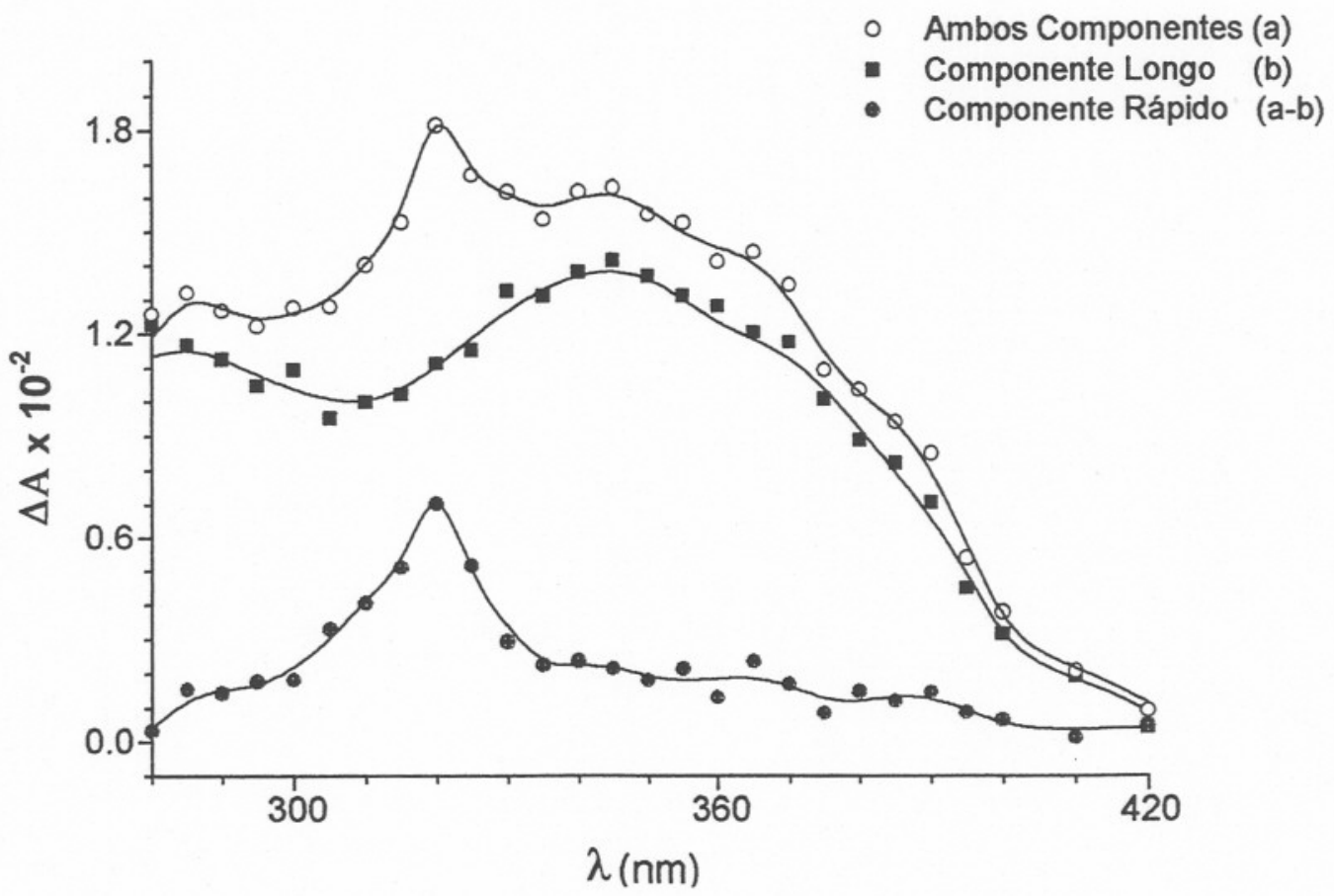

Figura IV.16 - Espectros de absorção para os transientes gerados na fotólise de MBX, em iso-octano $\left(\lambda_{\text {exc }}=266 \mathrm{~nm}\right)$.

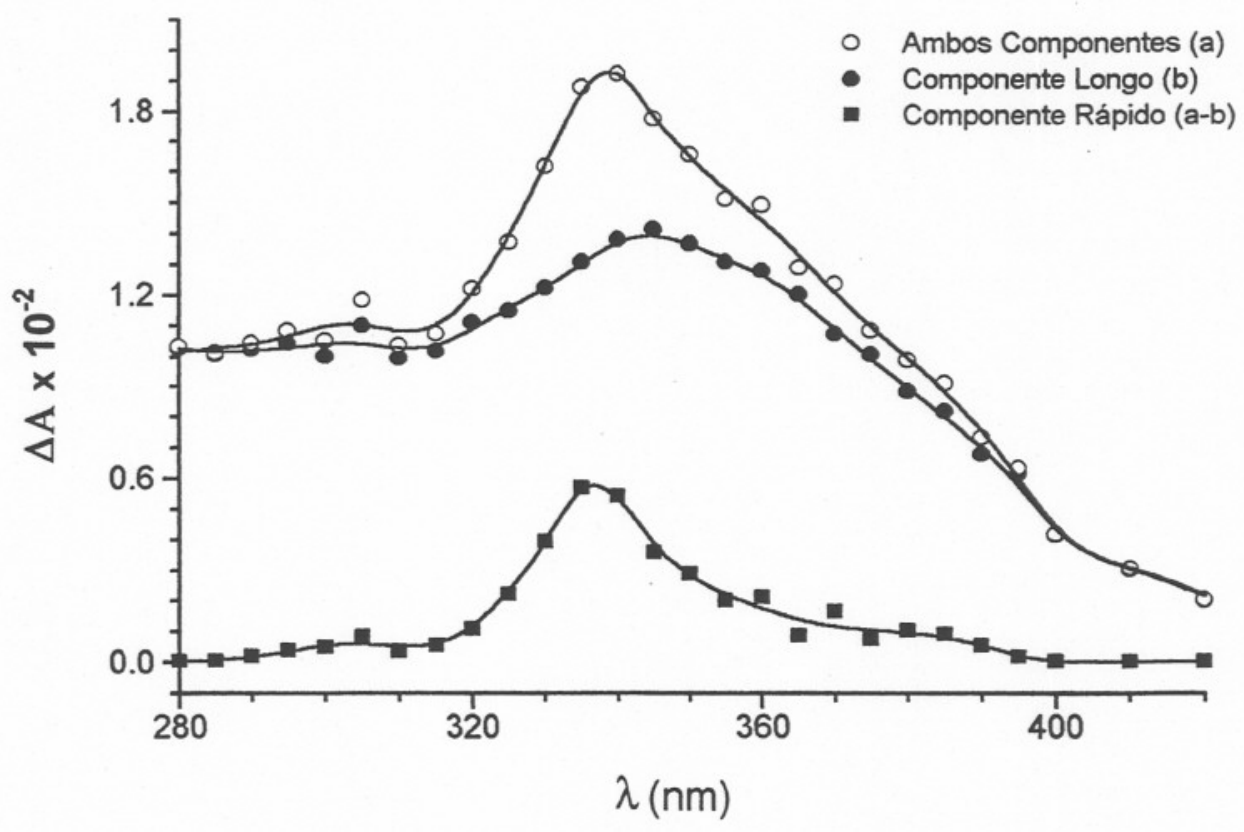

Figura IV.17 - Espectros de absorção para os transientes gerados na fotólise de DBX, em iso-octano ( $\left.\lambda_{\text {exc }}=266 \mathrm{~nm}\right)$. 
Analisando-se, com cuidado, a Tabela IV.10, que sumariza alguns dados de literatura referentes à absorção $\mathbf{T}_{\mathbf{n}} \leftarrow \mathbf{T}_{\mathbf{1}}$ de compostos aromáticos, conclui-se que os dados obtidos para os máximos de absorção da espécie de tempo curto, no presente estudo de fotólise por pulso de laser, não sugerem que este transiente seja um triplete. $\mathrm{O}$ conjunto de dados referentes a naftaleno e a naftalenos substituídos permite a observação de que a faixa de variação dos máximos de absorção é relativamente estreita $( \pm 10 \mathrm{~nm})$, o que indica pouca ou nenhuma influência dos substituintes sobre os máximos de absorção. Por outro lado, enquanto o triplete de benzeno absorve em $235 \mathrm{~nm}$, os dos halo-benzenos apresentam máximos de absorção bem semelhantes entre si, ainda que ocorram a comprimentos de onda $c a$. $60 \mathrm{~nm}$ maiores. Assim, seria de se supor que o máximo de absorção devido aos bromo-xilenos se encontrasse entre 235 e $310 \mathrm{~nm}$, estando possivelmente mais próximo deste último valor, em analogia ao que se verifica nos casos dos halo- e dos halo-metil-naftalenos.

Tabela IV.10: Máximos de absorção $\mathbf{T}_{\mathbf{n}} \leftarrow \mathbf{T}_{\mathbf{1}}$, para alguns compostos aromáticos, em ciclo-hexano.

\begin{tabular}{l||c|c}
\hline \multicolumn{1}{c||}{ Composto } & $\lambda$ (nm) & Referência \\
\hline \hline benzeno & 235 & CARMICHAEL \& HUG, 1986 \\
fluoro-benzeno & 290 & $"$ \\
cloro-benzeno & 295 & $"$ \\
cloro-benzeno & 305 & PREVITALI \& EBBESEN, 1984 \\
o-dicloro-benzeno & 290 & ALFASSI \& PREVITALI, 1985 \\
m-dicloro-benzeno & 310 & $"$ \\
p-dicloro-benzeno & 290 & $"$ \\
\hline naftaleno & 415 & CARMICHAEL \& HUG, 1986 \\
1-cloro-metil-naftaleno & 422 & $"$ \\
1-cloro-naftaleno & 427 & $"$ \\
2-cloro-naftaleno & 420 & $"$ \\
1-bromo-metil-naftaleno & 426 & $"$ \\
1-bromo-naftaleno & 424 & $"$ \\
2-bromo-naftaleno & 425 & $"$ \\
1-metil-naftaleno & 420 & $"$ \\
2-metil-naftaleno & 420 & $"$ \\
1,2-dimetil-naftaleno & 420 & $"$ \\
2,3-dimetil-naftaleno & 420 & $"$ \\
\hline
\end{tabular}

Portanto, eliminada a hipótese de que os transientes de menor tempo de vida fossem os primeiros estados triplete excitados dos substratos irradiados, a espécie obtida, no caso da fotólise de MBX, deve ser o radical o-metil-benzila. O máximo de absorção determinado (320nm) confirma esta atribuição, pois seu valor é compatível com os de literatura, como mostram as Tabelas I.1 (p. 10) e IV.11, a seguir. Já no caso de 
DBX, o comprimento de onda de máxima absorção do transiente é maior do que o esperável pois, tanto a presença de diferentes substituintes, como alterações significativas no meio, alteram muito pouco o máximo de absorção determinado para os radicais benzila, como demonstra uma análise dos valores sumarizados nas já referidas Tabelas I.1 e IV.11. Pode-se admitir, entretanto, que a presença do substituinte bromometil em orto tenha um efeito mais pronunciado do que substituições diretas no anel (caso dos compostos para os quais há dados disponiveis na literatura). Isso se deveria à maior facilidade de dispersão de carga através dos orbitais $\mathrm{d}$, propiciada pela presença do bromo ligado ao anel aromático através de uma metilena, em condições de alcançar um arranjo geométrico particularmente favorável ao estabelecimento de uma estrutura do tipo anel de cinco membros.

Tabela IV.11: Máximos de absorção ( transição $\mathbf{D}_{\mathbf{3}} \leftarrow \mathbf{D}_{\mathbf{0}}$ ) para os radicais benzila gerados nas fotólises por pulso de laser, em comparação a dados de literaturac .

\begin{tabular}{|c|c|c|c|c|}
\hline Composto & $\begin{array}{l}\text { Radicais } \\
\text { Benzila } \\
\end{array}$ & Solvente & $\begin{array}{c}\lambda \\
(\mathrm{nm})^{a}\end{array}$ & Referência \\
\hline & $\mathrm{H}$ & $\begin{array}{l}\text { ciclo-hexano } \mathrm{c} \\
\text { hexano }+\mathrm{O}_{2} \mathrm{c} \\
\text { hexano } \mathrm{c} \\
\text { benzeno } \mathrm{c} \\
\text { matriz de EPA c }\end{array}$ & $\begin{array}{ll}316 & \mathrm{c} \\
312 & \mathrm{c} \\
315 & \mathrm{c} \\
310 & \mathrm{c} \\
321 & \mathrm{c} \\
\end{array}$ & $\begin{array}{l}\text { CLARIDGE \& FISCHER (1983) } \\
\text { TOKUMURA et alif (1990) } \\
\text { TOKUMURA et ali (1987) } \\
\text { SCAIANO \& SUGAMORI (1988) } \\
\text { OKAMURA \& TANAKA (1975) }\end{array}$ \\
\hline MBX & o-metil- (44) & $\begin{array}{l}\text { iso-octano }^{\text {a }} \\
\text { ciclo-hexano } \\
\text { matriz de EPA }\end{array}$ & $\begin{array}{ll}320 & \mathrm{a} \\
321,5 & \mathrm{c} \\
323 & \mathrm{c}\end{array}$ & $\begin{array}{l}\text { CLARIDGE \& FISCHER (1983) } \\
\text { PORTER \& STRACHAN (1958) }\end{array}$ \\
\hline DBX & o-(bromo-metil)- (41) & $\begin{array}{l}\text { iso-octano }{ }^{a} \\
\text { benzeno } b\end{array}$ & $\begin{array}{ll}338 & \text { a } \\
333 & \text { b }\end{array}$ & \\
\hline TBX & $\alpha$-bromo-o-(dibromo-metil)- (49) & benzeno $\mathbf{b}$ & 361 b & \\
\hline & $\begin{array}{l}\text { 4-bromo- } \\
\text { 2-cloro- } \\
\text { 3-cloro- } \\
\text { 4-cloro- }\end{array}$ & $\begin{array}{l}\text { hexano } \\
\text { ciclo-hexano } \\
\text { ciclo-hexano } \\
\text { hexano }+\mathrm{O}_{2} \mathrm{c} \\
\text { ciclo-hexano } \mathrm{c}\end{array}$ & $\begin{array}{ll}314 & \mathrm{c} \\
325 & \mathrm{c} \\
324 & \mathrm{c} \\
314 & \mathrm{c} \\
317 & \mathrm{c}\end{array}$ & $\begin{array}{l}\text { TOKUMURA et ali (1989b) } \\
\text { CLARIDGE \& FISCHER (1983) } \\
\text { CLARIDGE \& FISCHER (1963) } \\
\text { CLARIDGE \& FISCHER (1983) } \\
\text { CLARIDGE \& FISCHER (1983) }\end{array}$ \\
\hline
\end{tabular}

a. determinado com laser de Nd:YAG $(\lambda=266 \mathrm{~nm})$, no presente trabalho;

b. determinado com laser de exímero $(\lambda=308 \mathrm{~nm})$, no presente trabalho;

c. dados de literatura.

Com o objetivo de confirmar a atribuição dos intermediários de tempo de vida mais curto como sendo radicais, estudou-se a fotólise de DBX, em iso-octano, na presença de ciclo-hexeno (vide Figura IV.18, p. 97). Observou-se diminuição da magnitude do tempo de vida do intermediário rápido $(\tau=(3,1 \pm 0,5) \mu \mathrm{s})$, em comparação com as medidas feitas em iso-octano puro. Este resultado seria o previsível caso a espécie 
transiente fosse um radical, pois, como o ciclo-hexeno é um doador de $\mathrm{H}^{\bullet}$ mais eficaz do que iso-octano, o radical $o$-(bromo-metil)benzila (41) deveria ser suprimido mais eficientemente nesta situação do que em iso-octano puro, pois uma rota alternativa que favorece a desativação do radical por abstração de hidrogênio é criada. Comparandose as curvas de decaimento obtidas para DBX na presença e na ausência de ciclohexeno (Figuras IV.13, p.91, e IV.18, a seguir), verifica-se que não houve alteração significativa na absorbância da espécie excitada, detectada imediatamente após o pulso de laser. Esta observação indica que ciclo-hexeno é um supressor seletivo destes radicais, não afetando o estado excitado do qual eles provêm. Isto sugere que estes estados precursores sejam estados singlete excitados de DBX, com tempo de vida muito mais curto do que o determinado para o radical $o$-(bromo-metil)benzila (41), pois $0^{3}\left[\mathbf{D B X} \mathbf{X}^{*}\right]$, de tempo de vida da mesma ordem de grandeza daquela do radical, também seria suprimido.

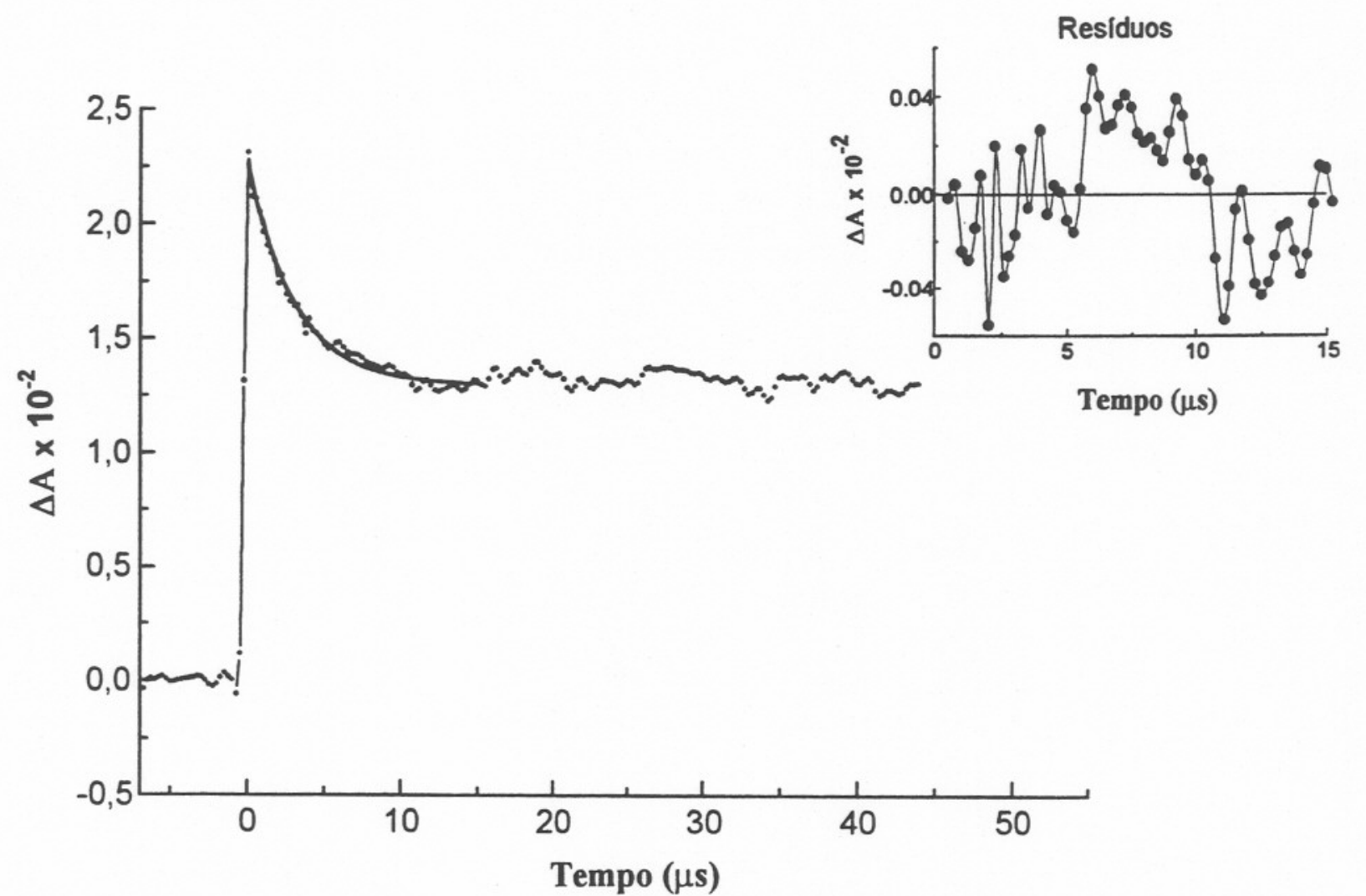

Figura IV.18 - Decaimento $\left(\tau=(3,1 \pm 0,5) \cdot 10^{-6} \mathrm{~s}\right)$, monitorado a $340 \mathrm{~nm}$, para uma solução de DBX, em iso-octano $\left(A_{266}=1,023\right)$, em presença de ciclo-hexeno $\left(\mathrm{C}_{\text {molar }}=3,9.10^{-2} \mathrm{~mol}_{\mathrm{L}} \mathrm{L}^{-1}\right)$.

Dados adicionais sobre a fotólise de dois dos compostos bromados (DBX e TBX) foram obtidos no laboratório da Dra. Cornelia Bohne, na Universidade de Victoria (Victoria, B.C., Canadá), a nosso pedido. Lá, os experimentos de fotóliserelâmpago foram realizados utilizando-se um laser de exímero de $\mathrm{XeCl}$, cujo $\lambda$ de emissão (308nm) possibilitou que se empregasse benzeno como solvente. Estes resul- 
tados deveriam permitir que se estabelecesse uma correlação mais direta entre a fotorreatividade destes compostos, analisada a partir da fotólise convencional, e as informações sobre os transientes, obtidas da fotólise por pulso de laser. Perfis típicos dos decaimentos cinéticos devidos às espécies transientes geradas nestes experimentos (monitorados a 330nm) estão apresentados nas Figuras IV.19 e IV.20, a seguir. A análise destes decaimentos de acordo com uma cinética de primeira ordem (ou seja, admitindo-se que a desativação do radical se dê predominantemente por um processo de pseudo-primeira ordem) mostra que o tempo de vida de DBX aumenta, em relação ao que havia sido observado em iso-octano (vide Tabela IV.11, à página 99).

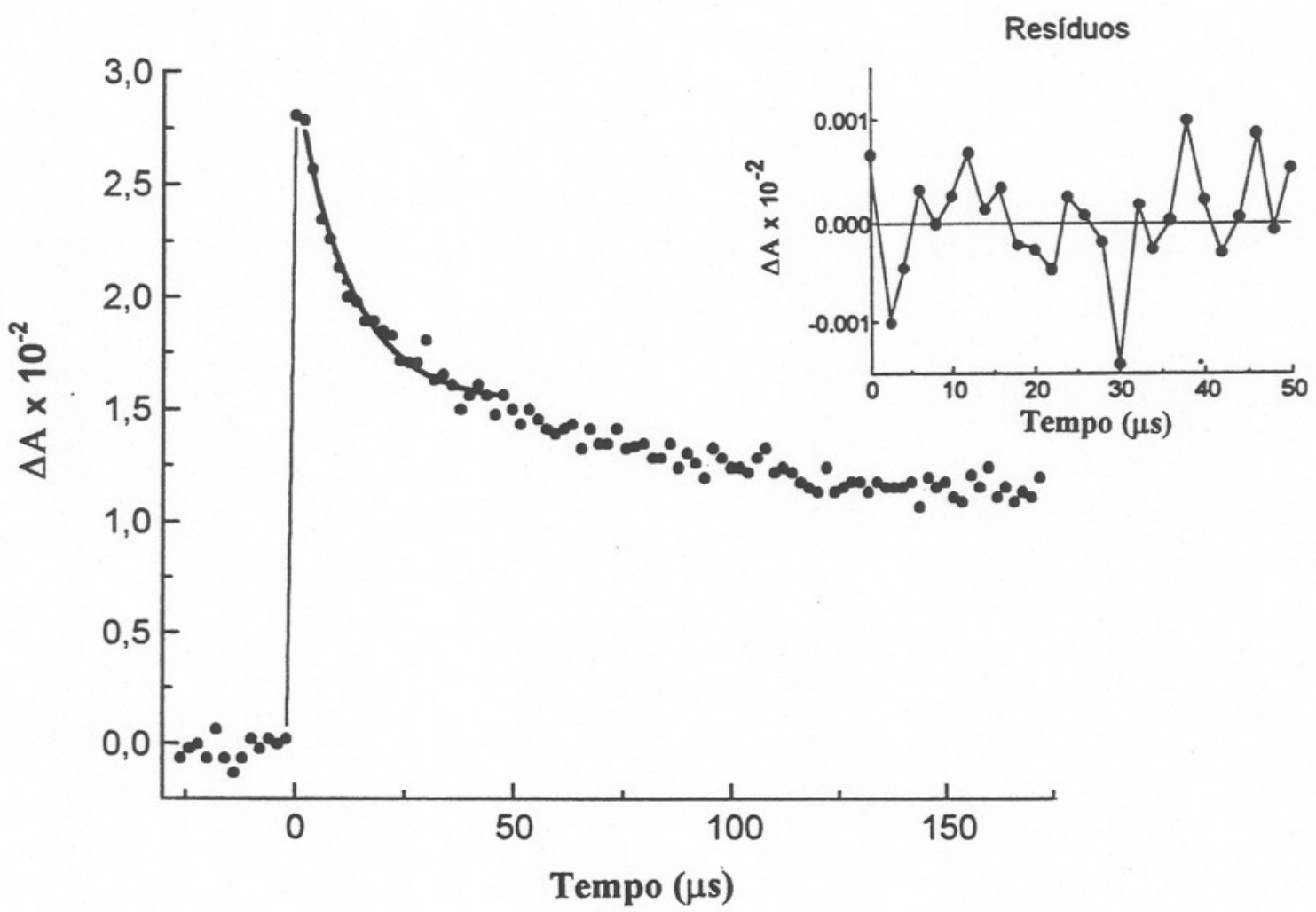

Figura IV.19 - Decaimento, monitorado a $330 \mathrm{~nm}\left(\lambda_{\text {exc }}=308 \mathrm{~nm}\right)$, para uma solução de DBX, em benzeno $\left(\tau=(13,2 \pm 0,5) \cdot 10^{-6} \mathrm{~s}\right.$.

Apenas nas medidas cinéticas feitas em benzeno foi detectada a componente rápida de TBX (Figura IV.20, p.99), o que não havia sido possível ao se fotolisarem soluções de TBX em iso-octano com o laser de Nd:YAG (quadruplicado: $\lambda=266 \mathrm{~nm}$; vide Figura IV.15, p.92). Os valores encontrados para os tempos de vida aparentes, determinados a partir das constantes obtidas por ajuste (através da relação $1 / \mathrm{k}_{\mathrm{obs}}=\tau$ ), para cada um dos decaimentos rápidos (em iso-octano e em benzeno), estão sumarizados na Tabela IV.12, a seguir, para facilitar a comparação entre os dados obtidos nos dois solventes. 


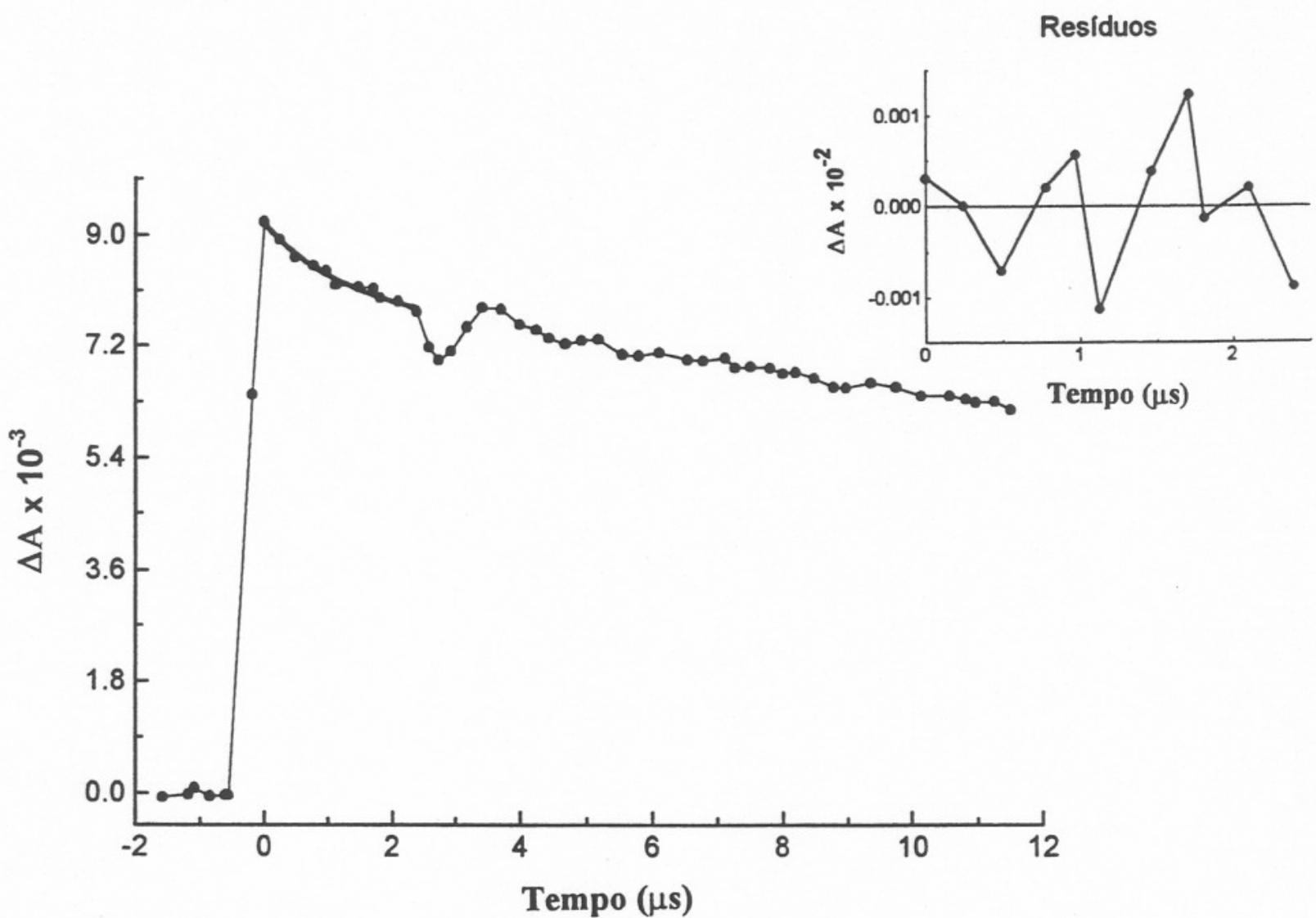

Figura IV.20 - Decaimento, monitorado a 330nm, para uma solução de TBX $\left(\lambda_{\text {exc }}=308 \mathrm{~nm}\right)$, em benzeno $\left(\tau=1,5 \cdot 10^{-6} \mathrm{~s}\right)$.

Tabela IV.12: Tempos de vida aparentes, para os transientes gerados na fotólise por pulso de laser.

\begin{tabular}{c||l|c|c|c|c}
\hline Composto & \multicolumn{1}{|c|}{ Radicais Benzila $^{\mathbf{d}}$} & Solvente & $\begin{array}{c}\tau^{\mathbf{a}} \\
(\mu \mathrm{s})\end{array}$ & Solvente & $\begin{array}{c}\tau^{\mathbf{b}} \\
(\mu \mathrm{s})\end{array}$ \\
\hline \hline MBX & o-metil- (44) & iso-octano & $4,0 \pm 0,5$ & benzeno & - \\
DBX & o-(bromo-metil)- (41) & iso-octano & $8,8 \pm 0,5$ & benzeno & 13,2 \\
DBX & o-(bromo-metil)- (41) & iso-octano/ciclo-hexeno & $3,1 \pm 0,5$ & - & - \\
GBX & $\alpha$-bromo-o-metil- (52) & iso-octano & $\mathbf{c}$ & benzeno & - \\
TBX & $\alpha$-bromo-o-(dibromo-metil)- (49) & iso-octano & $\mathbf{c}$ & benzeno & 1,5 \\
\hline
\end{tabular}

a. laser de Nd:YAG $(\lambda=266 \mathrm{~nm})$; b. laser de exímero $(\lambda=308 \mathrm{~nm})$; c. não-detectável.

d. os números em negrito remetem aos ESQUEMAS IV.1 a 5 (vide item IV.1), referentes à discussão sobre as fotólises convencionais.

A ordem de grandeza dos tempos de vida determinados, na faixa de $\mu$ s, é consistente com a hipótese de que os transientes responsáveis pelo componente rápido do sinal sejam radicais (vide Tabela I.3, à p.14). O fato de as magnitudes dos tempos de vida aparentes serem maiores, em benzeno, do que em iso-octano, vem a fortalecer esta suposição, pois este solvente, diferentemente de benzeno, apresenta um hidrogênio terciário, passível de abstração, em sua estrutura. Assim, não é de surpreender que, em benzeno, tenha sido possível a detecção do decaimento do transiente rápido gerado na fotólise de TBX, enquanto, em iso-octano, este decaimento estaria fora dos limites temporais de detecção do sistema. 
Os espectros de absorção das espécies transientes geradas nas fotólises de TBX e DBX, em benzeno, foram obtidos monitorando-se os decaimentos cinéticos a vários comprimentos de onda, e encontram-se nas Figuras IV.21 e IV.22. Os comprimentos de onda em que ocorrem os máximos destes espectros de absorção também são compatíveis com os dados de literatura referentes à transição $\mathbf{D}_{\mathbf{3}} \leftarrow \mathbf{D}_{\mathbf{0}}$ para radicais benzila (vide Tabelas I.1, p.10, e IV.11, à página 96), como o haviam sido aqueles determinados em iso-octano (Figuras IV.16 e IV.17, p.94).

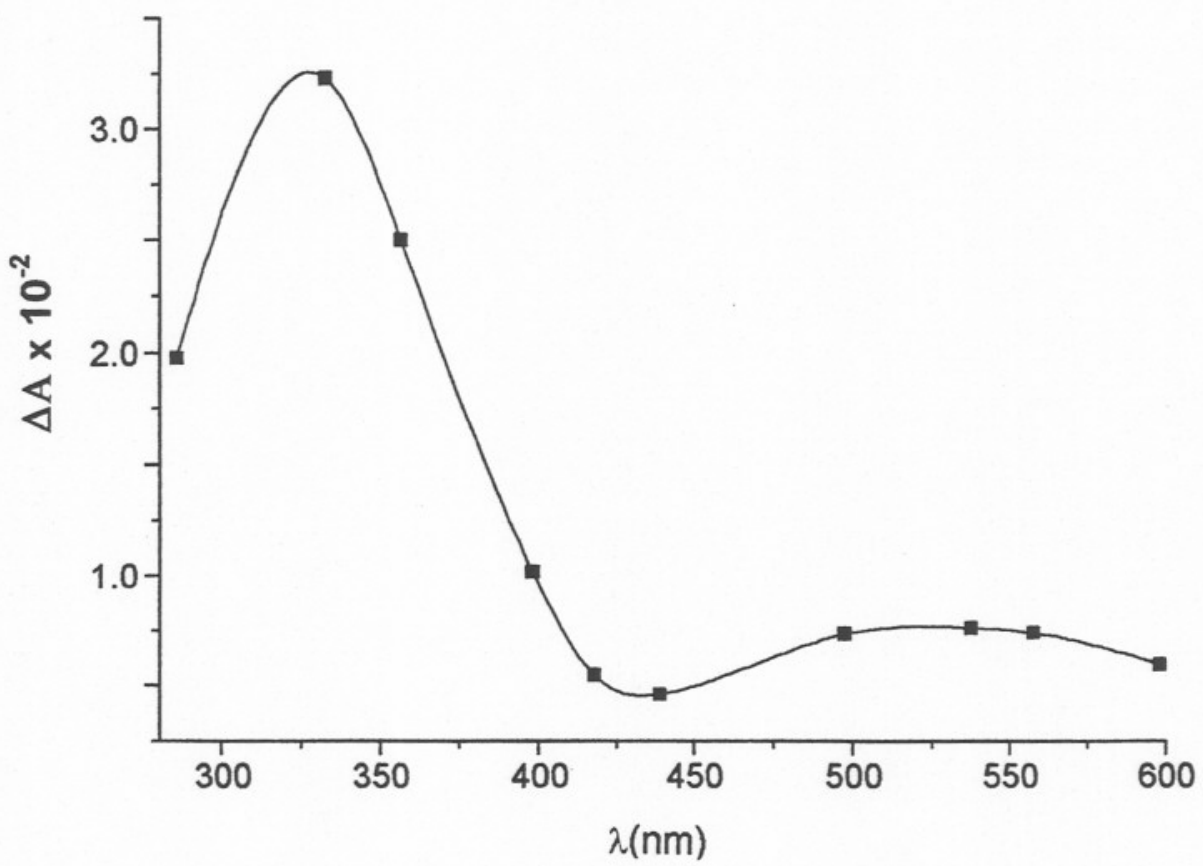

Figura IV.21 - Espectros de absorção para os transientes gerados na fotólise de DBX, em benzeno $\left(\lambda_{\text {exc }}=308 \mathrm{~nm}\right)$.

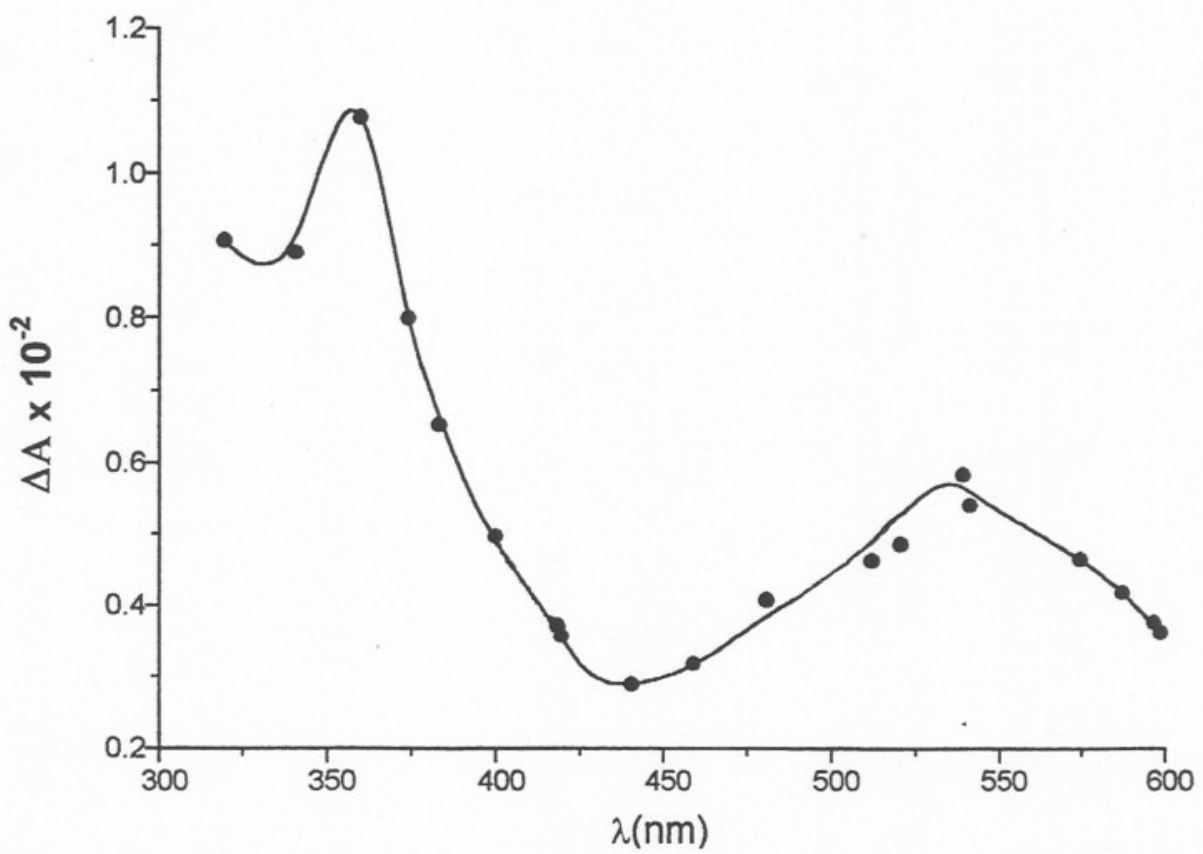

Figura IV.22 - Espectros de absorção para os transientes gerados na fotólise de TBX em benzeno $\left(\lambda_{\text {exc }}=308 \mathrm{~nm}\right)$. 
Nas distribuições espectrais obtidas em solução benzênica discerne-se, ainda, uma banda larga adicional ( $\lambda_{\max } \sim 500-550 \mathrm{~nm}$ ), cujo decaimento apresenta uma cinética diferente daquela devida ao radical benzila proveniente do substrato fotolizado, como mostra a Figura IV.23, para a fotólise de TBX em benzeno. Analisando-se esse decaimento, verifica-se que o tempo de vida obtido por um tratamento de primeira ordem $(\tau=0,33 \mu \mathrm{s})$ difere significativamente daqueles determinados para os outros transientes (vide Tabela IV.12, à p.99), mostrando que esta banda deve-se à formação de uma nova espécie transiente. Uma curva de decaimento com perfil semelhante foi observada no caso de DBX, ao se monitorar o sinal nesse mesmo comprimento de onda $(550 \mathrm{~nm})$, indicando que a nova espécie está presente também nesse caso. Os espectros de absorção desse novo transiente obtidos, tanto de DBX, quanto de TBX, em benzeno, são compatíveis com aqueles descritos na literatura (BOSSY et alii,1970; BÜHLER, 1972; MCGIMPSEY \& SCAIANO, 1988; WEIR, JOHNSTON \& SCAIANO, 1988) como sendo devidos ao complexo $\mathrm{Br}$ /benzeno, o que explica a sua ocorrência apenas em benzeno, além de reforçar a identificação da banda principal como sendo correspondente à absorção do radical benzila.

Por outro lado, a complexação, ao dificultar a recombinação do par radicalar, contribui para aumentar o tempo de vida aparente dos radicais benzila, em relação ao que se observou em iso-octano, o que explica o fato de, apenas em benzeno, se ter observado o transiente devido ao radical $\alpha$-bromo-o-(dibromo-metil)benzila (49).

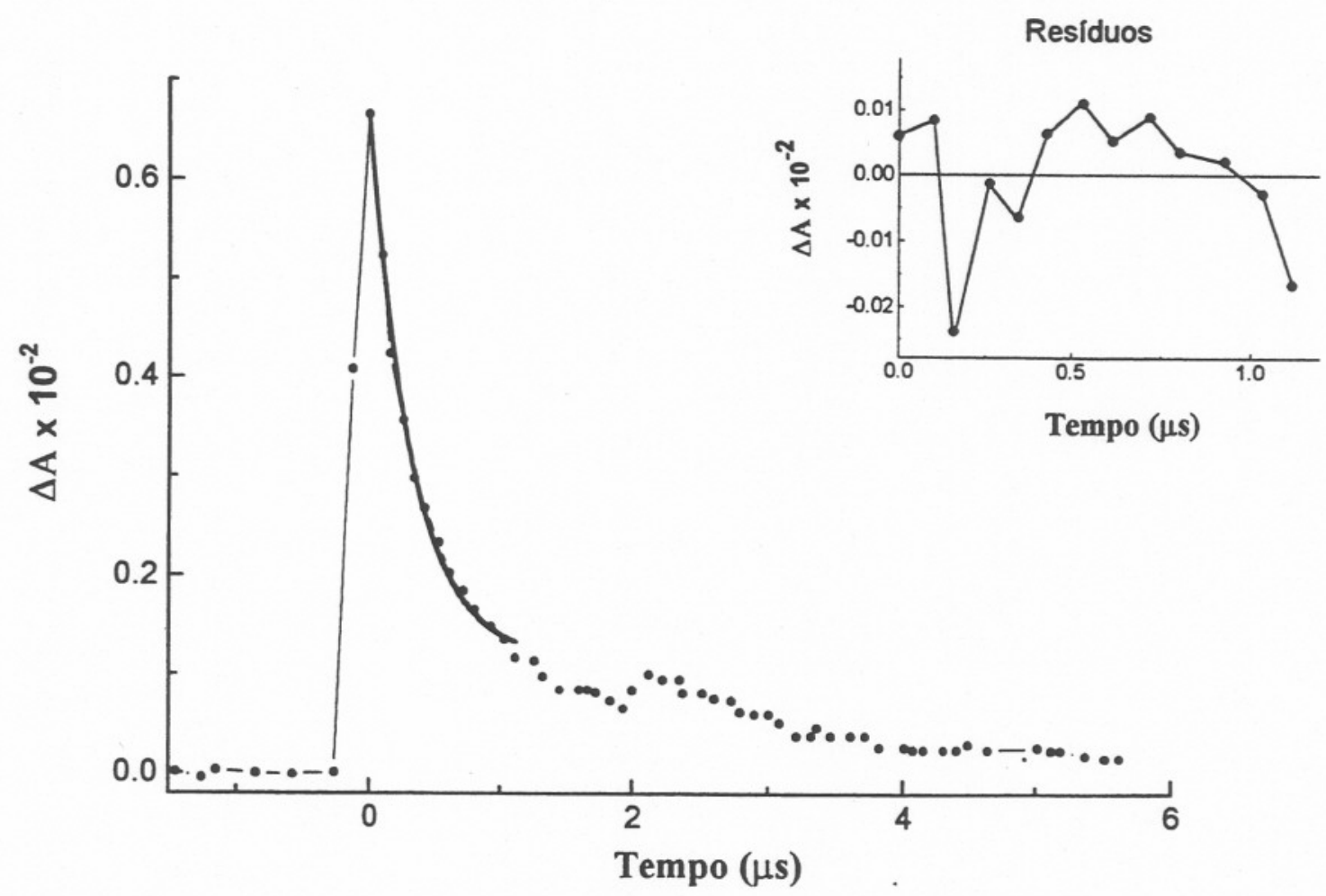

Figura IV.23 - Decaimento, monitorado a 550nm, para a fotólise de uma solução de TBX $\left(\lambda_{\text {exc }}=308 \mathrm{~nm}\right)$, em benzeno $\left(\tau=0,33 \cdot 10^{-6} \mathrm{~s}\right)$. 
Considerando-se a totalidade dos dados obtidos para os transientes de menor tempo de vida, conclui-se serem, estas espécies, radicais gerados pela foto-homólise da ligação $\mathrm{C}-\mathrm{Br}$ (vide estruturas abaixo), a partir de um estado singlete excitado (provavelmente $\mathbf{S}_{2}$; vide Figura I.V B, à p.5).

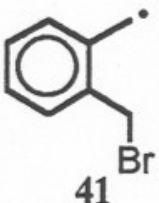

41

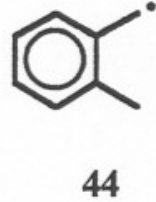

44
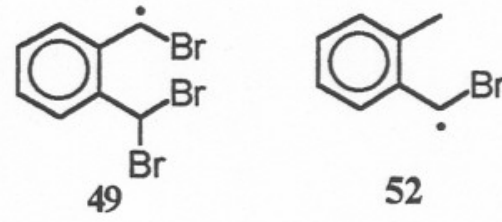

52

Sendo os transientes radicais, compreende-se que a espécie 41, o-(bromo-metil)benzila, seja estabilizada em relação à 44 (o-metil-benzila), em cerca de duas vezes, pela presença de um substituinte bromo-metila em orto, que facilitaria a deslocalização do elétron do orbital não-ligante, por interação envolvendo os orbitais d. Por outro lado, seria de se esperar que o radical 49, obtido pela fotólise de TBX, fosse estabilizado pela presença de um átomo de bromo em ipso. Entretanto, tanto o radical 49, como o radical $\mathbf{5 2}$ (gerado na fotólise de GBX), têm constantes de decaimento mais altas do que as observadas para o caso dos radicais 41 e 44, como mostram os dados da Tabela IV.12 (vide p.99). Este conjunto de dados sugere que a recombinação do par radicalar $\mathrm{R}^{\cdot} / \mathrm{Br}^{*}$, regenerando o composto de partida, deva ser um processo mais significativo para os radicais 49 e 52, do que para os radicais 41 e 44 . Em sendo assim, a aparente incongruência entre o aumento da foto-estabilidade, verificado nas fotólises convencionais, e a diminuição do tempo de vida da espécie transiente, verificada nas fotólises por pulso de laser, pode ser compreendida de maneira simples, caso se admita que os radicais provenientes dos xilenos bromados geminais, embora mais reativos, tenham a recombinação com bromo fortemente favorecida sobre a abstração de hidrogênio, com o efeito macroscópico de diminuir a conversão em produtos. Este tropismo por $\mathrm{Br}^{*}$ apresentado pelos radicais benzila gerados a partir de GBX e TBX (49 e 52) seria, de alguma forma, efeito da presença de bromo em ipso, nestes radicais.

Os máximos observados nas distribuições espectrais obtidas nas fotólises -relâmpago de MBX, DBX e TBX (em iso-octano e/ou em benzeno, vide Tabela IV.11, p.96), contribuem para consolidar a atribuição proposta para o transiente de tempo de vida curto. Para MBX, como já discutido, o comprimento de onda em que ocorre a transição concorda com os valores apresentados na literatura (vide Tabelas I.1, p.10 e IV.11, p.96) como sendo devidos à transição $\mathbf{D}_{\mathbf{3}} \leftarrow \mathbf{D}_{\mathbf{0}}$ do radical $o$-metil-benzila (44). Entretanto, os transientes gerados nas fotólises, tanto de DBX, como de TBX, absorvem em comprimentos de onda maiores que o esperado, visto o pequeno efeito de substituinte verificado nos vários estudos anteriores (vide Tabelas I.1, p.10 e IV.11, p.96). No caso de DBX, propusemos (vide p.96) que o deslocamento observado, em relação a $\mathbf{M B X}(\Delta=+18 \mathrm{~nm}$, em iso-octano), se devesse à maior estabilização do radical 41, devida à presença do grupo bromo-metila em orto. Para TBX $\left(\lambda_{\max }=361 \mathrm{~nm}\right.$, 
em benzeno), seria de se prever que ocorresse um deslocamento ainda maior, para menores energias, causado pela combinação dos efeitos de um bromo em ipso e de um substituinte gem-dibromo-metila em orto, no radical 49. Pode-se considerar que este último substituinte tenha, no mínimo, o mesmo efeito que o causado por bromo-metila e, no máximo, seja duas vezes mais estabilizante. Quanto ao bromo em ipso, seu efeito pode ser estimado por analogia àquele exibido por cloro, com base nos dados referentes aos radicais 57e e f (Tabela IV.13), os quais mostram que o $\Delta$ é de $+10 \mathrm{~nm}$.<smiles>Cc1ccccc1C(Br)Br</smiles>
55<smiles>[Z]c1ccc(Cc2ccc([Z])cc2)cc1</smiles>

56<smiles>[Z]c1ccc(C([Y])c2ccc([Z])cc2)cc1</smiles>

57

A hipótese alternativa (vide p.90) de, no caso de GBX e TBX, o transiente de vida curta ser um carbeno, pode agora ser refutada, à vista dos dados coligidos na Tabela IV.13, referentes a carbenos e radicais de mesmo esqueleto carbônico: em uma série, carbenos (56) sempre absorvem a menores comprimentos de onda que os correspondentes radicais (57); um eventual carbeno derivado de TBX (55) deveria absorver a comprimentos de onda menores (ou próximos) ao observado para o radical 41, considerado o efeito do substituinte em orto, discutido acima. Entretanto, 41 absorve a $333 \mathrm{~nm}$ (em benzeno), e a absorção devida ao transiente de TBX encontra-se deslocada em $+28 \mathrm{~nm}$ desse valor, sendo, portanto, incompatível com um carbeno, mas razoável para um radical (i.e. 49), como discutido no parágrafo anterior.

Tabela IV.13: Máximos de absorção para difenilcarbenos e radicais benzidrila.

\begin{tabular}{c||c|l|c|c|c}
\hline Composto & $\mathbf{Y}$ & $\mathbf{Z}$ & Solvente & $\lambda_{\max }(\mathbf{n m})$ & File $^{\mathbf{a}}$ \\
\hline \hline 56a & -- & $\mathrm{Cl}$ & ciclo-hexano & 320 & 50 \\
$\mathbf{5 6 b}$ & --- & $\mathrm{Br}$ & ciclo-hexano & 320 & 53 \\
\hline $\mathbf{5 7 a}$ & $\mathrm{H}$ & $\mathrm{Cl}$ & ciclo-hexano & 340 & 190 \\
$\mathbf{5 7 b}$ & $\mathrm{H}$ & $\mathrm{Br}$ & ciclo-hexano & 350 & 52 \\
$\mathbf{5 7 c}$ & $\mathrm{H}$ & $\mathrm{Me}$ & ciclo-hexano & 340 & 51 \\
$\mathbf{5 7 d}$ & $\mathrm{H}$ & $\mathrm{MeO}$ & ciclo-hexano & 350 & 49 \\
$\mathbf{5 7 e}$ & $\mathrm{H}$ & $\mathrm{H}$ & ciclo-hexano & 330 & 54 \\
$\mathbf{5 7 f}$ & $\mathrm{Cl}$ & $\mathrm{H}$ & iso-octano & 340 & 158 \\
\hline
\end{tabular}

a. a entrada file indica o número do arquivo que contém o espectro, em Scaiano \& Sugamori (1988). 
Resta, entretanto, uma última questão: qual espécie seria a responsável pela absorção transiente detectada a tempos longos, em todas as fotólises?

Estes transientes, de tempo de vida aparente da ordem de mili-segundos, apresentam uma distribuição espectral na qual se observa uma banda larga e desestruturada $\left(\lambda_{\max }=345 \mathrm{~nm}\right.$, vide curva $\mathrm{b}$ das Figuras IV.16 e IV.17, à p.94). TOKUMURA et alii (1987; 1989a e 1991), tendo observado fenômeno análogo nas fotólises-relâmpago de outros haletos de benzila, sugeriram que a espécie observada fosse um cátion benzílico, cujo tempo de vida deveria ser longo, em solvente apolar, na ausência de nucleófilos. Uma análise da Figura I.5 (à p.5) reforça esta suposição, pois cátions poderiam ser formados a partir de estados $S_{1}$ de energias e geometrias semelhantes às daqueles envolvidos (possivelmente, $\mathbf{S}_{\mathbf{2}}$ ) quando da formação dos radicais benzila detectados em nossos experimentos de fotólise por pulso de laser. Alternativamente, também de $\mathbf{S}_{\mathbf{1}}$, poderiam ser obtidos radicais bromo e benzila excitado, o qual tem a opção de emitir um elétron como uma das vias de decaimento, de forma que o processo global, neste caso, levaria à formação de cátion benzila, radical bromo e elétron.

Por outro lado, a existência de cátions benzila encontra-se, atualmente, bem documentada na literatura (vide, por exemplo, DORFMAN et alii, 1976; LIFSHITZ, 1994; OLAH, 1995); alguns dados selecionados, referentes a espectros de absorção deste tipo de cátions, na região do UV/Vis, estão apresentados na Tabela IV.14, a seguir. A análise dos valores relatados para os máximos de absorção desta série de cátions mostra que o comprimento de onda em que ocorre a transição mais favorecida abrange uma faixa razoavelmente larga, variando de $318 \mathrm{~nm}$ (para 2,4,6-trimetil-benzila) a $364 \mathrm{~nm}$, para 4-bromo-2,3,5,6-tetrametil-benzila, sendo as absortividades molares da ordem de $10^{4} \mathrm{~L} \cdot \mathrm{mol}^{-1} \cdot \mathrm{cm}^{-1}$. Os espectros apresentados na literatura mostram que estas bandas são largas e desestruturadas. Estes dados de literatura são compatíveis com os resultados experimentais que obtivemos para as espécies de tempo de vida longo, em nossos estudos de fotólise por pulso de laser (vide distribuição espectral mostrada nas Figuras IV.16 e IV.17, à p.94).

Na Tabela IV.15 estão sumarizados alguns dados referentes a difenil- e trifenilcarbocátions, que permitem avaliar o efeito de solvente sobre a posição dos máximos de absorção de cátions de carbono e evidenciam diversas características desse tipo de cromóforo. Para facilitar a análise dos dados coligidos nas Tabelas IV.14 e IV.15, é necessário ressaltarem-se alguns pontos: (i) os cátions benzílicos costumam apresentar mais de um máximo de absorção, sendo a banda a menores comprimentos de onda a de maior intensidade; (ii) já no caso dos difenil- e trifenil- carbocátions apresentados na Tabela IV.15, a banda de maior intensidade é a detectada a maiores comprimentos de onda; (iii) em alguns casos, os autores relatam o valor correspondente a apenas uma das bandas, em geral, a mais intensa dentre as observáveis, como, por exemplo, o fizeram JONES \& DORFMAN (1974) e SUJDAK et alii (1976), em seus estudos de radiólise por pulso de elétrons. 
Tabela IV.14: Espectros de absorção devidos a cátions benzila.

\begin{tabular}{|c|c|c|c|c|}
\hline Cátion & $\begin{array}{l}\lambda_{\max } \\
(\mathbf{n m})\end{array}$ & 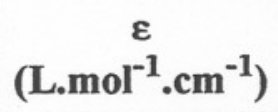 & Solvente & Referência \\
\hline$\Phi \mathrm{CH}_{2}{ }^{\oplus}$ & 363 & -- & $\mathrm{ClCH}_{2} \mathrm{CH}_{2} \mathrm{Cl}$ & JONES \& DORFMAN, 1974. \\
\hline$\Phi \mathrm{CMe}_{2} \oplus$ & $\begin{array}{l}326 \\
390\end{array}$ & $\begin{array}{l}1,1.10^{4} \\
1,4.10^{3}\end{array}$ & $\begin{array}{c}\mathrm{FSO}_{3} \mathrm{H} / \mathrm{SbF}_{5} \\
\left(-50^{\circ} \mathrm{C}\right)\end{array}$ & OLAH et alii, 1968. \\
\hline$\Phi \mathrm{MeCF}_{3} \mathrm{C}^{\oplus}$ & 347 & $3,4.10^{3}$ & $"$ & OLAH et alii, 1968. \\
\hline & $\begin{array}{l}318 \\
370 \\
480\end{array}$ & $\begin{array}{l}1,1 \cdot .10^{4} \\
4,4 \cdot 10^{3} \\
1,2 \cdot 10^{3}\end{array}$ & $\begin{array}{c}\mathrm{FSO}_{3} \mathrm{H} / \mathrm{SbF}_{5} \\
\left(-50^{\circ} \mathrm{C}\right)\end{array}$ & BOLLINGER et alii, 1967. \\
\hline & $\begin{array}{l}329 \\
338 \\
392 \\
520\end{array}$ & $\begin{array}{cc}1,7 & .10^{4} \\
1,6 & .10^{4} \\
2,1 & .10^{3} \\
2,1 & .10^{3}\end{array}$ & $"$ & BOLLINGER et alii, 1967. \\
\hline & $\begin{array}{l}362 \\
455\end{array}$ & $\begin{array}{l}7,2.10^{3} \\
1,5.10^{3}\end{array}$ & $"$ & BOLLINGER et alii, 1967. \\
\hline & $\begin{array}{l}364 \\
540\end{array}$ & $\begin{array}{l}1,2.10^{4} \\
2,4.10^{3}\end{array}$ & " & BOLLINGER et alii, 1967. \\
\hline & 338 & $1,2.10^{4}$ & $"$ & BOLLINGER et alii, 1967. \\
\hline & $\begin{array}{l}334 \\
416\end{array}$ & $\begin{array}{l}2,4.10^{3} \\
0,7.10^{3}\end{array}$ & " & BOLLINGER et alii, 1967. \\
\hline
\end{tabular}


Tabela IV.15: Espectros de absorção devidos a cátions di- e tri-fenil-metila.

\begin{tabular}{|c|c|c|c|c|}
\hline Cátion & $\lambda_{\max }(\mathrm{nm})$ & $\varepsilon\left(\mathrm{L} \cdot \mathrm{mol}^{-1} \cdot \mathrm{cm}^{-1}\right)$ & Solvente & Referência \\
\hline \multirow{5}{*}{$\Phi_{2} \mathrm{CH}^{\oplus}$} & $295^{a}$ & $1,6 \cdot 10^{3}$ & \multirow[t]{2}{*}{$\mathrm{H}_{2} \mathrm{SO}_{4} 100 \%$} & \multirow[t]{2}{*}{ GOLD \& TYE, 1952} \\
\hline & 440 & $4,4.10^{4}$ & & \\
\hline & 292 & $2,9.10^{3}$ & \multirow{2}{*}{$\mathrm{FSO}_{3} \mathrm{H} / \mathrm{SbF}_{5}$} & \multirow[t]{2}{*}{ OLAH et alii, 1966} \\
\hline & 440 & $3,8.10^{4}$ & & \\
\hline & 443 & -- & $\mathrm{ClCH}_{2} \mathrm{CH}_{2} \mathrm{Cl}$ & SUJDAK et alii, 1976 \\
\hline \multirow{3}{*}{$\Phi_{2} \mathrm{CCl}^{\oplus}$} & 291 & $1,30.10^{4}$ & \multirow{3}{*}{$\mathrm{FSO}_{3} \mathrm{H} / \mathrm{SbF}_{5}$} & \multirow[t]{3}{*}{ OLAH et alii, 1966} \\
\hline & 334 & $2,49.10^{4}$ & & \\
\hline & 434 & $2,54.10^{4}$ & & \\
\hline \multirow[t]{2}{*}{$\Phi_{2} \mathrm{CCF}_{3}{ }^{\oplus}$} & 331 & $4,30.10^{3}$ & \multirow[t]{2}{*}{$\mathrm{FSO}_{3} \mathrm{H} / \mathrm{SbF}_{5}$} & \multirow[t]{2}{*}{ OLAH et alii, 1966} \\
\hline & 485 & $2,15.10^{4}$ & & \\
\hline \multirow{4}{*}{$\Phi_{2} \mathrm{CMe}^{\oplus}$} & $310^{a}$ & $8,90.10^{3}$ & \multirow[t]{2}{*}{$\mathrm{H}_{2} \mathrm{SO}_{4} 100 \%$} & \multirow[t]{2}{*}{ GOLD \& TYE, 1952} \\
\hline & 430 & $3,16.10^{4}$ & & \\
\hline & 312 & $1,11.10^{4}$ & \multirow{2}{*}{$\mathrm{FSO}_{3} \mathrm{H} / \mathrm{SbF}_{5}$} & \multirow{2}{*}{ OLAH et alii, 1966} \\
\hline & 422 & $3,70.10^{4}$ & & \\
\hline \multirow{5}{*}{$\Phi_{3} C^{\oplus}$} & $280^{a}$ & $1,6 \cdot 10^{3}$ & \multirow[t]{3}{*}{$\mathrm{H}_{2} \mathrm{SO}_{4} 100 \%$} & \multirow[t]{3}{*}{ NEWMAN \& DENO, 1951} \\
\hline & 404 & $4,0.10^{4}$ & & \\
\hline & 431 & $4,0.10^{4}$ & & \\
\hline & 415 & -- & \multirow[t]{2}{*}{$\mathrm{ClCH}_{2} \mathrm{CH}_{2} \mathrm{Cl}$} & \multirow[t]{2}{*}{ JONES \& DORFMAN, 1974} \\
\hline & 439 & - & & \\
\hline \multirow[t]{2}{*}{$(o-\mathrm{Tol})_{3} \mathrm{C}^{\oplus}$} & $300^{a}$ & $1,3 \cdot 10^{3}$ & \multirow[t]{2}{*}{$\mathrm{H}_{2} \mathrm{SO}_{4} 100 \%$} & \multirow[t]{2}{*}{ NEWMAN \& DENO, 1951} \\
\hline & $450^{a}$ & $2,8 \cdot 10^{4}$ & & \\
\hline
\end{tabular}

a. medidos diretamente do espectro apresentado na referência.

Analisando-se os valores relatados para os máximos de absorção que estão sumarizados nestas duas tabelas, conclui-se que, embora os comprimentos de onda em que ocorrem as transições sejam razoavelmente insensíveis ao meio, pequenas variações no esqueleto da molécula podem causar uma alteração maior do que a esperável, no valor observado para os $\lambda$. Assim, medidas realizadas em solventes de polaridades tão diferentes quanto 1,2-dicloro-etano, $\mathrm{H}_{2} \mathrm{SO}_{4} 100 \%$ e $\mathrm{FSO}_{3} \mathrm{H} / \mathrm{SbF}_{5}$ são razoavelmente compativeis entre si, como mostram os dados para os cátions difenil- e trifenil-metila apresentados na Tabela IV.15: observa-se uma variação de $11 \mathrm{~nm}$, para uma das bandas e, de $8 \mathrm{~nm}$, para a outra, no caso de trifenil-metila e, de apenas $3 \mathrm{~nm}$, para difenil-metila, isto é, uma variação considerável na polaridade do solvente empregado redunda em 
pequenas mudanças nos valores dos máximos de absorção. Com efeito, por se tratarem de transições $\pi \rightarrow \pi^{*}$ de compostos aromáticos, seria de se esperar que a sensibilidade das bandas à polaridade do solvente fosse pequena ou desprezível. Por outro lado, para um mesmo solvente, comparando-se, por exemplo, os dois máximos de absorção determinados para o cátion 2,4,6-trimetil-benzila com aqueles observados para 2,6-dimetil-4-t-butil-benzila (vide Tabela IV.14, p.105), verifica-se que a simples substituição de um grupo metila por um grupo $t$-butila, na posição para, os desloca para comprimentos de onda menores: $-8 \mathrm{~nm}$, no caso da banda de maior energia e, $-25 \mathrm{~nm}$, para a menos energética, uma variação surpreendentemente grande para uma modificação estrutural pequena e remota. Além disso, comparando-se os dados referentes ao cátion benzila com aqueles devidos ao $\alpha, \alpha$-dimetil-benzila (Tabela IV.14, p.105), verifica-se que a banda a $363 \mathrm{~nm}$ sofre um deslocamento de $-37 \mathrm{~nm}$ quando da troca de dois hidrogênios por duas metilas no centro catiônico (ainda que se deva admitir uma incerteza de cerca de $10 \mathrm{~nm}$ nesse $\Delta$, por terem sido os dados obtidos em solventes e temperaturas diferentes); fenômeno análogo foi observado por OLAH et alii (1968) para $\alpha$-ciclo-propil-benzila $\left(\lambda_{\max }=343 \mathrm{~nm}\right)$ e seu metil derivado $\left(\lambda_{\max }=316 \mathrm{~nm}\right)$, em $\mathrm{FSO}_{3} \mathrm{H} / \mathrm{SbF}_{5}\left(\mathrm{a}-50^{\circ} \mathrm{C}\right)$, tendo sido atribuído à hiperconjugação, por esses autores.

Em síntese, considerando-se, tanto a região em que absorvem os cátions benzílicos relacionados à Tabela IV.14 (p.105), como as características gerais de suas distribuições espectrais, fica evidente que as curvas de absorção obtidas para os transientes de maior tempo de vida detectados nas fotólises de MBX e DBX, em iso-octano, podem ser atribuídas aos cátions $o$-metil-benzila e $o$-(bromo-metil)benzila. À objeção de os dados terem sido determinados em um solvente apolar, enquanto a maioria daqueles de literatura refere-se a meios polares, contrapõe-se o efeito de solvente ser pouco pronunciado, como mencionado no parágrafo anterior. De fato, o valor que determinamos ( $\lambda_{\max }=347 \mathrm{~nm}$, em iso-octano) encontra-se deslocado para $\lambda$ s menores, em relação ao modelo de literatura: $\lambda=363 \mathrm{~nm}$, para o cátion benzila, em 1,2-dicloro-etano (JONES \& DORFMAN, 1974). Considerados os dados de literatura, não seria de se prever a ocorrência de uma variação de $16 \mathrm{~nm}$ no comprimento de onda do máximo de absorção por simples efeito de solvente, principalmente porque, neste caso, a diferença de polaridade entre os solventes não chega a ser tão significativa. Por outro lado, o efeito dos substituintes metila e bromo-metila, em orto, deve exercer um papel mais expressivo na ordem de grandeza da diferença observada entre os valores dos comprimentos de onda dos máximos de absorção do composto-modelo e MBX ou DBX, sendo, presumivelmente, atribuível à hiperconjugação.

Deve-se ressaltar que, em se tratando de um cátion, uma hipótese alternativa seria a de que se estivesse formando um metil-tropílio. Esta hipótese, no entanto, é facilmente refutável: o espectro de absorção de metil-tropílio, no UV, apresenta duas bandas com $\lambda_{\max }=226$ e $288 \mathrm{~nm}$, em $\mathrm{H}_{2} \mathrm{SO}_{4}$ conc. (DAUBEN,Jr., et alii, 1957) enquanto, aquele de tropílio não-substituído exibe essas bandas a 247 e $275 \mathrm{~nm}$, em $\mathrm{H}_{2} \mathrm{O}$ (OLAH et 
alii, 1968); estes valores são incompatíveis com o espectro que observamos para o transiente $\left(\lambda_{\max }=347 \mathrm{~nm}\right)$, especialmente considerando-se que as bandas dos tropílios devem apresentar pouca sensibilidade à polaridade do solvente, por se tratarem de transições $\pi \rightarrow \pi^{*}$. Em resumo, não é de se prever que, caso os transientes de vida longa fossem metil-tropílios, as distribuições espectrais apresentassem máximos acima de $300 \mathrm{~nm}$

Foram, ainda, feitos alguns estudos qualitativos de supressão, com o objetivo de melhor caracterizar o transiente em questão. Assim, investigou-se o efeito de oxigênio sobre a cinética de decaimento de soluções de DBX em iso-octano, através da comparação das curvas obtidas para uma mesma solução degaseada e após ter-se borbulhado oxigênio durante 20 minutos, sob ação de ultra-som. Finalmente, analisou-se o efeito causado pela adição de cis-piperileno ao sistema degaseado. Decaimentos representativos, obtidos para este último conjunto de experimentos, estão apresentados na Figura IV.24, com a concentração inicial de DBX corrigida para um mesmo valor e as curvas referentes aos diferentes experimentos superpostas, de maneira a facilitar a comparação dos dados entre si.

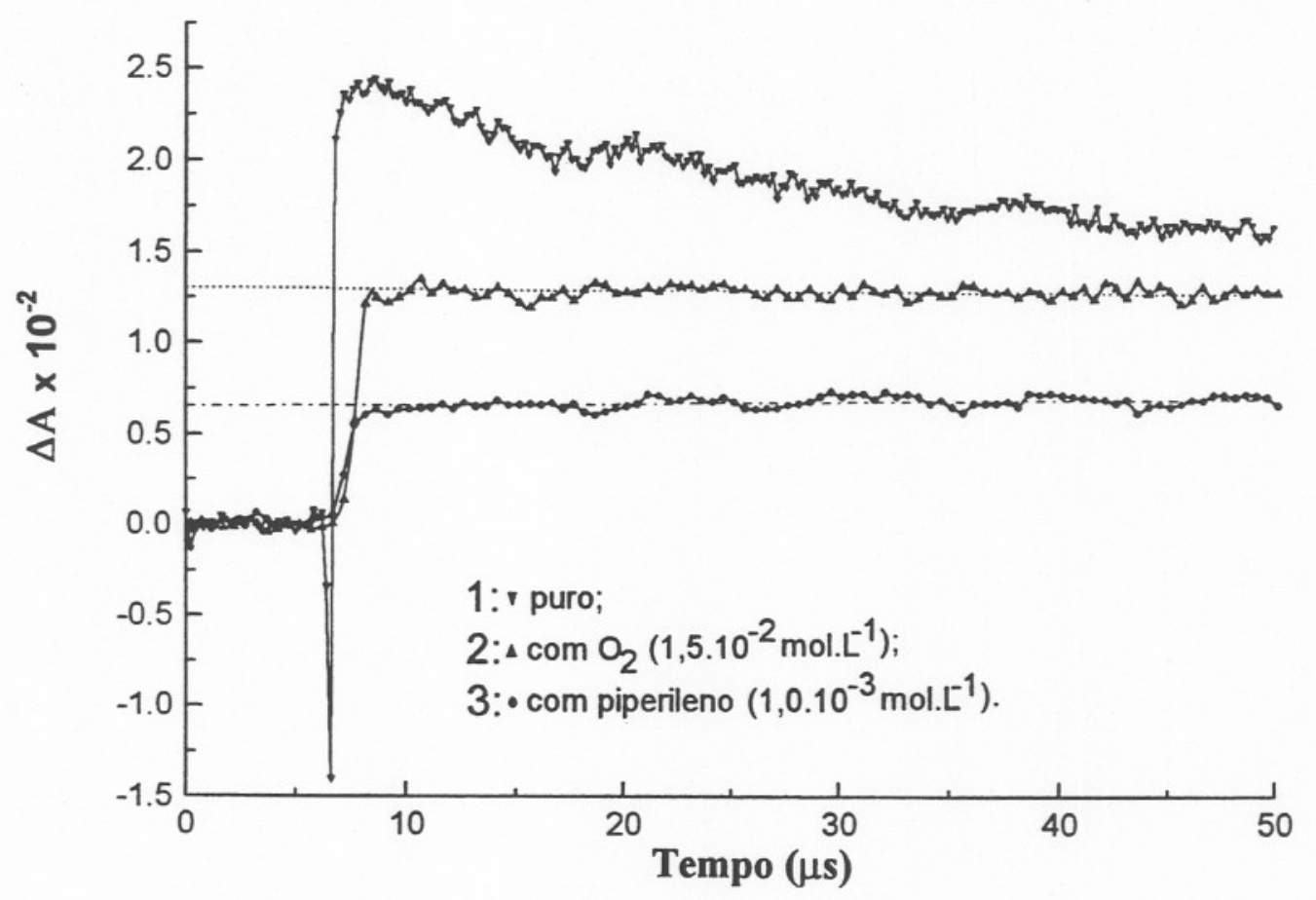

Figura IV.24 - Decaimento, monitorado a 320nm, para uma solução de DBX $(\mathrm{A}=0,850)$, em iso-octano.

Observa-se, na Figura IV.24, que a componente rápida é totalmente suprimida por oxigênio, como seria de se esperar para os radicais, os quais reagem com constantes de supressão da ordem de $10^{7}$, formando peróxi-radicais : Entretanto, não se verifica supressão tão significativa da espécie de tempo mais longo. Este resultado confirma a atribuição que propusemos para este transiente, pois cátions não são suprimidos por 
oxigênio (DORFMAN et alii, 1976). Portanto, a diminuição de $\triangle \mathrm{A}$ que se verifica para os transientes de tempo longo, ao se analisar a Figura IV.24, deve-se, necessariamente, à supressão dos estados excitados precursores do cátion. Os resultados obtidos ao se utilizar piperileno como supressor consolidam estas suposições, pois o cátion, como era de se prever, não é totalmente suprimido mesmo nesta condição, enquanto os estados precursores desta espécie o são. Este último dado parece sugerir que o caminho envolvendo a formação prévia de um radical excitado seja o que prevalece como via para a obtenção destes cátions, pois os estados singlete excitados têm tempo de vida muito curto para serem suprimidos eficientemente por piperileno, nas concentrações utilizadas neste trabalho. Embora piperileno possa reagir com o cátion, esta reação (de polimerização do piperileno) não é muito eficiente, na condição de trabalho. Entretanto, esta reação lateral provavelmente seja a responsável pela diminuição de $\Delta \mathrm{A}$ observada neste último experimento, em relação ao que se observa na supressão por oxigênio molecular.

Os experimentos de supressão seletiva por oxigênio e por piperileno, em conjunto, sugerem que os cátions originam-se, preferencialmente, do radical excitado, por perda de um elétron e não diretamente de $\mathbf{S}_{1}$, por cruzamento para um estado dissociativo $\sigma \rightarrow \sigma^{*}$, como se poderia hipotizar ao analisar os diagramas de correlação de estados apresentados na página 5 desta Tese.

O elétron que seria ejetado ao se admitir este mecanismo para a formação do cátion não é detectável na região do UV/Vis: a banda de absorção devida elétrons depende da solvatação, pois elétrons livres ou quase-livres não absorvem. Entretanto, a interação com hidrocarbonetos não é desprezivel, tendo sido determinados espectros de absorção de elétrons em iso-pentano e em hexanos, com máximo na região entre $2000 \mathrm{e}$ $2500 \mathrm{~nm}$ (5000 e $4000 \mathrm{~cm}^{-1}$, respectivamente), na região do infra-vermelho próximo (SCHINDEWOLF, 1978).

Admitindo-se a ocorrência de cátions benzila no sistema, torna-se também possível oferecer uma explicação alternativa e mais convicente para a formação do produto $\mathbf{B B z B r}$, observado na fotólise convencional de $\mathbf{D B X}$ em benzeno, a tempos mais longos de irradiação: este seria, simplesmente, o produto da benzilação (de FriedelCrafts) do solvente, reação com constante de velocidade da ordem de $5.10^{7} \mathrm{~L} \cdot \mathrm{mol}^{-1} \cdot \mathrm{s}^{-1}$, em 1,2-dicloro-etano (GIACOMELLO et alii, 1989). 


\section{BIBLIOGRAFIA}

ABDEL - WAHAB, A.-M.A. ; ISMAIL, M.T.; MOHAMEd, O.S. \& KHALAF, A.A., (1985), Gazz. Chim. Ital., 115:591.

Alfassi, Z.B. \& PreVITALI, C.M., (1985), J. Photochem., 30:127.

Alonso, E.O.; Johnston, L.J.; ScaiAno, J.C. \& Toscano, V.G., (1990), J. Am. Chem. Soc., 112:1270.

Alonso, E.O.; Johnston, L.J.; ScAiAnO, J.C. \& TOSCANO, V.G., (1992), Can. J. Chem., 70:1784.

APPLETON, D.C.; BROCKLEHURST, B.; MCKENNA, J.; MCKENNA, J.M.; SMITH, M.J.; TAYLOR, P.S., ThaCKERAY, S. \& WAlley, A.R., (1977), J. Chem. Soc. Chem. Commun., 108.

APPleton, D.C.; BROCKLehURSt, B.; MCKenNA, J.; MCKenNA, J.M.; THACKeRAY, S. \& Walley, A.R.,(1980), J. Chem. Soc., Perkin Trans 2, 87.

ARnold, B.; DonAld, L.; JuRgens, A. \& Pincock, J.A., (1985), Can. J. Chem., 63:3140.

ATKINSON. E.F.J. \& THORPE, J.F., (1907), J. Chem. Soc., 91:1687.

BAKER, W. ; MCOMIE, J.F.W. \& PREStON, D.R., (1961), J. Chem. Soc., 2971.

BARNETT, E. DE B.; COOK, J.W. \& NIXON, I.G., (1927), J. Chem. Soc., 504.

Barnett, E. De B. \& LaWrence, C.A., (1935), J. Chem. Soc., 1104.

BEILSTEIN, Beilsteins Handbuch der Organischen Chemie, 4aㅡ ed., Springler Verlag.

BENSON, S.W., (1976), Thermochemical Kinetics, $2^{\text {nd }}$ ed., John Wiley and Sons, N.York.

BENT, D.V. \& HAYON, E., (1975), J. Am. Chem. Soc., 97:2599.

BERLMAN, I.B., (1951), Handbook of fluorescence spectra of aromatic molecules, Academic Press, N.York.

BILL, J.C. \& TARBELL, D.S., (1963), Org. Synth. Coll. Vol, 4, 807.

BINDLEY, T.F. \& WALKER, S., (1955), Trans. Faraday Soc., 58:217.

BINDLEY, T.F.; WATTS, A.T. \& WALKER, S., (1962), J. Chem. Soc., 4327.

Bollinger, J.M.; Comisarow, M.B., CupAs, C.A. \& OlaH, G.A., (1967), J. Am. Chem. Soc., 89:5687.

Bossy, J.M.; BÜHLeR, R.E. \& EBeRT, M., (1970), J. Am. Chem. Soc., 92:1099.

Bradlow, H. L. \& VANDerWerf, C.A., (1947), J. Am. Chem. Soc., 69: 1254.

BÜHLER, R.E., (1972), Rad. Res. Rev., 4:233.

BUNCE, N.J., (1987), J. Photochem., 38:99.

CAlvert, J.G. \& ReChen, H.J.L., (1952), J. Am. Chem. Soc., 74:2101. 
Carmichael, I. \& Hug, G.L., (1986), J. Phys. Chem. Ref. Data, 15:1.

CARMichael, I. \& HUG, G.L., (1987), in CRC Handbook of Organic Photochemistry, ed. J.C.Scaiano, CRC Press, Inc., Boca Raton, Florida, vol. 1, cap.16, p.369.

Carpino, L.A., (1962), J. Am. Chem. Soc., 84:2196.

CARPINO, L.A., (1966), J. Chem. Soc. Chem. Commun., 494.

CARPINO, L.A., (1969), J. Org. Chem., 34:461.

Cava, M.P. \& Deana, A.A., (1959), J. Am. Chem. Soc., 81:4266.

Cava, M.P.; Deana, A.A. \& Muth, K., (1959), J. Am. Chem. Soc., 81:6458.

ChANG, H.M. \& JAFFÉ, H.H., (1973), Chem. Phys. Lett., 23:146.

Chang, H.M.; JAfFÉ, H.H. \& MAsmanidis, C.A., (1975), J. Phys. Chem., 79:1118.

Chapman, O.L.; Johnson, J.W.; MCMAHON, R.J. \& WeSt, P.R., (1988), J. Am. Chem. Soc., 110:501.

ClARIDGe, R.F.C. \& FISCHER, H., (1983), J. Phys. Chem., 87:1960.

Cossart-Magos, C. \& Leach, S., (1976), J. Chem. Phys., 64:4006.

CRC, (1973), Handbook of Chemistry and Physics, ed. R.C. Weast, CRC Press, Inc., 59 a . ed., Boca Raton, Florida.

CRISTOL, S.J. \& BINDEL, T.H., (1980), J. Org. Chem., 45:951.

CRISTOL, S.J. \& BINDEL, T.H., (1981), J. Am. Chem. Soc., 103:7287.

CRISTOL, S.J. \& GREENWALD, B.E., (1976), Tetrahedron Lett., 2105.

CUNDALL. R.B.; RoBInson, D.A. \& Voss, A.J.R., (1973/1974), J. Photochem., 2:231.

CuthBeRTON, E. \& MACNiCOL, D.D., (1975), Tetrahedron Lett., 1893.

DE FONSEKA, K.K.; MCCUlLOUgh, J.J. \& YARWOOD, A.J., (1979), J. Am. Chem. Soc., 101:3277.

DAuben, JR., H.J.; GAdeCKI, F.A. ; Harmon, K.M. \& PEARson, D.L., (1957), J. Am. Chem. Soc., 79:4557.

DORFMAN, L.M.; SUJDAK, R.J. \& BOCKRATH, B., (1976), Acc. Chem. Res., 9:352.

EBERson, L., (1987), Reactivity and Structure Concepts in Organic Chemistry; 25.

Electron Transfer Reactions in Organic Chemistry, Springer Verlag, Berlin.

FINKELSTEIN, H., (1910), Dissertação, Estrasburgo, apud OPPOLZER, W., (1978), Synthesis, 793.

FLYNN, C.R. \& MICHL, J., (1973), J. Am. Chem. Soc., 95:5802.

FLYNN, C.R. \& MICHL, J., (1974), J. Am. Chem. Soc., 96:3280.

Friedrich, D.M. \& AlbRECHT, A.C., (1973), J. Chem. Phys., 58:4766.

FRIEDRICH, D.M. \& ALBRECHT, A.C., (1974), Chem. Phys., 6:366.

Giacomello, P.; Angelini, G.; Sparapani, C. \& Speranza, M., (1989), J. Phys. Org. Chem., 2:467. 
Gold, V. \& TYE, F.L., (1952), J. Chem. Soc.,2172.

Goodman, J.L. \& Berson, J.A., (1985), J. Am. Chem. Soc., 107:5409.

Haider, K.; Platz, M.S.; Despres, A.; LeJeune, V.; Migirdicyan, E.; Bally, T. \& HASELBACH, E., (1988), J. Am. Chem. Soc., 110:2318.

HAIDER, K.W. \& PLATZ, M.S., (1989), J. Phys.Org. Chem., 2:623.

haider, K.W., Migirdicyan, E.; Platz, M.S.; Soundararajan, N. \& DESPRES, A., (1990), J. Am. Chem. Soc., 112:733.

HALFORD, J.O \& Weissmann, B., (1953), J. Org. Chem., 18:30.

HAN, B.H. \& BOUDJOUK, P., (1982), J. Org. Chem., 47:751.

HaRT, H.; HaRtLAGe, J.A.; Fish, R.W. \& Rafos, R.R., (1966), J. Org. Chem., 31:2244.

HARTCHARD, C.G. \& PARKeR, C.A. (1956), Proc. Roy. Soc. (London), A235:518.

hayashibara, K.; KRuppa, G.H. \& Beauchamp, J.L., (1986), J. Am. Chem. Soc., 108:5441.

HiRatsuka, H.; OKamura, T.; TANaka, I. \& TANizaki, Y., (1980), J. Phys. Chem., 84:285.

HORNBACK, J.M., (1976), Tetrahedron Lett., 38:3389.

HORNBACK, J.M. \& VADLAMANI, B., (1980), J. Org. Chem., 45:3524.

HORNBACK. J.M. \& BARROWS, R.D., (1982), J. Org. Chem., 47:4285.

Huggenberger, C. \& Fischer, H., (1981), Helv. Chim. Acta, 64: 338.

HUISGEN, R. \& SEIDL, H., (1964), Tetrahedron Lett., 3381.

IRIE, M.; SHIMizU, M. \& YoshidA, H., (1976), J. Phys. Chem., 80:2008.

Jensen, F.R. \& Coleman, W.E., (1958), J. Am. Chem. Soc., 80:6149.

JoHNS, H.E., (1969), Methods Enzymol., 16, 274.

Johnson, P.M. \& ALBRECHT, A.C., (1968), J. Chem. Phys., 48:851.

JOHNSTON, L.J. (1993), Chem. Rev., 93:251.

JOHNSTON, L.J. \& SCAIANO, J.C., (1989), Chem. Rev., 89:521.

JONES, R.L. \& DORFMAN, L.M., (1974), J. Am. Chem. Soc., 96:5715.

KORNBLUM, N.; JONES, W.J. \& ANDERSON, G.J., (1959), J. Am. Chem. Soc., 81:4113.

LAMOLA, A.A. \& TURRO, N.J. (1977) in The Science of Photobiology, p.65, (K.C.

Smith, ed), Plenum/ Rosetta, New York, 1 a ed.

LANSINGER, J.M. \& RONALD, R.C. (1979), Synth. Commun., 9:341.

LAPOSA, J.D. \& MORRISON, V., (1974), Chem. Phys. Letters, 28:270.

LÄUFER, M. \& DREESKAMP, H., (1984), J. Magn. Reson., 60:357.

LEHNI, M.; SCHUH, H. \& FISCHER, H., (1979), Int. J. Chem. Kinet., 11:705.

LEONHARD, N.J.; KRESGe, A.J. \& OKI, M., (1955), J. Am. Chem. Soc., 77:5078. 
LIFSHITZ, C., (1994), Acc. Chem. Res., 27:138.

LOEFF, I.: LUTZ, H. \& LINDQVIST, L. (1970), Isr. J. Chem, 8:141.

LUND \& BJERRUM (1931), Ber., 64:210.

Margaretha, P., (1982), Top. Curr. Chem., 103:5.

MARQUARDT, D.W. (1963), J. Soc. Ind. Appl. Math., 11:431.

MCGIMPSEY, W.G. \& SCAIANO, J.C., (1988), Can. J. Chem., 66:1474.

MCMAHON, R.J. \& CHAPMAN, O.L, (1987), J. Am. Chem. Soc., 109:683.

MCOMIE, J.F.W. \& PERRY, D.H., (1973), Synthesis, 416.

Meisel, D.; Das, P.K.; Hug, G.L.; Bhattacharyya, K. \& Fessenden, R.W., (1986), J. Am. Chem. Soc., 108:4706.

MICHL, J. \& BONACIC-KOUTECKY, V. (1990), "Electronic Aspects of Organic Photochemistry", New York, John Wiley \& Sons, p. 137-139.

Migirdicyan, E., (1968), Hebd. Seances Acad. Sci., 266:756.

MigiRdicyan, E.\& BAUDET, J., (1975), J. Am. Chem. Soc., 97:7400.

Mitsuo, N.; Kunieda, T. \& TAKIZAWA, T., (1973), J. Org. Chem., 38:2255.

Morgante, C.G. \& Struve, W.S. (1979), Chem. Phys. Lett., 66:272.

MULLIKEN, R.S., (1955), J. Chem. Phys., 23:1997.

MUROV, S.L., (1973), "Handbook of Photochemistry”, Marcel Dekker, Inc., 1a. ed.

Murov, S.L.; CARMichael, I., HUG, G.L.,(1993), Handbook of Photochemistry, 2a ${ }^{a}$. ed., Marcel Dekker, N.York.

NAUTA, W.T.; ERnShing, M.J.E. \& FABer, A.C., (1941), Recl. Trav. Chim. Pays-Bas, 60:915.

OKamuRa, T. \& TANAKA, I., (1975), J. Phys. Chem., 79:2728.

OLAH,G.A.; PITTMAN, JR., C.U. \& SYMONS, M.C.R., (1968), in Carbonium lons, G.A.

Olah and P.von R. Schleyer, eds, volume I, Wiley Interscience, N.Y., cap.5, p.153.

OLAH, G.A., (1995), Angew. Chem. Int. Ed. Engl., 34:1393.

Oliver, J.A. \& ONGLEY, P.A., (1965), Chem. Ind. (London), 1024.

OPPOLZER, W., (1978), Synthesis, 793.

PadWA, A. \& AU, A., (1976), J. Am. Chem. Soc., 98:5581.

PadWA, A.; Au, A.; LeE, G.A. \& OWens, W., (1975), J. Org. Chem., 40:1142.

Perrin, D.D.; Armarego, W.L.F. \& Perrin, D.R., (1966), Purification of Laboratory Chemicals, Pergamon Press, p. 121.

Petragnani, N., (1994), Tellurium in Organic Synthesis, Academic Press, London, Cap. 4, 113.

PORTER, G. \& STRACHAN, E. (1958), Trans. Faraday Soc., 54:1595.

PORTER,G. \& WRIGHT, F.J., (1955), Trans. Faraday Soc., 51:1469. 
PRESS, W.H.; FlanNeRY, B.P.; TeNKOLSKY, S.A. \& VetTERLING, W.T., (1986), Numerical Recipes (versão em Fortran), Cambridge University Press, 540.

PreVitali, C.M. \& EbBesen, T.W., (1984), J. Photochem., 27:9.

QUINA, F.H. (1982), in Chemical and Biological Generation of Excited States, p.1, (W.

Adam \& G. Cilento, eds.), Academic Press, New York.

QUINKERT, G.; OPITZ, K.; WIERSDORFF, W.W. \& FINKE, M., (1966), Justus Liebigs Ann. Chem., 693:44.

QUINKERT, G; WIERSDOFF, W.W.; FINKE, M; OPITZ, K. \& VAN DER HAAS, G.F., (1968), Chem. Ber., 101:2302.

QUINKERT, G.; PALMOWSKI, J.; LORENZ, H.P.; WIERSDORFF, W.W. \& FINKE, M., (1971), Angew. Chem. Int. Ed. Engl., 10:198.

SAMMES, P.G., (1976), Tetrahedron, 32:405.

Santiago, C., Houk, K.N., Snow, R.A. \& Paquette, L.A., (1976), J. Am. Chem. Soc., 98:7443.

SCAIANO, J.C. (1982), Acc. Chem. Res., 15:252.

SCAIANO, J.C., \& SUGAMORI, S.E., (1988), Speclib, Version 3.0, Division of Chemistry, National Research Council, Ottawa, Canadá.

SCHINDEWOLF, U., (1978), Angew. Chem. Int. Ed. Eng., 17:887.

SCHUH, H. \& FISCHER, H., (1976), Int. J. Chem. Kinet., 8:341.

ScHUH, H. \& FISCHER, H., (1978), Helv. Chim. Acta, 61:2130.

ShabaroV, Y.S.; VASIL'EV, N.I. \& LeVINA, R.Y., (1961), Zh. Obshch. Khim., 31:2478, C.A. $56: 7312$

SHRINER, R.L. \& FUSON, R.C., (1948), The Systematic Identification of Organic Compounds, $3^{\text {a }}$ ed., John Wiley \& Sons, N.Y. 171, USA.

SPANGLER, R.J. \& BECKMANN, B.G., (1976), Tetrahedron Lett., 2517.

Spangler, R.J.; Beckmann, B.G. \& Ho Kim, J., (1977), J. Org. Chem., 42:2989.

STEPHENSON, E.F.M., (1963), Org. Synth. Coll. Vol., 4, 984.

SUJDAK, R.J., JONES, R.L. \& DORFMAN, L.M., (1976), J. Am. Chem. Soc., 98:4875.

TOKUMURA, K. \& ITOH, M., (1989), Nippon Kagaku Kaishi, 1311.

Tokumura, K.; Udagawa, M.; OzaKI, T. \& ITOH, M., (1987), Chem. Phys. Lett., 141:558.

TOKUMURA, K.; OZAKI, T. \& ITOH, M., (1989a), J. Am. Chem. Soc., 111:5999.

TOKumuRa, K.; OzaKI, T.; UdagaWa, M. \& ITOH, M., (1989b), J. Phys. Chem., 93:161.

TOKumura, K.; Nosaka, H. \& OzAKI, T., (1990), Chem. Phys. Letters, 169:321.

TOKumuRA, K.; OzAKI, T.; Nosaka, H.; SAIGUSA, Y. \& ITOH, M., (1991), J. Am. Chem. Soc., 113:4974. 
Tournier, A.; Deglise, X. \& André, J.C., (1983), J. Photochem., 22:223.

TSENG, K.L. \& MICHL, J. (1977), J. Am. Chem. Soc., 99:4840.

TURRO, N.J. (1978), Modem Molecular Photochemistry, The Benjamin/Cummings Publishing Co., Inc, Menlo Park, California.

TURRo, N.J.; RAmAmuRTHY, V.; CherRY, W. \& FARNeth, W., (1978), Chem. Rev., 78:125.

TURRO, N.J.; ZHANG, Z.; TRAHANOVSKY, W.S. \& CHOU, C. -H., (1988), Tetrahedron Lett., 29:2543.

VesLey, G.F., (1971), Mol. Photochem., 3:193.

VogeL, A.I., (1967), A Textbook of Practical Organic Chemistry, $3^{\mathrm{a}}$ ed., Longman, Londres, 739.

WATTS, A. \& WALKER, S., (1962), J. Chem. Soc., 4323.

WEIR, D.; JOHNSTON, L.J. \& SCAIANO, J.C., (1988), J. Phys. Chem., 92:1742.

WENTRUP, C. (1984), in Reactive Molecules, John Wiley, New York, p 1-3.

Wiesenfeld, J.M. \& IPPEN, E.P. (1979), Chem. Phys. Lett., 67:213.

Wintgens, V.; NetTo-FerReiRA, J.C.; CASAL, H.L. \& SCAIANO, J.C., (1990), J. Am. Chem. Soc., 116:2363.

WRIGHT, B.B. \& PLATZ, M.S., (1983), J. Am. Chem. Soc., 105:628.

Zimmerman, H.E. \& SANDEL, V.R., (1963), J. Am. Chem. Soc., 85:915.

Zimmerman, H.E. \& SOMASEKHARA, S., (1963), J. Am. Chem. Soc., 85:922. 


\section{CURRICULUM VITAE}

NOME:

(anteriormente:

LOCAL e DATA DE NASCIMENTO:

\section{DAISY DE BRITO REZENDE DAISY DE REZENDE MOREIRA)}

São Paulo, 07 de setembro de 1953

\section{EDUCAÇÃO:}

Nível Médio:

Curso Ginasial: Colégio Dante Alighieri, São Paulo, SP, 1965.

Colégio Andrews, Rio de Janeiro, RJ, 1966 e 1967.

Colégio Dante Alighieri, São Paulo, SP, 1968.

Curso Científico: Colégio Dante Alighieri, São Paulo, SP, de 1969 a 1971.

Nível Superior:

Licenciatura em Química: Faculdade de Educação da USP, SP, de 1972 a 1977.

Bacharelado em Química: Instituto de Química da USP, SP, de 1972 a 1978.

Mestrado em Química Orgânica: pelo Instituto de Química da USP, SP, em 1986.

\section{OCUPAÇÃO:}

Professora do $2^{\circ}$ grau:

Professora do $2^{\circ}$ grau:

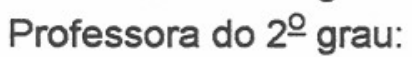

Bolsista - FAPESP:

Professora do $2^{\circ}$ grau:

Professora do $2^{\circ}$ grau:

Bolsista - CNPq:

Bolsista - FAPESP:

Professora do $2^{\circ}$ grau:

Bolsista - CNPq:

Docente:
Colégio COE, São Paulo, SP, 1975.

EEPSG Oswaldo Aranha, São Paulo, SP, 1976.

EESG Prof. Andronico de Mello, São Paulo, SP, 1977 (1ํsemestre). Inic. Científica, de agosto de 1977 a julho de 1978.

Instituto Mackenzie, São Paulo, SP, 1978 a 1980.

Colégio Gávea, São Paulo, SP, 1981 (1ํ semestre).

Mestrado, de março de 1980 a fevereiro de 1982.

Mestrado I, de março de 1982 a agosto de 1983.

Logos Escola de $2^{\circ}$ Grau, São Paulo, SP, 1983 a julho de 1987.

Doutoramento, de agosto de 1987 a fevereiro de 1991.

Instituto de Química da USP, SP, a partir de setembro de 1991.

\section{PUBLICAÇÕES:}

5- D. de B. Rezende, I. P. de ArRuda Campos, V. G. Toscano \& L. H. Catalani, "Photolysis of a Series of $\alpha$-Brominated o-Xylenes in Apolar Solvents", J. Chem. Soc., Perkin Trans. 2, 1995 (10), 1863 - 8.

4- I. P. de Arruda Campos, D. B. Rezende, M. E. R. Marcondes \& V. G. Toscano, "An empirical method for the evaluation of electron affinities", J. Chem. Soc., Perkin Trans. 2, 1991, 23-24.

3- M. H. R. Beltran, N. O. Beltran, M. E. R. marcondes, A. B. Mazon, D. DE B. Rezende, L. I. ROMANELLI \& R. P. SCHNETZLER, "Projeto de ensino de química para o $2^{\circ}$ grau - PROQUIM", edição dos autores, apoiada por CAPES/MEC/PADCT, São Paulo, 1987.

2- D. DE B. REZENDE, "Desativação de estados singlete excitados de: (i) aldeídos alifáticos, por haletos de alquila; (ii) antraceno, por sulfetos aromáticos", Dissertação de Mestrado, defendida junto ao Depto. de Química Fundamental do Instituto de Química da Universidade de São Paulo, São Paulo,SP, em 1986.

1- E. C. AICHINGer, S. BACH \& D. R. MOREIRA, "Química 3 (Fisico-Química)", Ed. Pedagógica e Universitária, São Paulo, 1980. 